\title{
Metabolismus und Biomineralisation in anaerob Methan-oxidierenden Lebensgemeinschaften
}

\author{
Dissertation zur Erlangung des Doktorgrades \\ der Mathematisch-Naturwissenschaftlichen Fakultäten \\ der Georg-August-Universität zu Göttingen
}

\author{
vorgelegt von \\ Christoph Wrede \\ aus Norden
}

Göttingen 2010 
D7

Referent:

Korreferent:

Tag der mündlichen Prüfung:
PD Dr. Michael Hoppert

Prof. Dr. Jörg Stülke

26.01.2011 
„Faszinierend.“

Spock 


\section{Danksagung}

Mein besonderer Dank gilt PD Dr. Michael Hoppert für die Ermöglichung meiner Doktorarbeit in einem so interessanten Bereich der Mikrobiologie. Seine stets freundliche, engagierte und kompetente Betreuung hat mir die Arbeit sehr erleichtert.

Ich danke Prof. Dr. Jörg Stülke für die Übernahme des Korreferats, für die angenehmen Arbeitsbedingungen in der Abteilung sowie sein Interesse an meinem Thema.

Bei Prof. Dr. Joachim Reitner bedanke ich mich neben der Teilnahme an der Prüfungskommission auch für die gute Kooperation, die Bereitstellung der Proben und nicht zuletzt dafür, dass er mir die Geobiologie und die besondere Bedeutung eines guten Weines bei der Arbeit im Gelände nahe gebracht hat.

Ebenso bedanke ich mich bei PD Dr. Rolf Daniel für die Teilnahme an meiner Prüfungskommission sowie für die Unterstützung bei der Bearbeitung unserer Proben. Natürlich gilt mein Dank auch Prof. Dr. Botho Bowien und PD Dr. Boris Görke für das freundliche Mitwirken in der Prüfungskommission.

Prof. Dr. Marco Taviani sowie Augusta und Luciano Callegari gilt mein Dank für Ihre Hilfe und Gastfreundschaft in Italien.

Christina Heller, Silja Brady und Stephanie Rockstroh danke ich für die freundschaftliche Unterstützung und gute Zusammenarbeit. Anne Dreier und Sebastian Kokoschka, ich danke Euch für Eure Existenz als Freunde und Kollegen und zum Beitragen an dieser Arbeit. Meinen älteren und neueren Mitstreitern Sebastian Hübner, Claudine Hames, Nico Pietack, Hinnerk Eilers, Sebastian Schmidl, Tini Diethmaier, Arne Schmeisky (auch nochmal für das Lesen), Christina Herzberg, Fabian Rothe, Lope Flórez, Fredo Meyer, Martin Lehnik, Denise Lüttmann und Jens Landmann et al. danke ich für die schöne Zeit zusammen, nicht nur bei der Arbeit. Ich werde es vermissen. Ich danke auch denen, die meine „Lehre“ ertragen und meine Arbeit unterstützt haben: Viola Krukenberg, Sandra Heinzelmann, Marcel Liebick, Konstantin Albrecht, Lea Georges. Und natürlich Dank an unsere ganze weitere (aktuelle und ehemalige) Laborcrew, deren einzelne Namen leider dem Platz zum Opfer fallen - ich habe Euch nicht vergessen. Danke auch an die weiteren Expeditionsteilnehmer für die schöne Zeit unterwegs. Dr. Petra Neumann-Staubitz, Bärbel Herbst, Julia Busse und Sabine Lentes danke ich für die gute Zusammenarbeit. Caro und Jan gilt mein Dank für die Hilfe fortgeschrittener EMI's und ENI's in allen Lebenslagen. 
Ich danke meinen Freunden in Göttingen, die mich jetzt schon solange „,beglücken“ und wissen was lange Göttinger Nächte bedeuten ;-).

Ich danke meinem besten Bruder auf der Welt, Sebastian, der immer da ist wenn man ihn braucht - natürlich sei Annes Unterstützung dabei nicht vergessen.

Mein besonderer Dank gilt natürlich meiner Freundin Katrin in der Mikrobiologie und im Leben. Danke, dass es Dich gibt.

Und zu guter Letzt danke ich meinen Eltern Claire ${ }^{\dagger}$ und Bernhard, die mich und Katrin überall unglaublich unterstützt haben. Ihr habt mir gezeigt, was wichtig ist im Leben. Danke! 


\section{Table of Contents}

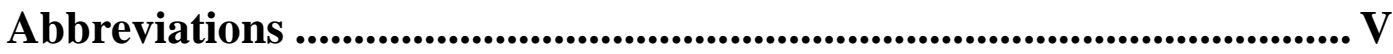

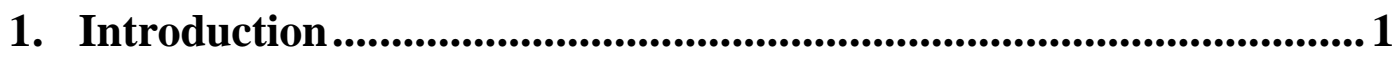

1.1. Global role of methane............................................................................................... 1

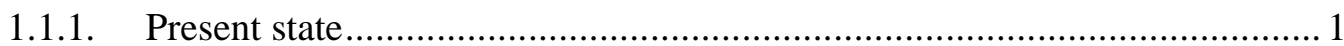

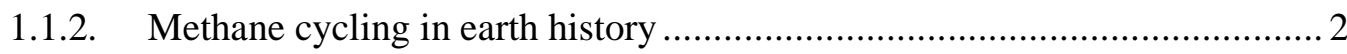

1.2. Microbial processes involved in methane turnover ......................................... 4

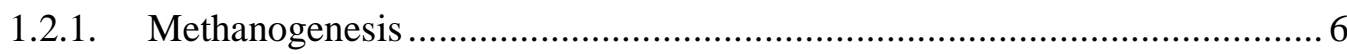

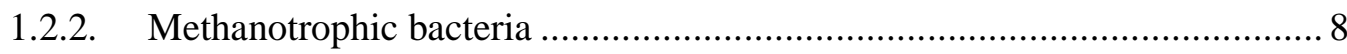

1.2.3. Anaerobic oxidation of methane (AOM) .............................................. 11

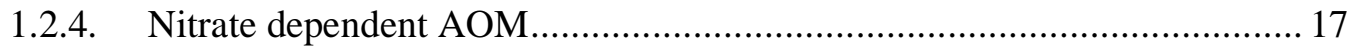

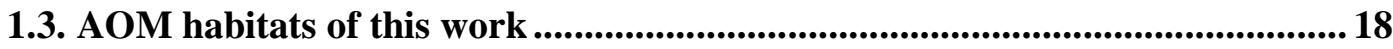

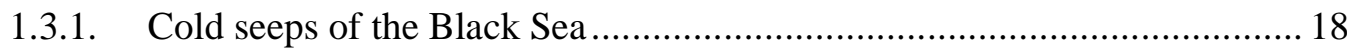

1.3.2. Terrestrial mud volcanoes in the Northern Apennines ............................. 21

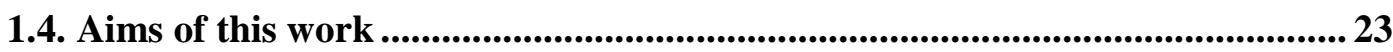

2. Materials and Methods ................................................................24

2.1. Organisms and plasmids....................................................................................... 24

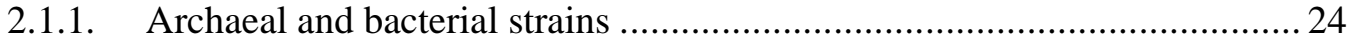

2.1.2. Samples of Black Sea cold seeps (Reitner et al., 2005b).........................25

2.1.3. Samples of terrestrial mud volcanoes of the Emilia Apennines, Italy.........26

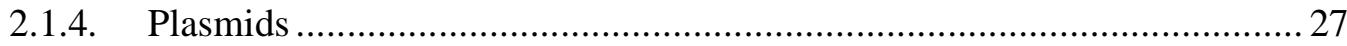

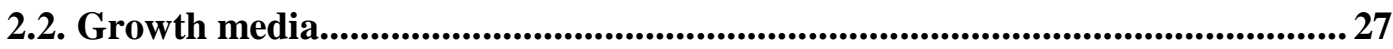

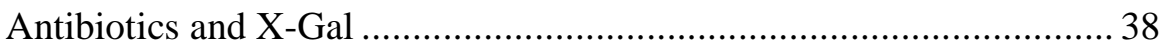

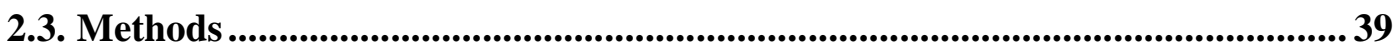

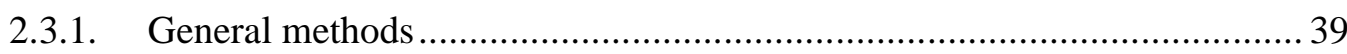

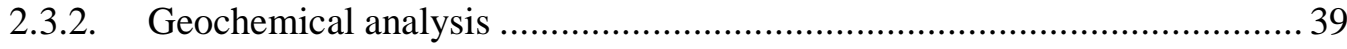

2.3.3. Cultivation of archaea and bacteria ..................................................... 40

Cultivation of D. vulgaris Hildenborough ......................................... 40

Cultivation of E. coli .................................................................. 40 
Cultivation of M. extorquens AM1 and methylotrophic isolates ........... 40

Cultivation and enrichment of methanotrophs .................................. 40

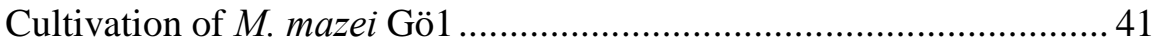

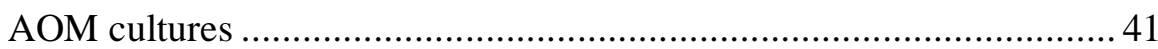

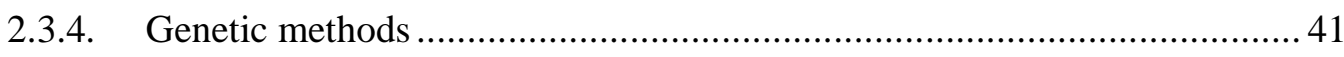

Preparation of chromosomal DNA from D. vulgaris Hildenborough .... 41

Preparation of DNA from cold seep microbial mats ........................... 42

Preparation of plasmid DNA from E. coli ........................................ 42

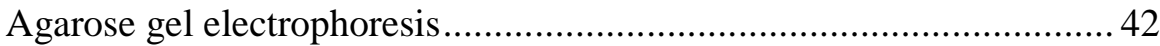

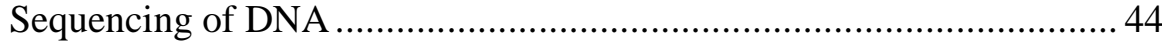

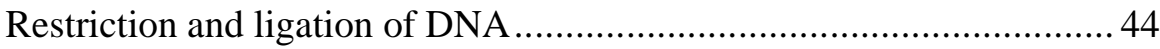

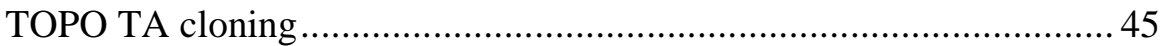

Polymerase chain reaction (PCR) .................................................. 45

Purification of PCR products......................................................... 48

Denaturant gradient gel electrophoresis (DGGE) analysis ................... 48

Construction of 16S rDNA clone library and phylogenetic tree ........... 49

Preparation of competent E. coli cells (Inoue et al., 1990) .................... 50

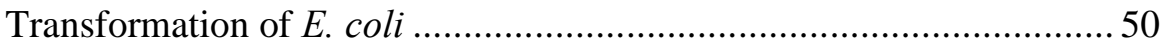

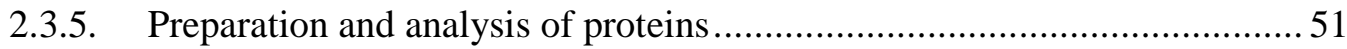

Discontinuous SDS polyacrylamide gel electrophoresis (SDS-PAGE).. 51

Overexpression of proteins in E. coli .................................................. 53

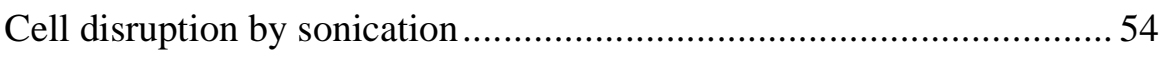

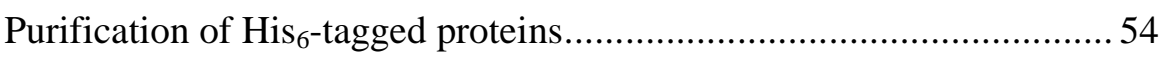

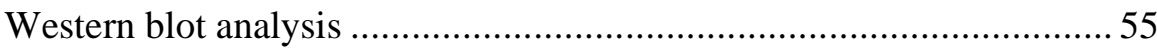

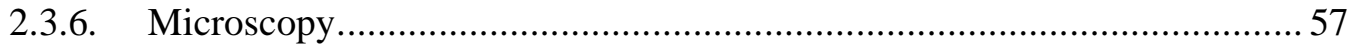

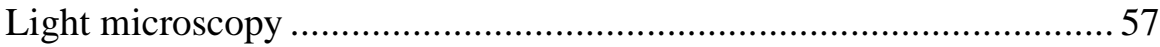

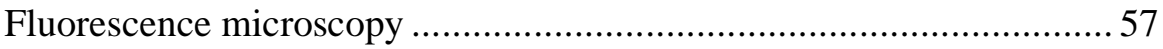

Transmission electron microscopy (TEM) .....................................57

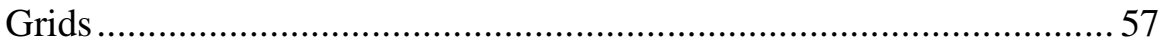

Support films (Mahl and Möldner, 1973) ......................................... 58

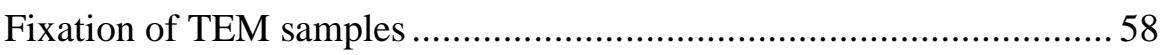

Low temperature embedding in Lowicryl K4M resin (Roth et al., 1981;

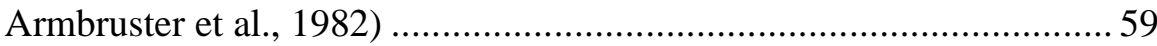


Spurr resin embedding (Spurr, 1969; Hoppert, 2003) ......................... 60

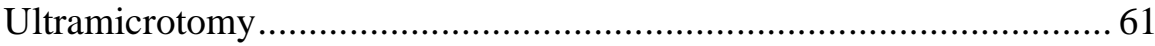

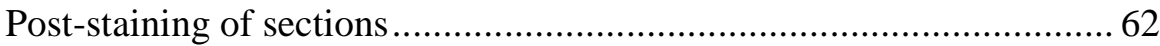

Immunocytochemistry for TEM and fluorescence microscopy ............ 63

Cell extraction from volcano fluids (Kallmeyer et al., 2008)................ 64

Enumeration of total archaea and bacteria .......................................... 66

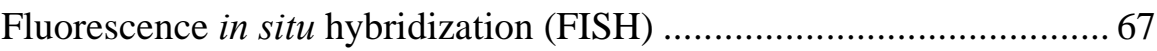

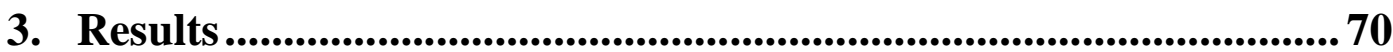

3.1. Detections of metabolic key enzymes in anoxic GHOSTDABS cold seeps ...... 70

3.1.1. Methanol dehydrogenase detection of active methano- and methylotrophic

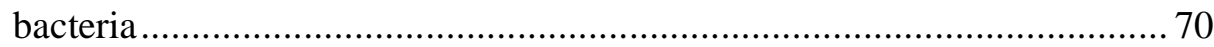

Production and characterization of $\alpha-\mathrm{MDH}$ antibodies ........................ 70

MDH expression in microbial mats ............................................... 72

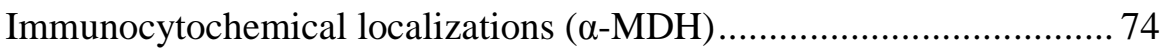

3.1.2. APS reductase detection for active SRB ........................................... 79

Novel method for generation of $\alpha$-AprB antibodies and testing of the

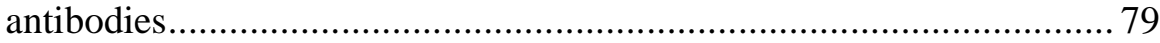

Immunocytochemical localizations $(\alpha-\mathrm{AprB}) \ldots \ldots \ldots \ldots \ldots \ldots \ldots \ldots \ldots \ldots \ldots \ldots . . . . . . . . \ldots \ldots$

\subsection{Aerobic and anaerobic methane oxidation in terrestrial mud volcanoes in the}

Northern Apennines................................................................................... 87

3.2.1. Geological setting and mud volcano fluid composition .......................... 87

3.2.2. Detection of organisms in mud volcano fluids..................................... 89

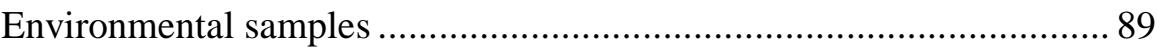

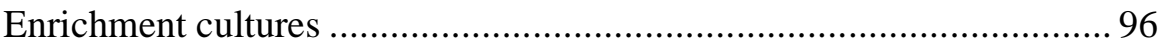

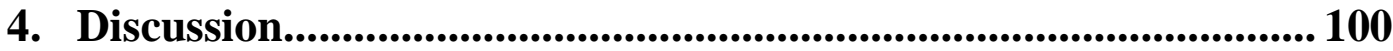

4.1. Anaerobic methane oxidation - a view on the protein level .......................... 100

4.1.1. Are syntrophic bacteria of ANME cells active SRB? ............................ 100

4.1.2. AOM, syntrophy of reverse methanogenesis and sulfate reduction? ........ 102

4.1.3. Aerobic methanotrophic pathway in anoxic cold seeps ........................ 103

4.1.4. Electron acceptors and microniches ................................................ 104 
4.1.5. Co-occurrence of ANME and methanotrophic bacteria, a unique phenomenon? 108

4.1.6. Implications for biomarkers ........................................................ 108

4.2. Terrestrial mud volcanoes in Nirano ................................................................109

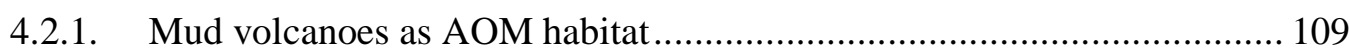

4.2.2. Role of detected microorganisms ….............................................. 111

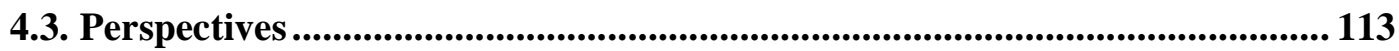

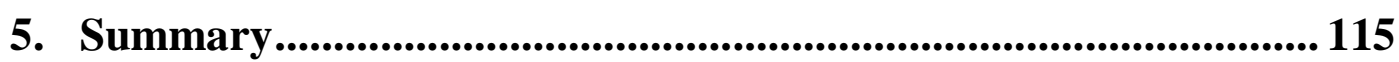

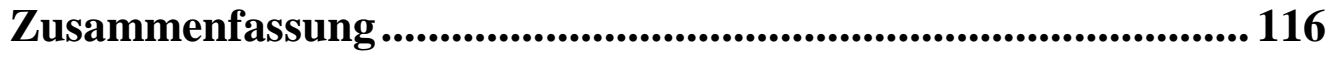

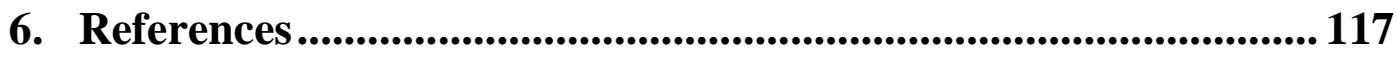

7. Appendix .......................................................................................... 147

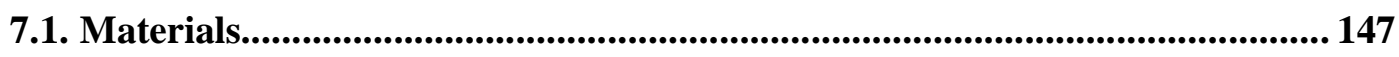

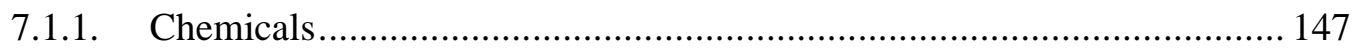

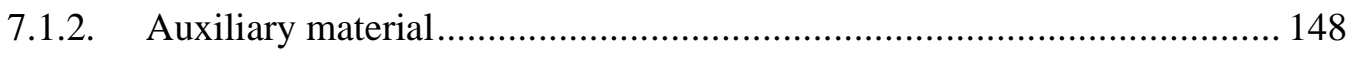

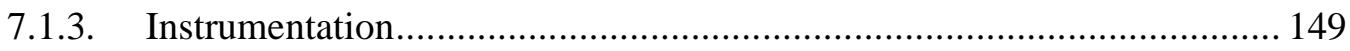

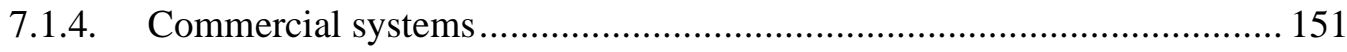

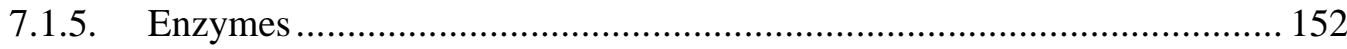

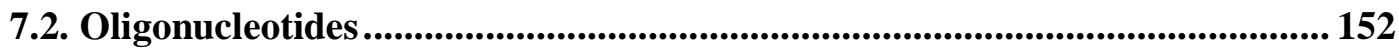

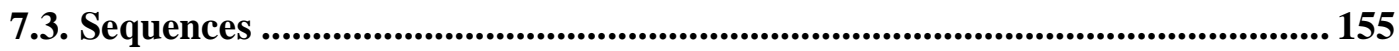

7.4. Internet programs and software.......................................................... 164 


\section{Abbreviations}

\begin{tabular}{|c|c|}
\hline$\%(\mathrm{v} / \mathrm{v})$ & $\%$ (volume/volume) \\
\hline$\%(\mathrm{w} / \mathrm{v})$ & $\%$ (weight/volume) \\
\hline$A$. & Archaeoglobus \\
\hline AMP & adenosine monophosphate \\
\hline ANME & anaerobic methane oxidizer \\
\hline $\mathrm{AOM}$ & anaerobic oxidation of methane \\
\hline AprA & APS reductase $\alpha$-subunit \\
\hline AprB & APS reductase $\beta$-subunit \\
\hline APS & adenosine-5' -phosphosulfate/ammonium peroxodisulfate \\
\hline ATP & adenosine triphosphat \\
\hline BSA & bovine serum albumin \\
\hline CDP-Star & disodium 2-chloro-5-(4-methoxyspiro\{1,2-dioxetane-3,2`-(5'- \\
\hline & chloro)tricyclo[3.3.1.1 $\left.1^{3,7}\right]$ decan $\left.\}-4-y l\right)-1$-phenyl phosphate \\
\hline$D$. & Desulfovibrio \\
\hline DAPI & 4',6-diamidino-2-phenylindole dihydrochloride \\
\hline DMSO & dimethyl sulfoxide \\
\hline DNA & desoxyribonucleic acid \\
\hline dNTP & desoxyribonucleic triphosphate \\
\hline DSS & Desulfosarcina/Desulfococcus \\
\hline$E$. & Escherichia \\
\hline EDTA & ethylenediaminetetraacetic acid \\
\hline EM & electron microscopy/microscope \\
\hline EPS & extracellular polymeric substances \\
\hline FE-SEM & field emission scanning electron microscopy/microscope \\
\hline FISH & fluorescence in situ hybridization \\
\hline ICM & intracytoplasmatic membranes \\
\hline $\operatorname{IgG}$ & immunoglobulin $\mathrm{G}$ \\
\hline IPTG & isopropyl- $\beta$-D-thiogalactopyranoside \\
\hline LB & Luria Bertani \\
\hline LEW & lysis/equilibration/wash \\
\hline
\end{tabular}


M.

MCR

$\mathrm{MDH}$

NMS

NTA

$\mathrm{OD}_{\mathrm{x}}$

OTU

PAA

PAGE

PBS

PCR

PIPES

pMMO

$\mathrm{PP}_{\mathrm{i}}$

PVDF

PWS

RT

SDS

sMMO

SMTZ

SRB

TAE

Taq

TB

TBS

TED

TEM

TEMED

Tm

Tris

ZAP
Methanosarcina/Methanospirillum/Methylobacterium

methyl coenzyme $\mathrm{M}$ reductase

Methanol dehydrogenase

nitrate mineral salts

nitrilo-tri-acetic acid

optical density, measured wavelength $\lambda=\mathrm{x} \mathrm{nm}$

operational taxonomic unit

polyacrylamide

polyacrylamide gel electrophoresis

phosphate buffered saline

polymerase chain reaction

piperazine-1,4-bis(2-ethanesulfonic acid)

particulate methane monooxygenase

pyrophosphate

polyvinylidene difluoride

phosphotungstic acid

room temperature

sodium dodecyl sulfate

soluble methane monooxygenase

sulfate-methane transition zone

sulfate reducing bacteria

Tris-acetate-EDTA

Thermus aquaticus

Transformation buffer

Tris-buffered saline

Tris-(carboxymethyl)-ethylenediamine

transmission electron microscopy/transmission electron microscope

$\mathrm{N}, \mathrm{N}, \mathrm{N}^{\prime}, \mathrm{N}^{\prime}$-tetramethylethylendiamine

melting temperature

tris-(hydroxymethyl)-aminomethane

Zellaufschluss-Puffer (cell lysis buffer) 


\section{Introduction}

\subsection{Global role of methane}

\subsubsection{Present state}

Methane is the most abundant hydrocarbon in the atmosphere (Wahlen, 1993). Like other important green house gases (water vapor, carbon dioxide, nitrous oxide, ozone and chlorofluorocarbon compounds) methane plays an important role in climate change. Methane gas absorbs long wave radiation emitted from the earth's surface and consequently affects atmospheric temperature directly (Lacis et al., 1981; Hansen et al., 1988; Ramanathan, 1988). Moreover, it influences the global temperature indirectly by chemical reactions with other atmospheric gases. Methane affects the abundance of ozone in the troposphere and in the stratosphere (Johnston, 1984), and represents a major source of stratospheric water (Ehhalt, 1979; Pollock et al., 1980). These characteristics result in a 25 -fold higher global warming potential than carbon dioxide, calculated over a 100-year time horizon (Forster et al., 2007). As a result, methane shows the second most effect on global warming after carbon dioxide (Rodhe, 1990). Thus the role of global methane cycle is of concern since the concentration of methane in the troposphere has increased over the past 100 years from 0.9 to 1.8 parts per million (Thauer et al., 2008).

Methane is released by different processes. Microbial formation of methane is the final step of anaerobic degradation of organic matter (details in section 1.2.1). This process represents a dominant part of methane production. But also abiotic production of methane by the serpentinization reaction is of relevance. This is a rock/water reaction occurring in hydrothermal systems as the midocean ridges and spreading centers. There, seawater induces the transition of olivine to magnetite. As a result $\mathrm{Fe}$ (II) in olivine is oxidized to $\mathrm{Fe}(\mathrm{III})$ in magnetite and hydrogen is produced (see Eq. 1). Hydrogen reacts with carbon dioxide in the presence of an iron or iron oxide catalyst at $300{ }^{\circ} \mathrm{C}$ and 500 bar to methane (Fischer-Tropsch synthesis; Eq. 2; Reeburgh, 2007):

$$
\begin{gathered}
6\left[\left(\mathrm{Mg}_{1.5} \mathrm{Fe}_{0.5}\right) \mathrm{SiO}_{4}\right]+7 \mathrm{H}_{2} \mathrm{O} \rightarrow 3\left[\mathrm{Mg}_{3} \mathrm{Si}_{2} \mathrm{O}_{5}(\mathrm{OH})_{4}\right]+\mathrm{Fe}_{3} \mathrm{O}_{4}+\mathrm{H}_{2} \\
\text { (olivine) } \\
\text { (serpentine) }
\end{gathered}
$$


$\mathrm{CO}_{2}+4 \mathrm{H}_{2} \rightarrow \mathrm{CH}_{4}+2 \mathrm{H}_{2} \mathrm{O}$

In addition, leaks from near-surface petroleum deposits and release of methane from clathrate hydrates represent methane sources (Reeburgh, 2007).

In contrast to terrestrial methane sources, oceans emit just a small part (2\%) of methane to the atmosphere due to consumption of methane before emission (Ehhalt, 1978; Lambert and Schmidt, 1993; Bange et al., 1994). The annual rate of methane production in the oceans is calculated to $85-300 \mathrm{Tg}$ methane of which $\geq 90 \%$ is consumed (Hinrichs and Boetius, 2002; Reeburgh, 2007).

Four major methane sources of about equal relevance contribute to the atmospheric inventory, namely: natural wetlands and tundra, animals (especially ruminants), anthropogenic land use (especially rice production), and fossil methane (natural gas and coal mining; Fung et al., 1991). In marine habitats coastal runoff, organic-rich anoxic sediments and seeps, vents and mud volcanoes emitting methane rich gas or fluids are major methane sources. However, the effective microbial consumption lowers the concentration of methane of most oceanic habitats to nanomolar level, undersaturated with respect to the atmosphere (Reeburgh, 2007). Nevertheless it remains uncertain, if rapid release of methane from clathrate hydrates in the future caused by warming can be microbially consumed (Dickens, 2003).

\subsubsection{Methane cycling in earth history}

Anaerobic oxidation of methane $(\mathrm{AOM})$ results in carbonate formation (see section 1.3.1.). This is the main reason why deposits of ancient seeps are still preserved. To identify limestones formed by methane seepage several aspects have to be considered: (a) the geological setting, (b) the occurrence of characteristic faunal assemblages (Campbell and Bottjer, 1995), (c) specific carbonate fabrics and phases (e.g. inverted stromatactoid cavities), (d) low $\delta^{13} \mathrm{C}$ values of early diagenetic carbonate phases and (e) characteristic ${ }^{13} \mathrm{C}$-depleted biomarkers (Peckmann and Thiel, 2004). Most ancient methane seepage deposits are described for Cenozoic strata, few are known from Mesozoic strata (Gaillard et al., 1992; Campbell and Bottjer, 1993; Kelly et al., 1995; Kauffman et al., 1996; Kelly et al., 2000; Campbell et al., 2002). The oldest methane dependent deposits with biomarker evidence were tracked back to the Jurassic 
(Peckmann et al., 1999b; Birgel et al., 2006). Nevertheless Palaeozoic deposits of methane seeps were demonstrated, too (Peckmann et al., 1999a; Peckmann et al., 2001a). One study is implicating AOM also in the formation of carbonate systems from the Archaean (approximately 2.7 billion years old), based on low ${ }^{13} \mathrm{C}_{\text {org }}$ isotopes (Hinrichs, 2002).

Isotopic data of kerogens and organic carbon reveal an important role of methanotrophy 2.7 billion years ago. It is assumed that with the increase of oxygen concentration in ocean water, methanotrophic bacteria were able to spread (Hayes, 1994). In spite of raising aerobic methanotrophy, the main process of Archaean carbonate formation was suggested to be AOM. This hypothesis is supported by two observations: (a) also in the present oxic oceans, carbonate accumulations are based on AOM metabolism, (b) at the beginning of Proterozoic a significant change in the sulfur cycle came up, putatively based upon AOM activity (Hinrichs, 2002; Hinrichs and Boetius, 2002).

A hypothesis for temporal evolution of biogeochemical cycles is depicted in Fig. 1.1. (Hinrichs and Boetius, 2002). On the left in Fig. 1.1. the sulfate-methane transition zone (SMTZ) is shown, as it is found in almost all anoxic aquatic systems (Reeburgh, 2007). The SMTZ represents the ecological niche for AOM associated organisms. Methane is reduced with sulfate as electron acceptor. Thus, both methane oxidation rate and sulfate reduction rate show a peak in the SMTZ. During the Archaean, fermentation may has been the only relevant process of degradation of organic matter. Methane and carbon dioxide were final products, quite stable due to only few available biologically utilizable electron acceptors. With oxygenation of the earth by oxygenic photosynthesis, also the sulfate concentration increased and enabled methane oxidation with sulfate as electron acceptor. For this time period it is assumed that sulfate was predominately reduced by methane oxidation. Even today, in certain sediments the sulfate is completely metabolized by AOM (Aharon and Fu, 2000; Boetius et al., 2000). Besides sulfate, also other oxidized compounds (e.g. iron or nitrate) promoted anaerobic respiration while fermentation processes decreased. Hence, also methane production per mole $\mathrm{C}_{\text {org }}$ was reduced. Due to reduced methanogenesis and consumption of accumulated methane, AOM activity declined. In conclusion AOM in marine sediments as well as in earth's history shows the highest activity, where high methane and sulfate concentrations are co-occurring (Hinrichs and Boetius, 2002). 


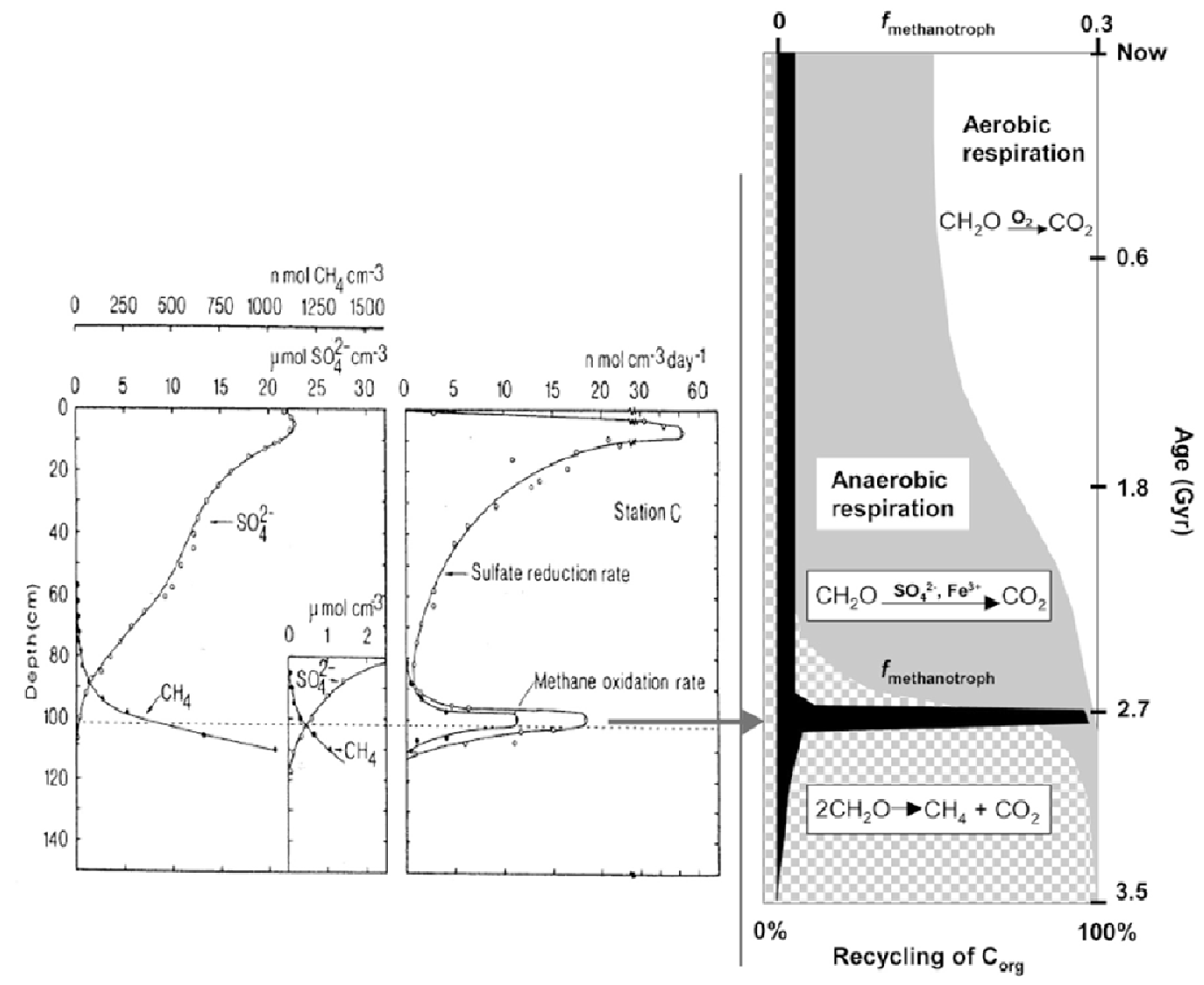

Figure 1.1.: Methanotrophy over the time (Hinrichs and Boetius, 2002).

Left: geochemical profile and sulfate reduction/methane oxidation rate. The high rate of sulfate reduction and methane oxidation is due to AOM activity in the sulfate-methane transition zone (SMTZ) where methane gets in contact to sulfate. Right: hypothetical temporal evolution of carbon cycle in earth's history. First microbial processes were based on fermentation leading to an accumulation of methane. With increasing concentrations of oxidized compounds AOM increased, too. The high AOM activity decreased with methane production, since fermentation processes were mainly displaced by microbial respiration (Figure from Hinrichs and Boetius, 2002; with kind permission of Springer Science + Business Media).

\subsection{Microbial processes involved in methane turnover}

Estimations vary, but approximately $85 \%$ of the annual methane production and approximately $60 \%$ of its consumption is based on microbial processes (McDonald et al., 2008; Knittel and Boetius, 2009). Ongoing studies mainly aim at metabolic processes, participating microorganisms and fluxes of substrates and products.

Four microbial key processes are presently known (cf. Reeburgh, 2007): (a) the formation of methane by methanogenic archaea (Thauer et al., 2008), (b) the aerobic 
consumption of methane by methanotrophic bacteria (Hanson and Hanson, 1996), (c) the anaerobic consumption of methane by syntrophic consortia of anaerobic methane oxidizers (ANME) and sulfate reducing bacteria (SRB; Knittel and Boetius, 2009), (d) anaerobic consumption by bacteria of the NC10 phylum (Ettwig et al., 2009; Ettwig et al., 2010). Especially the recently discovered AOM turned out to be very important in carbon cycling. Over $90 \%$ of the microbially produced methane in the oceans is consumed by this process (Hinrichs and Boetius, 2002).

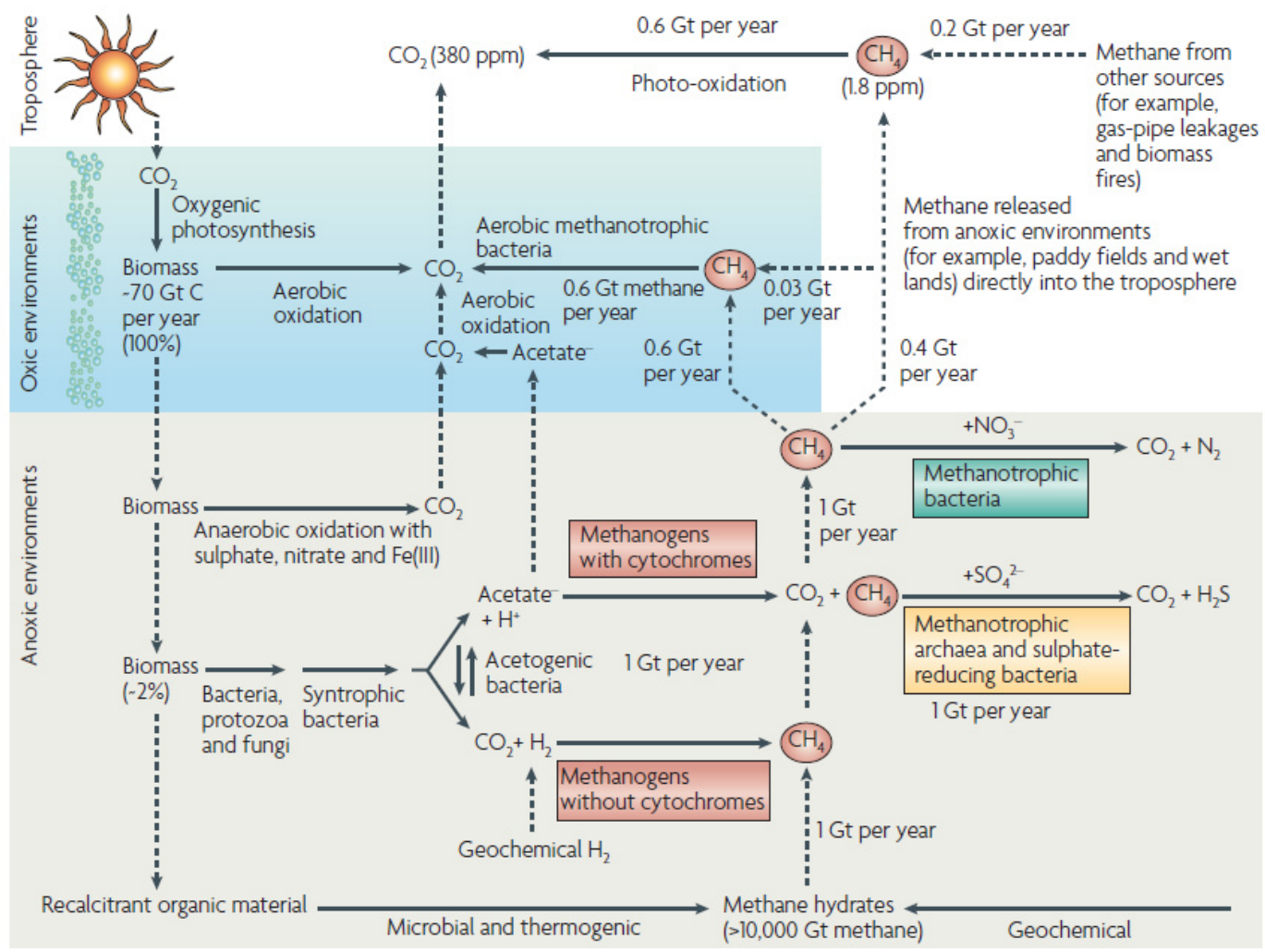

Figure 1.2.: Methane turnover in global cycle (Thauer et al., 2008).

Continuous arrows indicate a reaction and dashed arrows indicate diffusion and/or convection. $1 \mathrm{Gt}$ methane is produced by methanogenesis sourced from organic compounds. In addition $1 \mathrm{Gt}$ is released from methane hydrates. From this amount $1 \mathrm{Gt}$ is oxidized by AOM and $0.6 \mathrm{Gt}$ by aerobic bacteria. Remaining 0.4 Gt and 0.2 Gt from other sources reach the troposphere (Lelieveld et al., 1998; Lee and Holder, 2001; Krüger et al., 2005; Thauer et al., 2008). Reprinted by permission from Macmillan Publishers Ltd: Nature Reviews Microbiology (Thauer et al., 2008), copyright 2008. 
The metabolic key pathways of the methane cycle are depicted in Fig. 1.2. Dissociation of methane hydrates and methanogenesis produce approximately $2 \mathrm{Gt}$ of methane per year. Approximately $0.6 \mathrm{Gt}$ are oxidized to $\mathrm{CO}_{2}$ by aerobic bacteria, approximately $1 \mathrm{Gt}$ is oxidized by anaerobic archaea and approximately $0.4 \mathrm{Gt}$ are released to the atmosphere. Further 0.2 GT are emitted by other sources, such as industrial gas leakages or biomass fires (Lelieveld et al., 1998; Lee and Holder, 2001; Krüger et al., 2005; Thauer et al., 2008). These data stress that the importance of AOM is not limited to marine environments, but represents a crucial part of global methane degradation.

\subsubsection{Methanogenesis}

The formation of methane is restricted to methanogenic archaea, a phylogenetical diverse group of strictly anaerobic Euryarchaeota (Garcia et al., 2000). They are classified in the five orders Methanobacteriales, Methanococcales, Methanomicrobiales, Methanopyrales and Methanosarcinales. Carbon dioxide and hydrogen, formate, methanol, methylamines and acetate represent the compounds for methane formation (Thauer, 1998). The compounds are metabolized by only three methanogenic pathways, namely: reduction of carbon dioxide, methyl-group reduction and the aceticlastic reaction. Only members of the Methanosarcinales ferment acetate to carbon dioxide and methane with $\mathrm{C}_{1}$ compounds (methanol, methylthiols or methylamines) as sole energy sources (Thauer, 1998; Liu and Whitman, 2008). As depicted in Fig. 1.2. the methanogenic archaea hold an important role in global methane cycle by producing annually approximately $1 \mathrm{Gt}$ methane. Methanogenesis represents the final step of anaerobic biomass degradation (Eq. 3; Thauer, 1998):

$$
\mathrm{C}_{6} \mathrm{H}_{12} \mathrm{O}_{6} \rightarrow 3 \mathrm{CO}_{2}+3 \mathrm{CH}_{4} \quad \delta G^{0^{\prime}}=-418.1 \mathrm{~kJ} / \mathrm{mol}
$$

Biomass is degraded in anaerobic environments by syntrophic associations of microorganisms. After degradation of biopolymers to monomers, the organic compounds are fermented where concentrations of electron acceptors like sulfate, nitrate, oxidized manganese or iron are low. In the presence of these oxidized compounds, methanogenesis is out-competed by anaerobic respiration due to thermodynamic reasons (Schönheit et al., 1982; Thauer et al., 2008). That is why in the 
upper layer of marine sediments, where sulfate concentration is high, methanogenesis is restricted to substrates such as methylamines, which are not metabolized by sulfate reducing bacteria. The prevalent substrate cellulose, for example, is degraded by microorganisms to the monomer glucose. Then, glucose is fermented to acetate, carbon dioxide and hydrogen or to acetate, formate and hydrogen (Eq. 4 and Eq. 5; Thauer, 1998):

$\mathrm{C}_{6} \mathrm{H}_{12} \mathrm{O}_{6}+2 \mathrm{H}_{2} \mathrm{O} \rightarrow 2 \mathrm{CH}_{3} \mathrm{COO}^{-}+2 \mathrm{H}^{+}+2 \mathrm{CO}_{2}+4 \mathrm{H}_{2}$

$\delta G^{0^{\prime}}=-215.7 \mathrm{~kJ} / \mathrm{mol}$

$\mathrm{C}_{6} \mathrm{H}_{12} \mathrm{O}_{6}+2 \mathrm{H}_{2} \mathrm{O} \rightarrow 2 \mathrm{CH}_{3} \mathrm{COO}^{-}+2 \mathrm{HCOO}^{-}+4 \mathrm{H}^{+}+2 \mathrm{H}_{2}$

$\delta G^{0^{\prime}}=-208.7 \mathrm{~kJ} / \mathrm{mol}$

In a second step the products are converted by methanogenic archaea to methane (Eq. 6,7,8):

$\mathrm{CH}_{3} \mathrm{COO}^{-}+\mathrm{H}^{+} \rightarrow \mathrm{CO}_{2}+\mathrm{CH}_{4} \quad \delta G^{0^{\prime}}=-36 \mathrm{~kJ} / \mathrm{mol}$

$4 \mathrm{H}_{2}+\mathrm{CO}_{2}+\mathrm{H}^{+} \rightarrow \mathrm{CH}_{4}+2 \mathrm{H}_{2} \mathrm{O}$

$\delta G^{0^{\prime}}=-131 \mathrm{~kJ} / \mathrm{mol}$

$4 \mathrm{HCOO}^{-}+4 \mathrm{H}^{+} \rightarrow 3 \mathrm{CO}_{2}+\mathrm{CH}_{4}+2 \mathrm{H}_{2} \mathrm{O} \quad \delta G^{0^{\prime}}=-144.5 \mathrm{~kJ} / \mathrm{mol}$

$\mathrm{C}_{1}$ compounds get disproportionated to carbon dioxide and methane or get reduced to methane with $\mathrm{H}_{2}$ (cf. Eq. 9 and 10, exemplary for methanol; Thauer, 1998):

$$
\begin{array}{ll}
4 \mathrm{CH}_{3} \mathrm{OH}+2 \mathrm{H}_{2} \mathrm{O} \rightarrow \mathrm{CO}_{2}+3 \mathrm{CH}_{4}+4 \mathrm{H}_{2} \mathrm{O} & \delta G^{0^{\prime}}=-106.5 \mathrm{~kJ} /\left(\mathrm{mol} \mathrm{CH}_{4}\right) \\
\mathrm{CH}_{3} \mathrm{OH}+\mathrm{H}_{2} \rightarrow \mathrm{CH}_{4}+\mathrm{H}_{2} \mathrm{O} & \delta G^{0^{\prime}}=-112.5 \mathrm{~kJ} / \mathrm{mol}
\end{array}
$$

The methanogenic archaea represent the only group of microorganisms capable of this metabolic pathway, but have no alternative ways for energy conservation. Thus, they are strictly limited to their ecological niche. In addition, methanogenic archaea are very sensitive to small amounts of oxygen. Nevertheless, they are able to survive in aerated 
natural habitats. In that case, activities of other organisms using oxygen for respiration can protect methanogens by providing anoxic microenvironments (Brusa et al., 1987; Belay et al., 1988; Whitman et al., 2006).

\subsubsection{Methanotrophic bacteria}

The aerobic microbial oxidation of methane has been already discovered by the beginning of the $20^{\text {th }}$ century. The first methanotrophic bacterium was isolated by Söhngen (1906). Thus, today there is already extensive knowledge, in comparison to other methane oxidation pathways, about ecology, physiology and genetic as well as enzymatic background of aerobic methanotrophy (Hanson and Hanson, 1996). Methanotrophs represent a subset of a physiological group of bacteria known as methylotrophs. They distinguish from methylotrophic bacteria by their ability to utilize methane as a sole carbon and energy source. Methylotrophic bacteria utilize one-carbon compounds, higher reduced than formic acid, as substrates. These compounds are for example methanol, methylated amines, halomethanes, and methylated compounds containing sulfur (Anthony, 1982, 1986; Hanson et al., 1990; Anthony, 1991; Lidstrom, 2006).

As shown in Fig. 1.2., methanotrophic bacteria have an important role in the global methane cycle by oxidizing annually approximately $0.6 \mathrm{Gt}$ methane. Methanotrophic bacteria are present in nearly all habitats where methane and oxygen is available, such as in swamps, rivers, rice paddies, soils from meadows, deciduous woods, freshwater and marine water as well as in technical processes, e.g. in sewage sludge (Whittenbury et al., 1970; Hanson, 1980; Heyer et al., 1984; Strand and Lidstrom, 1984; Corpe, 1985; Sieburth et al., 1987; Holmes et al., 1995; Dedysh et al., 1998; McDonald et al., 2008; Conrad, 2009). Moreover, methanotrophs exist as symbionts in mussels, clams and Pogonophora (Distel and Cavanaugh, 1994; DeChaine and Cavanaugh, 2006; Duperron et al., 2009). In particular, methanotrophic bacteria were detected in oxic environments near methane seeps and hydrothermal vents where they provide the basis of a food chain independent of photosynthesis (Childress et al., 1986; Cavanaugh et al., 1987; Fisher, 1990; Cavanaugh et al., 1992; Cavanaugh, 1993; Fisher et al., 1993; Distel and Cavanaugh, 1994; Larock et al., 1994; Dubilier et al., 1998; DeChaine and Cavanaugh, 2006; Conrad, 2009). For example samples of marine mud volcanoes, like Haakon 
Mosby (Barents Sea) and Kazan mud volcano (eastern Mediterranean sea), contained methanotrophs (Niemann et al., 2006; Heijs et al., 2007; Lösekann et al., 2007). Also in the water column above methane seeps of the Black Sea type I methanotrophs were detected (Durisch-Kaiser et al., 2005; Schubert et al., 2006).

Type I methanotrophs belong to the subdivision of $\gamma$-Proteobacteria including the genera Methylobacter, Methylomicrobium, Methylomonas, Methylocaldum, Methylosphaera, Methylothermus, Methylosarcina, Methylohalobius, Methylosoma, and Methylococcus. Methylococcus and Methylocaldum are also referred as type X methanotrophs, which are distinguished by certain physiological, biochemical and phylogenetic characteristics (Bowman, 2006; McDonald et al., 2008). The group of type I methanotrophs metabolize methane by the ribulose monophosphate (RuMP) pathway and exhibit intracytoplasmic membranes (ICM) as stacks of membrane disks (Fig. 1.3.a; Hanson and Hanson, 1996; Trotsenko and Murrell, 2008).
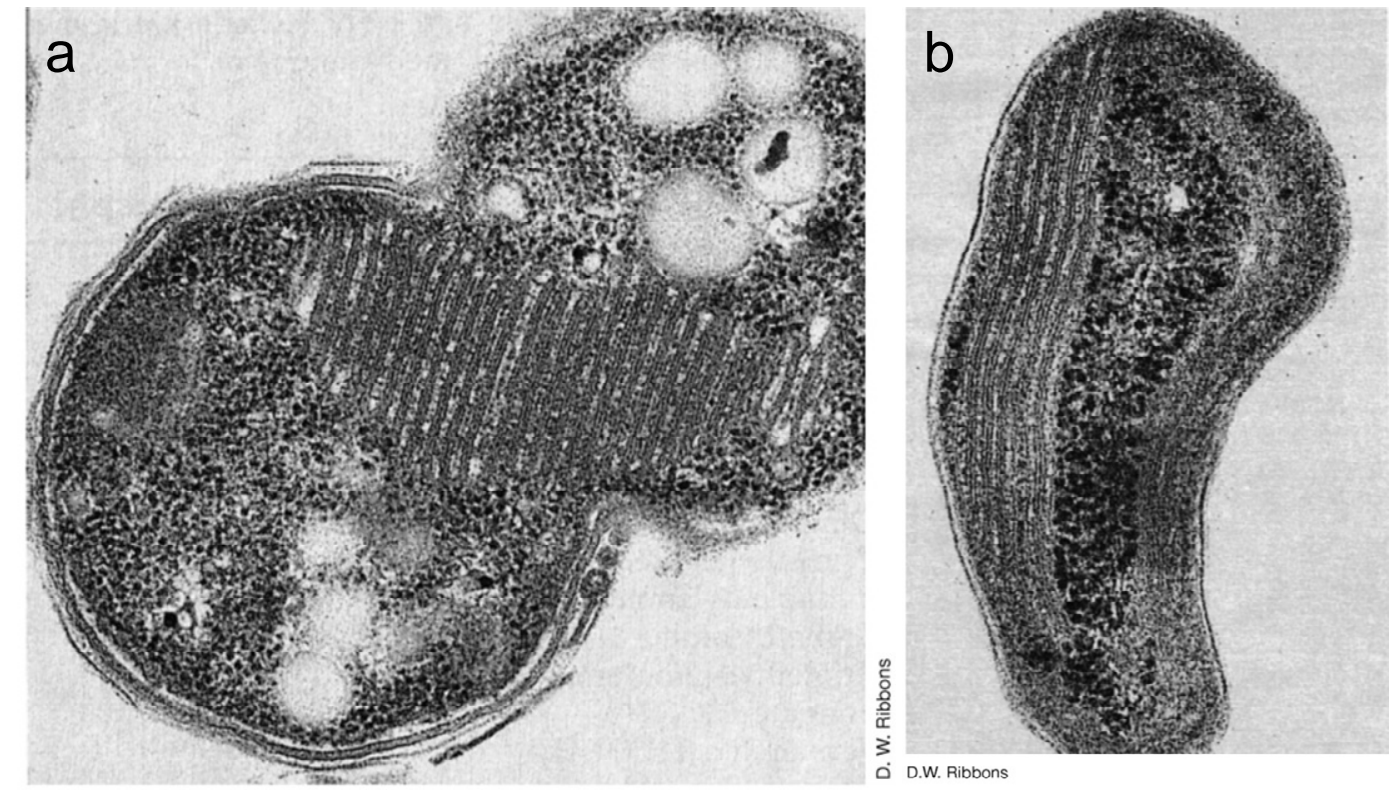

Figure 1.3.: Intracytoplasmic membranes of methanotrophs (Madigan and Martinko, 2006).

(a) type I methanotrophic bacterium, Methylococcus capsulatus, with ICM as stacks of membrane disks (cell diameter: $1 \mu \mathrm{m}$ ). (b) type II methanotrophic bacterium, Methylosinus, with ICM parallel to the cytoplasmic membrane (cell diameter: $0.6 \mu \mathrm{m}$; Figure from Madigan and Martinko, 2006; with kind permission of Pearson Education Deutschland GmbH). 
Type II methanotrophs Methylocystis, Methylosinus, Methylocella, and Methylocapsa are in the subdivision $\alpha$-Proteobacteria (McDonald et al., 2008). They utilize methane by the serine pathway and exhibit ICM parallel to the cytoplasmic membrane (Fig. 1.3.b; Hanson and Hanson, 1996; Trotsenko and Murrell, 2008). Methylocella is also known for vesicular membranes (Dedysh et al., 1998).

Recently some new aerobic methylotrophs were described. Crenothrix polyspora and Clonothrix fusca are the first described filamentous methane oxidizers, both related to type I methanotrophs (Stoecker et al., 2006; Vigliotta et al., 2007). Moreover, methanotrophs belonging to the phylum Verrucomicrobia (Dunfield, 2007; Pol et al., 2007; Islam et al., 2008) were recently described and placed in the new genus Methylacidiphilum (Op den Camp et al., 2009).

By stable isotope probing two groups of methanotrophs were detected at marine hydrocarbon seeps, Methylophaga ( $\gamma$-Proteobacteria) and Methylophilaceae-genera ( $\beta$ Proteobacteria; Redmond et al., 2010). These new findings indicate that presumably more bacterial phylotypes are capable of methane oxidation than previously thought.

The first enzyme of the methanotrophic pathway (cf. Fig. 3.1.), methane monooxygenase (MMO), oxidizes methane to methanol. Two variants of the enzyme are known, the membrane-bound particulate $\mathrm{MMO}(\mathrm{pMMO})$ and the soluble MMO (sMMO). The pMMO is the canonical enzyme, abundant in almost all methanotrophs. The sMMO is only abundant in a few strains. The sMMO has a broader substrate specificity (for diverse aliphatic and aromatic hydrocarbons) and is more stable than the pMMO exhibiting a smaller range for substrates. In methanotrophs with both MMO, the sMMO is only expressed under copper limitation (Hanson and Hanson, 1996; Lidstrom, 2006). Just one genus, Methylocella, was described, which contains solely the sMMO (Conrad, 2009).

The methanol dehydrogenase $(\mathrm{MDH})$ catalyzes the second step of aerobic methane oxidation and represents a key enzyme for methanotrophic as well as methylotrophic bacteria. It converts methanol to formaldehyde. For carbon assimilation, formaldehyde is used for ribulose monophosphate pathway or the serine cycle, for type I and type II methanotrophs, respectively. Some methylotrophs assimilate carbon dioxide in the Calvin-Benson-Bassham cycle (Hanson and Hanson, 1996; Lidstrom, 2006). 
Since methane represents highly reduced carbon, the energy yield of the methanotrophic pathway is high (see Eq. 11; Widdel, 2002):

$$
\mathrm{CH}_{4}+2 \mathrm{O}_{2} \rightarrow \mathrm{CO}_{2}+2 \mathrm{H}_{2} \mathrm{O} \quad \delta G^{0}=-818 \mathrm{~kJ} /\left(\mathrm{mol} \mathrm{CH}_{4}\right)
$$

\subsubsection{Anaerobic oxidation of methane (AOM)}

The AOM is a widely abundant process of importance in the global methane cycle. Approximately $\geq 90 \%$ of the annually produced methane in the oceans is oxidized in anoxic, marine sediments (cf. section 1.1.1.; Hinrichs and Boetius, 2002). Thus, only $2 \%$ of the global methane budget originates from oceanic systems (cf. section 1.1.1.). The anaerobic oxidation of methane is usually associated with the precipitation of carbonates and sulfides, which was observed in marine mud volcanoes as well as in cold seeps (Aloisi et al., 2000; Peckmann et al., 2001b; Aloisi et al., 2002). The process of AOM was already postulated in 1974. Methane and sulfate concentration profiles in anoxic sediments and water columns gave indications to this process (Martens and Berner, 1974; Barnes and Goldberg, 1976; Reeburgh, 1976). These findings were confirmed by tracer measurements using $\left[{ }^{14} \mathrm{C}\right]-\mathrm{CH}_{4},\left[{ }^{3} \mathrm{H}\right]-\mathrm{CH}_{4}$ or $\left[{ }^{35} \mathrm{~S}\right]-\mathrm{SO}_{4}{ }^{2-}$ for turnover rates of methane and sulfate. The results were also substantiated by natural ${ }^{13} \mathrm{C} /{ }^{12} \mathrm{C}$ ratio of methane and $\mathrm{CO}_{2}$. In the water column and in oxic sediments these compounds showed a low depletion of ${ }^{13} \mathrm{C}$ isotopes, whereas in deposits of methane seeps a high depletion of ${ }^{13} \mathrm{C}$ isotopes was observed. This shift in the isotopic ratio was due to the preference of compounds containing lighter isotopes in enzyme-catalyzed reactions (Reeburgh, 1980; Iversen and Blackburn, 1981; Oremland and Desmarais, 1983). Therefore, the anaerobic oxidation of methane coupled to reduction of sulfate is usually related to marine, anaerobic sites since in oceanic systems high sulfate concentrations are available (D'Hondt et al., 2002).

It was postulated that archaea can reverse the methanogenic pathway for methane oxidation, while electrons are transferred to SRB (Hoehler et al., 1994). This hypothesis is still corresponding to the opinion of actual research (Knittel and Boetius, 2009). The energy yield of AOM is extreme low (Eq. 12) and methane oxidation is only favorable in syntrophy with sulfate reduction (Eq. 13 and Eq. 14; Thauer and Shima, 2008). The 
measured stoichiometric ratios of 1:1 (methane:sulfate) are in accordance with Eq. 12 (Nauhaus et al., 2002; Seifert et al., 2006; Wegener et al., 2008).

$$
\begin{array}{ll}
\mathrm{CH}_{4}+\mathrm{SO}_{4}{ }^{2-}+\mathrm{H}^{+} \rightarrow \mathrm{CO}_{2}+\mathrm{HS}^{-}+2 \mathrm{H}_{2} \mathrm{O} & \delta G^{0^{\prime}}=-21 \mathrm{~kJ} / \mathrm{mol} \\
\mathrm{CH}_{4}+2 \mathrm{H}_{2} \mathrm{O} \rightarrow \mathrm{CO}_{2}+4 \mathrm{H}_{2} & \delta G^{0^{\prime}}=+131 \mathrm{~kJ} / \mathrm{mol} \\
4 \mathrm{H}_{2}+\mathrm{SO}_{4}{ }^{2-}+2 \mathrm{H}^{+} \rightarrow \mathrm{H}_{2} \mathrm{~S}+4 \mathrm{H}_{2} \mathrm{O} & \delta G^{0^{\prime}}=-152 \mathrm{~kJ} / \mathrm{mol}
\end{array}
$$

The first evidence for anaerobic methanotrophy was given by Hinrichs et al. (1999) based on the isolation of archaeal lipids depleted in ${ }^{13} \mathrm{C}$. Considering the hypothesis of a reversed methanogenic pathway, ANME archaea require homologous enzymes of methanogenesis. The methyl-coenzyme M reductase (MCR) catalyzes in methanogenic archaea the terminal step of methane formation. In reversal, MCR is needed in a reversed methanogenic pathway for the initial step of AOM. The MCR of methanogens is a $300 \mathrm{kDa}$ enzyme with three subunits $\left(\alpha_{2} \beta_{2} \gamma_{2}\right)$ and two tightly bound molecules of the nickel porphinoid cofactor F430 with a molecular mass of $905 \mathrm{Da}$ (Thauer, 1998). Novel DNA sequences ( $m c r A$ gene) of MCR could be detected in ANME archaea (Hallam et al., 2003). Krüger et al. (2003) were able to identify the MCR on protein level in cold seeps of the Black Sea. A 951 Da nickel porphinoid cofactor, similar to F430, is bound to the enzyme. This Ni-protein I was present in concentrations of maximum $7 \%$ of the bulk protein mass and was assigned to ANME-1 group. The new nickel cofactor was identified as 172-methylthio-F430 (Mayr et al., 2008). MCR from ANME-2 cells use apparently the 905 Da nickel cofactor known from methanogens (Krüger et al., 2003). The MCR expression of ANME-1 and ANME-2 cells was shown by Heller et al. (2008) on cellular level. A further direct proof for anaerobic methanotrophy was based on isotopic evidence in combination with FISH analysis demonstrating the uptake of methane by ANME-2 cells (Orphan et al., 2001a). In addition, almost all methanogenic enzymes were found by genome analysis. Genes of dissimilatory sulfate reduction could not be detected in ANME archaea. Thus, syntrophy with SRB appears to be obligatory (Hallam et al., 2004; Meyerdierks et al., 2005; Pernthaler et al., 2008; Meyerdierks et al., 2010). 
Intermediates for a necessary transfer of reducing equivalents between the syntrophic partners are still unknown. Model based calculations suggested formate as a possible intermediate (Sörensen et al., 2001), but in in vitro feeding studies, hydrogen, formate, acetate and methanol could be excluded (Nauhaus et al., 2002; Widdel et al., 2006). Also methyl sulfides were suggested (Moran et al., 2008), but this finding could not be proved by other studies (Knittel and Boetius, 2009). A further hypothesis proposed a transfer of reducing equivalents via electron shuttles. Tests with compounds like phenazines and humic acids gave no positive results (Nauhaus et al., 2005). Transfer of reducing equivalents by nanowires (Gorby et al., 2006) was hitherto not reported. Recent analysis of the ANME-1 genome also suggests $c$-type cytochromes as possible carrier (Meyerdierks et al., 2010). In vitro analysis of ANME/SRB consortia with stable isotopes suggested autotrophy of the syntrophic SRB partner cell. Only archaeal lipids indicated incorporation of ${ }^{13} \mathrm{C}$-labeled methane, for SRB only incorporation of ${ }^{13} \mathrm{C}$ labeled carbon dioxide was observed (Wegener et al., 2008). Thus, it is unlikely that the SRB take up organic substrates derived from the AMNE-1 metabolism. Assimilation of $\mathrm{CO}_{2}$ is known for SRB to occur via the reductive citric-acid cycle (Schauder et al., 1987) or the acetyl-CoA pathway (Jansen et al., 1984; Jansen et al., 1985; Schauder et al., 1989).

Studies of physiology and biochemistry of AOM organisms are challenging since no pure cultures are available in the laboratory. Analyses have to be performed with enrichment cultures exhibiting a very slow growth due to the small energy yield of $\operatorname{AOM}$ (Eq. 12). The doubling time of the cells is approximately between 2 and 7 month (Nauhaus et al., 2007; Krüger et al., 2008a).

For the detection of AOM communities the approach of lipid biomarker analysis is well established. Isoprenoidal dialkyl glycerol diethers (archaeol, hydroxyarchaeol), tetramethylhexadecane (crocetane) and pentamethylicosenes are frequently used for identification. Depletion of ${ }^{13} \mathrm{C}$ isotopes in biomarkers indicate consumption of methane by $\mathrm{AOM}$ metabolism (usually -40 to $-70 \%$ o compared to the stable carbon isotope ratio of the source methane; Blumenberg et al., 2004; Blumenberg et al., 2005; Reeburgh, 2007; Niemann and Elvert, 2008). Isotopic analysis of biomarkers can also be applied for identification of ancient AOM systems (Thiel et al., 1999; Peckmann and Thiel, 2004). For identification of sulfate reducing partner of ANME cells, characteristic ${ }^{13} \mathrm{C}$ depleted fatty acids such as $\mathrm{C}_{16: 1 \omega 5}$, cy- $\mathrm{C}_{17: 0 \omega 5,6}$, and $\mathrm{C}_{17: 1 \omega 6}$ are used (Niemann and 
Elvert, 2008). Notably, sometimes hopanoids from methanotrophic bacteria are found at AOM sites (Elvert et al., 2000; Pancost et al., 2000; Thiel et al., 2001; Thiel et al., 2003; Birgel and Peckmann, 2008). It is under discussion, if also certain groups of marine SRB or other anaerobic bacteria produce these hopanoids (Fischer et al., 2005; Härtner et al., 2005; Blumenberg et al., 2006; Birgel and Peckmann, 2008).

Different groups catalyzing AOM have been identified yet. Most studies are based on 16s rRNA and mcrA genes, supported by lipid biomarker fingerprints with stable isotope analysis (Knittel and Boetius, 2009).

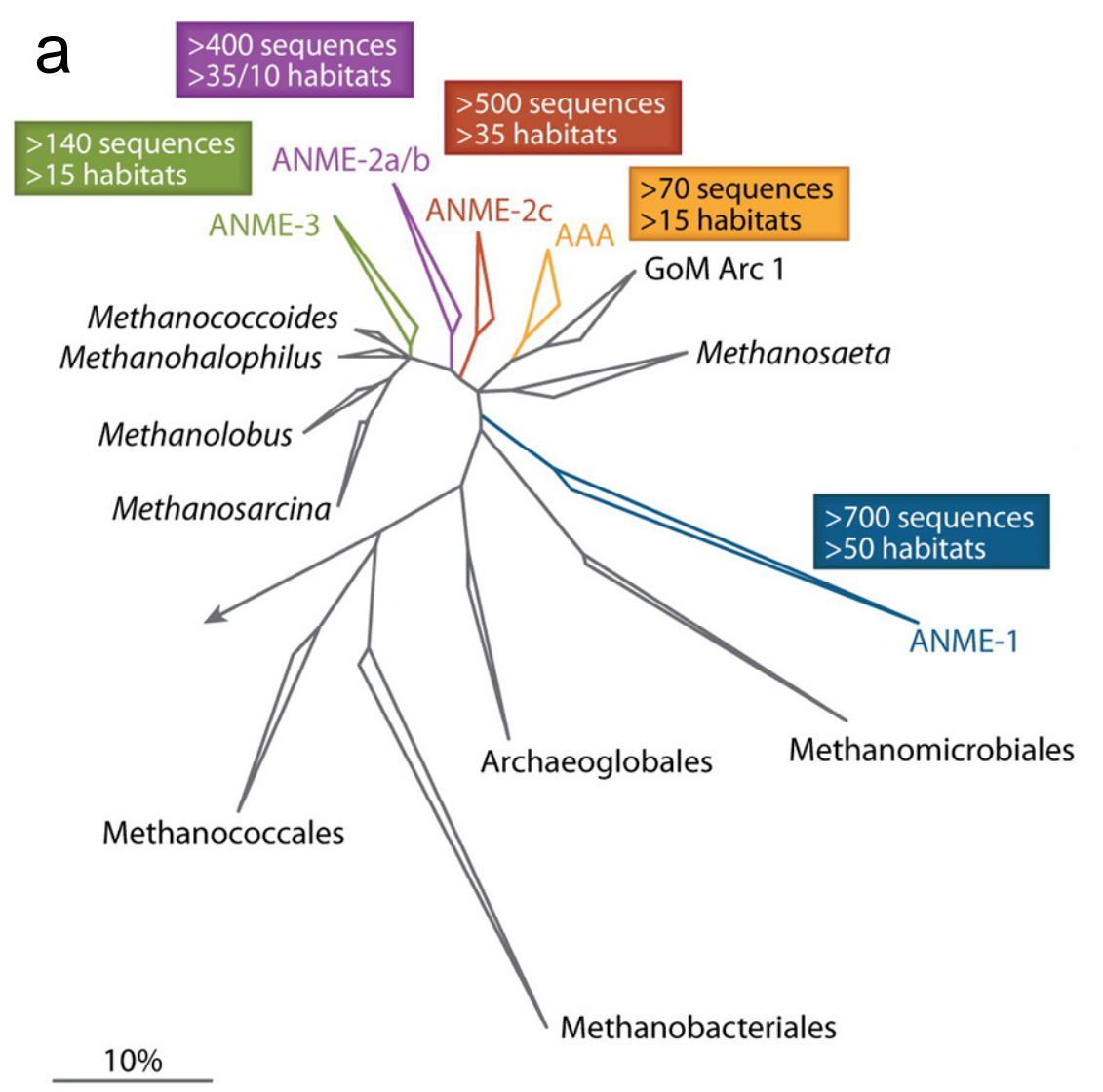

\section{Figure 1.4.: Phylogenetic tree of ANME cluster (Knittel and Boetius, 2009).}

Phylogenetic tree of ANME 16S rRNA gene sequences and other sequences within the archaeal domain. Data in colored boxes give information about the distribution and abundance of sequences. Bar, $10 \%$ estimated sequence divergence. Reproduced with permission of ANNUAL REVIEWS, INC, from Anaerobic Oxidation of Methane: Progress with an Unknown Process, K. Knittel and A. Boetius, 63, 311 334, copyright 2009; permission conveyed through Copyright Clearance Center, Inc. 
The three ANME clusters are: ANME-1, ANME-2 with the subclasses $-2 a,-2 b$, and $-2 c$, and ANME-3. The euryarchaeal groups are not monophyletic. ANME-1 are distantly related to Methanomicrobiales (Fig. 1.4.; Hinrichs et al., 1999), while ANME-2 and ANME-3 are distantly related to Methanosarcinales (Fig. 1.4.; Orphan et al., 2001b; Niemann et al., 2006). A fourth group has been described as ANME-2d or GoM Arc I; this group is not monophyletic with the other ANME-2 subgroups (Mills et al., 2005; Lloyd et al., 2006; Martinez et al., 2006). AOM metabolism for this novel group has not yet been proven (Knittel and Boetius, 2009). Fig. 1.4. illustrates that ANME-1 and ANME-2 are the most diverse groups detected in a multitude of habitats. ANME-3 and GoM Arc I, representing new described groups, are less abundant.

The ANME groups show differences in cell morphology, aggregate structure and related syntrophic partners.

ANME-1 cells exhibit a cylinder-shaped morphology with an external sheath and were observed as single cells or in filaments (Fig. 1.5.a,b and Fig. 1.6.; Eller et al., 2005; Reitner et al., 2005a). In microbial mats they were found in loose association with SRB of Desulfococcus/Desulfosarcina (DSS) group (Reitner et al., 2005a; Reitner et al., 2005b).

ANME-2 cells are coccoid and frequently detected in consortia with SRB. ANME-2a form mixed-type aggregates with SRB showing a randomly distribution of both cell types (Fig. 1.5.c-e), while ANME-2c/SRB aggregates reveal a shell-like structure (Fig. 1.5.f,g). ANME-2 are usually associated with SRB of the DSS group (Boetius et al., 2000), in particular with subgroup SEEP-SRB1a (Schreiber et al., 2010). But also partner cells of $\alpha$-Proteobacteria, $\beta$-Proteobacteria or Desulfobulbus-related SRB were described (Pernthaler et al., 2008). Single ANME-2 cells were reported as well (Fig. 1.5h; Orphan et al., 2002; Durisch-Kaiser et al., 2005; Eller et al., 2005; Schubert et al., 2006; Treude et al., 2007).

The phylogenetic group of ANME-3 was observed as shell-type aggregates with SRB (Fig. 1.5.i) or as single cells. Syntrophic partners are related to the Desulfobulbus group (Niemann et al., 2006; Lösekann et al., 2007). In some cases SRB of the DSS subgroup SEEP-SRB1a were reported (Schreiber et al., 2010). The described syntrophic associations suggest that ANME cells are not restricted to distinct bacterial partners. 


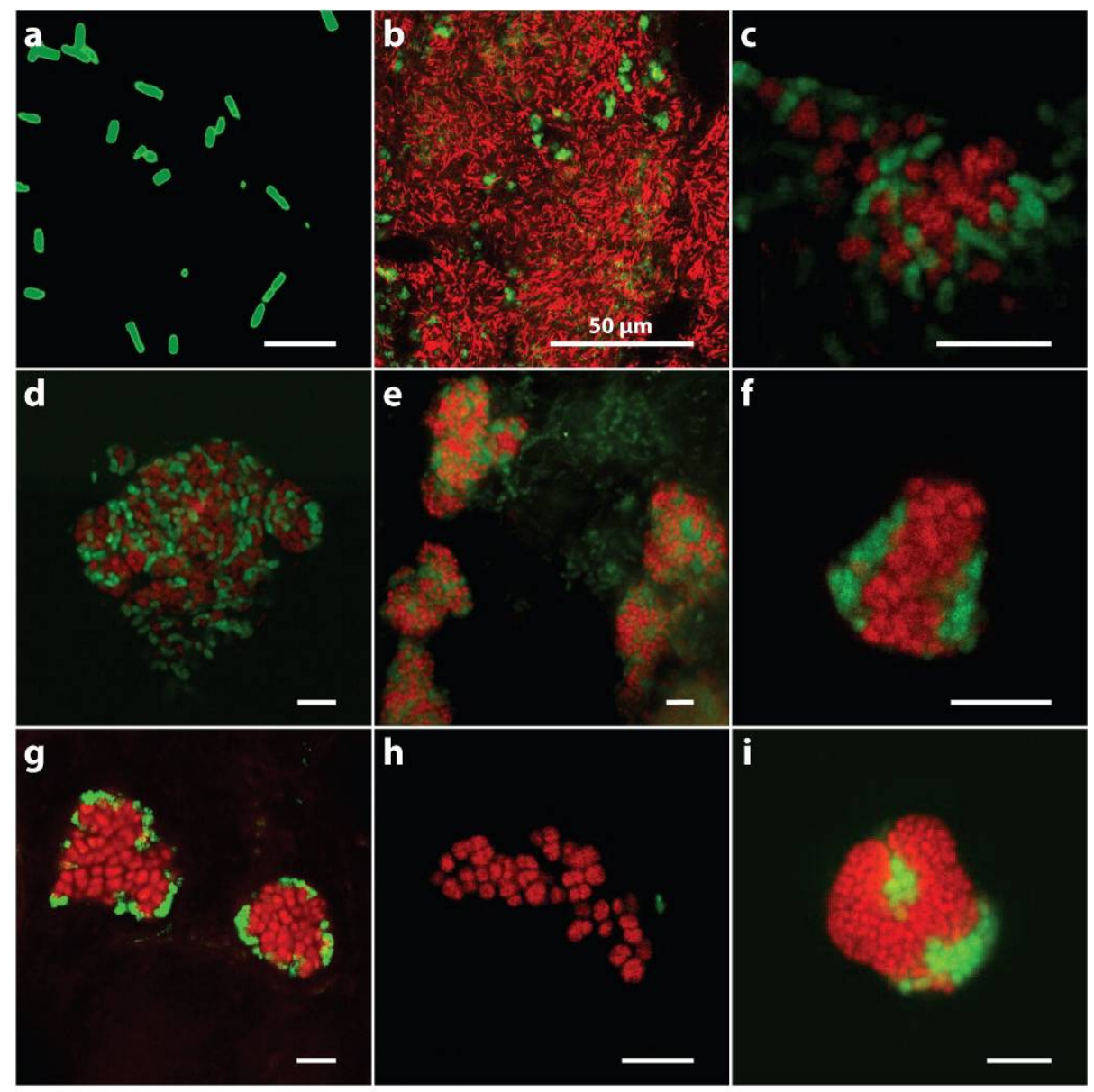

Figure 1.5.: Different ANME cells and aggregates (Knittel and Boetius, 2009).

Epifluorescence micrographs of different ANME single cells and aggregates visualized by fluorescence in situ hybridization (FISH) or CARD-FISH (Catalyzed Reporter Deposition-FISH). (a) single ANME-1 cells from a Black Sea microbial mat. (b) mat-type consortia formed by ANME-1 (red) and DSS cells (green). (c-e) mixed-type consortia of ANME-2a (red) and DSS (green) cells observed in different seep sediments. (f,g) shell-type consortia of ANME-2c (red) and DSS cells (green) and (h) single ANME-2c cells observed in different seep sediments. (i) ANME-3/Desulfobulbus consortia. Unless otherwise indicated, scale bar is $5 \mu \mathrm{m}$. Reproduced with permission of ANNUAL REVIEWS, INC, from Anaerobic Oxidation of Methane: Progress with an Unknown Process, K. Knittel and A. Boetius, 63, 311-334, copyright 2009; permission conveyed through Copyright Clearance Center, Inc. 

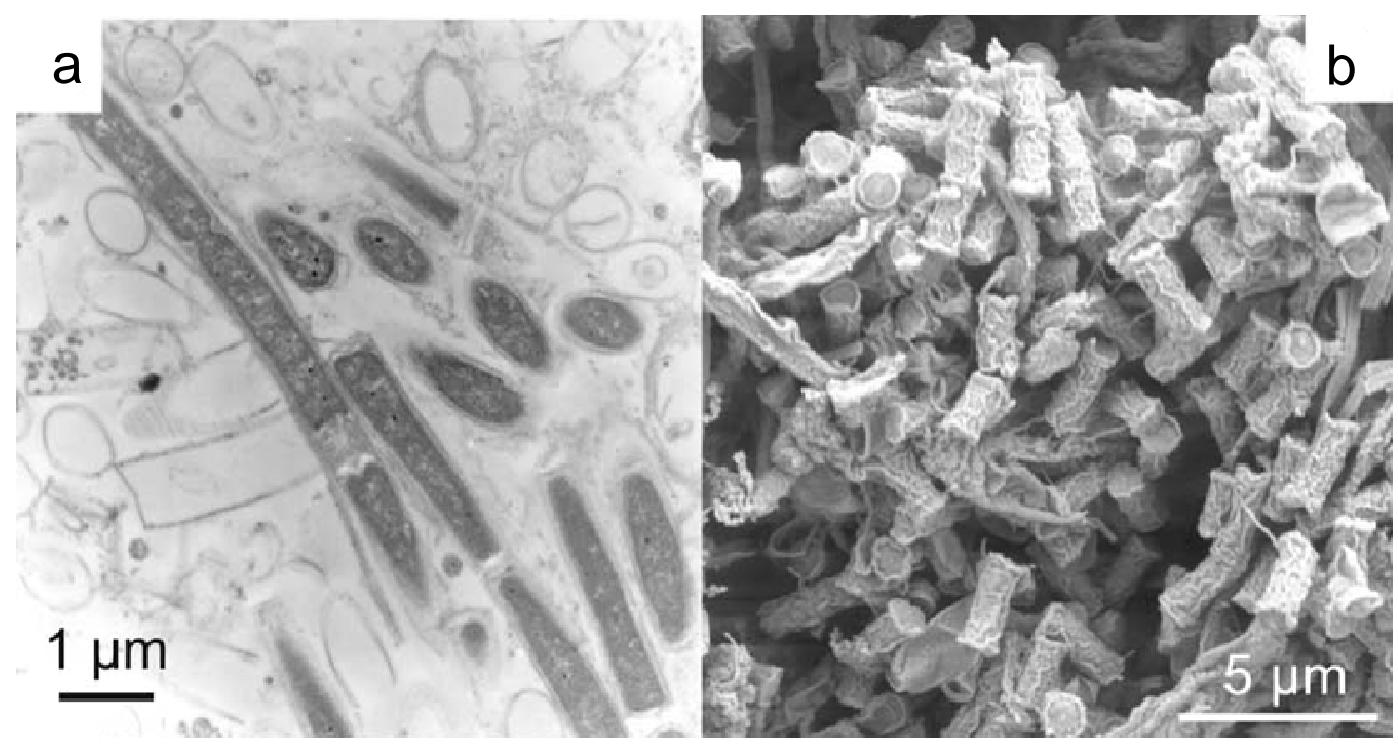

Figure 1.6.: ANME-1 morphology (Reitner et al., 2005a).

ANME-1 archaea in the Black Sea microbial mat. (a) transmission electron microscopic (TEM) micrograph of cylinder-shaped ANME-1 archaea. (b) Image of field emission scanning electron microscope (FE-SEM) depicts cylinder-shaped ANME-1 sheaths.

Very recently AOM with iron and manganese as electron acceptors were described. Regarding thermodynamic aspects this reaction allows approximately ten times as much as energy as sulfate dependent AOM (with respect to higher energy yield per mol but lower reaction rate). In principle it is likely that this AOM variant depends on reverse methanogenesis, but it remains unknown if the electron acceptors have an direct or indirect influence on the process (Beal et al., 2009).

\subsubsection{Nitrate dependent AOM}

During the last few years a novel mechanism was discovered for the anaerobic oxidation of methane. An enrichment culture from a water drain in the Netherlands was grown in a methane atmosphere with nitrate and nitrite as electron acceptors. Phylogenetic analysis revealed that $10 \%$ archaeal species, related to the ANME cluster, and $90 \%$ bacterial species were present, suggesting that this AOM variant also depends on ANME related archaea (Raghoebarsing et al., 2006). However, further studies demonstrated that archaea disappeared in the cultures while AOM activity remained. $80 \%$ of the bacterial species were represented by the phylum NC10 (Ettwig et al., 2008). The genome of one organism from enrichment cultures (Candidatus 
Methylomirabilis oxyfera) representing a member of the NC10 phylum, was assembled and subject of further studies (Ettwig et al., 2010). The energy yield for nitrate and nitrite dependent AOM (Eq. 15 and Eq. 16) is higher than for sulfate dependent AOM (Eq. 12; Thauer and Shima, 2008):

$5 \mathrm{CH}_{4}+8 \mathrm{NO}_{3}^{-}+8 \mathrm{H}^{+} \rightarrow 5 \mathrm{CO}_{2}+4 \mathrm{~N}_{2}+14 \mathrm{H}_{2} \mathrm{O}$

$\delta G^{0^{\prime}}=-765 \mathrm{~kJ} /\left(\mathrm{mol} \mathrm{CH}_{4}\right)$

$3 \mathrm{CH}_{4}+8 \mathrm{NO}_{2}^{-}+8 \mathrm{H}^{+} \rightarrow 3 \mathrm{CO}_{2}+4 \mathrm{~N}_{2}+10 \mathrm{H}_{2} \mathrm{O}$

$\delta G^{0^{\prime}}=-928 \mathrm{~kJ} /\left(\mathrm{mol} \mathrm{CH}_{4}\right)$

From genome as well as transcriptome and proteome analyses it was concluded that in nitrate/mitrite dependent AOM nitric oxide is decomposed to nitrogen and oxygen by a hitherto unknown mechanism. The oxygen is then used for oxidation of methane by the known aerobic methanotrophic pathway (cf. section 1.2.2.; Ettwig et al., 2010).

\subsection{AOM habitats of this work}

\subsubsection{Cold seeps of the Black Sea}

The AOM consortia of the Black Sea cold seeps exhibit a characteristic feature by forming microbial mats, which can reach several centimeters in diameter. In the Black Sea the water column shows a strict stratification caused by a low salt concentration of surface water and a higher salinity of the deep water. Due to this stratification about $80 \%$ of the deep water of the Black Sea is anoxic (Peckmann et al., 2001b). The anaerobic methanotrophic mats, used in this study, are abundant in approximately $230 \mathrm{~m}$ depth in the permanent anoxic bottom water along the shallow Crimean shelf (Luth et al., 1999; Michaelis et al., 2002). Further AOM sites of the Black Sea were observed at different locations of the Crimean shelf and at the Sorokin Trough mud volcanoes at $2000 \mathrm{~m}$ depth (Stadnitskaia et al., 2005; Krüger et al., 2008b). 

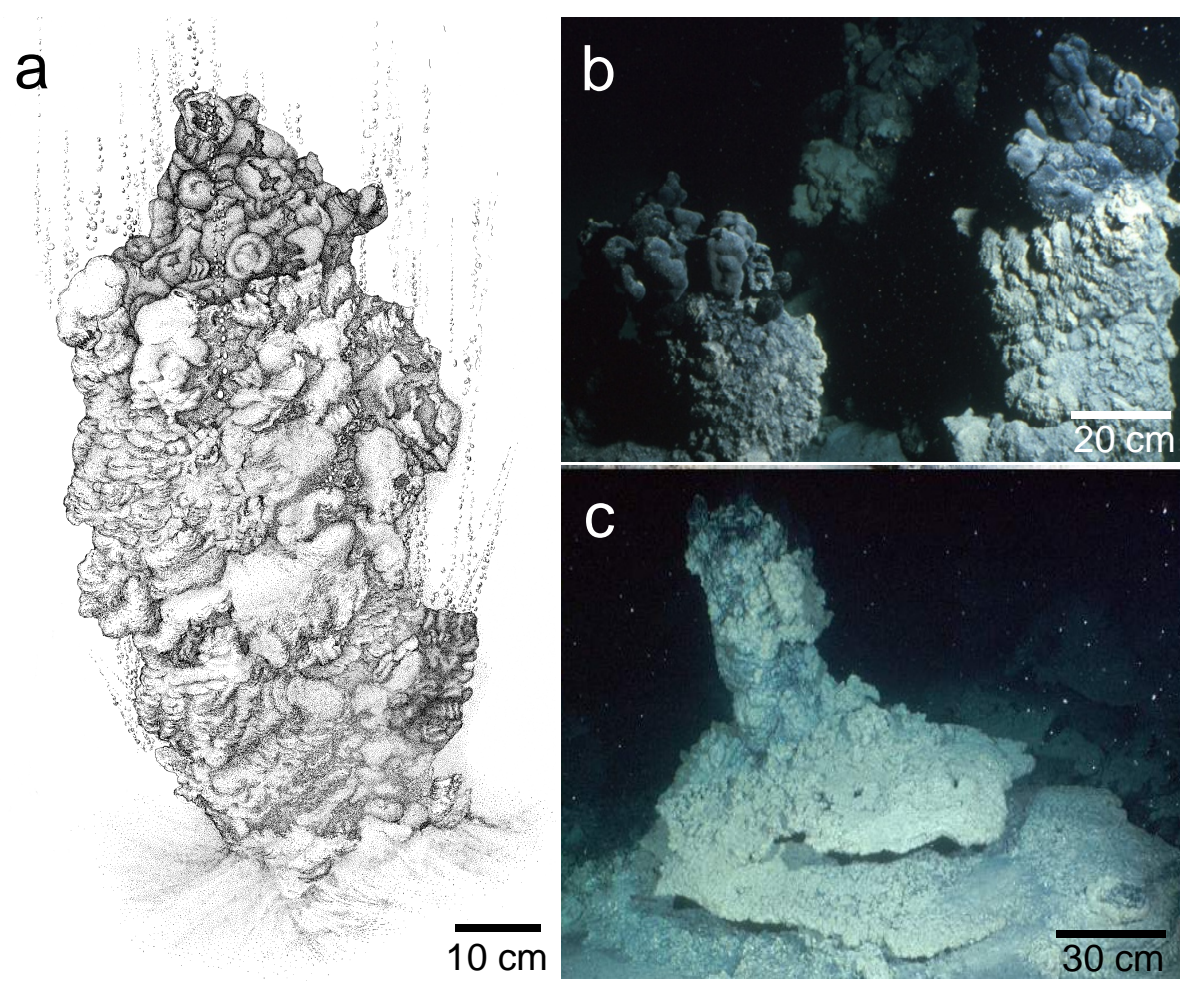

Figure 1.7.: Morphology of carbonate towers (Reitner et al., 2005b).

Carbonate towers of Black Sea cold seeps. (a) drawing of a large, active tower. (b) group of growing, carbonate towers in an area of intense gas seepage. (c) subrecent tower devoid of microbial mats with bottom plate of carbonate-cemented sediment.

The anoxic water column and the methane seepage out of the sediment allow extensive AOM activity leading to alkalinization of the surrounding water (cf. Eq. 15; Reitner et al., 2005b):

$\mathrm{CH}_{4}+\mathrm{SO}_{4}{ }^{2-} \rightarrow \mathrm{HCO}_{3}^{-}+\mathrm{HS}^{-}+\mathrm{H}_{2} \mathrm{O}$

This reaction causes precipitation of carbonates (Aloisi et al., 2000; Peckmann et al., 2001b; Aloisi et al., 2002; Peckmann and Thiel, 2004) forming cold seep carbonate towers. For the AOM associated carbonates in the Black Sea several morphologies are known (Ivanov et al., 1991; Luth et al., 1999; Peckmann et al., 2001b; Lein et al., 2002; Michaelis et al., 2002; Reitner et al., 2005a; Reitner et al., 2005b; Pape et al., 2008). These precipitates are formed (a) in the sediment as carbonate-cemented plates and large tabular constructions (b) below the chemocline as tall build-ups and tower-like 
constructions that may reach several meters in height growing free into the anoxic water column (Peckmann et al., 2001b; Lein et al., 2002; Michaelis et al., 2002).

The carbonate towers studied in this work exhibit no distinct central channel. A diffuse system of cavities within the towers is percolated by methane. Openings release gas in a continuous flow or in intervals (Fig. 1.7.; Reitner et al., 2005b).

It is assumed that the towers grow from microbial mats at the sediment surface slowly into the anoxic water column (Treude et al., 2005). The microbial mats grow at the inner and outer surfaces of the carbonate towers and show a remarkable degree of organization (cf. also Wrede et al., 2008). Macroscopically, three layers were discriminated. On the surface, exposed to the sea water, the black layer consists mainly of ANME-2/SRB aggregates. SRB of this mat type exhibit often intracytoplasmic magnetosome-like chains of greigite precipitations (Reitner et al., 2005a). The underlying pink layer is characterized by a matrix of ANME-1 cells with embedded SRB colonies. A green layer lines the internal open spaces of the carbonate towers and shows a more heterogeneous distribution of cell types (Reitner et al., 2005b). At micrometer scale the sphere-like aggregates composed of ANME/SRB and unknown organisms, are embedded in a matrix of EPS \{Reitner, 2005a \#10;Wrede, $2008 \# 138$ \}.

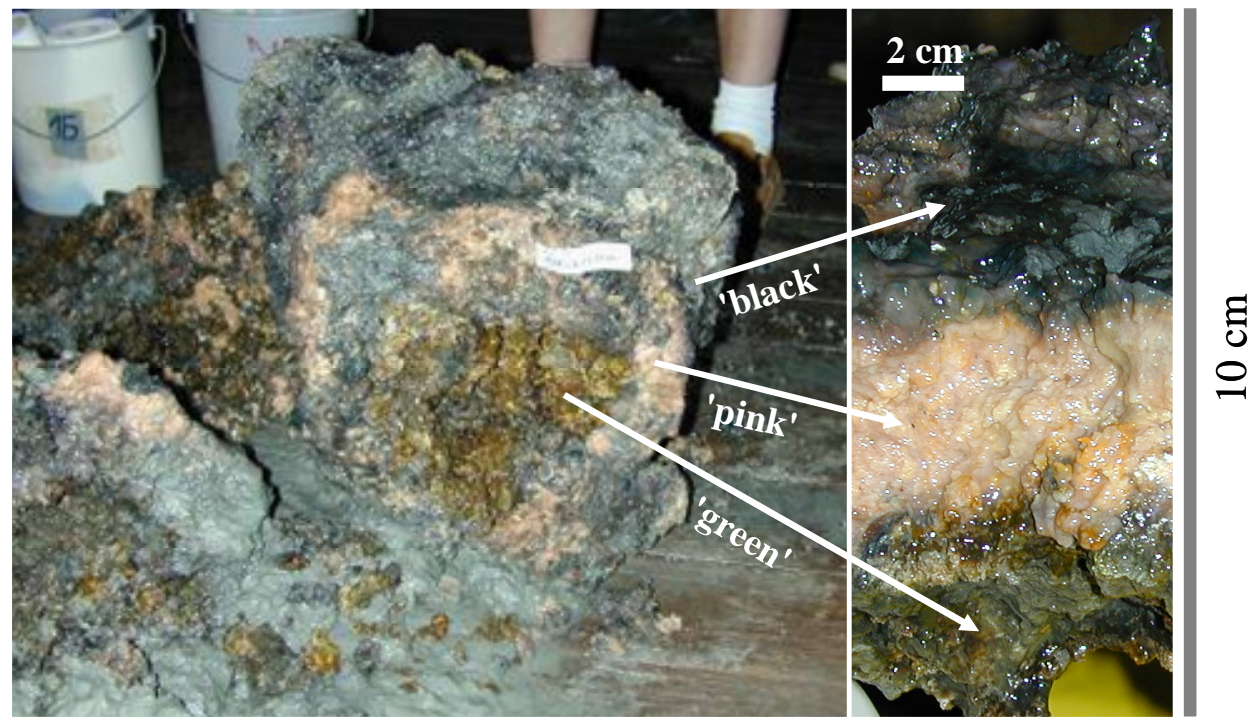

Figure 1.8.: Structure of microbial mats (Reitner et al., 2005b).

The figure depicts a broken tower revealing the microbial mats. In the enlarged figure (right), the three microbial layers are visible. On the surface, exposed to the sea water, the black layer is present. The underlying layers show pink or orange colors. The cavities are lined by a green layer. (Photo: GHOSTDABS - BMBF \& Jago team: K. Hissmann \& J. Schauer) 


\subsubsection{Terrestrial mud volcanoes in the Northern Apennines}

Terrestrial mud volcanoes are peculiar geological structures within zones of tectonical compression that are mostly associated with local plate tectonic activity. They are found in the forelands of Alpide orogenic structures, namely in the Apennines, the Carpathians or the Caucasus (Dimitrov, 2002). Along the Apennines, these fluid venting structures could be traced back to the Oligocene (e.g. Taviani, 2001). Recent mud volcanoes at the Emilia Apennines, but also elsewhere in Italy, are mostly cold springs, expelling hydrocarbon-enriched, saline waters (Martinelli and Judd, 2004). The transported sedimentary material leads to the formation of mud cones, which can reach several meters in height.
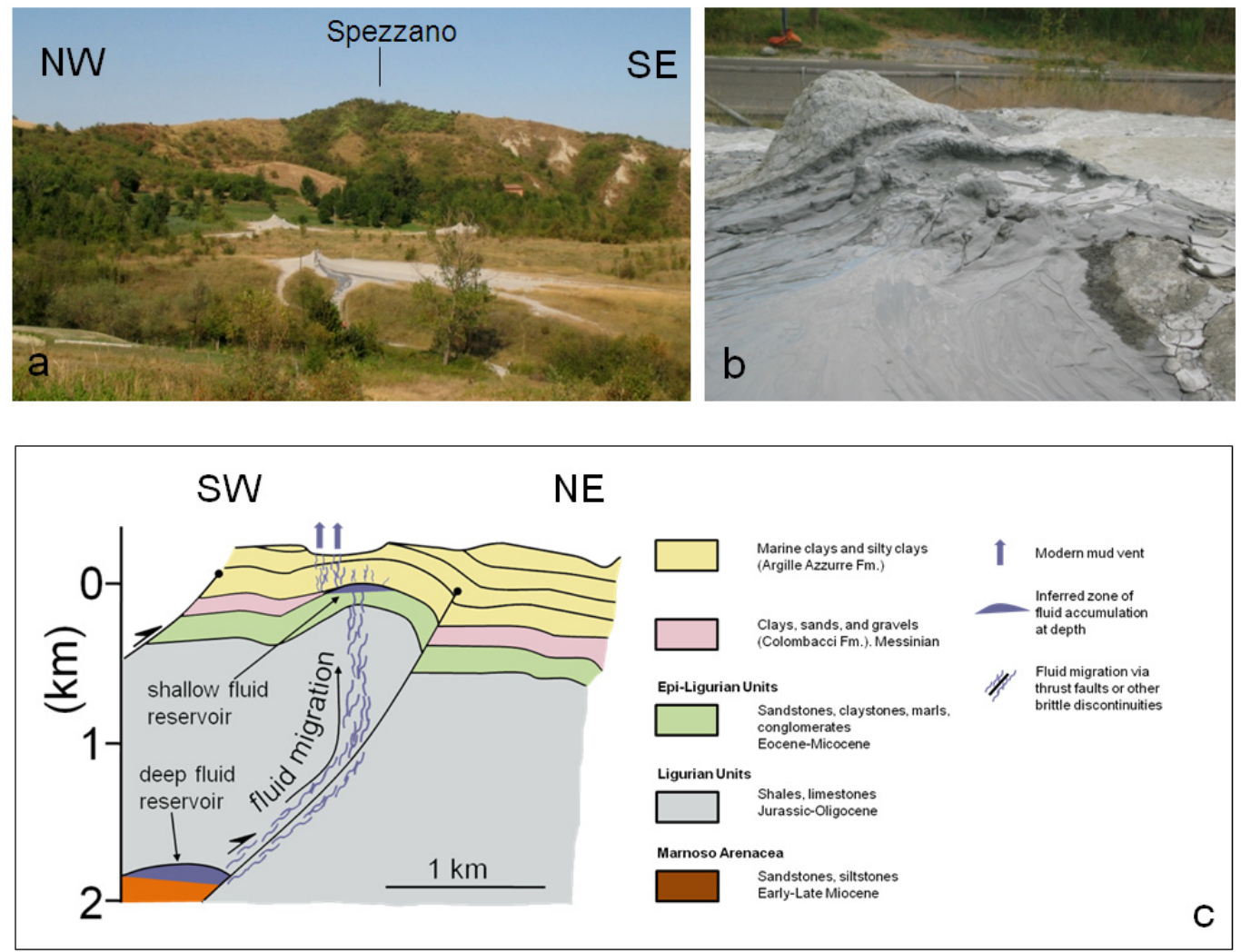

Figure 1.9.: Geological setting of the Nirano mud volcano field.

(a) panoramic view of the Nirano mud volcano field towards NE. (b) active mud cone analyzed in this work. (c) geological cross section in the direction of the view axis of (a) (adapted from Bonini, 2008). 
At the Nirano mud volcano site, fluids enriched with clay fractions are transported to the surface forming mud cones of maximum $5 \mathrm{~m}$ height (cf. Fig. 1.9.). Analysis of microfossils retrieved from mud volcano fluids revealed that the fluids pass the Pliocene-Pleistocene Argille Azzurre formation (marine silty clays) and the underlying Epi-Ligurian (Eocene-Miocene) and Ligurian (Cretaceous) units (Bonini, 2007 and references therein). Thus, fluids pass through sedimentary material of different permeability (cf. Fig. 1.9.). Along lithological boundaries, overpressure or expansion will lead to the formation of fluid reservoirs, namely, along the Upper Marnoso Arenacas unit boundary (below the rather impermeable Ligurian unit) and along the Epi-Ligurian unit (below the impermeable claystones of the Argille Azzurre formation). Along the two km-paths between the deep fluid reservoir and the surface, a temperature difference of $20{ }^{\circ} \mathrm{C}$ per $\mathrm{km}$ has to be expected (della Vedova et al., 2001).

Moreover, the upwelling pressurized fluid will be enriched with minerals from different geological units. It is likely that the fluids come also into contact with the lagoonal and marine deposits of the late Messinian, but possibly not with early Messinian evaporitic (gypsum-rich) deposits. However, it may be expected that due to a hiatus readily at the Nirano mud volcano site, some of the fluids also pass directly the Epi-Ligurian/ArgilleAzzurre boundary (Fig. 1.9.c). This feature may also be reflected by geochemical data, collected from different mud cones over time, showing a certain variability of the mineral concentrations in the fluid, especially sulfate (Martinelli and Judd, 2004; Duchi et al., 2005; this work). Thus, it must be expected that microbial communities from these mud volcanoes have to be adapted to different temperatures and available electron acceptors along the path of the fluid to the surface. 


\subsection{Aims of this work}

Up to now, most facts of AOM, i.e. phylogenetic or genomic analyses, are based on environmental DNA (cf. sections 1.2.3. and 1.3.1.). FISH analyses were used to localize the phylotypes inside environmental samples, but direct information about metabolic activities of the cells are still missing, even after combining FISH analysis with isotopic data (Orphan et al., 2001a). Proteomic data are rare and most studies do not discriminate between cells of distinct species (cf. sections 1.2.3. and 1.3.1.).

In this work antibody based marker systems were generated. The antibodies are directed against key enzymes of anaerobic methane consumption. Though MCR, the key enzyme of (reverse) methanogenesis, could be already detected in ANME cells (Heller et al., 2008), sulfate reduction could not be directly assigned to a specific cell type. Therefore, a conserved key enzyme of the dissimilatory sulfate reduction pathway, the dissimilatory adenosine-5'-phosphosulfate (APS) reductase was selected to detect and localize active SRB on protein level.

Another focus of this work is the metabolic pathway of aerobic, including nitrate/nitrite dependent methanotrophs (Ettwig et al., 2010). Regarding this metabolic pathway there is a big gap in knowledge for anoxic Black Sea cold seeps. To analyze active methanoor methylotrophic bacteria, a marker system based on the methanol dehydrogenase (MDH) was developed.

Regarding current knowledge of AOM habitats, there are only few data concerning terrestrial sites (Alain et al., 2006). For this reason, the Nirano mud volcano field near Modena, Emilia Romagna area, Northern Italy, was also one focus of this work. It is reasonable to assume that also in terrestrial mud volcanoes methane is oxidized either anaerobically with various electron acceptors (Beal et al., 2009; Knittel and Boetius, 2009) or aerobically, if oxygen (or nitrite, cf. Ettwig et al., 2010) is present. This study aimed at the detection of the relevant organisms. 


\section{Materials and Methods}

Materials: Chemicals, utilities, equipments, commercial systems as well as proteins, antibodies, enzymes, oligonucleotides and respective manufacturers are listed in the appendix (section 7.).

\subsection{Organisms and plasmids}

\subsubsection{Archaeal and bacterial strains}

Cloning and protein overexpression experiments were performed with Escherichia coli strains. Methanosarcina mazei Gö1, Methanospirillum hungatei strains, Desulfovibrio vulgaris Hildenborough, Methylobacterium extorquens AM1 and isolates of aerobic methanotrophs were used for structural and comparative analyses. Details are given in Tab. 2.1.

Table 2.1.: Applied archaeal and bacterial strains.

\begin{tabular}{|c|c|c|}
\hline Strain & Relevant genotype/strain no. & Reference/construction \\
\hline D. vulgaris & DSM 644 & (Postgate and Campbell, \\
\hline Hildenborough & & 1966) \\
\hline E. coli $\mathrm{DH} 5 \alpha$ & $\begin{array}{l}\text { recAl endA1 gyrA96 thi } \\
\text { hsdR1 } 1 \mathrm{r}_{\mathrm{K}}{ }^{-} \mathrm{m}_{\mathrm{K}}{ }^{+} \text {relA1 supE44 } \\
\Phi 80 \Delta l a c \mathrm{Z} \Delta M 15 \Delta(\text { lacZYA- } \\
\operatorname{argF}) \mathrm{U} 169\end{array}$ & (Sambrook et al., 1989) \\
\hline E. coli $\mathrm{TOP} 10$ & 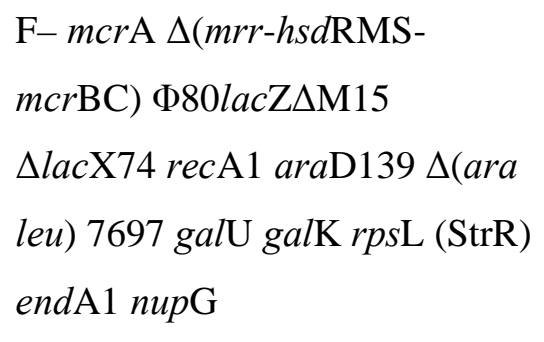 & $\begin{array}{l}\text { Commercial product of } \\
\text { Invitrogen, Carlsbad, USA }\end{array}$ \\
\hline M. extorquens AM1 & DSM 1338 & (Vuilleumier et al., 2009) \\
\hline M. hungatei & DSM $864^{\mathrm{T}}$ & (Ferry et al., 1974) \\
\hline
\end{tabular}




\begin{tabular}{lll}
\hline Strain & Relevant genotype/strain no. & Reference/construction \\
\hline M. hungatei & DSM 1101 & (Patel et al., 1976) \\
M. mazei Gö1 & DSM 3647 & (Maestrojuan et al., 1992) \\
\hline
\end{tabular}

\subsubsection{Samples of Black Sea cold seeps (Reitner et al., 2005b)}

Microbial mat samples were taken from the methane seep area on the lower Crimean shelf, Black Sea, explored during a German-Russian-Ukrainian joint expedition (GHOSTDABS) in 2001. The submersible Jago was used from aboard the Russian R/V 'Professor Logachev'. The samples originated from the GHOSTDABS-field (44 $46.510^{\prime} \mathrm{N}, 31^{\circ} 59.570^{\prime} \mathrm{E}$; Fig. 2.1.) at approximately $230 \mathrm{~m}$ water depth. Material for transmission electron microscopy (TEM) and immunofluorescence analyses was chemically fixed in a $4.0 \%(\mathrm{w} / \mathrm{v})$ formaldehyde solution and kept at $4{ }^{\circ} \mathrm{C}$ in $100 \mathrm{mM}$ PBS (phosphate buffered saline, $\mathrm{pH}$ 7.0). For DNA extractions and protein analyses, unfixed samples were stored at $-20{ }^{\circ} \mathrm{C}$.

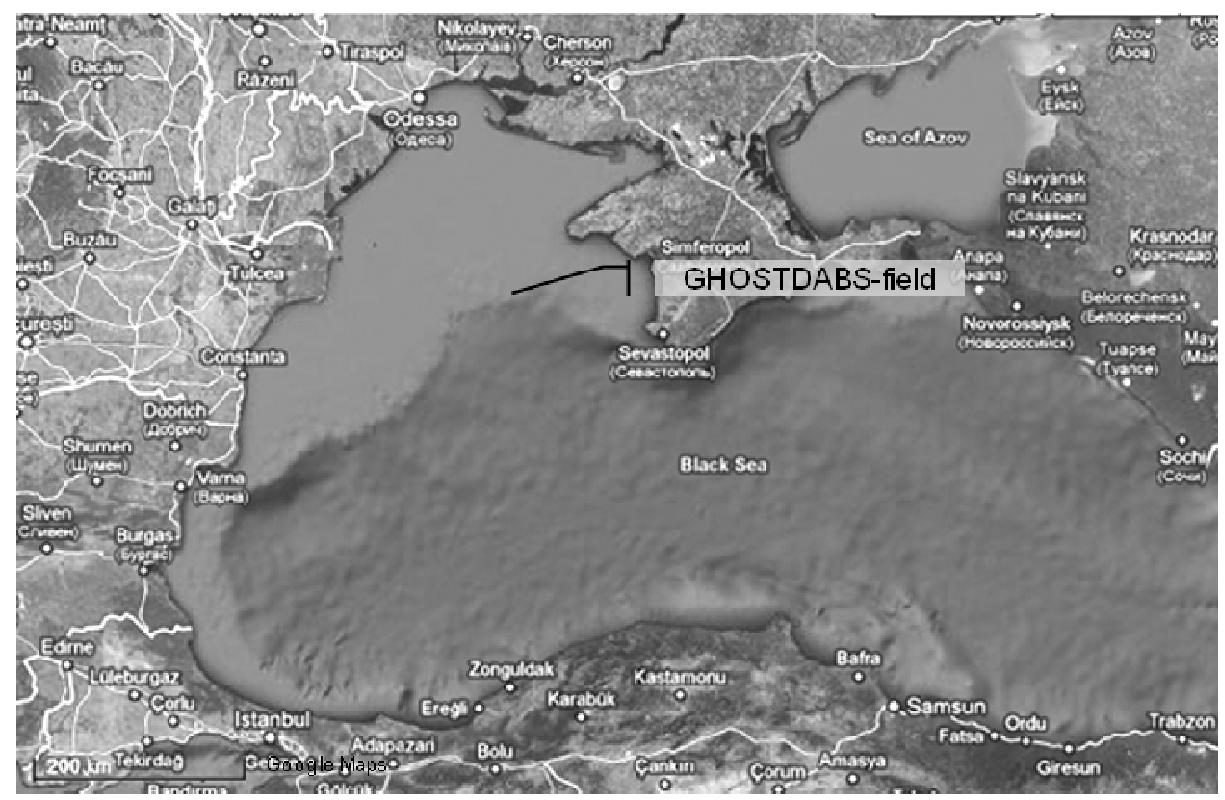

Figure 2.1.: GHOSTDABS-field, Black Sea.

Satellite image of Black Sea. Marker shows location of the GHOSTDABS-field $\left(44^{\circ} 46.510^{\prime} \mathrm{N}, 31^{\circ} 59.570^{\prime} \mathrm{E}\right)$ in approximately $230 \mathrm{~m}$ depth. 


\subsubsection{Samples of terrestrial mud volcanoes of the Emilia Apennines, Italy}

Samples were collected from two mud volcano cones, showing high and permanent activity of gas bubbling $\left(44^{\circ} 30.759^{\prime} \mathrm{N}, 10^{\circ} 49.290^{\prime} \mathrm{E}\right.$; 44 $30.848^{\prime} \mathrm{N}, 10^{\circ} 49.527^{\prime} \mathrm{E}$; Fig. 2.2.). Sites were designated as volcanoes NR4 and NR9.

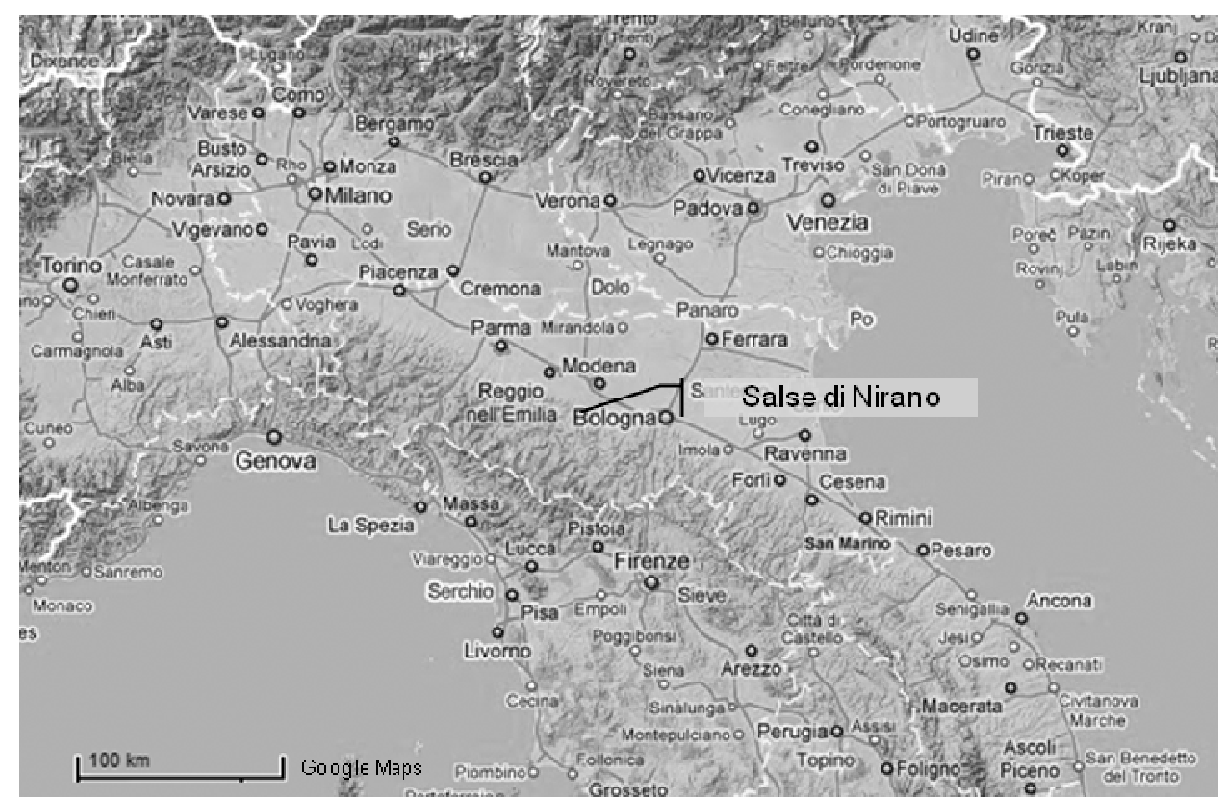

Figure 2.2.: GHOSTDABS-field, Black Sea.

Map of northern Italy. Marker shows location of the Salse di Nirano.

The samples were taken with a sterilized fluid sampler. The sampler consisted of a short metal pipe connected by a $3 \mathrm{~m}$ flexible tube with a flask, which is evacuated with a hand-operated vacuum pump. The sampling depth was about $1.5 \mathrm{~m}$. Pipe, tube and flask were sterilized and kept under sterile conditions until sampling.

For chemical analysis the fluids were kept in completely filled, tightly sealed glass bottles and transported to the laboratory under continuous refrigeration at $7{ }^{\circ} \mathrm{C}$. For DNA isolation, fluids were immediately frozen in dry ice. Samples from mud volcano fluids for fluorescence in situ analysis (FISH) were fixed for $24-48 \mathrm{~h}$ at $4{ }^{\circ} \mathrm{C}$ with $4 \%$ (w/v) formaldehyde in phosphate buffered saline (PBS; $10 \mathrm{mM}$ sodium phosphate, $130 \mathrm{mM} \mathrm{NaCl}$ ), washed twice with PBS at $4{ }^{\circ} \mathrm{C}$ and stored in $\mathrm{PBS} / \mathrm{EtOH}(1: 1)$ at $-20{ }^{\circ} \mathrm{C}$. Serum bottles for cultivation experiments were inoculated on site and kept refrigerated at $7{ }^{\circ} \mathrm{C}$ until appropriate incubation conditions (see 2.2. and 2.3.3.) were possible. AOM cultures were inoculated with anaerobic fluids from $1.5 \mathrm{~m}$ depth. 
Cultures for aerobic methanotrophs were inoculated with samples either taken from the aerobic fluid outlet or from a depth of $1.5 \mathrm{~m}$. Temperature, redox potential and the $\mathrm{pH}-$ values were measured directly in the fluids on-site.

\subsubsection{Plasmids}

The Tab. 2.2. shows the plasmids applied in this work.

Table 2.2.: Used plasmids.

\begin{tabular}{lll}
\hline Plasmid & Resistance & Reference \\
\hline pWH844 & ampicillin & (Schirmer et al., 1997) \\
pCR2.1-TOPO & $\begin{array}{l}\text { commercial product of } \\
\text { kanamycin }\end{array}$ & Invitrogen, Carlsbad, USA \\
This work: & ampicillin & $1.8 \mathrm{~kb}$ mxaF gene from $M$. \\
pCW4 & extorquens by BamHI und \\
& HindIII in pWH844 \\
pCW5 & $0.5 \mathrm{~kb}$ aprB gene from Black \\
& & Sea cold seeps by Bam HI und \\
& & HindIII in pWH844 (subcloned \\
& & from pCR2.1-TOPO) \\
\hline
\end{tabular}

\subsection{Growth media}

Buffers, solutions and media were prepared with deionized water and autoclaved for 20 min at $121{ }^{\circ} \mathrm{C}$ and 2 bar. Thermolabile substances were dissolved and sterilized by filtration. Solutions are related to water, other solvents are indicated. Agar plates were prepared by adding $15 \mathrm{~g} / \mathrm{l}$ agar. In case of minimal medium Bacto-Agar was used. 
AOM Media (Widdel et al., 2006; modified)

Full marine medium

$\mathrm{NaCl}$

$\mathrm{MgCl}_{2} \cdot 6 \mathrm{H}_{2} \mathrm{O}$

$26.0 \quad \mathrm{~g}$

$\mathrm{CaCl}_{2} \cdot 2 \mathrm{H}_{2} \mathrm{O}$

$\mathrm{NH}_{4} \mathrm{Cl}$

$5.0 \quad \mathrm{~g}$

$\mathrm{KH}_{2} \mathrm{PO}_{4}$

$1.4 \mathrm{~g}$

$\mathrm{KCl}$

$\mathrm{Na}_{2} \mathrm{SO}_{4}$

Resazurin

$300 \quad \mathrm{mg}$

$100 \quad \mathrm{mg}$

$0.5 \mathrm{~g}$

$4.0 \quad \mathrm{~g}$

$1 \quad \mathrm{mg}$

Trace element mixture

$1.0 \mathrm{ml}$

$\mathrm{NaHCO}_{3}$ solution

$30.0 \quad \mathrm{ml}$

$\mathrm{Na}_{2} \mathrm{~S}$ solution

$0.5 \mathrm{ml}$

Vitamin mixture

$1.0 \quad \mathrm{ml}$

Thiamine solution

$1.0 \mathrm{ml}$

Vitamin $\mathrm{B}_{12}$ solution

$1.0 \mathrm{ml}$

$\mathrm{H}_{2} \mathrm{O}$

$\operatorname{ad} 1000 \quad \mathrm{ml}$

\section{Saltwater medium}

$\mathrm{NaCl}$

$20.0 \quad \mathrm{~g}$

$\mathrm{MgCl}_{2} \cdot 6 \mathrm{H}_{2} \mathrm{O}$

$3.0 \quad \mathrm{~g}$

$\mathrm{CaCl}_{2} \cdot 2 \mathrm{H}_{2} \mathrm{O}$

$150 \quad \mathrm{mg}$

$\mathrm{NH}_{4} \mathrm{Cl}$

$300 \quad \mathrm{mg}$

$\mathrm{KH}_{2} \mathrm{PO}_{4}$

$200 \quad \mathrm{mg}$

$\mathrm{KCl}$

$0.5 \mathrm{~g}$

$\mathrm{Na}_{2} \mathrm{SO}_{4}$

$3.0 \mathrm{~g}$

Resazurin

$1 \quad \mathrm{mg}$


Trace element mixture

$\begin{array}{rr}1.0 & \mathrm{ml} \\ 30.0 & \mathrm{ml} \\ 0.5 & \mathrm{ml}\end{array}$

$\mathrm{Na}_{2} \mathrm{~S}$ solution

Thiamine solution

$1.0 \quad \mathrm{ml}$

Vitamin $B_{12}$ solution

$1.0 \mathrm{ml}$

Vitamin mixture

$1.0 \mathrm{ml}$

$\mathrm{H}_{2} \mathrm{O}$ $\operatorname{ad} 1000 \quad \mathrm{ml}$

\section{Nirano fluid medium}

$\mathrm{NH}_{4} \mathrm{Cl}$

$300 \quad \mathrm{mg}$

$\mathrm{KH}_{2} \mathrm{PO}_{4}$

$200 \quad \mathrm{mg}$

$\mathrm{Na}_{2} \mathrm{SO}_{4}$

$3.0 \quad \mathrm{~g}$

Resazurin

$1 \mathrm{mg}$

$\mathrm{NaHCO}_{3}$ solution $30.0 \quad \mathrm{ml}$

$\mathrm{Na}_{2} \mathrm{~S}$ solution $0.5 \mathrm{ml}$

Filtered and autoclaved fluids of the habitat ad $1000 \quad \mathrm{ml}$

The Nirano fluid medium is a modification of the media adapted to the mud volcano fluid composition. For this, salts, trace elements and vitamins were substituted by using sterilized and filtered original fluids of the habitat. 


\section{Trace element mixture}

$\mathrm{HCl} 25 \%(\mathrm{w} / \mathrm{v})$

$\begin{array}{rl}13 & \mathrm{ml} \\ 10 & \mathrm{mg} \\ 5 & \mathrm{mg} \\ 4 & \mathrm{~g} \\ 190 & \mathrm{mg} \\ 24 & \mathrm{mg} \\ 2 & \mathrm{mg} \\ 200 & \mathrm{mg} \\ 36 & \mathrm{mg} \\ \text { ad } 1000 & \mathrm{ml}\end{array}$

$\mathrm{NaHCO}_{3}$ solution

$\mathrm{NaHCO}_{3}$

$84 \quad \mathrm{~g}$

$\mathrm{H}_{2} \mathrm{O}$

ad $1000 \quad \mathrm{ml}$

The solution was saturated with $\mathrm{CO}_{2}$ (by shaking in a stoppered bottle under a head space of $\mathrm{CO}_{2}$ ) and autoclaved in vessels tightly sealed with butyl rubber stoppers.

\section{$\mathrm{Na}_{2} \mathrm{~S}$ solution}

$\mathrm{Na}_{2} \mathrm{~S} \cdot 9 \mathrm{H}_{2} \mathrm{O}$

$\begin{array}{rl}24 & \mathrm{~g} \\ \operatorname{ad} 50 & \mathrm{ml}\end{array}$

$\mathrm{H}_{2} \mathrm{O}$

$\mathrm{ml}$

Only clear crystals of sodium sulfide were used. Opaque or milky surface layers were removed by brief rinsing with distilled water on a plastic sieve. The sodium sulfide was dissolved by stirring under an $\mathrm{N}_{2}$ atmosphere. The vessels were tightly sealed with butyl rubber stoppers and autoclaved under a head space of $N_{2}(\geq 1 / 4$ of total volume). 


\section{Vitamin mixture}

Sodium phosphate (10 mM; pH 7.1)

$\begin{array}{rl}100 & \mathrm{ml} \\ 4 & \mathrm{mg} \\ 1 & \mathrm{mg} \\ 10 & \mathrm{mg} \\ 5 & \mathrm{mg} \\ 15 & \mathrm{mg}\end{array}$

Pyridoxine dihydrochloride $\mathrm{mg}$

Sterilized by filtration and stored dark at $4{ }^{\circ} \mathrm{C}$.

\section{Thiamine solution}

Sodium phosphate (10 mM; $\mathrm{pH} 3.4)$

$100 \quad \mathrm{ml}$

Thiamine chloride dihydrochloride

$10 \quad \mathrm{mg}$

Sterilized by filtration and stored dark at $4{ }^{\circ} \mathrm{C}$.

\section{Vitamin $B_{12}$ solution}

$\mathrm{H}_{2} \mathrm{O}$

$100 \mathrm{ml}$

Cyanocobalamin

$5 \quad \mathrm{mg}$

Sterilized by filtration and stored dark at $4{ }^{\circ} \mathrm{C}$.

\section{Preparation of the AOM media:}

The media were autoclaved and then cooled to room temperature under gassing with oxygen-free nitrogen. After this, the supplements were added (except $\mathrm{Na}_{2} \mathrm{~S}$ solution) and the $\mathrm{pH}$-value was adjusted with sulfuric acid or $1 \mathrm{M} \mathrm{Na} \mathrm{CO}_{3}$ to $\mathrm{pH}$ 7.8. The medium was filtered ( $25 \mathrm{ml}$ aliquots) through a $0.2 \mu \mathrm{m}$ filter in $100 \mathrm{ml}$ serum bottles tightly sealed, sterilized and under $\mathrm{N}_{2}$ atmosphere. Finally, $\mathrm{Na}_{2} \mathrm{~S}$ solution was added. 
Desulfovibrio medium (Postgate's Medium C, modified; Postgate, 1984)

\section{Solution A}

$\mathrm{K}_{2} \mathrm{HPO}_{4}$

$\mathrm{NH}_{4} \mathrm{Cl}$

$0.5 \mathrm{~g}$

$\mathrm{Na}_{2} \mathrm{SO}_{4}$

$1.0 \mathrm{~g}$

$\mathrm{CaCl}_{2} \cdot 2 \mathrm{H}_{2} \mathrm{O}$

$1.0 \mathrm{~g}$

$\mathrm{MgSO}_{4} \cdot 7 \mathrm{H}_{2} \mathrm{O}$

$0.1 \quad \mathrm{~g}$

DL-Na-Lactate

$2.0 \quad \mathrm{~g}$

Yeast extract

$2.0 \quad \mathrm{~g}$

Resazurin

$1.0 \mathrm{~g}$

$\mathrm{H}_{2} \mathrm{O}$

$1.0 \mathrm{~g}$

ad $980 \quad \mathrm{ml}$

\section{Solution B}

$\mathrm{FeSO}_{4} \cdot 7 \mathrm{H}_{2} \mathrm{O}$

$\begin{array}{cc}0.5 & \mathrm{~g} \\ \operatorname{ad} 10 & \mathrm{ml}\end{array}$

\section{Solution C}

Na-Thioglycolate

$\begin{array}{rl}0.1 & \mathrm{~g} \\ 0.1 & \mathrm{~g} \\ \operatorname{ad} 10 & \mathrm{ml}\end{array}$

For preparation of Desulfovibrio medium, solution A was boiled for several minutes and then cooled to room temperature under gassing with oxygen-free nitrogen. Subsequently, solution $\mathrm{B}$ and $\mathrm{C}$ were added and the $\mathrm{pH}$-value was adjusted to 7.8. Under continuous nitrogen gassing the medium was dispensed in Hungate tubes or serum bottles. Permanent stirring guaranteed an even distribution of the precipitates. The vessels were tightly sealed with butyl rubber stoppers and autoclaved. 


\section{LB medium}

Yeast extract

$\begin{array}{rl}5.0 & \mathrm{~g} \\ 10.0 & \mathrm{~g} \\ 10.0 & \mathrm{~g} \\ \operatorname{ad} 1000 & \mathrm{ml}\end{array}$

Methanosarcina mazei medium (Ehlers et al., 2002)

$\mathrm{KH}_{2} \mathrm{PO}_{4}$

$\begin{array}{cc}456 & \mathrm{mg} \\ 227 & \mathrm{mg} \\ 500 & \mathrm{mg} \\ 500 & \mathrm{mg} \\ 2 & \mathrm{mg} \\ 250 & \mathrm{mg} \\ 2.25 & \mathrm{~g} \\ 1.5 & \mathrm{~g} \\ 300 & \mu l \\ 1 & \mathrm{ml} \\ 2 & \mathrm{~g} \\ 2 & \mathrm{~g} \\ 1 & \mathrm{mg}\end{array}$

$\mathrm{K}_{2} \mathrm{HPO}_{4}$

ad $1000 \quad \mathrm{ml}$

$\mathrm{H}_{2} \mathrm{O}$

Sterilized by filtration and stored dark at $4{ }^{\circ} \mathrm{C}$.

Trace element solution SL6 (Pfennig and Lippert, 1966)

$\mathrm{ZnSO}_{4} \cdot 7 \mathrm{H}_{2} \mathrm{O}$

$100 \quad \mathrm{mg}$

$\mathrm{MnCl}_{2} \cdot 4 \mathrm{H}_{2} \mathrm{O}$

$30 \quad \mathrm{mg}$

Boric acid

$300 \quad \mathrm{mg}$

$\mathrm{CoCl}_{2} \cdot 6 \mathrm{H}_{2} \mathrm{O}$

$200 \quad \mathrm{mg}$

$\mathrm{CuCl}_{2} \cdot 2 \mathrm{H}_{2} \mathrm{O}$

$10 \quad \mathrm{mg}$

$\mathrm{Na}_{2} \mathrm{MoO}_{4} \cdot 2 \mathrm{H}_{2} \mathrm{O}$

$30 \quad \mathrm{mg}$

$\mathrm{H}_{2} \mathrm{O}$

$\operatorname{ad} 1000 \quad \mathrm{ml}$


Vitamin solution (Wolin et al., 1963; modified)

Biotin

Folic acid

Pyridoxine hydrochloride

Thiamine hydrochloride

Riboflavin

Nicotinic acid

Calcium D-pantothenate

Vitamin $\mathrm{B}_{12}$

p-aminobenzoic acid

Thioctic acid (alpha lipoic acid)

$\mathrm{H}_{2} \mathrm{O}$

$\begin{array}{cc}2 & \mathrm{mg} \\ 2 & \mathrm{mg} \\ 10 & \mathrm{mg} \\ 15 & \mathrm{mg} \\ 5 & \mathrm{mg} \\ 5 & \mathrm{mg} \\ 5 & \mathrm{mg} \\ 0.01 & \mathrm{mg} \\ 5 & \mathrm{mg} \\ 1 & \mathrm{mg} \\ \mathrm{ad} 1000 & \mathrm{ml}\end{array}$

Sterilized by filtration and stored dark at $4{ }^{\circ} \mathrm{C}$.

The medium was gassed for 30 min with $80 \% \mathrm{~N}_{2}$ and $20 \% \mathrm{CO}_{2}$, followed by the addition of:

$\mathrm{NaHCO}_{3}$ $850 \quad \mathrm{mg}$

The $\mathrm{pH}$-value was adjusted to 6.9. The medium was dispensed in Hungate tubes $(5 \mathrm{ml})$ under continuous gassing with $80 \% \mathrm{~N}_{2}$ and $20 \% \mathrm{CO}_{2}$. The Hungate tubes were then tightly sealed with butyl rubber stoppers and gassed for 2 min with $80 \% \mathrm{~N}_{2}$ and $20 \%$ $\mathrm{CO}_{2}$. After autoclaving, following solutions (separately autoclaved under $\mathrm{N}_{2}$ atmosphere) were added in each Hungate tube:

Methanol

Cysteine- $\mathrm{HCl} \cdot \mathrm{H}_{2} \mathrm{O}$ (stock solution $30 \mathrm{~g} / 50 \mathrm{ml}$ )

$\mathrm{Na}_{2} \mathrm{~S} \cdot 9 \mathrm{H}_{2} \mathrm{O}$ (stock solution $24 \mathrm{~g} / 50 \mathrm{ml}$ )
$30.4 \mu 1$

$3.0 \mu 1$

$2.5 \mu 1$ 
Mineral medium for methylotrophs

\section{Solution A}

$\mathrm{Na}_{2} \mathrm{HPO}_{4}$

$4.5 \quad \mathrm{~g}$

$\mathrm{KH}_{2} \mathrm{PO}_{4}$

$2.25 \mathrm{~g}$

$\mathrm{H}_{2} \mathrm{O}$

ad $50 \quad \mathrm{ml}$

\section{Solution B}

$\mathrm{MgSO}_{4} \cdot 7 \mathrm{H}_{2} \mathrm{O}$

$100 \quad \mathrm{mg}$

$\mathrm{NH}_{4} \mathrm{Cl}$

$500 \quad \mathrm{mg}$

Trace element solution SL7

$500 \quad \mu 1$

$\mathrm{H}_{2} \mathrm{O}$

ad $50 \quad \mathrm{ml}$

\section{Solution C}

$\mathrm{Fe}(\mathrm{III}) \mathrm{NH}_{4}$-Citrate or $\mathrm{Fe}(\mathrm{III})$-Citrate

$\begin{array}{rr}7.8 & \mathrm{mg} \\ 15.6 & \mathrm{mg} \\ \operatorname{ad} 16.6 & \mathrm{ml}\end{array}$

$\mathrm{H}_{2} \mathrm{O}$

ad 16.6

$\mathrm{ml}$

Autoclaved.

\section{Cycloheximide stock solution $20 \mathrm{mg} / \mathrm{ml}$}

Cycloheximide

$\mathrm{mg}$

$\mathrm{H}_{2} \mathrm{O}$

ad $10 \quad \mathrm{ml}$

Sterilized by filtration. 
Trace element solution SL7 (Pfennig and Trüper, 1981; modified)

$\mathrm{HCl} 25 \%(\mathrm{w} / \mathrm{v})$

Boric acid

$\mathrm{CoCl}_{2} \cdot 6 \mathrm{H}_{2} \mathrm{O}$

$\mathrm{CuCl}_{2} \cdot 2 \mathrm{H}_{2} \mathrm{O}$

$\mathrm{MnCl}_{2} \cdot 4 \mathrm{H}_{2} \mathrm{O}$

$\mathrm{Na}_{2} \mathrm{MoO}_{4} \cdot 2 \mathrm{H}_{2} \mathrm{O}$

$\mathrm{NiCl}_{2} \cdot 6 \mathrm{H}_{2} \mathrm{O}$

$\mathrm{ZnCl}_{2}$

Boric acid

$\mathrm{H}_{2} \mathrm{O}$

Adjusted to $\mathrm{pH} 6.5$.

$\begin{array}{rr}1.3 & \mathrm{ml} \\ 6 & \mathrm{mg} \\ 190 & \mathrm{mg} \\ 2 & \mathrm{mg} \\ 100 & \mathrm{mg} \\ 36 & \mathrm{mg} \\ 24 & \mathrm{mg} \\ 70 & \mathrm{mg} \\ 300 & \mathrm{mg} \\ \mathrm{ad} 1000 & \mathrm{ml}\end{array}$

Medium preparation

Solution A

Solution B

Bacto-Agar

$\mathrm{H}_{2} \mathrm{O}$

Autoclaved.

Added, after cooling to $50{ }^{\circ} \mathrm{C}$ :

Solution C

Methanol

Cycloheximide stock solution

$\begin{array}{rl}50 & \mathrm{ml} \\ 50 & \mathrm{ml} \\ 7.5 & \mathrm{~g} \\ \mathrm{ad} 490.5 & \mathrm{ml}\end{array}$

$\mathrm{ml}$

$\mathrm{ml}$ $\mathrm{ml}$

The plates were stored after a short time period for gelling in tightly sealed bags to prevent evaporation of methanol. 
Nitrate Mineral Salts Medium (NMS medium; Bowman, 2006):

$\mathrm{MgSO}_{4} \cdot 7 \mathrm{H}_{2} \mathrm{O}$

$\mathrm{KNO}_{3}$

$\mathrm{Na}_{2} \mathrm{HPO}_{4} \cdot 12 \mathrm{H}_{2} \mathrm{O}$

$\begin{array}{cc}1 & \mathrm{~g} \\ 1 & \mathrm{~g} \\ 0.717 & \mathrm{~g} \\ 0.272 & \mathrm{~g} \\ 200 & \mathrm{mg} \\ 5 & \mathrm{mg} \\ 1 & \mathrm{ml} \\ \mathrm{ml} & \mathrm{ml}\end{array}$

$\mathrm{H}_{2} \mathrm{O}$

ad 1000

Adjusted to $\mathrm{pH} 7.8$ with $\mathrm{KOH}$.

\section{Trace element solution}

Disodium EDTA

$\begin{array}{rl}0.5 & \mathrm{~g} \\ 200 & \mathrm{mg} \\ 30 & \mathrm{mg} \\ 20 & \mathrm{mg} \\ 30 & \mathrm{mg} \\ 10 & \mathrm{mg} \\ 3 & \mathrm{mg} \\ 3 & \mathrm{mg} \\ 2 & \mathrm{mg} \\ \mathrm{ad} 1000 & \mathrm{ml}\end{array}$

Adjusted to pH 6.8 with $\mathrm{KOH}$ (neutralize).

$25 \mathrm{ml}$ medium was dispensed in $100 \mathrm{ml}$ serum bottles. Serum bottles were tightly sealed with gray butyl rubber stoppers and autoclaved. Methane was added to an overpressure of 0.5 bar. 


\section{SOB medium}

Tryptone

Yeast extract

$\mathrm{NaCl}$

$\mathrm{KCl}$

$\mathrm{MgCl}_{2}$

$\mathrm{MgSO}_{4}$

$\mathrm{H}_{2} \mathrm{O}$

$\begin{array}{cl}5.0 & \mathrm{~g} \\ 1.25 & \mathrm{~g} \\ 146 & \mathrm{mg} \\ 47 & \mathrm{mg} \\ 508 & \mathrm{mg} \\ 516 & \mathrm{mg} \\ \operatorname{ad} 250 & \mathrm{ml}\end{array}$

\section{Antibiotics and X-Gal}

Antibiotics were prepared as 1000-fold concentrated stock solutions. Ampicillin was dissolved in deionized water. The solution was sterilized by filtration and stored at -20 ${ }^{\circ} \mathrm{C}$. Autoclaved medium was cooled down to approximately $50{ }^{\circ} \mathrm{C}$ and antibiotics were added to their final concentration of $100 \mu \mathrm{g} / \mathrm{ml}$.

For screenings with X-Gal, a stock solution of $40 \mathrm{mg} / \mathrm{ml} \mathrm{X-Gal} \mathrm{dissolved} \mathrm{in} \mathrm{DMF} \mathrm{was}$ prepared. The final concentration in the medium was $40 \mu \mathrm{g} / \mathrm{ml}$.

Media with light sensitive additives were incubated in the dark. 


\subsection{Methods}

\subsubsection{General methods}

Some general methods used in this work that are described in the literature are listed in Tab. 2.3.

Table 2.3.: General methods.

\begin{tabular}{ll}
\hline Method & Reference \\
\hline Absorption measurement & (Sambrook et al., 1989) \\
Ethidium bromide staining & (Sambrook et al., 1989) \\
Gel electrophoresis of DNA & (Sambrook et al., 1989) \\
Ligation of DNA fragments & (Sambrook et al., 1989) \\
Determination of protein amounts & (Bradford, 1976) \\
Gel electrophoresis of proteins (denaturating) & (Laemmli, 1970) \\
Sequencing according to the chain termination method & (Sanger et al., 1977)
\end{tabular}

\subsubsection{Geochemical analysis}

Particles were removed from sampled fluids by centrifugation at $4{ }^{\circ} \mathrm{C}$. The analyses of $\mathrm{Cl}^{-}, \mathrm{SO}_{4}{ }^{2-}, \mathrm{NO}_{3}{ }^{2-}, \mathrm{NO}_{2}{ }^{2-}$ were performed according to DIN EN ISO 103041-1, $\mathrm{NH}_{4}{ }^{+}$ according to DIN EN ISO 11732, $\mathrm{S}_{2}{ }^{-}$according to DIN 38405-7, $\mathrm{SO}_{3}{ }^{2-}$ according to DIN EN ISO 103041-3, $\mathrm{HCO}_{3}{ }^{2-}$ according to DEV D8 and $\mathrm{Fe}$ (total), $\mathrm{Fe}^{2+}, \mathrm{K}^{+}, \mathrm{Mg}^{2+}$, $\mathrm{Na}^{+}, \mathrm{Ni}^{2+}, \mathrm{P}$ (total) according to DIN EN ISO 11885 by the SGS INSTITUT FRESENIUS GmbH (Göttingen, Germany). 


\subsubsection{Cultivation of archaea and bacteria}

\section{Cultivation of $D$. vulgaris Hildenborough}

Manipulations were carried out under an anoxic $\mathrm{N}_{2}$-atmosphere using the Hungate technique and its modifications (Sowers and Noll, 1995). D. vulgaris Hildenborough was grown in Desulfovibrio medium in Hungate tubes or serum bottles with nitrogen in the Headspace (1/3 of the total volume). For inoculation sterile disposable syringes were used. Cultures were incubated at $30{ }^{\circ} \mathrm{C}$. Growth was controlled by microscopy.

\section{Cultivation of $E$. coli}

Unless otherwise stated, E. coli was grown in LB medium at $37{ }^{\circ} \mathrm{C}$ under agitation at $200 \mathrm{rpm}$ in test tubes and culture flasks with baffles. Fresh colonies from plates or overnight liquid cultures were used for inoculation. Growth was measured at a wavelength of $\lambda=600 \mathrm{~nm}$.

\section{Cultivation of M. extorquens AM1 and methylotrophic isolates}

M. extorquens AM1 and methylotrophic isolates were preferentially grown on plates (Mineral medium for methylotrophs) in tightly sealed bags at $30{ }^{\circ} \mathrm{C}$. Methylotrophic bacteria were isolated from leaves of dicot plants according to Green (2006).

\section{Cultivation and enrichment of methanotrophs}

$100 \mathrm{ml}$ serum bottles with $25 \mathrm{ml}$ NMS medium were inoculated with $3.5 \mathrm{ml}$ original fluid directly on-site. For the controls, nitrogen instead of methane was injected into the headspace. For inoculation, sterile disposable syringes were used. The cultures were grown in a rotary shaker $(200 \mathrm{rpm})$ at $28^{\circ} \mathrm{C}$. Growth was controlled by microscopy. 


\section{Cultivation of M. mazei Gö1}

Manipulations were carried out under an anoxic $\mathrm{N}_{2}-\mathrm{CO}_{2}$-atmosphere using the Hungate technique and its modifications (Sowers and Noll, 1995). M. mazei Gö1 was grown in Methanosarcina mazei medium in serum bottles with $80 \% \mathrm{~N}_{2}$ and $20 \% \mathrm{CO}_{2}$ in the Headspace (3/4 of the total volume). For inoculation sterile disposable syringes were used. Cultures were incubated at $30{ }^{\circ} \mathrm{C}$. Growth was controlled by microscopy.

\section{AOM cultures}

Manipulations were carried out under an anoxic $\mathrm{N}_{2}$-atmosphere using the Hungate technique and its modifications (Sowers and Noll, 1995). Prepared $100 \mathrm{ml}$ serum bottles with $25 \mathrm{ml} \mathrm{AOM}$ medium were inoculated with $3.5 \mathrm{ml}$ original fluid directly on-site. The cultures were incubated under a slight overpressure of pure methane at $20{ }^{\circ} \mathrm{C}$ and shaken for approximately $0.5 \mathrm{~min}$ once per $24 \mathrm{~h}$. For the controls, nitrogen instead of methane was injected into the headspace. For inoculation disposable syringes were used. Activity was checked by determining sulfide concentrations measured with the Nanocolor ${ }^{\circledR}$ Sulfid Kit, which is based on colorimetric detection of methylene blue formation. The commercial system was used according to the manufacturer's instructions with miniaturized reaction batches.

\subsubsection{Genetic methods}

\section{Preparation of chromosomal DNA from $D$. vulgaris Hildenborough}

A D. vulgaris Hildenborough culture $(500 \mathrm{ml})$ was vacuum filtrated with a Büchner funnel using 3 layers of filter paper to remove iron precipitates. The cells were harvested by centrifugation $5,000 \mathrm{rpm}$ for $10 \mathrm{~min}$ at $4{ }^{\circ} \mathrm{C}$. The pellet was resuspended in $4 \mathrm{ml}$ medium and $200 \mu \mathrm{l}$ lysozyme $(10 \mathrm{mg} / \mathrm{ml})$, then $200 \mu \mathrm{l}$ EDTA $(0.25 \mathrm{M})$ were added. The solution was mixed by repeated inverting and incubated at $37{ }^{\circ} \mathrm{C}$ for 20 $30 \mathrm{~min}$. Subsequently, $200 \mu \mathrm{l}$ proteinase K $(2.5 \mathrm{mg} / \mathrm{ml})$ and $200 \mu \mathrm{l} \operatorname{SDS}(12.5 \%$ [w/v] $)$ were added and the solution was inverted until a cleared lysate was obtained. After an incubation time of $30-40 \mathrm{~min}$ at $37^{\circ} \mathrm{C}, 0.5 \mathrm{ml} \mathrm{NaCl}(5 \mathrm{M})$ were mixed into the solution and $4 \mathrm{ml}$ chloroform-octyl alcohol (5 vol. +1 vol.) were added. The reaction mixture 
was shaken until a fine emulsion was obtained. The solution was mixed by 5 further inverting steps. By centrifugation $\left(45 \mathrm{~min}, 5,000 \mathrm{rpm}, 4{ }^{\circ} \mathrm{C}\right.$ ) the two phases were separated. The upper, aqueous phase containing the DNA was removed with a cut pipet tip. This step was repeated until no proteins were left at the phase boundary. In a next step the DNA was precipitated with 2 volumes isopropanol at $-40{ }^{\circ} \mathrm{C}$ for $30 \mathrm{~min}$. The mixture was centrifuged (30 $\mathrm{min}, 13,000 \mathrm{rpm}, 4^{\circ} \mathrm{C}$ ) and the pellet was air dried. Finally the pellet was washed in $70 \%$ ethanol and resuspended in $100 \mu \mathrm{l}$ water.

\section{Preparation of DNA from cold seep microbial mats}

A volume of approximately $200 \mu 1$ microbial mats was resuspended by pipeting with a cut pipet tip and by vortexing in $1 \mathrm{ml}$ sterile saline. A cushion of $2 \mathrm{ml} 60 \%(\mathrm{w} / \mathrm{v})$ Nycodenz was layered below the slurry with a syringe and the sample was centrifuged (3 h, 5,000 rpm, swing-out rotor, without brake). Cells were removed and were mechanically disrupted with a Mikro-Dismembrator (3 min, $1800 \mathrm{rpm}$ ). The DNA was extracted from the disrupted cells with the High Pure PCR Template Preparation Kit. The DNA was eluted from the column with water.

\section{Preparation of plasmid DNA from $E$. coli}

Plasmid DNA was prepared from E. coli carrying the desired plasmid. An overnight culture $(4 \mathrm{ml})$ with cells carrying the desired plasmid was harvested (2 min; 13,000 rpm). The plasmid DNA was isolated using the peqGOLD Plasmid Miniprep Kit I according to the manufacturer's instructions. The DNA was eluted from the column with water.

\section{Agarose gel electrophoresis}

For analytical and preparative separation of DNA fragments, agarose gels containing 1 to $2 \%(\mathrm{w} / \mathrm{v})$ agarose (according to the expected fragment size) were prepared in TAE buffer. The DNA samples were mixed with $5 \mathrm{x}$ DNA loading dye to facilitate loading and to indicate the migration of the samples in the gel. A voltage of 80-120 V was applied until the bromophenol blue marker reached the last third of the gel. DNA fragments migrate towards the anode with a velocity proportional to the negative 
logarithm of their length. After electrophoresis, gels were incubated in ethidium bromide solution for $5 \mathrm{~min}$ and briefly rinsed with water. The DNA was detected and documented via its fluorescence under UV light $(\lambda=254 \mathrm{~nm})$. For estimation of the size of the DNA fragments, the Quick-Load ${ }^{\circledR} 1$ kb DNA Ladder (Fig. 2.3.) was used. For the isolation of DNA fragments from preparative gels, the bands were visualized at a wavelength of $\lambda=365 \mathrm{~nm}$. The bands were cut out and extracted with the peqGOLD Gel Extraction Kit according to the manufacturer's instructions.

Solutions for agarose gel electrophoresis:

$1 \%$ Agarose gel

Agarose

$\begin{array}{rl}1 & \mathrm{~g} \\ \operatorname{ad} 100 & \mathrm{ml}\end{array}$

\section{5 x DNA loading dye}

Glycerol (100\%)

$\begin{array}{rl}5 & \mathrm{ml} \\ 200 & \mu \mathrm{l} \\ 10 & \mathrm{mg} \\ 10 & \mathrm{mg} \\ 4.5 & \mathrm{ml}\end{array}$

\section{$50 \times$ TAE buffer}

Tris

$242 \mathrm{~g}$

acetic acid (100\%)

$57.1 \mathrm{ml}$

EDTA (0.5 M, pH 8.0)

$100 \mathrm{ml}$

$\mathrm{H}_{2} \mathrm{O}$

$\operatorname{ad} 1000 \quad \mathrm{ml}$




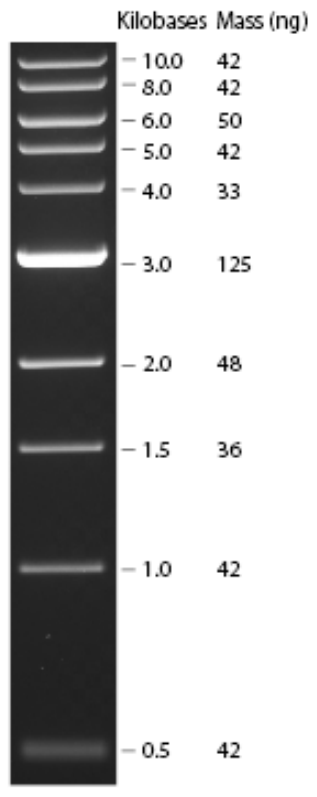

\section{Figure 2.3.: Quick-Load ${ }^{\circledR} 1$ kb DNA Ladder.}

$1 \mathrm{~kb}$ DNA Ladder on a $0.8 \%$ TAE agarose gel. Mass values are for $0.5 \mu \mathrm{g} / \mathrm{lane}$.

\section{Sequencing of DNA}

Sequencing was done based on the chain termination method (Sanger et al., 1977) with fluorescence labeled didesoxynucleotides. The sequencing reactions were conducted by the Göttingen Genomics Laboratory (Göttingen, Germany).

\section{Restriction and ligation of DNA}

The digestion of DNA with restriction endonucleases was performed with buffers recommended by the manufacturer. Reaction buffers, concentration of enzymes and DNA as well as incubation temperatures were chosen according to the manufacturer's instructions. To avoid re-circularization of a digested plasmid, the 5' phosphate groups of the linearized vector were removed prior to the ligation reaction. The dephosphorylation of the 5' end was performed with the calf intestinal alkaline phosphatase (CIAP). The products were purified with the peqGOLD MicroSpin CyclePure Kit following the manufacturer's instructions.

DNA fragments were ligated with the T4 DNA ligase with buffers supplied by the manufacturer. The ligation reaction contained 20-200 ng of vector DNA and an excess of the DNA fragment (insert to vector molar ratio of 5:1 to 20:1). The reaction was performed with $5 \mathrm{U}$ T4 DNA ligase in a final volume of $20 \mu \mathrm{l}$ for $1-2 \mathrm{~h}$ at RT or overnight at $16{ }^{\circ} \mathrm{C}$. 


\section{TOPO TA cloning}

For cloning of PCR products of environmental DNA with unknown sequence, e.g. the aprBA gene fragments from Black Sea cold seep microbial mats, the vector pCR2.1TOPO was used. The linearized TOPO TA vector has single, overhanging 3'deoxythymidine residues. Thus, DNA fragments with a desoxyadenosine overhang can be ligated with the vector. The TOPO TA vector includes a covalently bound topoisomerase I from the Vaccinia virus. The topoisomerase I binds to duplex DNA at specific sites and cleaves the phosphodiester backbone after 5'-CCCTT in one strand (Shuman, 1991). Subsequently, the phosphortyrosyl bond between the DNA and enzyme can be attacked by the 5'-hydroxyl of the original cleaved strand, reversing the reaction and releasing the topoisomerase (Shuman, 1994). The cloning reaction was carried out as recommended by the manufacturer.

\section{Polymerase chain reaction $(\mathrm{PCR})$}

DNA was amplified by PCR with specific oligonucleotide primers. For each DNA fragment of interest, primers were designed. In case of partly unknown target sequences degenerate primers were applied. For cloning of DNA fragments into plasmid vectors, recognition sequences for specific restriction endonucleases were added via primers at both ends of the amplified DNA fragments. All oligonucleotides used in this work are listed in the appendix. The PCR reactions were performed in a total volume of $50 \mu$ l. For amplifying genes from environmental templates and control PCR the Taq DNA

polymerase was used. For other templates the Phusion ${ }^{\circledR}$ High-Fidelity DNA Polymerase was applied according to the manufacturer's instructions.

The primers CWAprB1-fw and CWAprB3-fw were designed with Blockmaker (Henikoff et al., 1995) and CODEHOP (Rose et al., 1998) based on the aprBAsequences of Desulfovibrio desulfuricans G 20, Desulfotalea psychrophila LSv54, D. vulgaris Hildenborough and Archaeoglobus fulgidus. 


\section{Reaction mixture for the Taq DNA Polymerase (50 $\mu \mathrm{l})$ :}

$5 \mu \mathrm{l}$ forward primer $(5 \mu \mathrm{M})$

$5 \quad \mu \mathrm{l}$ reverse primer $(5 \mu \mathrm{M})$

$2 \mu$ template DNA (approximately $100 \mathrm{ng}$ )

$5 \mu \mathrm{l} 10 \mathrm{x}$ ThermoPol Reaction Buffer

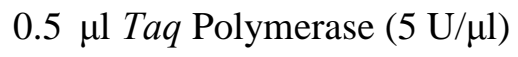

$2 \mu \mathrm{dNTPs}$ mixture $(10 \mathrm{mM})$

ad $50 \mu$ PCR water

The prepared reaction mixture was applied for the listed PCR programs (see below) in a thermocycler. The annealing temperatures were adapted to the melting temperatures (Tm) of the used primers. The elongation times were adjusted to the DNA fragment length.

Reaction conditions for standard PCR

\begin{tabular}{cccc}
\hline Cycles & Step & Temperature & Reaction time \\
\hline 1 & initial denaturation & $94{ }^{\circ} \mathrm{C}$ & $10 \mathrm{~min}$ \\
denaturation & $94{ }^{\circ} \mathrm{C}$ & 1 & $\mathrm{~min}$ \\
annealing & $\mathrm{Tm}-5^{\circ} \mathrm{C}$ & $1.5 \mathrm{~min}$ \\
elongation & $72{ }^{\circ} \mathrm{C}$ & $1 \mathrm{~min}$ per $1 \mathrm{~kb}$ \\
1 & final elongation & $72{ }^{\circ} \mathrm{C}$ & $10 \quad \mathrm{~min}$ \\
break & $12^{\circ} \mathrm{C}$ & $\infty$ \\
\hline
\end{tabular}


Touchdown and nested PCR conditions for aprBA fragment:

First step with degenerate primers CWAprB1-fw and AprA-5-RV;

Second step with degenerate primers CWAprB3-fw and APS-RV:

\begin{tabular}{|c|c|c|c|c|}
\hline Cycles & Step & Temperature & \multicolumn{2}{|c|}{ Reaction time } \\
\hline \multirow[t]{3}{*}{1} & initial denaturation & $94{ }^{\circ} \mathrm{C}$ & 3 & $\min$ \\
\hline & denaturation & $94{ }^{\circ} \mathrm{C}$ & 30 & $\mathrm{~S}$ \\
\hline & annealing & $55^{\circ} \mathrm{C}$ & 55 & $\mathrm{~S}$ \\
\hline \multirow[t]{4}{*}{20} & & each cycle & & \\
\hline & & $-0.5^{\circ} \mathrm{C}$ & & \\
\hline & elongation & $72^{\circ} \mathrm{C}$ & 2 & $\min$ \\
\hline & denaturation & $94{ }^{\circ} \mathrm{C}$ & 30 & $\mathrm{~S}$ \\
\hline \multirow[t]{2}{*}{20} & annealing & $45^{\circ} \mathrm{C}$ & 55 & $\mathrm{~s}$ \\
\hline & elongation & $72{ }^{\circ} \mathrm{C}$ & 2 & $\min$ \\
\hline 1 & final elongation & $72{ }^{\circ} \mathrm{C}$ & 10 & $\min$ \\
\hline 1 & break & $12^{\circ} \mathrm{C}$ & & $\infty$ \\
\hline
\end{tabular}

Primer 8f and 1492r for 16S rDNA amplifications were used as described elsewhere (Alain et al., 2006).

For DGGE analysis, products were used for a nested PCR adding a GC-clamp (341fGC/907aR and 907cR; Schäfer et al., 2001; Stadnitskaia et al., 2005):

\begin{tabular}{|c|c|c|c|c|}
\hline Cycles & Step & Temperature & React & on tim \\
\hline \multirow[t]{3}{*}{1} & initial denaturation & $94^{\circ} \mathrm{C}$ & 5 & $\min$ \\
\hline & denaturation & $94^{\circ} \mathrm{C}$ & 1 & $\min$ \\
\hline & annealing & $65^{\circ} \mathrm{C}$ & 1 & $\min$ \\
\hline \multirow[t]{4}{*}{20} & & each cycle & & \\
\hline & & $-0.5^{\circ} \mathrm{C}$ & & \\
\hline & elongation & $72{ }^{\circ} \mathrm{C}$ & 3 & $\min$ \\
\hline & denaturation & $94^{\circ} \mathrm{C}$ & 1 & $\min$ \\
\hline \multirow[t]{2}{*}{15} & annealing & $45^{\circ} \mathrm{C}$ & 1 & $\min$ \\
\hline & elongation & $72{ }^{\circ} \mathrm{C}$ & 3 & $\min$ \\
\hline 1 & final elongation & $72^{\circ} \mathrm{C}$ & 7 & $\min$ \\
\hline 1 & break & $12^{\circ} \mathrm{C}$ & & $\infty$ \\
\hline
\end{tabular}


For amplification of archaeal rDNA, the primer pair Arch21F/Arch958R were applied (Delong, 1992):

\begin{tabular}{|c|c|c|c|c|}
\hline Cycles & Step & Temperature & Reacti & on time \\
\hline \multirow[t]{3}{*}{1} & initial denaturation & $95^{\circ} \mathrm{C}$ & 2 & $\min$ \\
\hline & denaturation & $95^{\circ} \mathrm{C}$ & 90 & s \\
\hline & annealing & $56^{\circ} \mathrm{C}$ & 1 & $\min$ \\
\hline \multirow[t]{3}{*}{25} & & to & & \\
\hline & & $66^{\circ} \mathrm{C}$ & & \\
\hline & elongation & $72{ }^{\circ} \mathrm{C}$ & 80 & $\mathrm{~s}$ \\
\hline 1 & final elongation & $72{ }^{\circ} \mathrm{C}$ & 10 & $\min$ \\
\hline 1 & break & $12^{\circ} \mathrm{C}$ & & $\infty$ \\
\hline
\end{tabular}

\section{Purification of PCR products}

PCR products were purified with the peqGOLD MicroSpin Cycle-Pure Kit following the manufacturer's instructions.

\section{Denaturant gradient gel electrophoresis (DGGE) analysis}

Denaturant gradient gel electrophoresis was performed by using the INGENYphorU system according to the manufacturer's instructions. $25 \mu 1$ purified PCR of the products were mixed with $10 \mu 1$ loading buffer $(25 \%$ [w/v] Ficoll 400, $0.25 \%$ bromophenol blue, $0.25 \%$ xylene cyanol, in $\mathrm{H}_{2} \mathrm{O}$ ). PCR purification was done with peqGOLD MicroSpin Cycle-Pure Kit. Polyacrylamide gels (6\% [w/v]) were applied in $1 \times$ TAE, with a denaturing gradient from $20 \%$ to $70 \%$ (100\% denaturant corresponds to $7 \mathrm{M}$ urea and $40 \%$ formamide). Electrophoresis was performed at a constant voltage of $100 \mathrm{~V}$ and a temperature of $60{ }^{\circ} \mathrm{C}$ for $16 \mathrm{~h}$. The gels were stained for $20-40 \mathrm{~min}$ in $1 \times$ SybrGold solution $(1: 10,000)$ in $1 \times$ TAE and documented by a digital imaging system. DGGE bands were excised for sequence analysis using a sterile scalpel and incubated in $200 \mu \mathrm{l}$ of PCR water for $1 \mathrm{~h}$ at RT, followed by $30 \mu \mathrm{l}$ for $24 \mathrm{~h}$ at $4{ }^{\circ} \mathrm{C}$. The solution was taken as a template for the reamplification using the same PCR conditions as described above. The purified amplification products were sequenced. 


\section{Construction of $16 \mathrm{~S}$ rDNA clone library and phylogenetic tree}

The DNA was extracted from $5 \mathrm{~g}$ fluids as already described elsewhere (Henne et al., 1999). Obtained PCR products (primers Arch21F/Arch958R, see above) were analyzed for appropriate size and then purified by gel extraction peqGOLD Gel Extraction Kit. PCR products were cloned into pCR2.1-TOPO as recommended by the manufacturer. The PCR product-containing vectors were used to transform E. coli TOP10. Recombinant plasmids were isolated from randomly selected E. coli clones and sequenced. The 16S rRNA gene sequences from clone libraries were edited by using the gap4 program (Staden Package; Bonfield et al., 1995). All sequences were checked for chimeric artifacts by using Mallard (Ashelford et al., 2006), the CHIMERA_CHECK program (Maidak et al., 2001) of the Ribosomal Database Project (RDP) II database (Cole et al., 2003) and Bellerophon (Huber et al., 2004). 133 clones were used for further analyses. Taxonomic classification was performed by using the BLAST tool of the National Center for Biotechnology Information (NCBI) database (Altschul et al., 1990). Operational taxonomic units (OTUs) were determined at sequence similarity levels of $97 \%$ and $80 \%$ by using the furthest-neighbor method of DOTUR (Schloss and Handelsman, 2005). To determine the number of observed unique OTUs as a function of the distance between sequences and the number of sequences sampled, rarefaction analysis was performed. In addition to the Shannon-Weaver diversity index, the Chao1 richness estimator, and the abundance-based coverage estimator (ACE) were calculated by using DOTUR. Only one sequence per OTU (> $99 \%$ identity cutoff) was used for construction of phylogenetic trees. Sequences of the nearest neighbors were retrieved from the NCBI database. The 16S rRNA gene sequences from clone libraries and the most similar neighbors were imported into the most recent SSU Ref SILVA database (www.arb-silva/download/) of the ARB program package (Ludwig et al., 2004). Multiple sequence alignments were checked manually and improved by using the ARB editor tool. Phylogenetic trees were created by using the maximum-parsimony algorithm implemented in ARB. The robustness of obtained tree topologies was evaluated by bootstrap analysis with 100 resamplings. 


\section{Preparation of competent $E$. coli cells (Inoue et al., 1990)}

$250 \mathrm{ml} \mathrm{SOB}$ medium (see 2.2.) were inoculated with one colony E. coli DH5 $\alpha$ in a 11 culture flask without baffles and grown at RT under agitation (200 rpm) for at least $36 \mathrm{~h}$ $\left(\mathrm{OD}_{600 \mathrm{~nm}}=0.6\right)$. Then, the cells were incubated for $10 \mathrm{~min}$ on ice, before centrifugation (10 min, 2,500 g, $4{ }^{\circ} \mathrm{C}$ ). The pellet was resuspended in $80 \mathrm{ml} \mathrm{TB}$ and held on ice for 10 min, followed by a centrifugation step $\left(10 \mathrm{~min}, 2,500 \mathrm{~g}, 4{ }^{\circ} \mathrm{C}\right)$. The pelleted cells were resuspended in $20 \mathrm{ml} \mathrm{TB}$ and under gentle shaking DMSO was added (final concentration $7 \%$ ). The cell suspension was kept for 10 min on ice and then frozen in $200 \mu 1$ aliquots in liquid nitrogen. The cells were stored at $-70{ }^{\circ} \mathrm{C}$.

\section{Transformation buffer (TB)}

$\begin{array}{lrc}\text { PIPES } & 0.76 & \mathrm{~g} \\ \mathrm{CaCl}_{2} \cdot \mathrm{H}_{2} \mathrm{O} & 0.55 & \mathrm{~g} \\ \mathrm{KCl} & 4.66 & \mathrm{mg} \\ \mathrm{MnCl}_{2} \cdot \mathrm{H}_{2} \mathrm{O} & 2.71 & \mathrm{mg} \\ \mathrm{H}_{2} \mathrm{O} & \mathrm{ad} 250 & \mathrm{ml} \\ \text { The pH-value was adjusted to } \mathrm{pH} 6.7 \text { and the buffer was sterilized by filtration. } & \end{array}$

\section{Transformation of $E$. coli}

Competent cells were thawed on ice, and 10-100 ng DNA was added to $200 \mu \mathrm{l}$ cells. The suspension was mixed and incubated on ice for 30 minutes. Then, a heat shock was performed at $42{ }^{\circ} \mathrm{C}$ for 90 seconds. Afterwards, the samples were incubated for 5 minutes on ice. After addition of $600 \mu \mathrm{LB}$ medium, the samples were incubated for $1 \mathrm{~h}$ at $37{ }^{\circ} \mathrm{C}$ under agitation $(200 \mathrm{rpm}) .100 \mu \mathrm{l}$ and the concentrated rest were plated on LB selection plates (with ampicillin or kanamycin, respectively). 


\subsubsection{Preparation and analysis of proteins}

\section{Discontinuous SDS polyacrylamide gel electrophoresis (SDS-PAGE)}

The molecular weight of proteins was analyzed for by SDS-PAGE as described by Laemmli (1970). Protein samples were denatured by boiling in SDS loading dye at $95{ }^{\circ} \mathrm{C}$ for $10 \mathrm{~min}$. The polyacrylamide concentrations of the gels were chosen according to the expected protein sizes varying from 12 to $16 \%(\mathrm{v} / \mathrm{v})$. The gels consisted of a separating gel and a stacking gel. The whole gel measures $8.6 \times 7.7 \mathrm{~cm}(\mathrm{~W} \times \mathrm{L})$ with a thickness of $1 \mathrm{~mm}$. The wells of the prepared stacking gel were loaded with the samples.

Electrophoresis was performed at $120 \mathrm{~V}$ until the bromophenol blue had reached the lower end of the gel. During electrophoresis, proteins were first focused in the stacking gel and subsequently separated according to their molecular mass in the running gel. A prestained protein molecular weight marker was used as size standard (Fig. 2.4.). Gels

were stained with staining solution containing Coomassie Brilliant Blue R-250 and destained until the protein bands were clearly visible.

Preparative gels were run at low temperatures of approximately $8{ }^{\circ} \mathrm{C}$. The separated target proteins were excised with a sterile razor blade.

Solutions for SDS-PAGE:

5 x SDS loading dye

Glycerol

$3 \mathrm{ml}$

$1 \mathrm{M}$ Tris-HCl pH 7.0

$1.4 \mathrm{ml}$

$\mathrm{H}_{2} \mathrm{O}$

$2 \mathrm{ml}$

$20 \%(\mathrm{w} / \mathrm{v}) \mathrm{SDS}$

$2 \mathrm{ml}$

2-Mercaptoethanol

$1.6 \mathrm{ml}$

Bromophenol blue

$0.01 \mathrm{~g}$




\section{Electrophoresis buffer}

Tris

Glycine

$\mathrm{g}$

SDS

$\mathrm{H}_{2} \mathrm{O}$

$\begin{array}{rl}30 & \mathrm{~g} \\ 140 & \mathrm{~g} \\ 10 & \mathrm{~g} \\ \operatorname{ad} 1000 & \mathrm{ml}\end{array}$

\section{Stacking gel}

$30 \%$ Acrylamide-Bisacrylamide (37.5:1)

$1.5 \mathrm{M}$ Tris- $\mathrm{HCl} \mathrm{pH} 6.8$

$\begin{array}{cc}1.3 & \mathrm{ml} \\ 0.87 & \mathrm{ml} \\ 6.83 & \mathrm{ml} \\ 50 & \mu \mathrm{l} \\ 100 & \mu \mathrm{l} \\ 20 & \mu \mathrm{l}\end{array}$

$\mathrm{H}_{2} \mathrm{O}$

$20 \%$ (w/v) SDS

$10 \%(w / v)$ APS

TEMED

\section{Separating gel (12\%)}

$30 \%$ Acrylamide-Bisacrylamide (37.5:1)

\subsection{Tris- $\mathrm{HCl} \mathrm{pH} 8.8$}

$\mathrm{H}_{2} \mathrm{O}$

$20 \%$ (w/v) SDS

$4 \mathrm{ml}$

$2.6 \mathrm{ml}$

$3.2 \mathrm{ml}$

$10 \%(w / v)$ APS

$50 \mu \mathrm{l}$

TEMED

$100 \mu \mathrm{l}$

$10 \mu \mathrm{l}$

\section{Separating gel (16 \%)}

$30 \%$ Acrylamide-Bisacrylamide (37.5:1)

$\begin{array}{cc}5.12 & \mathrm{ml} \\ 2.6 & \mathrm{ml} \\ 2.08 & \mathrm{ml} \\ 50 & \mu \mathrm{l} \\ 100 & \mu \mathrm{l} \\ 10 & \mu \mathrm{l}\end{array}$

\subsection{Tris-HCl pH 8.8}

$\mathrm{H}_{2} \mathrm{O}$

$20 \%$ (w/v) SDS

$10 \quad \mu$ 


\section{Staining solution}

Coomassie Brilliant Blue R250

$\begin{array}{rl}5 & \mathrm{~g} \\ 100 & \mathrm{ml} \\ 450 & \mathrm{ml} \\ \text { ad } 1000 & \mathrm{ml}\end{array}$

\section{Destaining solution}

Acetic acid

$100 \mathrm{ml}$

$\mathrm{H}_{2} \mathrm{O}$

ad $1000 \quad \mathrm{ml}$

\begin{tabular}{|c|c|c|c|}
\hline & $\begin{array}{l}\text { Apparent } \\
\mathrm{MW}^{*}, \mathrm{kDa}\end{array}$ & Protein & Source \\
\hline & -118 & $\beta$-galactosidase & E.coli \\
\hline 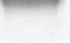 & 90 & Bovine serum albumin & bovine plasma \\
\hline 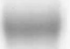 & -50 & Ovalbumin & chicken egg white \\
\hline$=$ & -36 & Carbonic anhydrase & bovine erythrocytes \\
\hline$=$ & -27 & $\beta$-lactoglobulin & bovine milk \\
\hline$=$ & -20 & Lysozyme & chicken egg white \\
\hline
\end{tabular}

Figure 2.4.: Prestained protein molecular weight marker.

\section{Overexpression of proteins in $E$. coli}

Prior to large scale overproduction, a small scale pretest was performed. For this purpose, $50 \mathrm{ml} \mathrm{LB}$ medium with ampicillin were inoculated with an overnight culture of an $E$. coli strain carrying the relevant overexpression vector to $\mathrm{OD}_{600}=0.1$. The culture was incubated at $37{ }^{\circ} \mathrm{C}$ under agitation $(200 \mathrm{rpm})$. The expression was started with a final concentration of $1 \mathrm{mM}$ isopropyl- $\beta$-D-thiogalactopyranoside (IPTG) for $2 \mathrm{~h}$. As control a parallel culture was grown, which was not induced. To test the expression, small aliquots (sample $[\mu \mathrm{l}]=100 / \mathrm{OD}_{600}$ ) were taken directly before and $2 \mathrm{~h}$ after the induction. The samples were boiled in SDS loading dye and analyzed by SDS-PAGE. In case of a positive pretest two 11 cultures of LB medium with ampicillin were inoculated with an overnight culture to an $\mathrm{OD}_{600}=0.1$ in a culture flask with baffles. The cultures 
were induced as described above. After $2 \mathrm{~h}$ the cells were harvested (15 min, 8,000 rpm, $\left.4{ }^{\circ} \mathrm{C}\right)$. After removing the supernatant the cells were stored at $-20{ }^{\circ} \mathrm{C}$.

Prior to cell disruption the pooled pellets were resuspended in $24 \mathrm{ml}$ LEW buffer with $8 \mathrm{M}$ urea and $10 \mathrm{mM}$ imidazole.

Solutions for overexpression:

\section{IPTG stock solution (1 M)}

IPTG

\section{$2.38 \mathrm{~g}$}

$\mathrm{H}_{2} \mathrm{O}$

ad $10 \quad \mathrm{ml}$

Sterilized by filtration and stored at $-20^{\circ} \mathrm{C}$.

\section{LEW buffer}

$\mathrm{NaH}_{2} \mathrm{PO}_{4} \cdot 2 \mathrm{H}_{2} \mathrm{O}$

$7.8 \quad \mathrm{~g}$

$\mathrm{NaCl}$

$17.5 \mathrm{~g}$

$\mathrm{H}_{2} \mathrm{O}$ ad $1000 \quad \mathrm{ml}$

Adjusted to $\mathrm{pH} 8.0$ with $\mathrm{NaOH}$.

\section{Cell disruption by sonication}

Volumes less than $2 \mathrm{ml}$ were treated six times with the ultrasonic probe at $60 \mathrm{~W}$ for 10 s. The cycle was adjusted to 0.6. Between each sonication step the samples were kept on ice for $10 \mathrm{~s}$. The samples were centrifuged (30 $\mathrm{min}, 13,000 \mathrm{rpm}, 4^{\circ} \mathrm{C}$ ) to remove remaining membrane compounds.

For larger volumes the samples were treated ten times with the ultrasonic probe at $85 \mathrm{~W}$ for $15 \mathrm{~s}$. The cycle was adjusted to 0.5 . Sonication steps were interrupted by $15 \mathrm{~s}$ breaks. The samples were kept on ice all the time. The samples were centrifuged two times (30 min, 8,000 rpm, $4{ }^{\circ} \mathrm{C}$ ) to remove remaining membrane compounds.

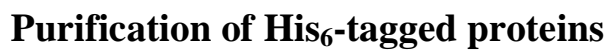

For protein purification, the described cell suspension was disrupted under denaturing conditions by sonication (see above). For purification of recombinant His $_{6}$-tagged proteins the supernatant fraction was loaded onto a $1 \mathrm{ml}$ bed volume of $\mathrm{Ni}^{2+}$-NTA resin 
in a chromatography column. The $\mathrm{Ni}^{2+}$-NTA resin had been pre-equilibrated with $8 \mathrm{ml}$ LEW buffer with $8 \mathrm{M}$ urea and $10 \mathrm{mM}$ imidazole. In a first $8 \mathrm{ml}$ washing step a higher ionic stringency was applied (LEW buffer with $8 \mathrm{M}$ urea, $10 \mathrm{mM}$ imidazole and additional $700 \mathrm{mM} \mathrm{NaCl}$ ). In a second $8 \mathrm{ml}$ washing step the proteins were renatured (LEW buffer with $10 \mathrm{mM}$ imidazole and additional $700 \mathrm{mM} \mathrm{NaCl}$ ). Finally, the target protein was eluted in five steps with increasing imidazole concentration. 50, 100, 200, 300 and $500 \mathrm{mM}$ imidazole were used in $3 \mathrm{ml}$ elution fractions. Each fraction was analyzed by SDS-PAGE. The protein concentration was determined according to the method of Bradford using the Roti-Quant solution with bovine serum albumin as standard (Bradford, 1976). Protein solutions were kept on ice throughout. Purified proteins were used for immunizations of rabbits (Eurogentec, Seraing, Belgium) using an 87-day protocol with Freund's adjuvant.

For purification of His $_{6}$-tagged MDH, Protino Ni-TED 2000 kit was used according to the manufacturer's instructions for denaturing conditions. Purified MDH was dialyzed against LEW buffer (see above) in relation 1 to 1000 in a dialysis tube at $8{ }^{\circ} \mathrm{C}$ for $36 \mathrm{~h}$ (12-14 kDa molecular weight cut off) to remove urea. LEW buffer was once renewed. Prior to dialysis, the dialysis tube was boiled in $115 \mathrm{mM}$ EDTA in $\mathrm{H}_{2} \mathrm{O}$. This step was repeated in $11 \mathrm{H}_{2} \mathrm{O}$.

\section{Western blot analysis}

Proteins were transferred from the gel to a polyvinylidene difluoride (PVDF) membrane with a semi-dry blotting apparatus. The PVDF membrane was activated in methanol and equilibrated in transfer buffer. A stack of following layers was prepared (from bottom to top): 3 layers Whatman paper soaked with transfer buffer, activated and equilibrated PVDF membrane, SDS-PAGE washed in transfer buffer, 3 layers of Whatman paper soaked with transfer buffer. The stack was loaded on the blotting apparatus and proteins were transferred for $1 \mathrm{~h}$ at $0.8 \mathrm{~mA} / \mathrm{cm}^{2}$. Protein transfer to the membrane was controlled by the applied prestained protein molecular weight marker. The membrane was incubated under continuous shaking in Blotto overnight to block unspecific binding sites on the membrane. Antibodies were diluted in Blotto and incubated with the membrane for $3 \mathrm{~h}$ at RT, while shaking. The antibody solution was removed and the membrane was washed three times for $30 \mathrm{~min}$ with Blotto. Then, the membrane was 
incubated in the solution with secondary antibodies (anti-rabbit IgG coupled with alkaline phosphatase, diluted $1: 100,000$ in Blotto) for $30 \mathrm{~min}$ at RT. Again, the membrane was washed 3 times for $30 \mathrm{~min}$ in Blotto, followed by a short rinse with water and by equilibration in Buffer III for $5 \mathrm{~min}$. Proteins were detected and quantified by chemiluminescence using CDP-Star (diluted 1:100 in Buffer III) as a substrate for alkaline phosphatase.

Solutions for western blot analysis:

\section{Blotto}

TBS $10 \mathrm{x}$

Skim milk

Tween 20

$\mathrm{H}_{2} \mathrm{O}$

\section{Buffer III}

Tris

$\mathrm{NaCl}$

$\mathrm{H}_{2} \mathrm{O}$

Adjusted to $\mathrm{pH} 9.5$ with $\mathrm{HCl}$.

\section{TBS $10 \mathrm{x}$}

Tris

$\mathrm{NaCl}$

$\mathrm{H}_{2} \mathrm{O}$

Adjusted to $\mathrm{pH} 7.6$ with $\mathrm{HCl}$.

\section{Transfer buffer}

Tris

Glycine

Methanol

$\mathrm{H}_{2} \mathrm{O}$

$\begin{array}{rl}100 & \mathrm{ml} \\ 25 & \mathrm{~g} \\ 1 & \mathrm{ml} \\ \operatorname{ad} 1000 & \mathrm{ml}\end{array}$

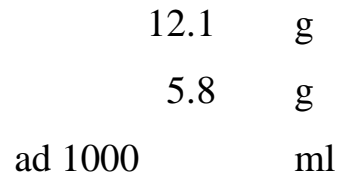

$\mathrm{ml}$ 


\subsubsection{Microscopy}

\section{Light microscopy}

For light microscopic analysis phase contrast was applied. Experiments were performed with the Axioskop $40 \mathrm{FL}$ fluorescence microscope, equipped with digital camera and AxioVision software for image processing and Neofluar series $10 \mathrm{x}, 40 \mathrm{x}$ and $100 \mathrm{x}$ objectives. For microscopy of all suspensions, a $50 \mu \mathrm{l}$ drop taken from liquid culture was applicated to a microscopy slide and covered with a coverslip. Semithin sections of samples embedded in Lowicryl K4M resin (see below, thickness approximately $400 \mathrm{~nm}$ ) were transferred to Formvar-coated $\mathrm{Cu}$ single slot grids (Hoppert and Holzenburg, 1998) and processed for light microscopy and immunofluorescence (cf. Wrede et al., 2008).

\section{Fluorescence microscopy}

For fluorescence microscopy, following filter sets were used: EGFP HC-Filterset (BP: 472/30, FT 495, LP 520/35) for AlexaFluor 488, Atto488 and 6-FAM fluorescence and filter set 43 (BP: 545/25, FT 570, LP: 605/70) for AlexaFluor 546 and CY3 visualization. DAPI signals were analyzed with filter set 49 (BP: 445/50, FT: 395, G: 365). Images were processed with Adobe Photoshop.

\section{Transmission electron microscopy (TEM)}

The analyses were performed with a Zeiss Transmission Electron Microscope 902A equipped with an in-column electron energy loss spectrometer at $80 \mathrm{kV}$ accelerating voltage and calibrated with a cross-lined grating replica. Micrographs were taken with a $1,024 \times 1,024$ charge-coupled device detector in combination with iTEM software. Images were processed with Adobe Photoshop or analyzed with ImageJ for line-density scan (Hoppert and Holzenburg, 1998; Collins, 2007).

\section{Grids}

Sections were transferred to Formvar-coated grids (diameter: $3.05 \mathrm{~mm}$ ), Ni G300 for TEM and Cu single slot for immunofluorescence (Hoppert and Holzenburg, 1998). 


\section{Support films (Mahl and Möldner, 1973)}

Ahead of uptaking the specimen, grids were coated with Formvar film for stabilization of ultrathin sections. Therefore, Formvar (Poly [vinyl formal]) was dissolved to a final concentration of $0.5 \%(\mathrm{w} / \mathrm{v})$ in water-free chloroform. The solution was filtered and stored in the dark. A microscopy slide was cleaned with detergent and water causing a thin residual layer of detergent on the surface. The microscopy slide was placed inside a cylindrical glass funnel (fitted with a tap and drain tube), filled with Formvar solution so that the slide was submersed at maximum $3 / 4$ of its length. The slice was incubated in the covered funnel for $30 \mathrm{~s}$, then the solution was drained off. After another $30 \mathrm{~s}$, the microscopy slide was removed from the glass funnel and dried in a dust-free vessel. The edges of the microscopy slides were scratched with a razor blade and the film was floated on a clean water surface at an angle of $30-45^{\circ}$. The grids were placed on the floating film with the dull site down. The backing paper of Parafilm was lowered onto the grids and gently pressed home. The whole construction was removed from the water surface and dried upside-down on filter paper. The coated grids were stored in dust-free Petri dishes.

\section{Fixation of TEM samples}

For embedding in Lowicryl K4M resin, which allows preservation of antigenic determinants in specimens, samples of the Black Sea cold seeps were cut into small cubes with approximate edge lengths of $2 \mathrm{~mm}$. The cubes were washed several times in PBS (50 mM, pH 7.5) and fixed in $0.3 \%$ (v/v) solution of glutardialdehyde and $0.5 \%$ (w/v) formaldehyde in PBS for $2 \mathrm{~h}$. Then free aldehyde groups were blocked by washing the cubes in PBS with $10 \mathrm{mM}$ glycine.

Cells from cultures were harvested $\left(20 \mathrm{~min}, 5,000 \mathrm{rpm}, 4^{\circ} \mathrm{C}\right)$ and washed in PBS. The cells were subsequently fixed as described above and 50-150 $\mu$ l aliquots were embedded by mixing with $2.5 \%$ (w/v) molten Bacto-Agar in PBS (kept at $60{ }^{\circ} \mathrm{C}$ ). After gelling, small cubes were cut and treated as described for the cold seep microbial mats. Since osmium tetroxide staining destroys the specific antigenic binding sites, it was omitted during sample preparation. All steps were performed at $4{ }^{\circ} \mathrm{C}$. 
For embedding in Spurr resin, cultured cells were harvested $\left(20 \mathrm{~min}, 5,000 \mathrm{rpm}, 4{ }^{\circ} \mathrm{C}\right)$ and washed in PBS (according to Spurr, 1969; modified). After that, cells were prefixed in $3.5 \%(\mathrm{v} / \mathrm{v})$ glutardialdehyde for $1.5 \mathrm{~h}$, washed with PBS and embedded in $2.5 \%$ (w/v) molten Bacto-Agar (kept at $60^{\circ} \mathrm{C}$ ). The gelled agar was cut in small cubes as already described. Microbial mats from GHOSTDABS cold seeps were directly cut into small cubes, followed by prefixation and washing in PBS. Then, the cubes were incubated with $1 \%(\mathrm{w} / \mathrm{v})$ osmium tetroxide in PBS for $1 \mathrm{~h}$ and washed in water for three times.

\section{Low temperature embedding in Lowicryl K4M resin (Roth et al., 1981;}

\section{Armbruster et al., 1982)}

Low temperature embedding preserves the native structure of proteins. For that reason the low temperature embedding was chosen to preserve the ultrastructure of cells and the antigenicity of proteins. For dehydration, an ascending ethanol series was used. The temperature was successively lowered down to $-35{ }^{\circ} \mathrm{C}$. Dehydrated samples were transferred to a dilution series of Lowicryl $\mathrm{K} 4 \mathrm{M}$ resin in ethanol, followed by pure resin, detailed protocol below:

Solution Incubation time Incubation temperature

$15 \%$ Ethanol

$15 \mathrm{~min}$

$0{ }^{\circ} \mathrm{C}$

$30 \%$ Ethanol

$30 \mathrm{~min}$

$0{ }^{\circ} \mathrm{C}$

$50 \%$ Ethanol

$30 \mathrm{~min}$

$-20{ }^{\circ} \mathrm{C}$

$70 \%$ Ethanol

$30 \mathrm{~min}$

$-35^{\circ} \mathrm{C}$

$95 \%$ Ethanol

$30 \mathrm{~min}$

$-35^{\circ} \mathrm{C}$

$100 \%$ Ethanol

$2 \times 30 \mathrm{~min}$

$-35^{\circ} \mathrm{C}$

$50 \%$ Methanol/50 \%

Lowicryl K4M resin

$60 \mathrm{~min}$

$-35^{\circ} \mathrm{C}$

$33 \%$ Ethanol/66 \%

Lowicryl K4M resin

$120 \min$

$-35^{\circ} \mathrm{C}$

$100 \%$ Lowicryl K4M resin $1 \mathrm{x}$ short change, then over

$-35^{\circ} \mathrm{C}$

night 
Subsequently, the samples were transferred to gelatin capsules, which were filled with Lowicryl K4M resin. Polymerization was catalyzed in the deep freezer at $-35{ }^{\circ} \mathrm{C}$ with ultraviolet light $(260 \mathrm{~nm})$ for $60 \mathrm{~h}$.

\section{Lowicryl K4M resin}

Crosslinker

$\begin{array}{rr}6.75 & \mathrm{~g} \\ 43.30 & \mathrm{~g} \\ 0.25 & \mathrm{~g}\end{array}$

Spurr resin embedding (Spurr, 1969; Hoppert, 2003)

For embedding, a dehydration protocol with an ascending acetone series was used.

Dehydrated samples were transferred to a dilution series of Spurr resin in acetone, followed by pure resin (detailed protocol below).

Solution

$10 \%$ Acetone

$30 \%$ Acetone

$50 \%$ Acetone

$70 \%$ Acetone with $2 \%$

(w/v) uranyl acetate

$70 \%$ Acetone

$90 \%$ Acetone

$100 \%$ Acetone

$66 \%$ Acetone $/ 33 \%$

Spurr resin

$25 \%$ Acetone $/ 75 \%$

Spurr resin

$100 \%$ Spurr resin

$100 \%$ Spurr resin
Incubation time

$10 \min$

$10 \mathrm{~min}$

10 min

$2 \mathrm{~h}$ or

overnight

$10 \mathrm{~min}$

$10 \mathrm{~min}$

$10 \mathrm{~min}$

$30 \mathrm{~min}$

$90 \min$

$16 \mathrm{~h}$

$3 \mathrm{~h}$
Incubation temperature

$0{ }^{\circ} \mathrm{C}$

$0{ }^{\circ} \mathrm{C}$

$0{ }^{\circ} \mathrm{C}$

$0{ }^{\circ} \mathrm{C}$

$0{ }^{\circ} \mathrm{C}$

$0{ }^{\circ} \mathrm{C}$

$0{ }^{\circ} \mathrm{C}$

RT

RT

RT

RT 
Subsequently, the samples were transferred to gelatin capsules, which were filled with Lowicryl K4M resin. Capsules were de-gassed in a vacuum chamber for $10 \mathrm{~min}$. Polymerization was performed at $70{ }^{\circ} \mathrm{C}$ for $24 \mathrm{~h}$.

\section{Spurr resin}

Vinylcyclohexene dioxide $15 \mathrm{~g}$

Diglycidyl ether of polypropylene glycol

$9 \mathrm{~g}$

(D.E.R. 736)

Nonenyl succinic anhydride (NSA)

$39 \quad \mathrm{~g}$

Dimethylaminoethanol

\section{Ultramicrotomy}

The embedded specimens were trimmed with a rotating milling cutter to a small flattopped pyramid with a face of about $0.2-2 \mathrm{~mm}^{2}$. For sectioning with an ultramicrotome glass knives were prepared from a glass strip of $25 \mathrm{~mm}$ width and $6.5 \mathrm{~mm}$ thickness. Prior to use, the glass strip was thoroughly cleaned. Glass squares (25 x $25 \mathrm{~mm})$ were made with a special knife-maker. By breaking the squares slightly off the diagonal axis, two usable knives were obtained. With a counterpiece of $0.5 \mathrm{~mm}$ thickness a real angle of $55^{\circ}$ at the cutting edge was obtained. Quality characteristics are well formed conchoidal fracture marks and a unbowed knife edge without flaws. Knives accomplishing these features obtained an plastic tray fixed with special wax.

Knives were stored dust-free. Glass knives were used for smoothing the trimmed specimen and semithin as well as ultrathin sectioning.

The preparation of semithin and ultrathin sections was performed with an ultramicrotome. The trimmed block was mounted and the glass knife was fixed at an angle of $5^{\circ}$. The cutting edge was adjusted parallel to the cut surface. The tray was filled with water until the water surface is almost flat and extends to the cutting edge. This allows an optimal floating of the sections on the water surface. The thickness of the sections was checked on the basis of interference colors (Tab. 2.4.). For TEM, 40-100 nm ultrathin sections were prepared. Sections were moved with a mounted eyelash on the water surface and picked up with Formvar-coated specimen grids. For this purpose the grid, orientated with the support film downwards, was slowly lowered 
onto the water surface. There the sections were allowed to adsorb on the support film for some seconds. Grids were withdrawn, the excessive liquid was drained off with a piece of filter paper and the grid was stored dust-free upside-down on filter paper.

Table 2.4.: Section thicknesses.

\begin{tabular}{lc}
\hline \multicolumn{1}{c}{ Interference color } & Section thickness \\
\hline Grey to silver & $60-90 \mathrm{~nm}$ \\
Gold & $90-150 \mathrm{~nm}$ \\
Purple-blue & $150-190 \mathrm{~nm}$ \\
blue & $190-240 \mathrm{~nm}$ \\
\hline
\end{tabular}

\section{Post-staining of sections}

For post-staining of ultrathin sections, phosphotungstic acid (PWS) was used. Therefore, phosphotungstic acid ( $\mathrm{pH} 7.0,1 \%$ [w/v]) was centrifuged for $10 \mathrm{~min}, 13,000$ rpm to remove particles. The grids with adsorbed specimen sections were incubated for 3 min on drops of particle-free PWS applicated on fixed Parafilm. The excessive liquid was drained off with a piece of filter paper. Grids were dried dust-free upside-down on filter paper.

Furthermore, staining with uranyl acetate was applied. Uranyl acetate (4\% [w/v]) was centrifuged for $10 \mathrm{~min}, 13,000 \mathrm{rpm}$ to remove particles. The grids were stained as described for staining with PWS.

To enhance staining of membranes, uranly acetate and lead citrate staining were applied (Venable and Coggesha, 1965). Therefore, grids were incubated for $2 \min$ on $0.1 \mathrm{M}$ EDTA solution, followed by uranyl acetate staining as described. Lead citrate solution was freshly prepared: $10 \%(\mathrm{w} / \mathrm{v})$ lead citrate in $0.1 \mathrm{M} \mathrm{NaOH}$ (solution in carbon dioxide-free [boiled] water), centrifuged for $10 \mathrm{~min}$ and 13,000 rpm. Then, staining was performed in carbon dioxide-free atmosphere obtained by moistened $\mathrm{NaOH}$ pellets in a Petri dish. Grids were incubated for $3 \mathrm{~min}$ on lead citrate drops and subsequently washed by repeated dipping in a series of three $10 \mathrm{ml}$ beakers of carbon dioxide-free water. 


\section{Immunocytochemistry for TEM and fluorescence microscopy}

Ultrathin sections $(60-100 \mathrm{~nm})$ were used for immunocytochemistry with TEM. Semithin sections (approximately $400 \mathrm{~nm}$ ) were used for immunofluorescence analyses (Wrede et al., 2008). Sections were transferred to Formvar-coated grids (Hoppert and Holzenburg, 1998), Ni 300 mesh for TEM and Cu single slot for immunofluorescence. For all labeling procedures grids were placed on drops of antibody dilutions and washing solutions with section facing downwards.

For TEM immunocytochemistry of Black Sea cold seep microbial mats the following protocol was applied: 30 min blocking with $3 \%(\mathrm{w} / \mathrm{v})$ bovine serum albumin (BSA) in PBS, $2 \mathrm{~h}$ primary antibodies (anti-MDH $[\alpha-\mathrm{MDH}]$ antibodies in $1 \%[\mathrm{w} / \mathrm{v}] \mathrm{BSA}$, anti-AprB $[\alpha-A p r B]$ antibodies in $0.2 \mu \mathrm{g} / \mu 1 \mathrm{M}$. mazei Gö1 crude extract with protease inhibitor, complete EDTA free) with appropriate dilutions ( $\alpha-\mathrm{MDH}$ antibodies 1:501:1000; $\alpha$-AprB antibodies 1:50-1:400; Wrede et al., subm.), three 5 min washing steps with PBS containing $0.05 \%(\mathrm{v} / \mathrm{v})$ Tween 20, 5 min washing step with PBS, $1 \mathrm{~h}$ secondary antibodies (goat-anti-rabbit IgG-10 nm gold conjugate) 1:80 diluted in the same solutions as first antibodies, three 5 min washing steps with PBS containing 0.05 $\%$ (v/v) Tween 20, 5 min washing step with PBS, two times 10 s desalting in $\mathrm{H}_{2} \mathrm{O}$. Poststaining was performed with $4 \%$ (w/v) uranyl acetate solution for $3 \mathrm{~min}$. All steps were performed at room temperature. The applied polyclonal antibodies were used as original antiserum. For controls embedded mixture of M. mazei Gö1 (AprB: not present, MDH: not present, MCR: present) and D. vulgaris Hildenborough (AprB: present, MDH: not present, MCR: not present) was used, to simulate a situation in the microbial mat layers. In addition, $M$. extorquens AM1 and 5 methylotrophic isolates were used as positive controls for the MDH labeling. Labeling without primary antibodies was applied to check the specificity of secondary antibodies. Furthermore, the specificity of all applied antibodies was checked by Western blot analyses.

For immunofluorescence, the protocol for TEM immunocytochemistry was applied (see above) with following modifications: 20 min blocking with $10 \%$ goat normal serum in PBS prior to blocking with BSA. As secondary antibody, a goat-anti-rabbit IgG AlexaFluor 546 conjugate, diluted 1:250, was applied. 
After desalting, the specimens were mounted with DPX on a microscopy slide. Modifications for double labeling: In a first labeling approach anti-MCR [ $\alpha-\mathrm{MCR}]$ labeling was performed as described (cf. for antibody Heller et al., 2008), but with $\mathrm{F}\left(\mathrm{ab}^{\prime}\right)_{2}$ fragment of goat-anti-rabbit $\operatorname{IgG}(\mathrm{H}+\mathrm{L})$ AlexaFluor 488 conjugate, diluted 1:100. After air drying the $\alpha$-AprB labeling was performed as described.

\section{Cell extraction from volcano fluids (Kallmeyer et al., 2008)}

Due to low cell counts, the fixed samples from the mud volcano fluids (see 2.1.3.) were extracted, concentrated and filtered onto $0.2 \mathrm{~mm}$ polycarbonate filters according to Kallmeyer et al. (2008).

Therefore, the stored samples were thoroughly mixed by vortexing. $33.3 \mu 1$ fluids were mixed with $66.6 \mu \mathrm{l} \mathrm{NaCl}$ solution (with $2 \%$ formalin). The slurry (100 $\mu 1$ ) was added to $500 \mu \mathrm{l}$ acetate buffer and incubated for $2 \mathrm{~h}$ under occasional vortexing. All carbonates were usually dissolved within $2 \mathrm{~h}$. Vials were opened several times during the carbonate dissolution to avoid $\mathrm{CO}_{2}$ overpressure. Carbonate-free slurries were centrifuged for 5 $\min$ at 3,000 g. The clean supernatant was removed and kept for further analysis, as the subsequent supernatants from the detergent mix/methanol treatment. The remaining pellet was used for further processing. The acetate buffer was completely removed from the sediment, as it may contain enough calcium ions interfering with the detergent mix. The pellet was washed twice with $\mathrm{NaCl}$ solution (with azide; 5 min, 3,000 g). The rinsing solution was kept for further analysis. The pellet was diluted with $300 \mu \mathrm{NaCl}$ solution (with azide) and $50 \mu \mathrm{l}$ each of the detergent mix and methanol were added. The mixture was vortexed for 60 min for suspension of cells. A cushion of $500 \mu 160 \%$ (w/v) Nycodenz was layered below the slurry with a syringe and the sample was centrifuged at $3,000 \mathrm{~g}$ for $10 \mathrm{~min}$ for separation of cells from suspension. The supernatant was carefully removed and kept for further analysis. The remaining Nycodenz was discarded. The remaining pellet was resuspended in $400 \mu \mathrm{l} \mathrm{NaCl}$ solution (with azide) and another $50 \mu \mathrm{l}$ each of detergent mix and methanol were added. Then, the vial was sonicated in an ice water bath for $3 \times 10 \mathrm{~s}$ with $20 \mathrm{~s}$ between the cycles $(20 \mathrm{ml}$ beaker with ice water; $20 \mathrm{~W}$, cycle 0.5$)$. Addition of Nycodenz and density centrifugation was repeated as described above. The supernatants were kept at 
$4{ }^{\circ} \mathrm{C}$ and used for cell counting and FISH analyses (Supernatants of two extractions were applicated onto one filter).

Solutions used for the cell extraction:

\section{$\mathrm{NaCl}$ solution (with $2 \%$ formalin)}
$\mathrm{NaCl}$
$0.39 \mathrm{~g}$
$\mathrm{H}_{2} \mathrm{O}$
ad $100 \quad \mathrm{ml}$

Autoclaved and $2 \%$ formalin (sterile filtered) added. Stored at $4{ }^{\circ} \mathrm{C}$. Salinity should be adapted to each habitat.

\section{$\mathrm{NaCl}$ solution (with azide)}

$\mathrm{NaCl}$

$\begin{array}{rl}0.39 & \mathrm{~g} \\ \operatorname{ad} 100 & \mathrm{ml}\end{array}$

$\mathrm{H}_{2} \mathrm{O}$

ach habitat.

\section{Acetate buffer}

Glacial acetic acid

$2 \mathrm{ml}$

Sodium acetate

$3.5 \mathrm{~g}$

$\mathrm{NaCl}$

$0.39 \mathrm{~g}$

$\mathrm{H}_{2} \mathrm{O}$

ad $100 \quad \mathrm{ml}$

Autoclaved and $2 \%$ formalin (sterile filtered) added. Stored at $4{ }^{\circ}$ C. Salinity should be adapted to each habitat.

\section{Detergent mix}

Disodium EDTA dihydrate

$3.7 \quad \mathrm{~g}$

Sodium pyrophosphate decahydrate

$\begin{array}{rl}3.7 & \mathrm{~g} \\ 4.5 & \mathrm{~g} \\ 1 & \mathrm{ml} \\ 0.39 & \mathrm{~g} \\ \operatorname{ad} 100 & \mathrm{ml}\end{array}$

Tween 80

Tween 80. Then $2 \%$

After autoclaving, the solution was cooled while stirring to avoid separation of Tween 80 .
formalin (sterile filtered) was added. Stored at $4{ }^{\circ} \mathrm{C}$. Salinity should be adapted to each habitat. 
Methanol was sterilized by filtration and stored at $4{ }^{\circ} \mathrm{C}$.

All materials were flamed or autoclaved.

\section{Enumeration of total archaea and bacteria}

The extracted cells of two batches (see above) were applicated onto one filter. For this purpose, a hand-operated vacuum pump in combination with a combusted filtration tower was used. The moistened cellulose nitrate support filter $(0.45 \mu \mathrm{m}$ pore size $)$ and the polycarbonate filter $(0.2 \mu \mathrm{m}$ pore size $)$ were placed into the filtration tower. The supernatants were applicated into the filter tower and filtered by applying a gentle vacuum of -200 mbar. Support filters were utilized for several samples. For washing, $5 \mathrm{ml}$ sterile $\mathrm{H}_{2} \mathrm{O}$ were filtered two times.

For enumeration of cells, the prepared filters were DAPI stained and counted using the protocol of Sherr et al. (2001). For this purpose, $2 \mathrm{ml}$ DAPI solution with a concentration $2 \mu \mathrm{g} / \mathrm{ml}$ in $\mathrm{H}_{2} \mathrm{O}$ were incubated for $10 \mathrm{~min}$ in the dark on the filter. The solution was removed by applying underpressure (-200 mbar). Subsequently, the filter was washed two times with $2 \mathrm{ml} \mathrm{H}_{2} \mathrm{O}$. The filter was put in a Petri dish and allowed to air-dry. Finally one half of a filter was mounted with DPX on a microscopy slide and analyzed by fluorescence microscopy.

Cells were counted per camera field of view with a $40 \mathrm{x}$ objective. The camera field of view corresponds $140 \times 105 \mu \mathrm{m}$ (W x L). The net filter surface of $2.3 \mathrm{~cm}$ in diameter corresponds to 28,264 camera fields of view. Because of the low cell counts, three microscopy slides were counted. On each microscopy slide 20 randomly selected camera fields of view were counted. The calculated average was extrapolated to the filter area.

Solutions used for the cell enumeration:

\section{DAPI stock solution}

DAPI

$\mathrm{H}_{2} \mathrm{O}$

Stored at $-20{ }^{\circ} \mathrm{C}$ in the dark.

$\begin{array}{rr}1 & \mathrm{mg} \\ \operatorname{ad} 1 & \mathrm{ml}\end{array}$

(n) 


\section{DAPI solution}

DAPI stock solution

$4 \quad \mu 1$

$\mathrm{H}_{2} \mathrm{O}$

$\operatorname{ad} 2$

$\mathrm{ml}$

Prepared directly prior to use. Protected from light.

\section{Fluorescence in situ hybridization (FISH)}

The described protocol refers to FISH with monolabeled fluorescent probes on membrane filters and glass slides (according to Pernthaler et al., 2001; modified). The extracted cells were applied to a polycarbonate filter $(0.2 \mu \mathrm{m}$ pore size $)$ as described for cell enumeration. The filter was air-dried, followed by mounting of the filter with molten $0.9 \%(\mathrm{w} / \mathrm{v})$ agarose in water on a microscopy slide. One half of a filter was used per microscopy slide. The molten agarose was applied as a very thin layer (spread with a coverslip).

$2 \mathrm{ml}$ of hybridization buffer were prepared in a microfuge tube. For the hybridization mixtures $4 \mu \mathrm{l}$ of probe working solution $(50 \mathrm{ng} / \mu \mathrm{l})$ were added to $36 \mu \mathrm{l}$ of hybridization buffer. The hybridization mixtures and the probe solutions were kept dark and on ice. A piece of blotting paper was placed in a $50 \mathrm{ml}$ polyethylene tube and soaked with the remaining hybridization buffer. Then, the agarose layer on the microscopy slide was covered with the hybridization mix. The slide was placed into the polyethylene tube in a horizontal position. The samples were incubated at $46^{\circ} \mathrm{C}$ for at least $90 \mathrm{~min}$ (maximum: 3 hours) in a hybridization oven. Subsequently the slides with the filter sections were quickly transferred into preheated washing buffer and incubated for $15 \mathrm{~min}$ at $48{ }^{\circ} \mathrm{C}$. In a next step the slides were rinsed by placing them into a Petri dish with distilled $\mathrm{H}_{2} \mathrm{O}$ for $5 \mathrm{~s}$. Then, the slides with filter sections were air-dried on blotting paper.

For counterstaining, filter sections were covered with $50 \mu \mathrm{l}$ of DAPI solution (see above) and were incubated for 3 minutes. Afterwards, filter sections were washed for 3 min with distilled $\mathrm{H}_{2} \mathrm{O}$ to remove unspecific staining, followed by mounting with distilled $\mathrm{H}_{2} \mathrm{O}$ or PBS in the case of applied fluorochrome 6-FAM (requires $\mathrm{pH} \geq 7$ ). Fluorescence of the hybridized probes fades much more rapidly than DAPI fluorescence, and UV excitation will also bleach the CY3 signal. Therefore, it is, recommend to analyze specifically stained cells first and in a second step the DAPI fluorescence under excitation by UV light with filter set 49. 
All working steps were performed in the dark and solutions were protected from light with aluminum foil. The applied probes with respective formamide concentrations and fluorochromes are given in Tab 2.6.

Solutions used for FISH analyses:

\section{Hybridization buffer}

$5 \mathrm{M} \mathrm{NaCl}$

$1 \mathrm{M}$ Tris-HCl pH 7.4

Formamide

$\mathrm{H}_{2} \mathrm{O}$

$10 \%(\mathrm{w} / \mathrm{v}) \mathrm{SDS}$

To avoid precipitation SDS is added last.
$360 \mu 1$

$40 \quad \mu 1$

$\%$ depending on probe

$\begin{array}{rr}\operatorname{ad} 2 & \mathrm{ml} \\ 2 & \mu 1\end{array}$

Washing buffer

$5 \mathrm{M} \mathrm{NaCl}$

depending on $\%$ formamide in

hybridization buffer (Tab. 2.5.)

$1 \mathrm{M}$ Tris- $\mathrm{HCl} \mathrm{pH} 7.4$

0.5 M EDTA

$1 \mathrm{ml}$

$\mathrm{H}_{2} \mathrm{O}$

$0.5 \mathrm{ml}$

$10 \%(\mathrm{w} / \mathrm{v}) \mathrm{SDS}$ ad $50 \quad \mathrm{ml}$

To avoid precipitation SDS is added last.

$50 \mu 1$

Table 2.5.: Concentrations of $\mathrm{NaCl}$ in washing buffer $\left(48^{\circ} \mathrm{C}\right)$ at different concentrations of formamide in hybridization buffer $\left(46^{\circ} \mathrm{C}\right)$.

\begin{tabular}{cc}
$\begin{array}{c}\text { \% formamide in } \\
\text { hybridization buffer }\end{array}$ & $\begin{array}{c}\text { mM NaCl in } \\
\text { washing buffer }\end{array}$ \\
\hline 5 & 900 \\
10 & 636 \\
15 & 450 \\
20 & 318 \\
25 & 225 \\
30 & 159
\end{tabular}




\begin{tabular}{cc}
$\begin{array}{c}\text { \% formamide in } \\
\text { hybridization buffer }\end{array}$ & $\begin{array}{c}\text { mM NaCl in } \\
\text { washing buffer }\end{array}$ \\
\hline 35 & 112 \\
40 & 80 \\
45 & 56 \\
50 & 40 \\
55 & 28 \\
60 & 20 \\
65 & 14 \\
70 & 10 \\
75 & 7 \\
80 & 5 \\
5 & 3.5 \\
\hline
\end{tabular}

Table 2.6.: Oligonucleotide probes used in this work.

\begin{tabular}{lllll}
\hline \multicolumn{1}{c}{ Probe } & \multicolumn{1}{c}{$\begin{array}{c}\text { Probe sequence (5'-3') } \\
\text { (Specificity) }\end{array}$} & \multicolumn{1}{c}{ Dye } & \% FA & \multicolumn{1}{c}{ Reference } \\
\hline Arch915 & GTGCTCCCCCGCCAATTCCT & CY3 or & 35 & (Stahl and Amann, \\
& (most archaea) & Atto & & 1991; Lösekann et al., \\
& & 488 & & 2007) \\
DSS658 & TCCACTTCCCTCTCCCAT & 6-FAM & 40 & (Manz et al., 1998; \\
& (Desulfosarcina/Desulfococcus & & & Boetius et al., 2000; \\
& branch) & & & Lösekann et al., 2007) \\
EelMS932 & AGCTCCACCCGTTGTAGT & CY3 & 40 & (Boetius et al., 2000) \\
& (ANME-2 archaea) & & & (Daims et al., 1999) \\
EUB338 I & GCTGCCTCCCGTAGGAGT & CY3 & 35 & (Daims et al., 1999) \\
EUB338 & GCAGCCACCCGTAGGTGT & CY3 & 35 & \\
II & & & & \\
EUB338 & GCTGCCACCCGTAGGTGT & CY3 & 35 & (Daims et al., 1999) \\
III & (EUB338 I-III most bacteria) & & & \\
\hline
\end{tabular}




\section{Results}

\subsection{Detections of metabolic key enzymes in anoxic GHOSTDABS cold seeps}

\subsubsection{Methanol dehydrogenase detection of active methano- and methylotrophic bacteria}

\section{Production and characterization of $\alpha$-MDH antibodies}

The MDH $\alpha$-subunit from Methylobacterium extorquens AM1 was selected as a metabolic marker for aerobic methane oxidation in Proteobacteria. M. extorquens is a model methylotroph with a sequenced and annotated genome (Vuilleumier et al., 2009). The subunit is highly conserved within the group and will also include organisms with a methylotrophic lifestyle.

The $M$. extorquens AM1-MDH is an $\alpha_{2} \beta_{2}$ heterotetrameric enzyme consisting of two $66 \mathrm{kDa} \alpha$-subunits (encoded in mxaF; Fig. 3.1.) and two $8 \mathrm{kDa} \beta$-subunits (encoded in mxaI; Fig. 3.1.; Williams et al., 2005). Since the enzyme catalyzes the oxidation of methanol, it is abundant in the metabolism of methylotrophic as well as methanotrophic bacteria. The MDH $\alpha$-subunit contains highly conserved sequences, which allows detection of MDH in different methanotrophic or methylotrophic species. The MDH $\alpha-$ subunit from $M$. extorquens AM1 was used as antigen for the production of polyclonal antibodies. Due to its small size, the MDH $\beta$-subunit contains less immunodominant regions and was not considered as suitable for antibody production.

For immunocytochemical localizations, polyclonal antibodies have to be monospecific for its target. Cross reaction of other proteins by the antibodies would be difficult to discriminate in microscopic labeling. 


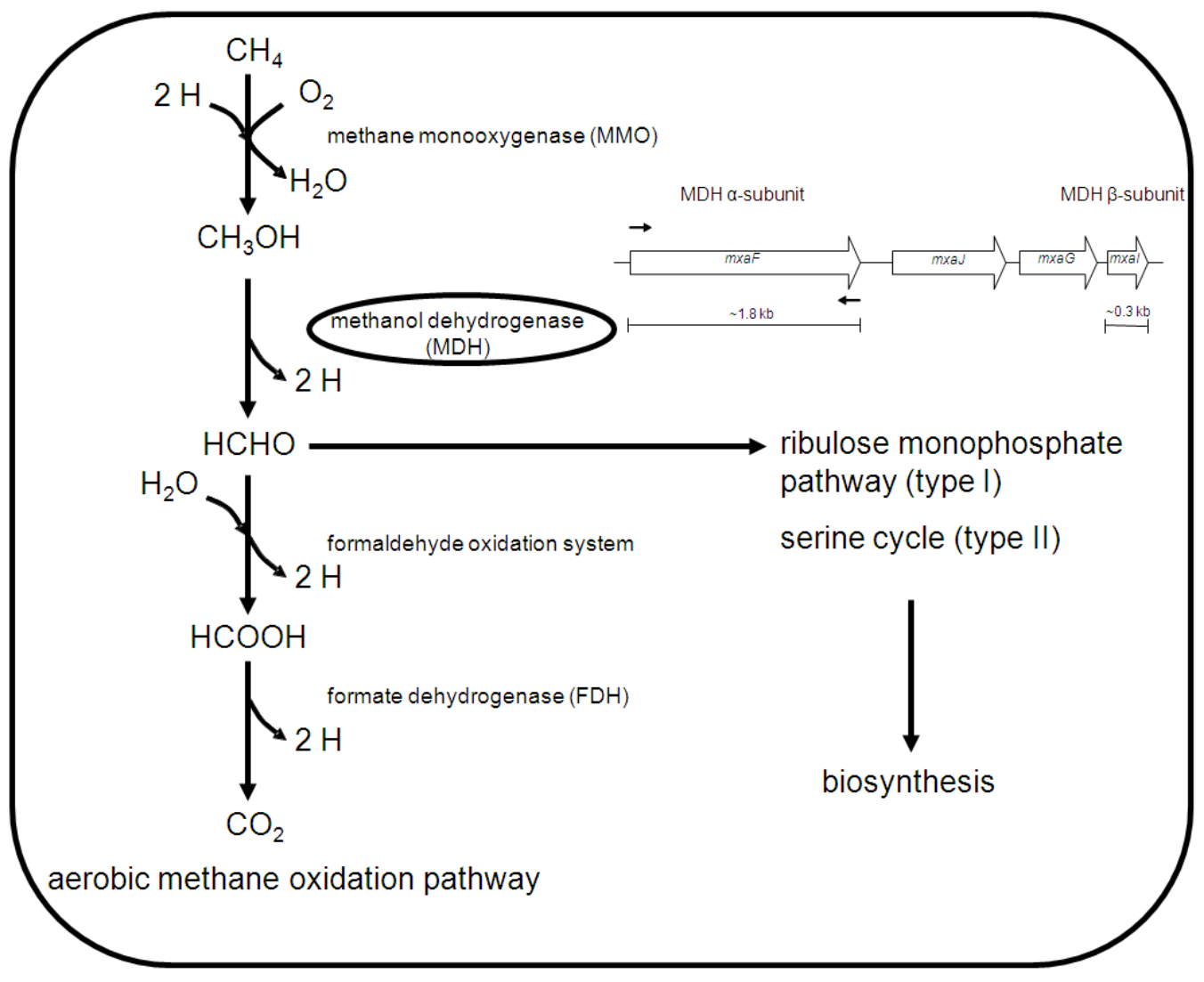

Figure 3.1.: Aerobic methane oxidation pathway.

Methanol dehydrogenase is the key enzyme for the aerobic oxidation of $\mathrm{C}_{1}$-compounds. Details of the gene region encoding the $\mathrm{MDH}$ in $M$. extorquens AM1 are depicted in the upper right part of the figure. The M. extorquens AM1-MDH is an $\alpha_{2} \beta_{2}$ heterotetrameric enzyme consisting of the $\alpha$-subunit $66 \mathrm{kDa}$ (encoded in $m x a F$ ) and the $\beta$-subunit $8 \mathrm{kDa}$ (encoded in $m x a I$; Williams et al., 2005).

The antibodies were produced as described in the Methods section (cf. 2.3.4., 2.3.5. and Krukenberg, 2009). In order to check cross-reactivity and specificity of the $\alpha$-MDH antibodies, respective antisera were tested by Western blot analysis (cf. 2.3.5.). Five isolates of methylotrophs (all of genus Methylobacterium) were used for this approach (Fig. 3.2.). The methylotrophs were isolated from dicot plants (see section 2.3.3.) and characterized by $16 \mathrm{~S}$ rDNA analysis. MDH was detected in each of the isolated strains. Background or unspecific labeling of other protein bands was completely absent or very low, which shows the sufficient specificity of the antibody. The experiment also showed, that the polyclonal antibody detects MDH in different host organisms. This is a necessary prerequisite for using the antibody as probe for unknown MDH-expressing organisms. 


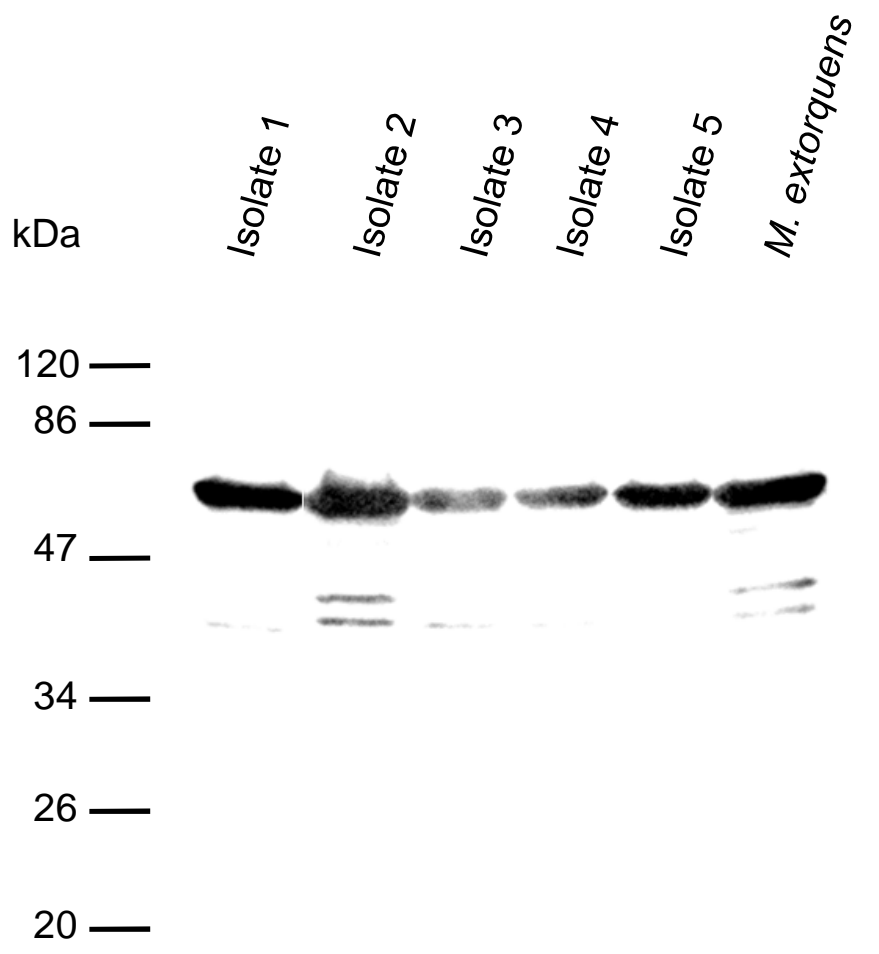

Figure 3.2.: Western blot analysis with $\alpha-\mathrm{MDH}$ antibodies.

Detection of the MDH (66 kDa) in crude extracts of 5 methylotrophic environmental isolates and M. extorquens AM1. Methylotrophic isolates 3 and 4 show a somewhat lower detection signal, due to less cross reactions of the antibodies with the respective MDH.

\section{MDH expression in microbial mats}

In a first study, the $\alpha-\mathrm{MDH}$ antibodies were applied to investigate the GHOSTDABS cold seep mats for expressed MDH, indicating the abundance of active methano- or methylotrophs. Samples were taken from the black (surface layer, exposed to sea water) and the pink layer (underlying the black layer) representing the major parts of the multilayered mat taken from carbonate towers of the GHOSTDABS field in the Black Sea Crimean shelf (Reitner et al., 2005b). Fig. 3.3. depicts the Western blot analysis of the separated proteins (Western blot analysis is described in section 2.3.5.). One distinct 
band is visible in the lane of the black layer at the expected molecular weight of the $\mathrm{MDH} \alpha$-subunit, corresponding to the results of Western blot analysis of the methylotrophs (Fig. 3.2.).

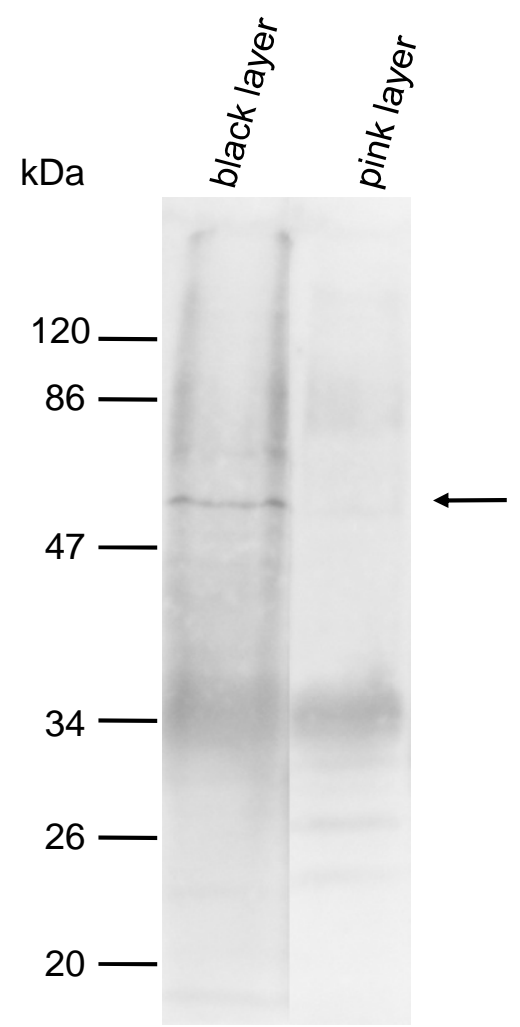

\section{Figure 3.3.: MDH detection in the GHOSTDABS cold seep mat.}

Western blot analysis of MDH (66 kDa; black arrow) in crude extracts of the black and the pink layers ( $\alpha-\mathrm{MDH}$ antibodies). Only the black layer exhibits a positive signal.

The positive MDH-signal in the black layer shows that methano- or methylotrophic bacteria in this part of the microbial mat are present and, due to the expression of one key enzyme, the pathway is active. The underlying pink layer of the cold seep carbonate towers seems to lack MDH-expressing cells, since the MDH-signal is missing there. The abundance of active methano- or methylotrophic bacteria is very remarkable for this habitat that has been considered as dysoxic so far, and is here described for the first time. 


\section{Immunocytochemical localizations ( $\alpha-\mathrm{MDH})$}

By using light and electron microscopic imaging, the question was addressed, in which microscale environment the target cells are metabolically active and if any kind of interplay with other organisms of the microbial community is detectable. Therefore, immunofluorescence localization was used to gain an overview of the distribution of MDH-expressing cells. Certain subcellular features, visible by electron microscopy of ultrathin sections are also helpful for distinction of different methylotrophic groups (see section 2.3.6. for details of microscopy). In this microscopical approach also a correlation between low resolution light microscopy and high resolution transmission electron microscopy was performed (cf. Wrede et al., 2008). The environmental samples were embedded with a low temperature embedding procedure in Lowicryl K4M resin (cf. section 2.3.6. for method; Armbruster et al., 1982). The low temperature and a minimized concentration of aldehyde fixatives ensure that the antigenicity of the sample proteins is preserved. As controls, the environmental methylotrophic isolates and M. extorquens AM1 were also embedded for immunocytochemistry.

The obtained labeling results show an intensive signal of the MDH in the immunocytochemistry approach (see section 2.3.6. for immunocytochemistry method), which is equivalent to the Western blot analysis (Fig. 3.2.). M. extorquens AM1 and the environmental isolates show the abundance of the MDH predominantly in the cell periphery, including the periplasm (Fig. 3.4.). This is according to previous data of MDH immunogold labeling (Fassel et al., 1992). The signal intensity is within the range of other metabolic key enzymes (cf. Rohde et al., 1988). Isolates 3 and 4 show a somewhat lower signal by Western blot analysis, which is also reflected in the immunogold labeling. Hence, for these bacteria higher antibody concentrations are applied (Fig. 3.4.c,d). These results suggest a weaker cross reaction of $\alpha-\mathrm{MDH}$ antibodies with MDH of methylotrophic isolates 3 and 4. This finding shows that, though strain-dependent differences in the signal strengths are observable, the enzyme is conserved enough to be detected by the antibodies and the signal remains specific. 

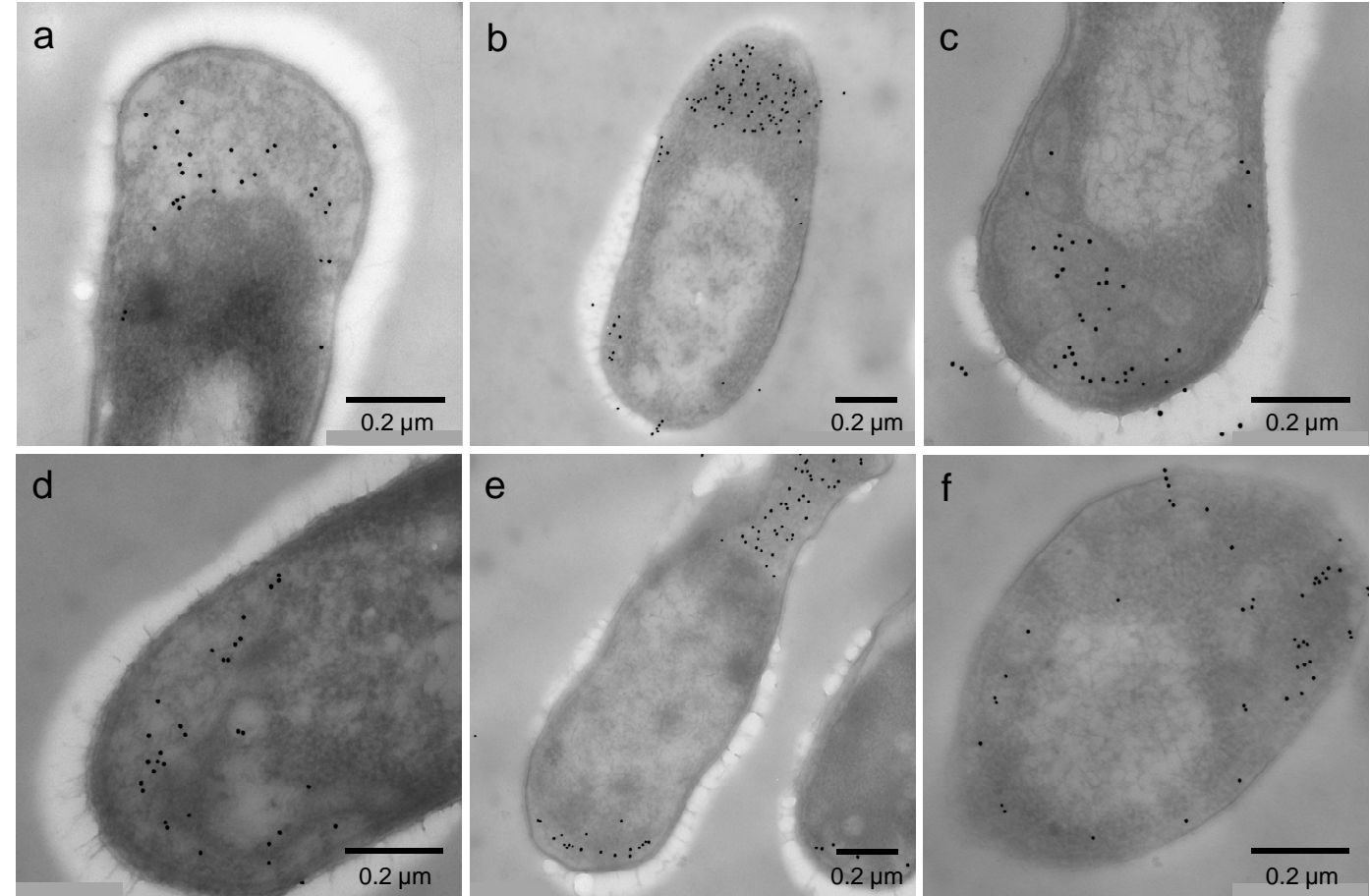

Figure 3.4.: TEM immunocytochemistry analysis with polyclonal $\alpha-M D H$ antibodies.

5 methylotrophic environmental isolates and M. extorquens AM1 were analyzed. $10 \mathrm{~nm}$ immunogold particles mark detected MDH. (a) methylotrophic isolate 1 ( $\alpha$-MDH antibodies diluted 1:1000). (b) methylotrophic isolate 2 ( $\alpha$-MDH 1:1000). (c) methylotrophic isolate 3 ( $\alpha$-MDH 1:100). (d) methylotrophic isolate 4 ( $\alpha$-MDH 1:100). (e) methylotrophic isolate 5 ( $\alpha$-MDH 1:1000). (f) $M$. extorquens AM1 ( $\alpha-\mathrm{MDH} 1: 1000)$.

For immunofluorescence detection, semithin sections of about $400 \mathrm{~nm}$ were applied (cf. section 2.3.6. for immunofluorescence technique). Cells expressing $\mathrm{MDH}$, were detected by orange fluorescence of AlexaFluor 546. The marked cells show a weak phase contrast and are located in interspaces between ANME-2/SRB aggregates in the black layer (Fig. 3.5.a). In order to obtain more details about the identified cells, we investigated the localized interspaces by TEM. This high resolution technique shows that the methano- or methylotrophic cells form microcolonies of some tens of cells (Fig. 3.5.b), embedded in the dense matrix of EPS (Fig. 3.5.b). In contrast to the ANME2/SRB consortia, the bacteria are not in close contact to cells of other morphotypes. 

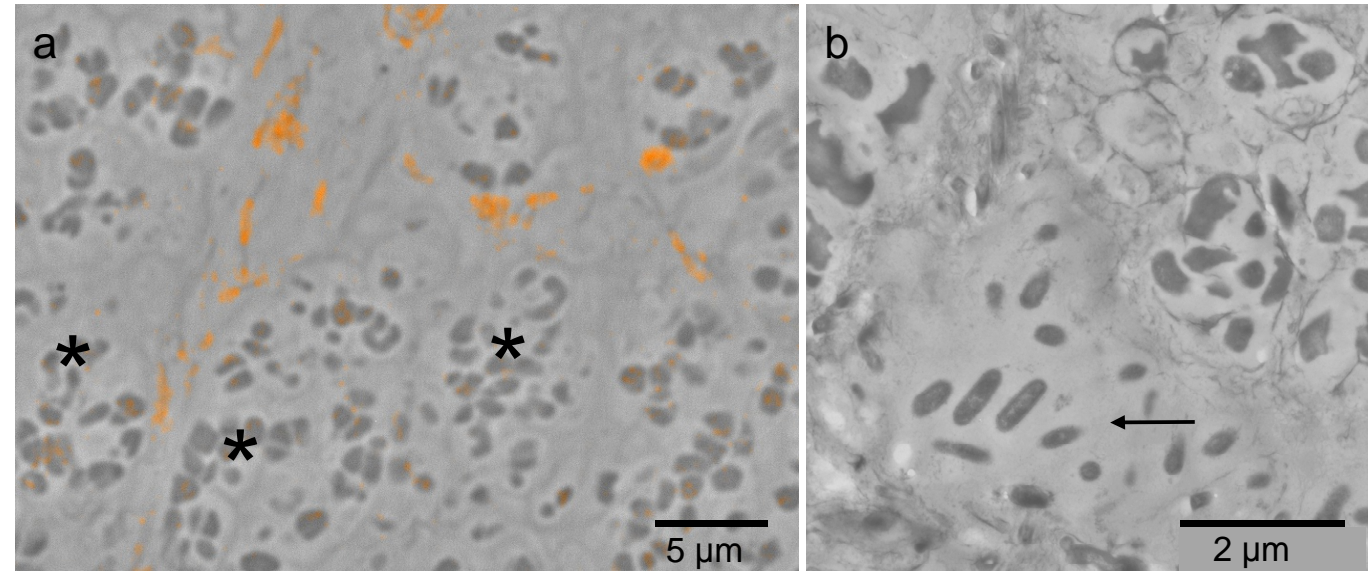

Figure 3.5.: Microscopical analysis of black layer of GHOSTDABS cold seeps.

(a) immunofluorescence labeling ( $\alpha-\mathrm{MDH}$ antibodies; AlexaFluor 546 as marker) in interspaces between ANME-2/SRB aggregates (asterisks). MDH expressing cells are depicted in orange. (b) TEM micrograph with microcolonies of MDH expressing cells (black arrow; cf. Fig. 3.6.) in interspaces between ANME2/SRB aggregates.

Two types of cell morphologies were found. Fig. 3.6.a-e show the first type of cells. These cells are rod like $(\sim 0.3 \mu \mathrm{m} x \sim 0.9 \mu \mathrm{m})$, with several concentric membrane layers located in the cell periphery. These membranes show similarity to intracytoplasmatic membranes of type II methanotrophs. The membrane layers are oriented parallel to the cytoplasmic membrane. In Fig. 2.6.e the membranes are highlighted by a grayscale inversion, indicating four membrane layers. This feature is also shown with a linedensity scan (see section 2.3.6.). In the densitogram (cf. Fig. 2.6.e) each peak points out one phospholipid double layer membrane. Since osmium tetroxide staining destroys the specific antigenic binding sites, it was omitted during sample preparation. 


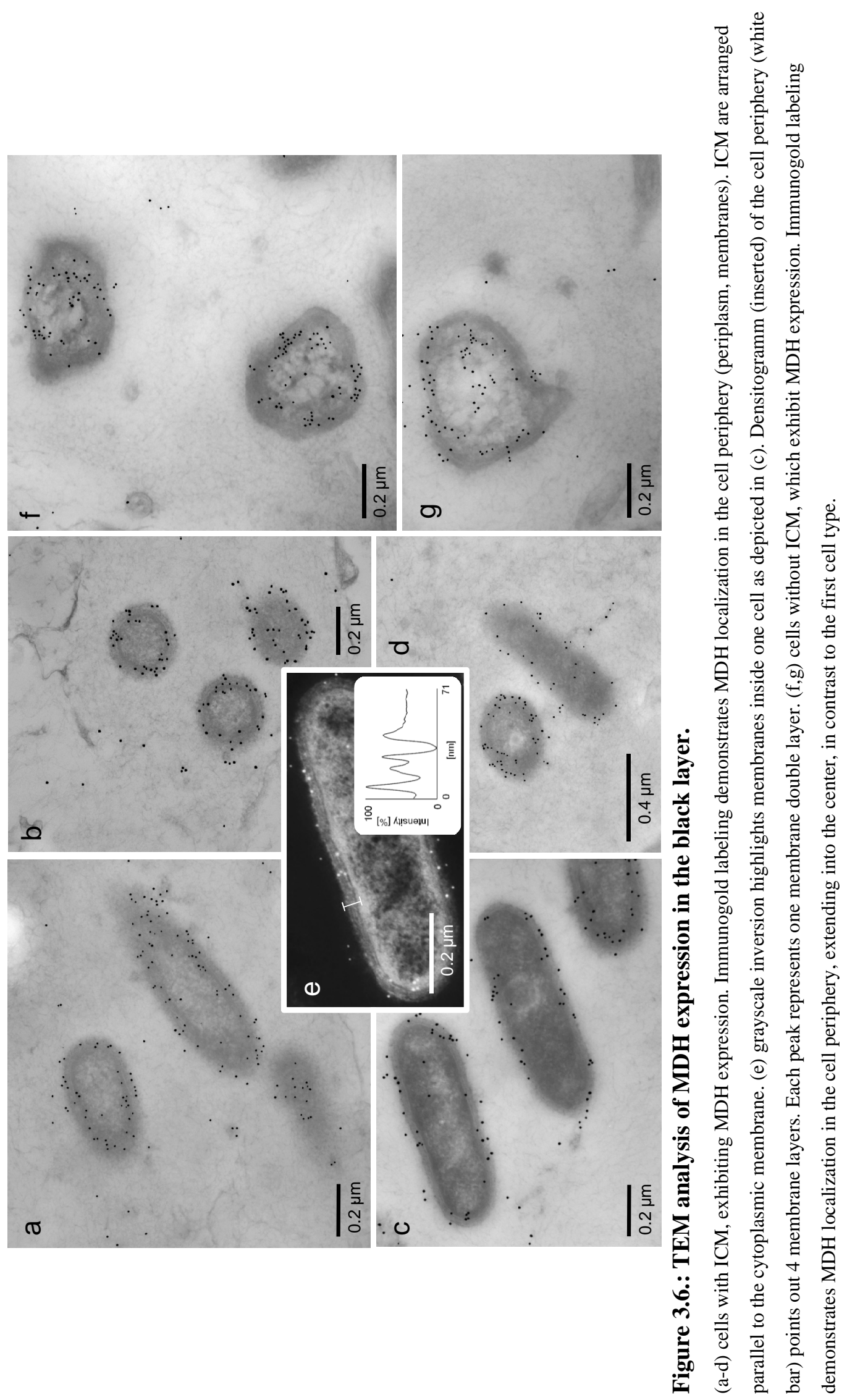


Thus, membranes do not show the typical triple layer feature (dark-bright-dark). Instead, the middle lipid layer shows a bright contrast, the dark layers, representing the phospholipid headgroups, are missing, which has to be considered in image analysis and interpretation (Hoppert and Holzenburg, 1998). The overall thickness of a bright layer (measured between both inflection points next to one peak) indicates that this layer represents a complete double membrane (cf. Hoppert and Holzenburg, 1998). The immunogold labeling reveals the localization of expressed MDH in the cell periphery, also at the membrane layers. The marked regions, periplasm and ICM, correspond to MDH localization from previous investigations (Fassel et al., 1992) and the control isolates (Fig. 3.4.).

The second cell morphotype of $\mathrm{MDH}$ expressing cells exposes an approximately isodiametric morphology with diameters ranging from 0.3 to $0.6 \mu \mathrm{m}$ (Fig. 3.6.f,g). As well as the first type, the organisms are arranged in microcolonies in interspaces, embedded in the EPS matrix. The cells are localized in areas of ANME-2/SRB aggregates. They are not in close contact to neighboring cells, as known from the ANME-2 cells. The immunocytochemical localization shows a strong immunogold labeling in the cell periphery, extending into the center, close to the nucleoid. Some of the methylotrophic isolates show a similar distribution of the MDH (Fig. 3.4.).

Several cells in the microbial mats contain membrane stacks, as described for type I methanotrophs (cf. section 1.2.2.). For these cells the expression of the MDH was checked. Fig. 3.7.a,b shows two representative cell morphotypes with this type of ICM, but no immunogold labeling was detectible. In contrast, the morphotype shown in Fig. 3.7.b will be identified as SRB (see section 3.1.2.). For the detection and localization of $\mathrm{MDH}$ it can be concluded, that two metabolic active methano- or methylotrophic cell types are located in interspaces between ANME-2/SRB aggregates, while cells with typical methanotrophic membrane stacks turned out to be no methanotrophs. 

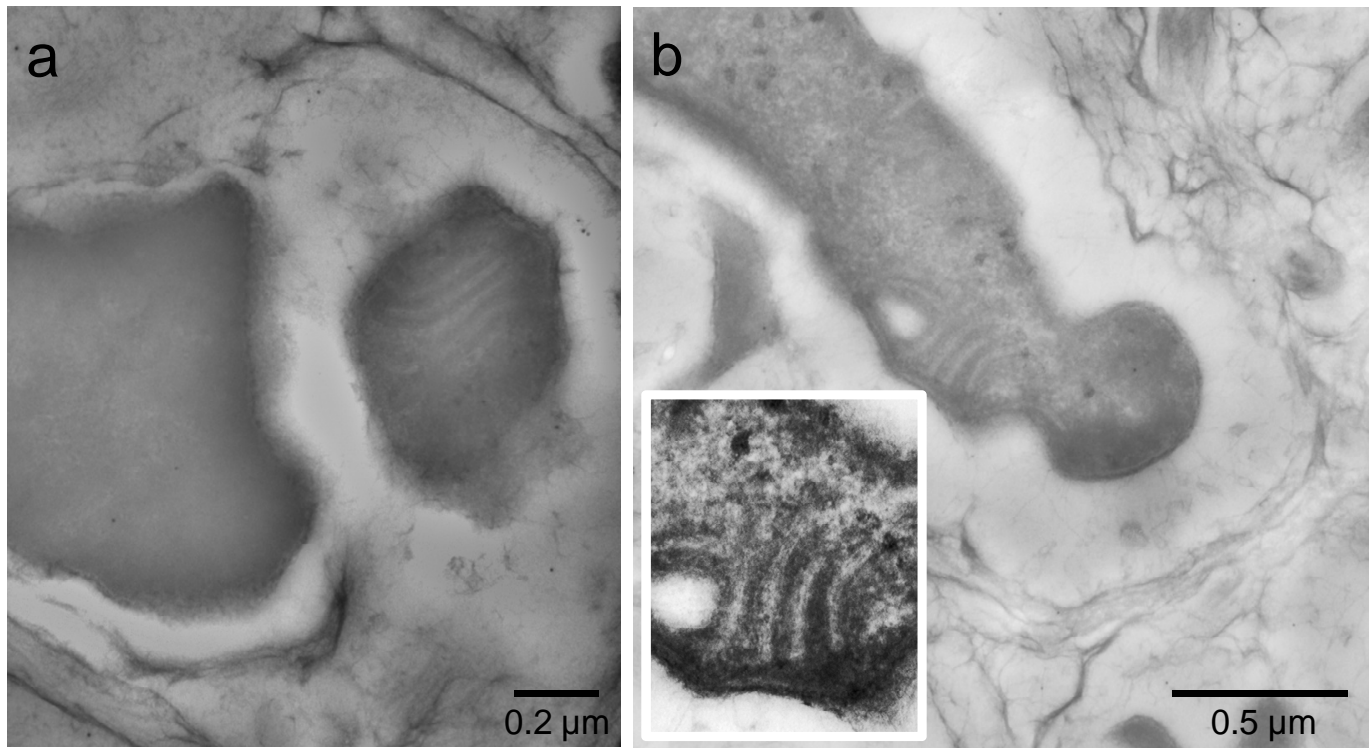

Figure 3.7.: TEM immunocytochemistry of cells exhibiting ICM ( $\alpha$-MDH antibodies).

(a,b) cell types from the black layer, exhibiting ICM stacks (known for type 1 methanotrophs) without MDH labeling (no MDH expression). Insert highlights the membrane stacks of the cell in (b).

\subsubsection{APS reductase detection for active SRB}

\section{Novel method for generation of $\alpha$-AprB antibodies and testing of the antibodies}

In a previous work, Heller et al. (2008) showed expression of the MCR in ANME-1 and ANME-2 archaea by immunocytochemistry. The MCR is a key enzyme of the reverse methanogenesis, representing the archaeal part of the AOM pathway (Krüger et al., 2003; Hallam et al., 2004). The necessary electron sink for reverse methanogenesis is the sulfate reduction pathway of the syntrophic SRB partner cells. To uncover cells with key enzymes of this pathway, antibodies were raised against the dissimilatory APS reductase, a key enzyme of SRB. 


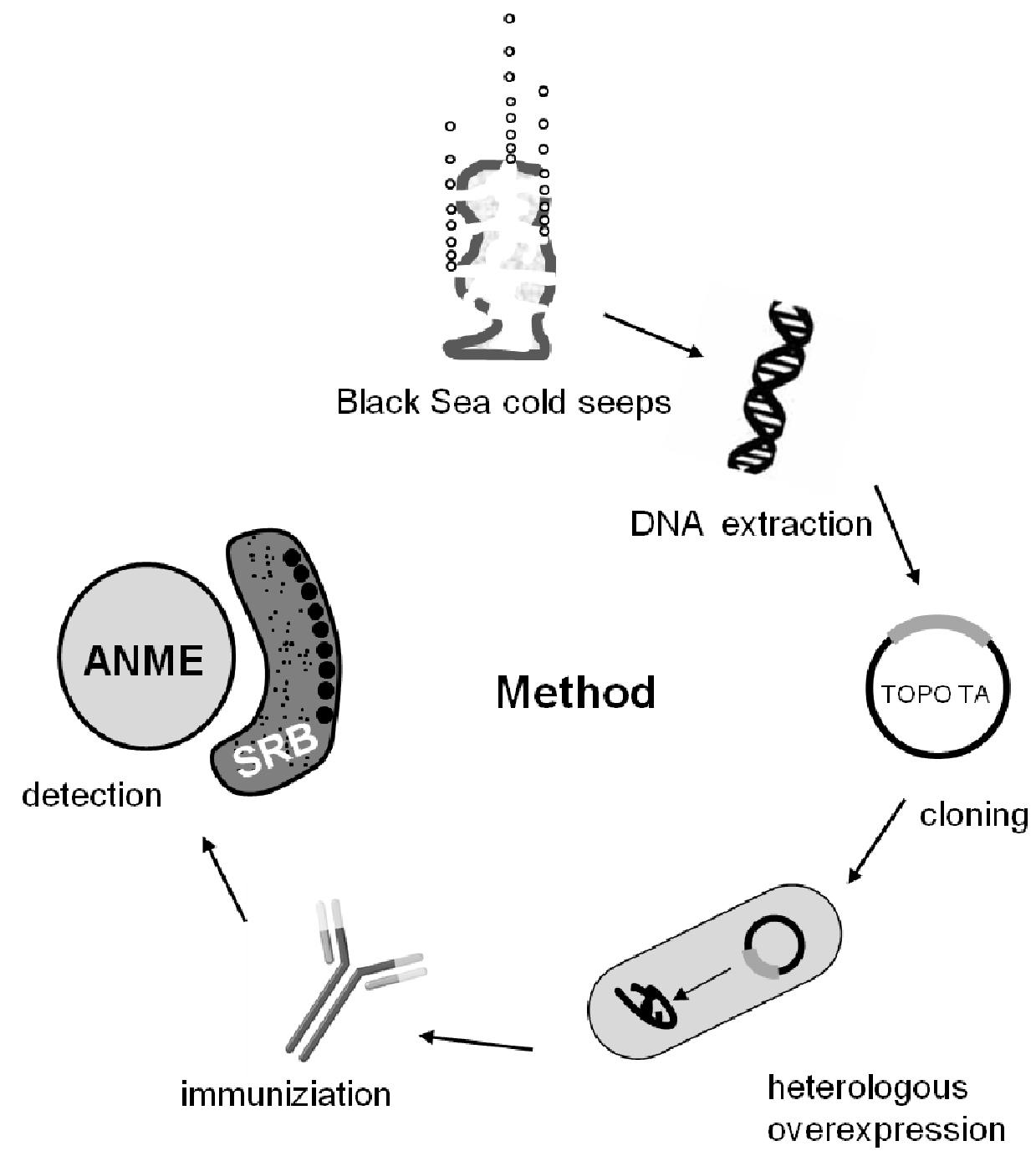

Figure 3.8.: Novel technique for antibody generation.

In brief: DNA is extracted from an environmental setting (e.g. a cold seep microbial mat). With degenerate primers a gene coding for a conserved enzyme is amplified and cloned with TOPO TA (e.g. the $\operatorname{apr} B$ gene). One distinct sequence is selected and fused to a hexahistidin-tag, heterologously overexpressed and affinity purified. The purified protein is used for immunization of e.g. rabbits. After checking the specificity, the raised antibodies can be applied for Western blot analysis and immunocytochemistry.

For the detection of active SRB, we used a novel method for generation of antibodies directed against an epitope derived from a microbial mat, cf. Fig. 3.8. By this way, the detection system is highly adapted to mat-inhabiting SRB. The dissimilatory APS reductase was chosen as metabolic key enzyme of SRB, catalyzing the second step of the sulfate reduction pathway (Fig. 3.9.). The dissimilatory APS reductase is an 
$\alpha \beta$ heteromer, consisting of the $\alpha$-subunit of $75-80 \mathrm{kDa}$ and the $18-23 \mathrm{kDa} \beta$-subunit. The subunits are highly conserved (encoded in the aprBA gene; Meyer and Kuever, 2007). To obtain the protein stable and - as far as possible - in its native structure, the whole $\beta$-subunit and not just a fragment was used for heterologous overexpression.

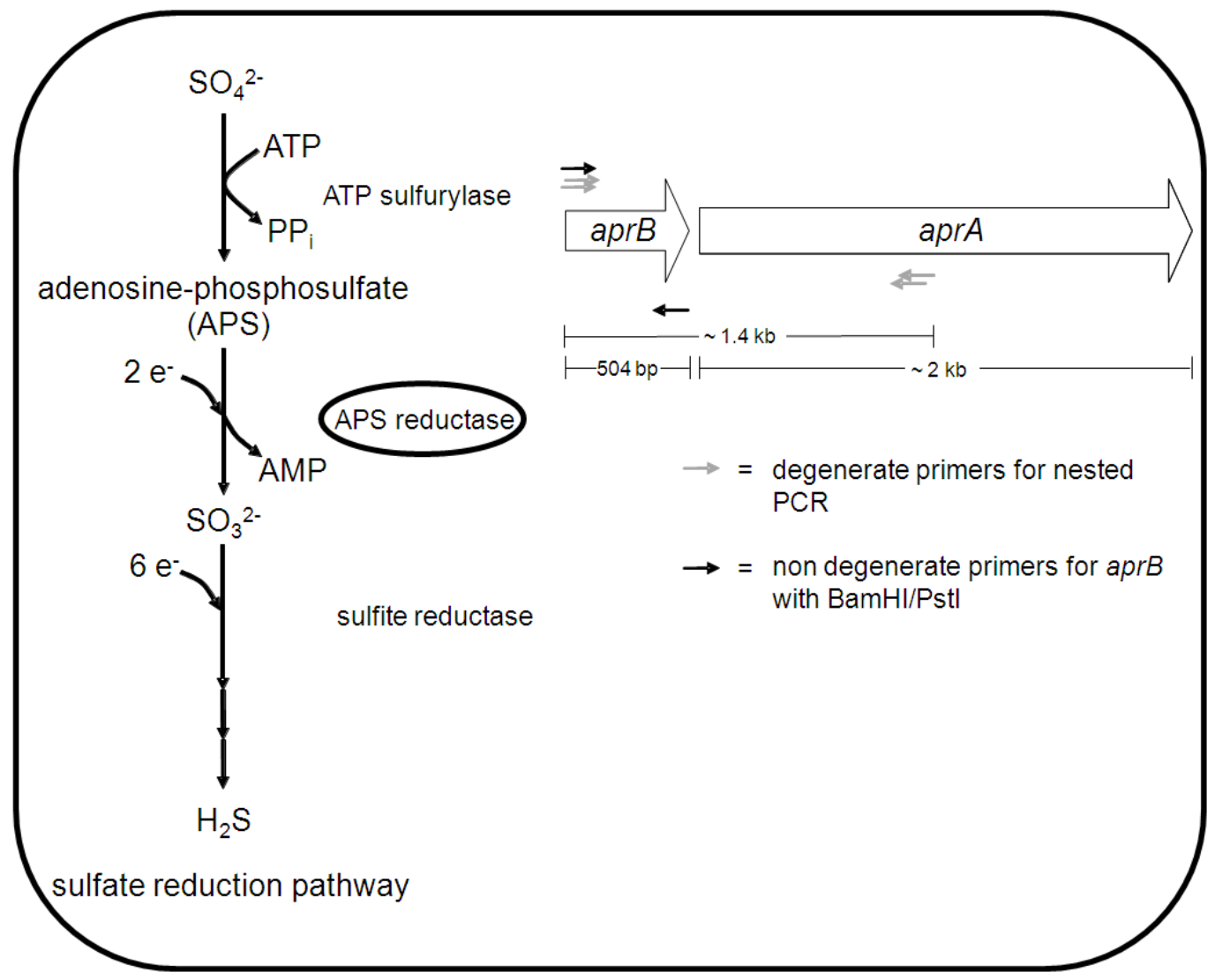

\section{Figure 3.9.: Sulfate reduction pathway.}

The dissimilatory APS reductase is a key enzyme of sulfate reduction. Details of the gene region encoding the enzyme in D. vulgaris Hildenborough are depicted in the upper right part of the figure. The dissimilatory APS reductase is an $\alpha \beta$ heteromer, consisting of the $\alpha$-subunit of $75-80 \mathrm{kDa}$ and the $18-23$ $\mathrm{kDa} \beta$-subunit (encoded in the aprBA gene; Meyer and Kuever, 2007).

It was aimed at the dissimilatory APS reductase $\beta$-subunit, because the complete, smaller subunit was better extractable from the microbial mats than the bigger $\alpha$-subunit, since the latter has just few suitable primer target sites and a generally low degree of conserved nucleotide positions in the 3' terminal region (Meyer and Kuever, 2007). Moreover, it is known from the quaternary structure of the enzyme, that major 
parts of the $\beta$-subunit are exposed to the surface allowing antibodies to detect its targets (Fritz et al., 2002; Meyer and Kuever, 2008; Chiang et al., 2009).

In a first step, a region including the $\operatorname{apr} B$ gene was amplified in a nested PCR approach. In combination with an established reverse primer annealing in the aprA gene, new degenerate forward primers were designed to get the whole aprB gene sequence as PCR product (cf. 2.3.4. for primer design and PCR conditions; Fig. 3.9.). The amplificates were cloned with TOPO TA cloning in E. coli TOP10 and sequenced. All sequences showed hits to sequences of Desulfovibrio as nearest neighbors. One sequence, representing the largest group of clones, was ligated in the plasmid pWH844 for fusing with a hexahistin-tag (cf. 2.3.4. for applied methods; Schirmer et al., 1997). For this step, specific primers were used, which amplified the $\operatorname{apr} B$ gene from start to stop codon. The resulting plasmid was used for AprB overexpression in E. coli DH5 $\alpha$. The protein was purified by affinity chromatography and used for the immunization of rabbits (cf. 2.3.5. for details of overexpression, purification and immunization).

$\mathrm{kDa}$

120

86

$47-$

$34-$

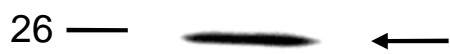

$20-$

\section{Figure 3.10.: Western blot analysis with $\alpha$-AprB antibodies.}

Detection of dissimilatory APS reductase $\beta$-subunit in crude extract of $D$. vulgaris Hildenborough with polyclonal $\alpha$-AprB antibodies in Western blot analysis. Black arrow indicates the AprB band. 
The generated $\alpha$-AprB antibodies were tested for their specificity by Western blot analysis (Fig. 3.10.; cf. section 2.3.5.). The $\alpha$-AprB antibodies detected specifically the dissimilatory APS reductase $\beta$-subunit $(\mathrm{AprB})$ without any background. Thus, the antibodies can be used for immunocytochemical localizations without the risk of false positive signals, caused by other than AprB epitopes.

D. vulgaris Hildenborough was used as positive control for immunogold labeling of AprB (cf. 2.3.6. for labeling technique). Ultrathin sections of D. vulgaris Hildenborough cells show cytoplasmic localization of AprB (Fig. 3.11.a). This labeling pattern is also common to other Desulfovibrio species (Kremer et al., 1988), analyzed with antibodies directed against the holoenzyme AprBA. No loss in signal strength could be observed by using the smaller $\beta$-subunit as target protein.
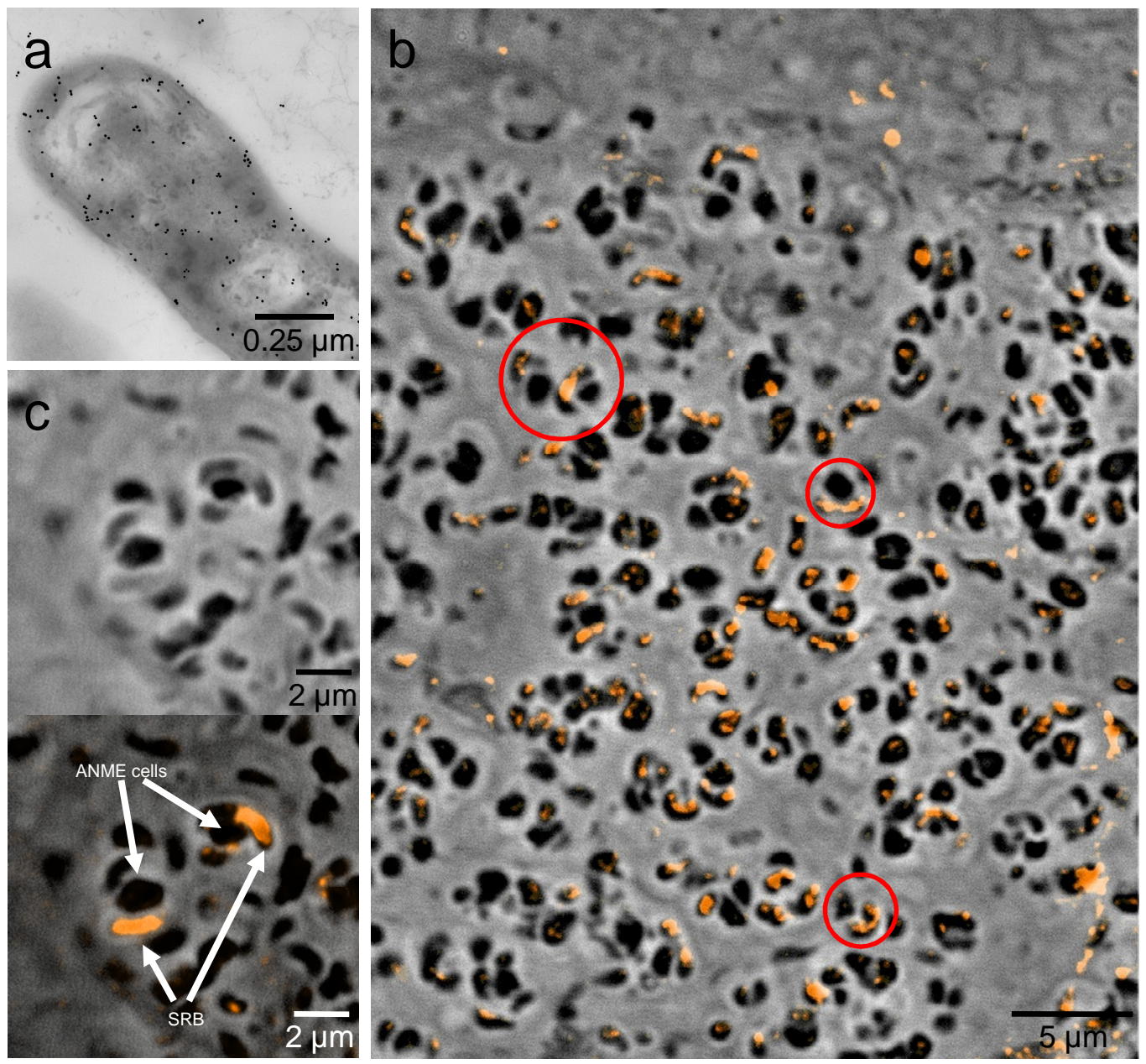

Figure 3.11.: See next page for figure legend. 


\section{Figure 3.11.: Microscopical analysis with $\alpha$-AprB antibodies.}

(a) TEM micrograph depicts AprB immunogold labeling in D. vulgaris Hildenborough. (b) immunofluorescence shows in orange AprB expressing cells, indicating active SRB ( $\alpha$-AprB antibodies; AlexaFluor 546 as marker). Predominantly vibrioid, active SRB, and coccoid, unmarked cells, next to the SRB are visible. Red circles highlight three examples of active SRB with ANME-2 partner cells. (c) details of ANME-2/SRB aggregates, at higher magnification. Image shows in the upper part light microscopy without fluorescence and below the same area with the AprB detection (orange fluorescence). Vibrioid cells show fluorescence.

\section{Immunocytochemical localizations ( $\alpha$-AprB)}

Investigations of the microbial mats for SRB followed the same strategy as for the detection of active methano- and methylotrophs. Previous FISH analysis could show that in the black layer the phylogenetic groups of SRB are localized in direct proximity to the ANME-2 cells (Knittel et al., 2005; Reitner et al., 2005b).

For immunofluorescence detection, the $\alpha$-AprB antibodies were applicated to the semithin sections of embedded samples. AlexaFluor 546-coupled antibodies were used as marker, indicating active SRB with bright orange fluorescence (cf. 2.3.6. for detailed method). Fig. 3.11.b depicts an overview of the black layer. Fluorescence signals revealed that cells performing sulfate reduction are often vibrioid and are located close to cells with coccoidal morphology (ANME-2). These findings are in accordance to the previously described FISH analysis, suggesting the direct association of ANME-2 and SRB. The vibrioid cells were assumed to be SRB (Reitner et al., 2005b), while Heller et al. (2008) gave already evidence that coccoid like cells express the MCR and represent active ANME-2. In Fig. 3.11.c the mentioned morphologies are shown in higher magnification.

The sometimes patchy distribution of the fluorescence signal is due to the fact that the antibody detection takes place at the surface of the sections. Consequently, only exposed cell parts can be labeled (Hoppert and Holzenburg, 1998). Especially the vibrioid morphology causes situations in the semithin sections where parts of the cells are exposed, whereas other parts remain covered by resin. Moreover, the expression level of the dissimilatory APS reductase may vary between individual cells.

Fig. 3.12.a depicts a typical AOM aggregate formed by ANME-2 and SRB cells. The immunocytochemistry at TEM resolution gives evidence for the expressed sulfate reduction pathway of the SRB on cellular level, i.e. the organisms perform sulfate 
respiration at significant level (cf. section 2.3.6. for description of immunocytochemistry).

Vibrioid cells containing magnetosomes were frequently found within the ANME2/SRB aggregates. It was shown that these magnetosome chains consist of greigite (Reitner et al., 2005a; Reitner et al., 2005b). The $\alpha$-AprB antibodies were applied to investigate if the magnetosome-bearing cells perform an active sulfate reduction pathway. Fig. 3.12.b,c depicts that this cell type shows indeed a strong AprB expression, revealing a high activity of sulfate reduction.

Cells with internal membrane stacks, typical for type I methanotrophs, are abundant in the microbial mats (cf. Fig. 3.7.). Evidence was already given, that the investigated cells are not active methano- or methylotrophs (see above). In contrast, Fig. 3.12.d,e reveals AprB expression in a vibrioid cell type with ICM stacks, corresponding the cell type depicted in Fig. 3.7.b. Thus ICM containing cells are largely active SRB and not methano- or methylotrophs. All detected types of SRB contain PHA-like granular inclusions.

In order to detect the catalyzed processes of reverse methanogenesis (ANME-2) and sulfate reduction (SRB) simultaneously, an $\alpha-\mathrm{MCR} / \alpha-\mathrm{AprB}$ double labeling was performed (cf. section 2.3.6. for detailed technique). In Fig. 3.12.f the MCR expression is depicted in green, marking the ANME-2 cells. The sulfate reducing partner is depicted in orange. AprB and MCR-expressing cells are in direct contact to each other. These immunofluorescence data prove that the reverse methanogenesis and the sulfate reduction pathway are catalyzed simultaneously and in directly neighbored cells. 


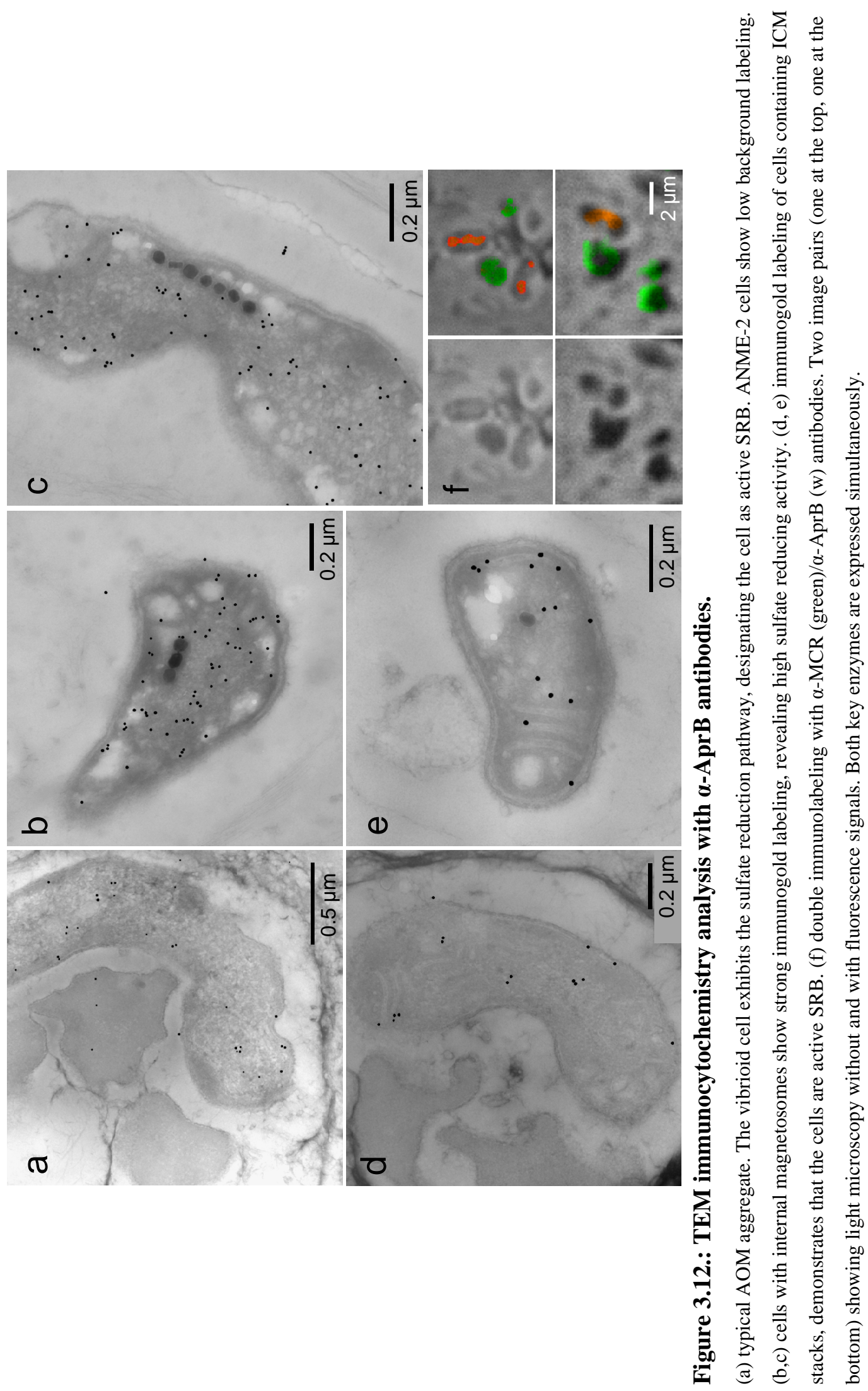




\subsection{Aerobic and anaerobic methane oxidation in terrestrial mud volcanoes in the Northern Apennines}

\subsubsection{Geological setting and mud volcano fluid composition}

The Nirano mud volcano field is located in an ellipsoidal depression at approximately $200 \mathrm{~m}$ above sea level. This caldera-like structure is surrounded by hills (approximately $260 \mathrm{~m}$ above sea level) with steep flanks (Bonini, 2008) cut in the marine claystones of the Argille Azzurre Formation (Fig. 1.9.a,c). At the time of sampling, the Nirano mud volcano field consisted of four main vents, each composed of a varying number of active cones and pools. Results described in this work focus to the mud cone NR9 as depicted in Fig. 1.9.b (44 $\left.30.848^{\prime} \mathrm{N}, 10^{\circ} 49.527 \mathrm{E}\right)$.

For the analysis of the geochemical data, fluids were sampled from approximately $1.5 \mathrm{~m}$ depth (for details see section 2.1.3). This sampling depth was used to ensure, that no perturbation of the surface fluids takes effect on the measurement. Of course, an influence of dilution by shallow ground water of meteoric origin cannot be ruled out. The redox potential of samples taken from a depth of $10 \mathrm{~cm}$ below the fluid outlet was as low as the redox potential measured in $1.5 \mathrm{~m}$ depth $(-110 \mathrm{mV})$. Hence, the fluids are rapidly anoxic beneath the surface.

For analysis of the dissolved anorganic ions in the mud volcano fluids, solid particles, mainly clay fractions, were removed by centrifugation. In Tab. 3.1., the ionic composition of the processed water from the mud volcano fluid is shown (for details see section 2.3.2.). The data are in accordance with similar investigations from other studies over the past years. The fluid may be classified as brackish, connate water (Boschetti et al., 2010). The $\mathrm{pH}$ value is slightly alkaline. Nitrate, nitrite as well as sulfate and iron are only present in low concentrations. These compounds represent electron acceptors for anaerobic respiration. Sulfide is not detectable, which corresponds to the low concentration of sulfate with $\leq 7 \mathrm{mg} / \mathrm{ml}$. Due to the chemical instability of hydrogen sulfide, however, small traces of this compound are difficult to measure after sample transportation. It has a low solubility in water, is volatile and shows autoxidation in the presence of oxygen. The redox potential measured just after sampling is below -110 $\mathrm{mV}$, providing an anaerobic surrounding for e.g. sulfate reducing bacteria and 
methanogenic or methanotrophic archaea. The low amounts of sulfate, however, will restrict microbial sulfate reducing activity, though it must be taken into account that the low sulfate concentration may be a result of sulfate reducing activity. The measured temperature of the fluids was $21.3^{\circ} \mathrm{C}$.

Table 3.1.: Mud volcano fluid composition (all results in $\mathrm{mg} / \mathrm{l}$, except $\mathrm{pH}$ ).

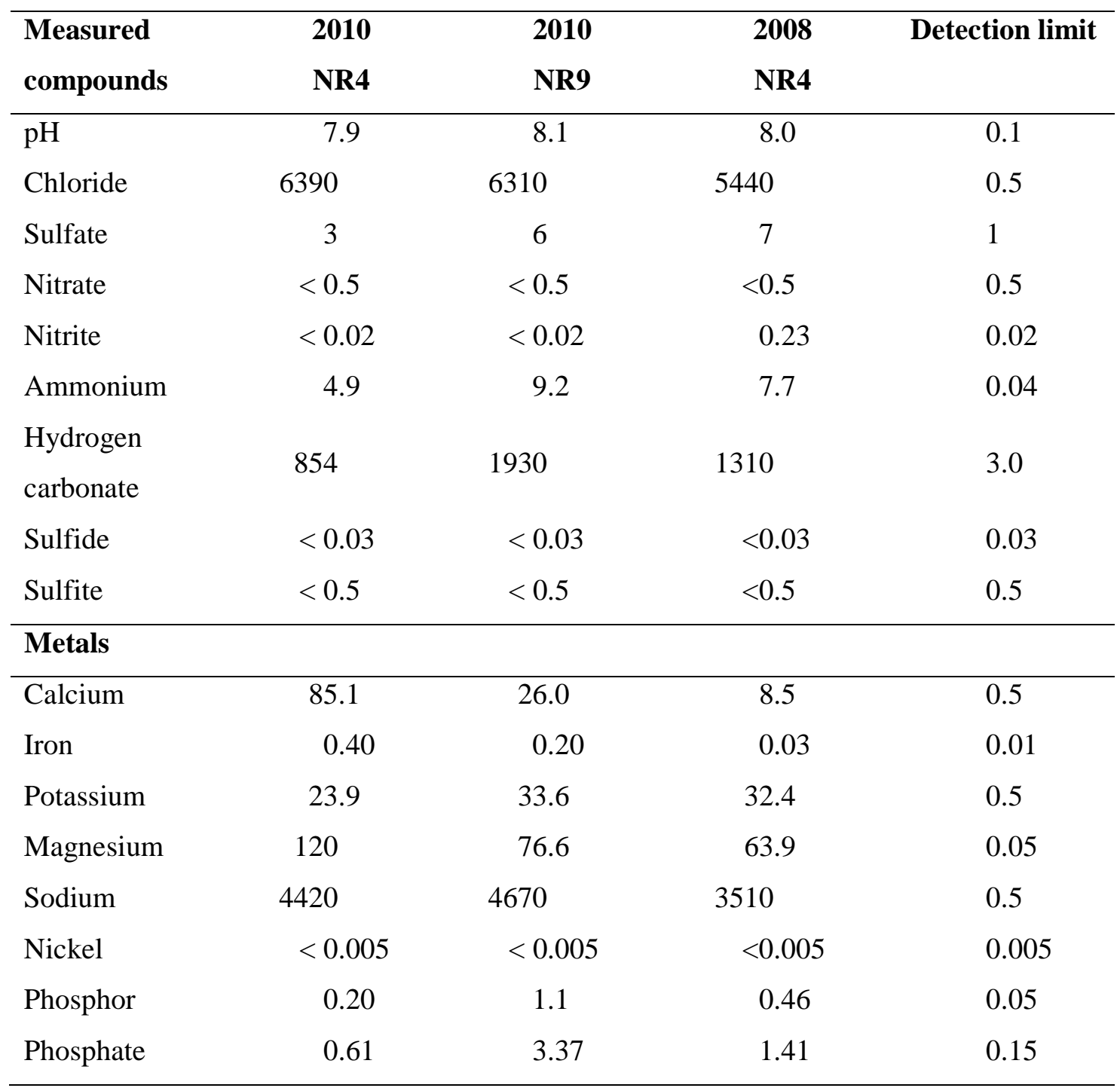




\subsubsection{Detection of organisms in mud volcano fluids}

\section{Environmental samples}

In comparison to marine habitats, there is only little knowledge about microbial diversity in terrestrial sites of methane release (cf. Alain et al., 2006). Therefore, aim of this work was to detect and to analyze methane catabolizing microbial communities of the volcanic fluids. By taking sterile samples from approximately $1.5 \mathrm{~m}$ depth, a contamination by organism of the volcano surface can be ruled out. A continuous upwelling of the volcanic fluids prevents contamination with surface organisms. However, contamination with organisms from shallow ground water cannot be excluded.

The suspended clay particles in the mud volcano fluids complicate detection of organisms. Due to the low cell densities in mud volcano fluids, direct counting of microbial cells turned out to be impossible. Also simple one step concentration methods like density centrifugation failed since microbial cells were not detectable in remaining clay particles. By the combined approach of a cell extraction method, the removal of sediment debris as well as a concentration of the cells according to Kallmeyer et al. (2008), countable cells could be obtained from the volcanic fluids (cf. section 2.3.6. for detailed method).

Enumeration of DAPI stained cells resulted in a total cell number of $0.7 \times 10^{6}$ prokaryotic morphotypes per ml fluid (cf. section 2.3.6. for method of cell counting). Most cells appeared as single, apparently planktonic organisms (Fig. 3.13.a). These cell counts are significantly lower as cell counts from the marine methane rich sediments from the Black Sea, where about $2.5 \times 10^{8}$ cells/ml were counted (Knab et al., 2009) or marine sediments with $0.25 \times 10^{8}$ to $4.4 \times 10^{9}$ cells/ml (Joergensen and Revsbech, 1989; Llobet-Brossa et al., 1998). To discriminate between bacteria and archaea, FISH analyses with EUBI-III and ARCH915 probes were conducted (cf. 2.3.6. for details of FISH analysis). These experiments revealed that the single organisms extracted and concentrated from the fluids were all bacterial phylotypes. No archaea could be detected. (Fig. 3.13.b). 


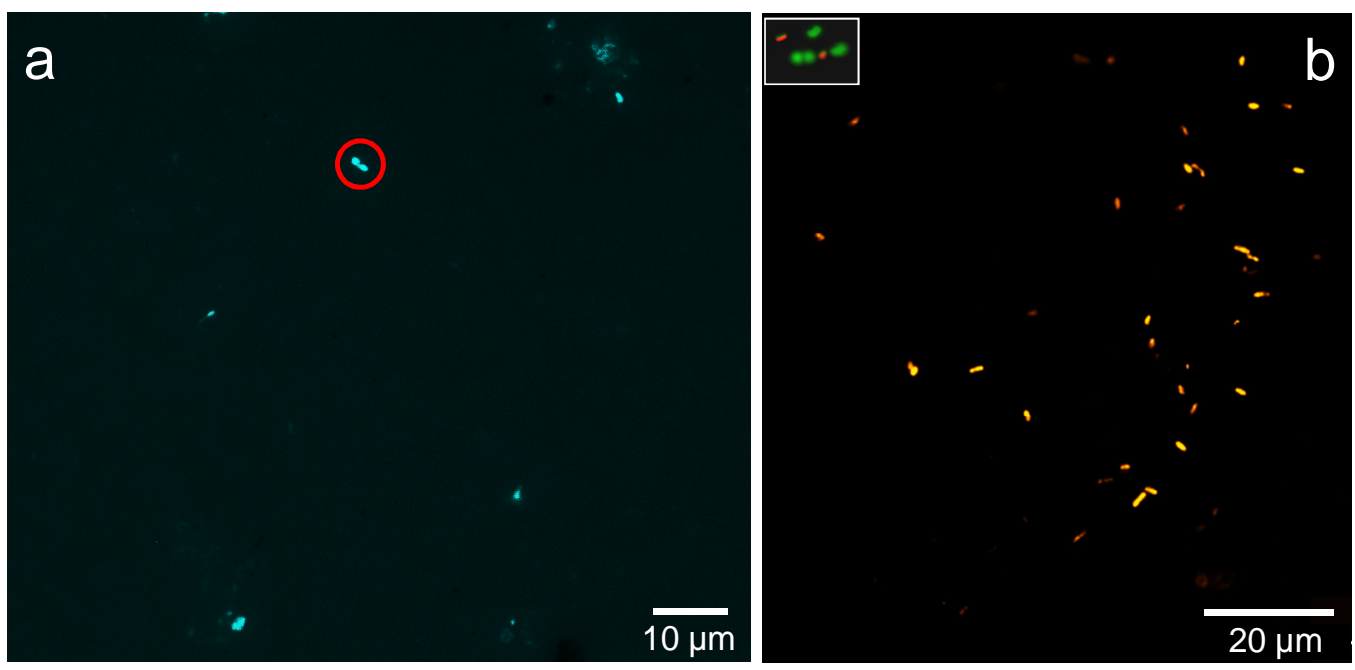

Figure 3.13.: Microscopic analyses of fluids.

(a) cells extracted from fluids of mud volcano NR9; a prokaryotic morphotype is marked with a red circle (DAPI stain). (b) cells extracted from fluids of mud volcano NR9; no planktonic archaea could be detected (probe EUB338 I-III and probe ARCH915; image: Anne Dreier). Inset: control experiment with E. coli DH5 $\alpha$ (orange) and M. mazei Gö1 (green).

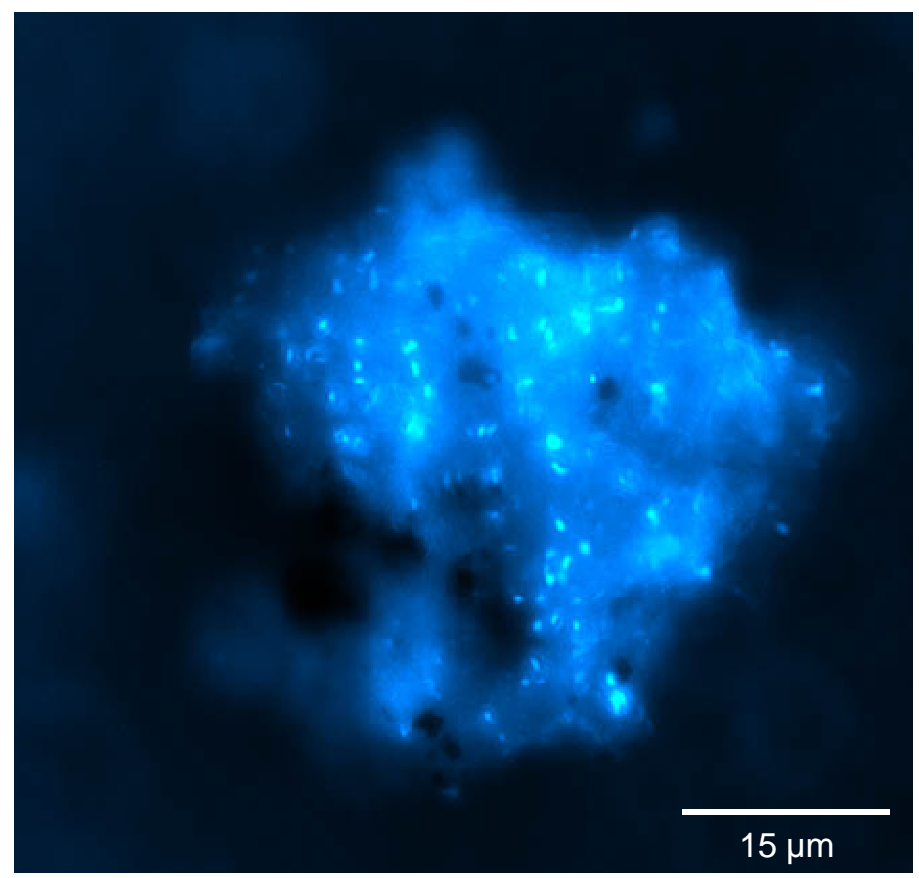

Figure 3.14.: Microscopic analysis of a microbial flake.

DAPI stain of a microbial biofilm flake. Dark mineral precipitates are visible embedded in the hyaline extracellular matrix. 
About $0.2-0.3 \%$ of the microbial cells were found associated in distinct flakes, embedded in a hyaline extracellular matrix (Fig. 3.14.). The microbial flakes represent rather large cell aggregates of often some hundreds of organisms.

Inside the matrix of the flakes, dark mineral precipitates could be observed by brightfield light microscopy (Fig. 3.15.a). The precipitates resemble raspberry-shaped structures. TEM analysis of samples, adsorbed onto Formvar-coated carbon grids (cf. 2.3.6.), showed, that some precipitates were morphologically equivalent to pyrite framboids (Fig. 3.15.b; Ohfuji et al., 2005). A single particle is of approximately 500 $\mathrm{nm}$ in diameter, roughly corresponding to the size of framboidal pyrite of the black layer biofilm from GHOSTDABS cold seeps (Wrede, 2007).
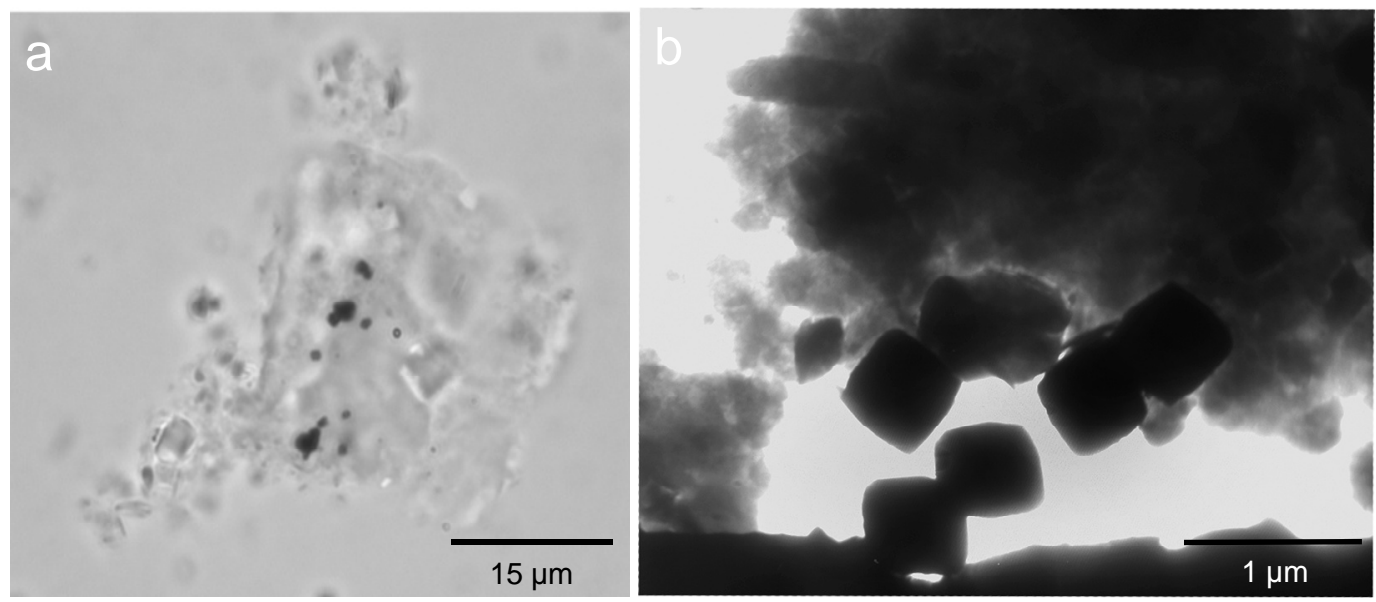

Figure 3.15.: Mineral precipitates in microbial flakes.

(a) brightfield image of a flake with dark mineral precipitates. (b) electron micrograph of a preparation similar to (a) depicting precipitates which are morphologically identical to framboidal pyrite.

As revealed by FISH analysis, the aggregates in environmental samples mainly consist of archaea (probe ARCH915). Also a filamentous archaean cell type was found to form microbial flakes (3.16.).

Most cells in the biofilm flakes could be identified as ANME-2 archaea by hybridization with the probe EelMS932 (Fig. 3.17.a,b). It is known, that ANME-2 archaea are associated with SRB, representing in most cases Desulfosarcina/ Desulfococcus branch (Schreiber et al., 2010). Consequently the abundance of this SRB group was investigated with the probe DSS658. 


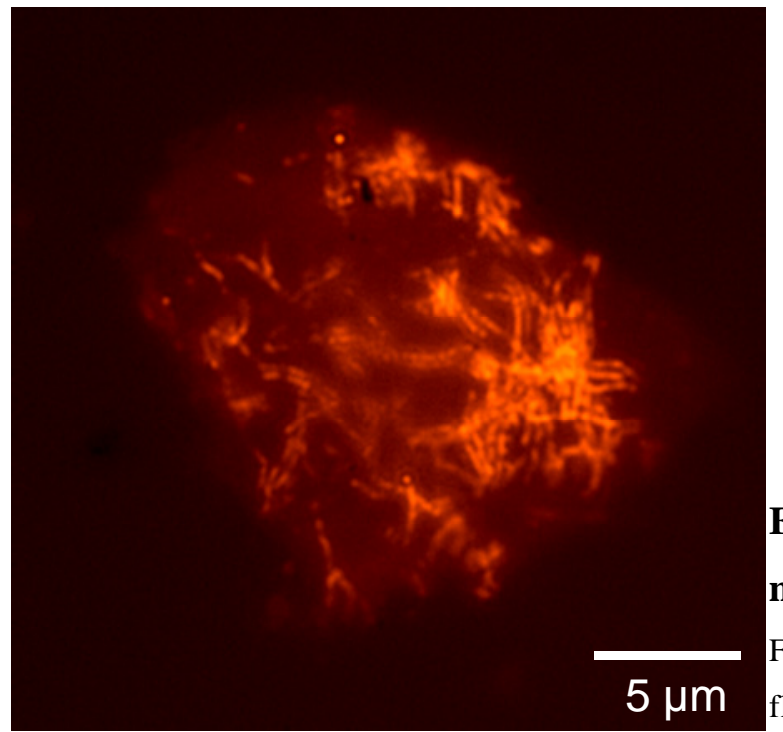

Figure 3.16.: Detection of archaeal microbial flakes by FISH analysis.

Filamentous archaea detected in microbial flake with the hybridization probe ARCH915.
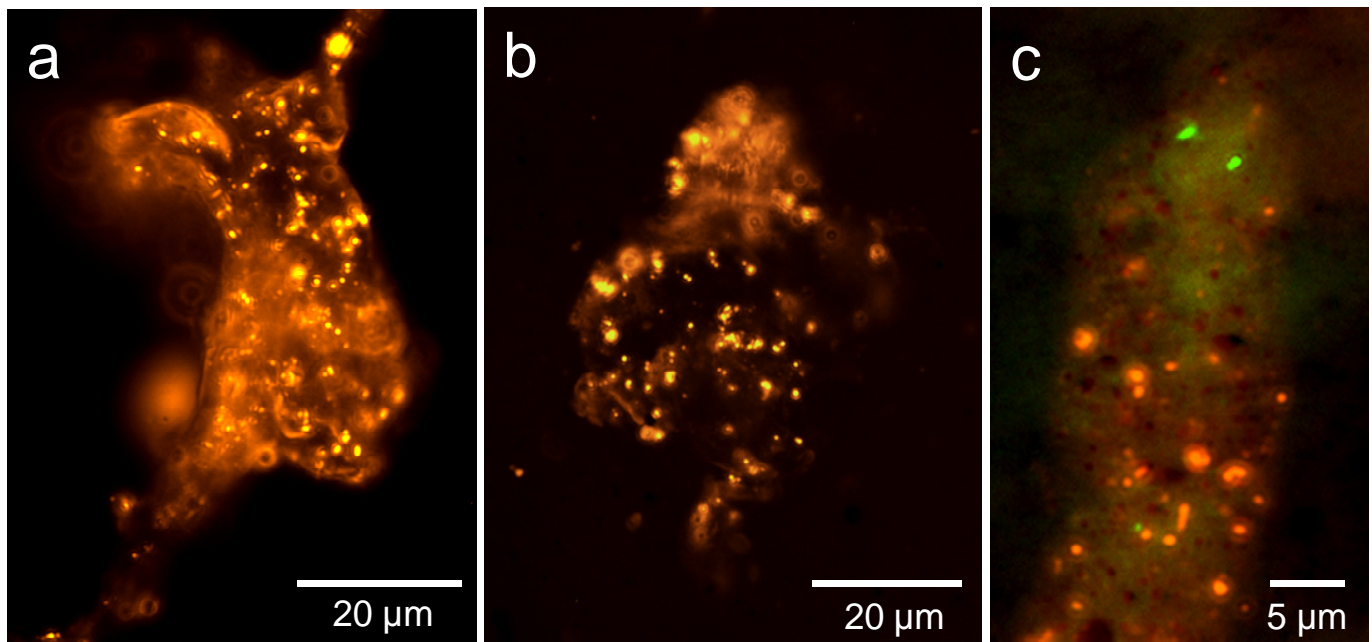

Figure 3.17.: Detection of ANME archaea and SRB by FISH analysis of microbial flakes.

Orange: ANME archaea (probe EelMS932), green: SRB of Desulfosarcina/ Desulfococcus branch (probe DSS658). SRB detection only in (c).

Symbiotic associations with sulfate reducing bacteria were not observed. Sulfate reducers could be detected with the DSS658 probe only in a very low number and never in direct association with ANME archaea (Fig. 3.17.c). 


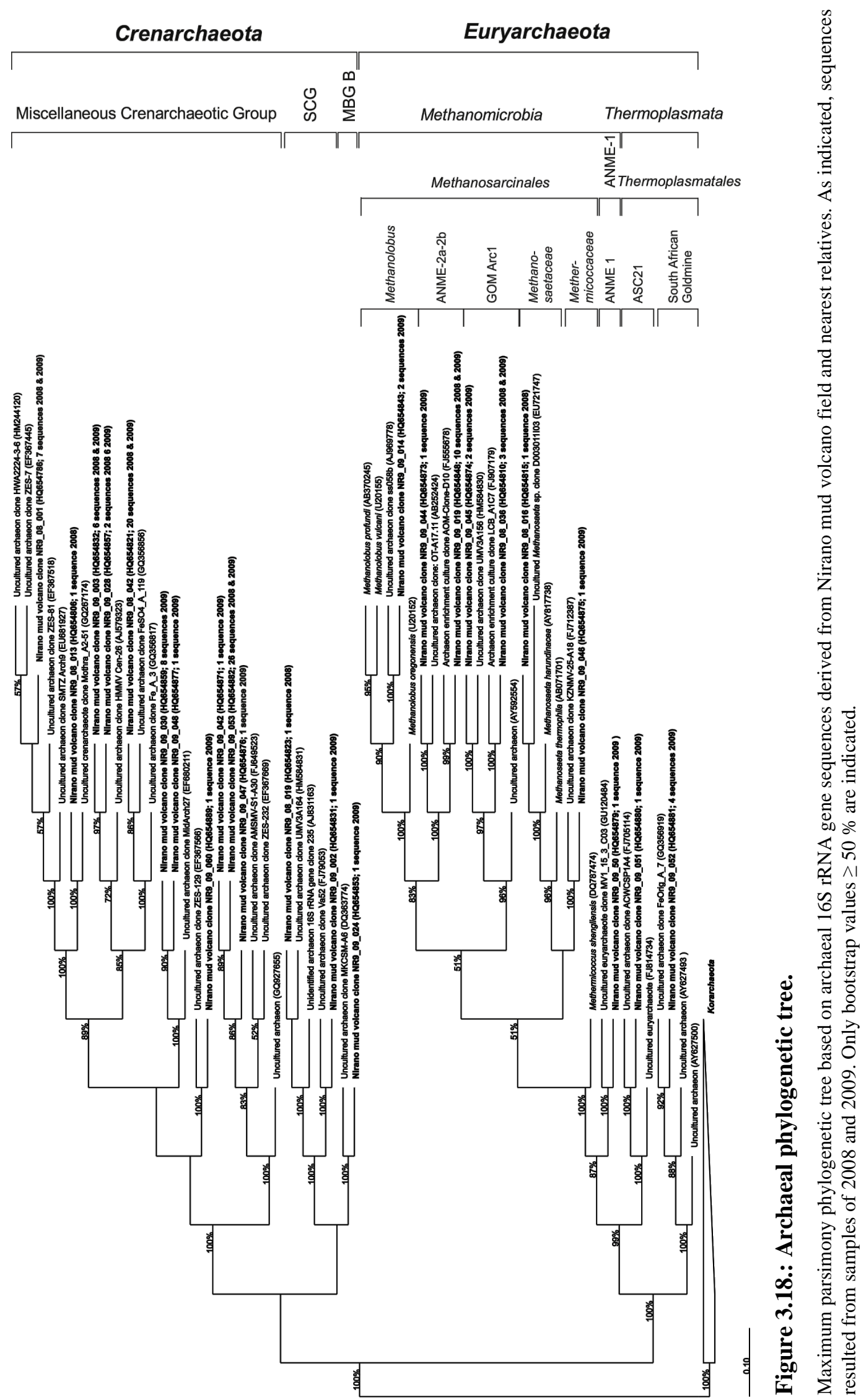


Diversity analysis from environmental DNA (contributed by Stephanie Rockstroh and Silja Brady) revealed a high abundance of groups involved in anaerobic oxidation of methane (Fig. 3.18.), conducting either iron or manganese dependent AOM, as well as sulfate dependent AOM (Beal et al., 2009). The nearest neighbors of the analyzed sequences derive from uncultured organisms, which were in most cases found in marine methane seepage habitats, in particular mud volcanoes (e.g. AJ579323, GQ356856, GQ356817, FJ649523, HM584831, FJ555678, HM584830, FJ712387, GU120484, GQ356919). One of the largest groups were Crenarchaeote sequences representing $68 \%$ (Fig. 3.19). Most notably, the sequences affiliated to clone GQ356856 and GQ356817 represent a dominant group of Crenarchaeota (20 sequences), which were detected in iron or manganese dependent AOM cultures (Fig. 3.18.; Beal et al., 2009). Approximately $14 \%$ of the sequences (Fig. 3.19.) represent ANME-2a-2b archaea, related to Methanosarcinales. The total percentage of sulfate dependent AOM archaea amounts to $22 \%$, consisting of ANME 2a-2b, ANME-1 and GoM Arc I.

The calculated Chao1 and ACE richness estimates, with 35 and 38 in comparison to 20 detected species or with 9 and 12 in comparison to 7 detected phyla, indicated that not all groups were covered with this analysis (cf. Fig 3.19.). However, the dominant archaeal groups should be detected. The archaeal Shannon-Weaver diversity index is low with 0.89 for phylotypes regarding to e.g. the marine Mediterranean Kazan mud volcano with an index between 2.63 and 2.57 (Heijs et al., 2007). 
Methanosaetaceae

Methanolobus

GOM Arc1

ASC21

Soil Crenarchaeotic Group

- Micellaneous Crenarchaeotic Group
ANME-2a-2b

Methermicoccaceae

ANME-1

South African Goldmine

Marine Benthic Group

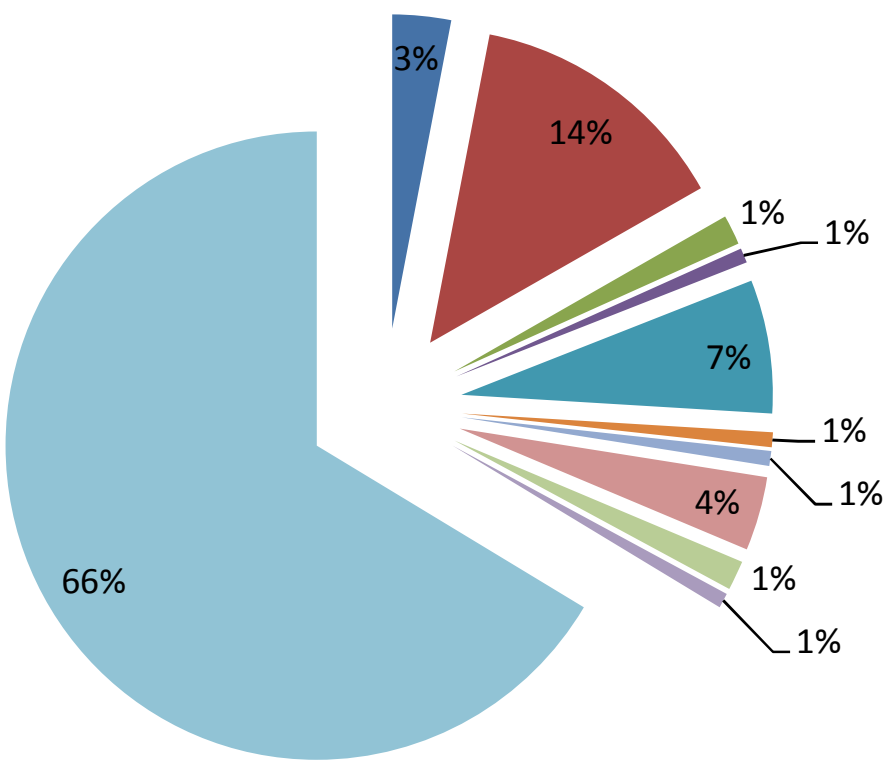

Estimates

\begin{tabular}{lcccc}
\hline Distance & $\begin{array}{l}\text { Detected } \\
\text { oTUs }\end{array}$ & Chao1 $^{1}$ & ACE $^{2}$ & Shannon $^{3}$ \\
\hline 0.01 & 24 & 44 & 50 & 2.45 \\
0.03 & 20 & 35 & 38 & 2.3 \\
0.2 & 7 & 9 & 12 & 0.89
\end{tabular}

Figure 3.19.: Distribution of phylogenetic groups and diversity estimates.

The pie chart depicts distributions of phylogenetic groups of archaeal 16S rRNA gene library. The table shows diversity estimates of the libraries. Estimates were calculated with DOTUR (Schloss and Handelsman, 2005). Footnotes: ' ${ }^{n}$ nonparametric richness estimator based on distribution of singletons and doubletons; ${ }^{2}$ abundance-based coverage estimator (ACE), nonparametric richness estimator regarding distribution of abundant $(>10)$ and rare $(\leq 10)$ OTUs; ${ }^{3}$ Shannon-Weaver Index of diversity. More diversity is related to higher numbers. 


\section{Enrichment cultures}

By FISH and 16s rRNA gene analyses the abundance of anaerobic methane oxidizers was shown in the fluid samples (see above). Complementary, long-term incubation experiments with anoxic methane-gassed cultures were performed to detect AOM activity. Since Methanosarcina, and accordingly ANME archaea, have a high oxygen sensitivity (Fetzer and Conrad, 1993), samples from approximately $1.5 \mathrm{~m}$ depth with a redox potential of below $-110 \mathrm{mV}$ were used for inoculation directly after sampling. By this way, anoxic conditions could be maintained. The incubation temperature was adjusted to $20^{\circ} \mathrm{C}$, i.e. the approximate temperature of the mud volcano fluid just after sampling (cf. sections 2.1.3., 2.2., and 2.3.3. for applied methods).

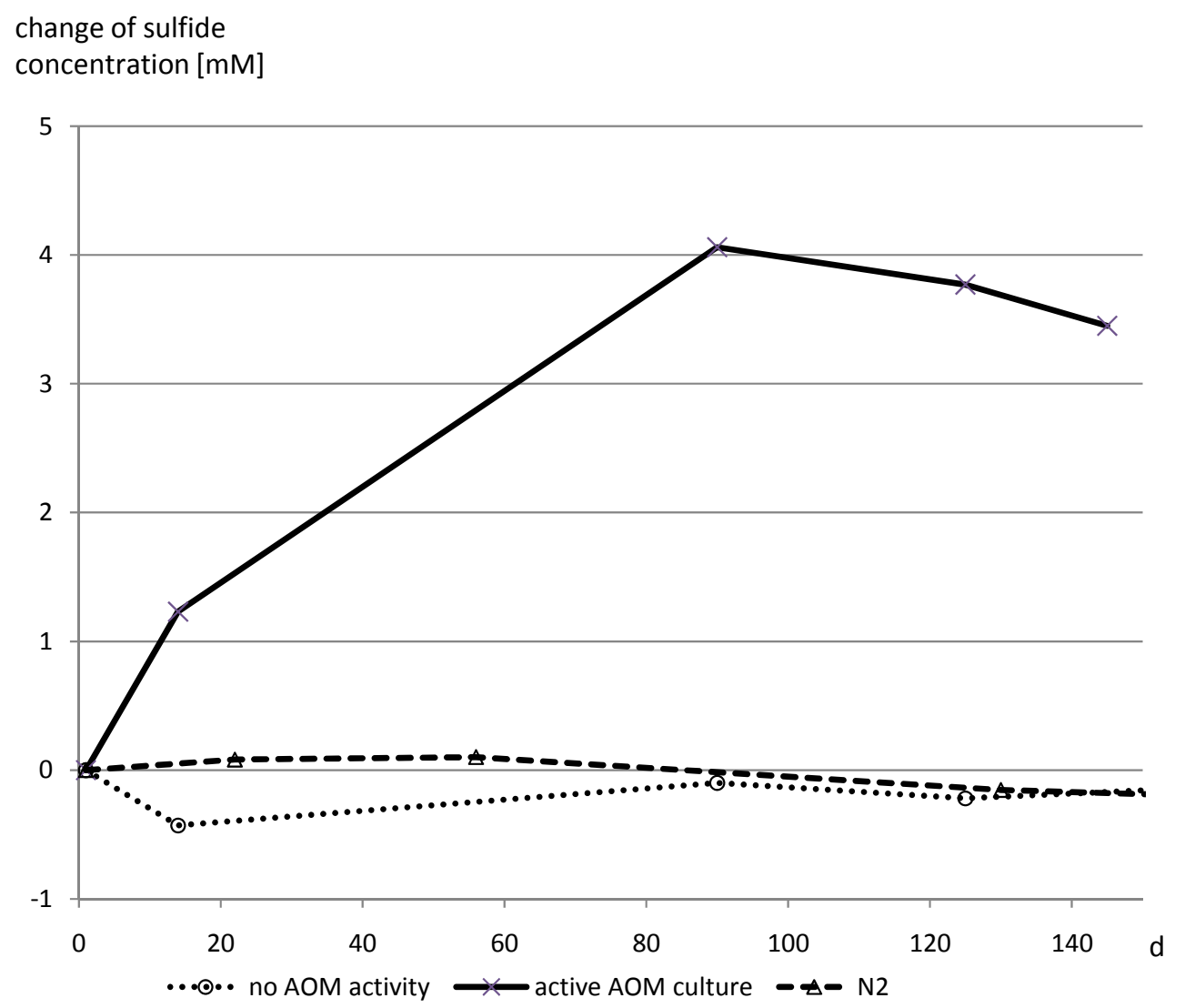

Figure 3.20.: AOM activity.

Formation of sulfide from sulfate with methane as electron donor in fluid cultures under strictly anaerobic conditions (indicating AOM activity). 
The development of hydrogen sulfide was used as indicator for anaerobic methane consumption (cf. 2.3.3.; Nauhaus et al., 2002). Actually, an increase of hydrogen sulfide was measured (Fig. 3.20.). From eleven inoculated samples, however, just four showed the development of hydrogen sulfide. This finding reflects the fact that just a low number of organisms, or, in fact biofilm flakes, must have been transferred as single units to the enrichment cultures and were activated during culturing. These results obtained with cultivated samples from mud volcano fluids are consistent with the presence of (sulfate dependent) methane oxidizers as identified by FISH and phylogenetic analysis (see above).

Aerobic or nitrite dependent methanotrophy could not be expected to occur in the low redox environment (below $-110 \mathrm{mV}$, see section 3.2.1.) of the mud volcano fluid. But as already described above, aerobic methano- or methylotrophic organisms were detected in anoxic biofilms from GHOSTDABS cold seeps (cf. section 3.1.). Due to the low cell counts, methylotrophic organisms could not be detected in environmental samples with techniques used for investigation of the cold seeps. For that reason, cultivation experiments were performed to detect $\mathrm{MDH}$ dependent methanotrophs in the oxic and the anoxic volcanic fluids (cf. sections 2.1.3., 2.2. and 2.3.3.).
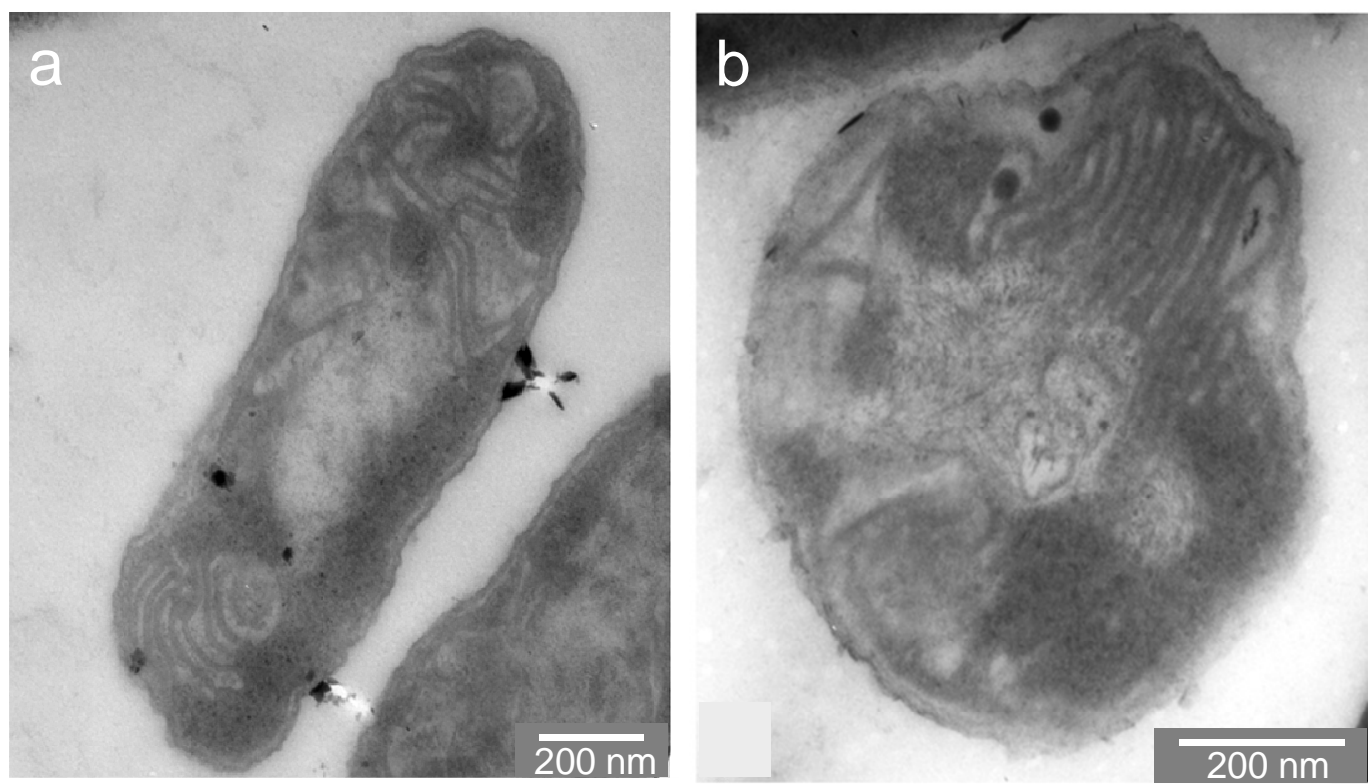

Figure 3.21.: TEM analysis of methanotrophic enrichment cultures.

Electron microscopy of aerobe methanotrophic enrichment cultures. Samples were embedded in Spurr resin and stained with uranyl acetate and lead citrate. Membrane stacks indicating type I methanotrophs. 
In cultivation experiments, inoculated with samples either taken from the aerobic fluid outlet or from a depth of $1.5 \mathrm{~m}$, aerobic methanotrophs were successfully enriched, even in the anaerobic fluids. DGGE analysis revealed the diversity of methanotrophs in enrichment cultures (Tab. 3.2.), mainly Methylophaga and Methylobacter-species (cf. 2.3.4. for DGGE technique). In the enrichment cultures from anaerobic fluids the abundance of a Methylococcaceae bacterium ET-SHO and a Methylophilus-related strain was shown (cf. Heinzelmann, 2010).

In order to obtain more information about the morphology of the enriched cells, especially with respect to internal membranes, cells from enrichment cultures were embedded in Spurr resin and ultrathin sectioned (cf. section 2.3.6. for methods). TEM analysis showed rod-like and coccoid cells, containing stacks of internal membrane layers. This ICM stacks are typical for type I methanotrophs, which corresponds to the DGGE data (Fig. 3.21.; Hanson and Hanson, 1996). 


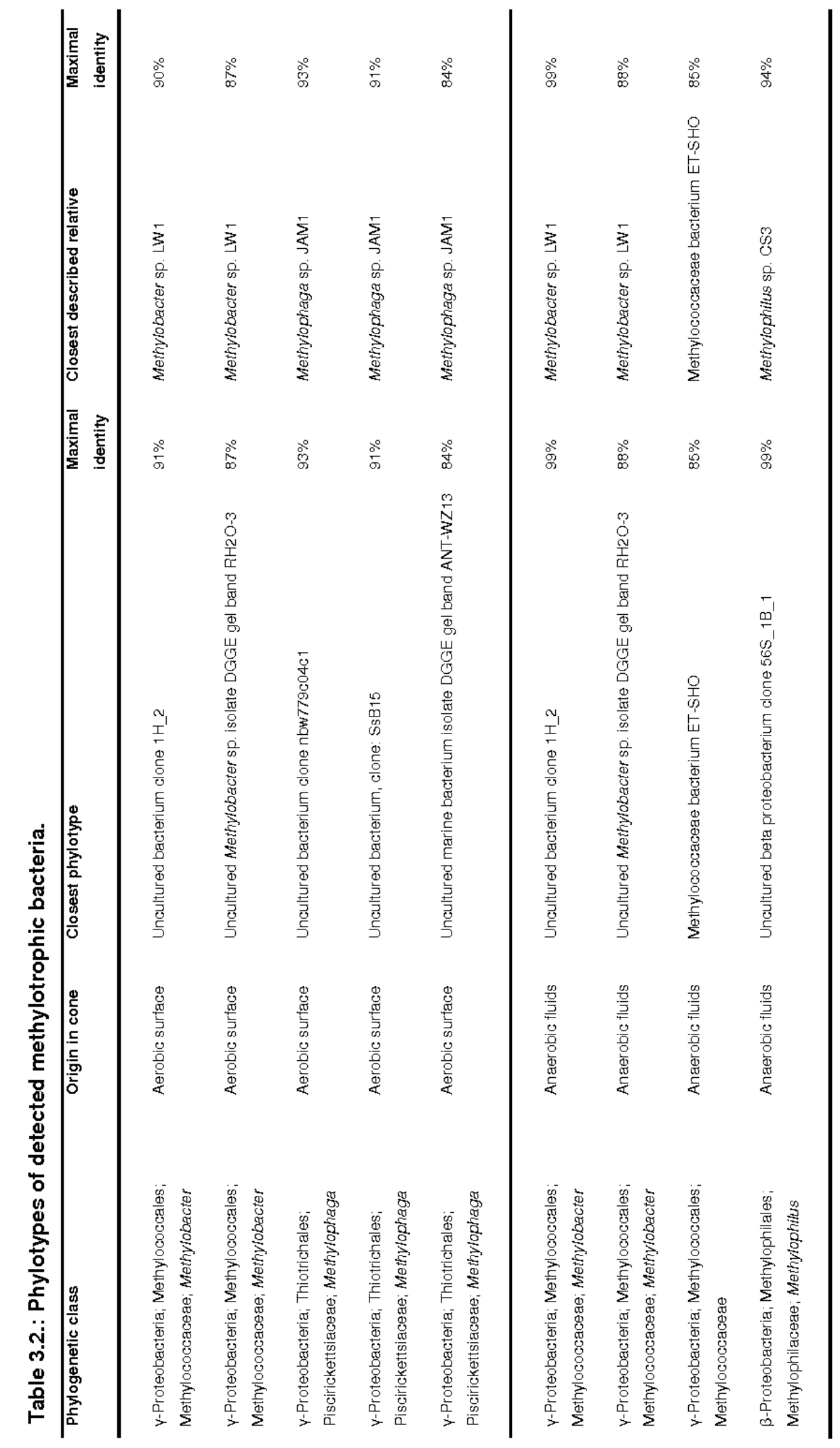




\section{Discussion}

\subsection{Anaerobic methane oxidation - a view on the protein level}

\subsubsection{Are syntrophic bacteria of ANME cells active SRB?}

Considering the current knowledge about sulfate dependent AOM, most details of the postulated pathway remain still unknown. For the archaeal organisms, more information is already available, than for the bacterial AOM partners (cf. section 1.2.3). Genomic analyses were supported by the detection of a (reverse) methanogenic key enzyme, the MCR protein, on cellular level of ANME-1 and ANME-2 cells (cf. section 1.2.3.; Krüger et al., 2003; Hallam et al., 2004). Most recently, metagenomic and mRNA analyses of ANME-1 archaea gave further evidence for the reverse methanogenic pathway (Meyerdierks et al., 2010).

Concerning the bacterial symbionts the knowledge is hitherto even more fragmentary (cf. section 1.2.3.). Recently, extensive FISH analysis could show that up to $95 \%$ of ANME-2 bacterial symbionts belong to the SEEP-SRB1a subcluster of the DSS group (Schreiber et al., 2010). In addition to these SRB, Desulfobulbus (so far only known for ANME-3) and a significant fraction of non sulfate reducing $\alpha$ - and $\beta$-Proteobacteria, related to Sphingomonas and Burkholderiaceae, respectively, were described in another study (Pernthaler et al., 2008).

Since no data on expressed metabolic pathways in these consortia were available, we used an $a p r B$ gene sequence, obtained from the microbial mat by degenerate primers, to overexpress the AprB protein heterologously in E .coli. The purified protein was used for immunization (see Fig. 3.8.). By this method, an antibody directed against APS reductases from the environmental sample was obtained.

The immunogold labeling of the APS reductase $\beta$-subunit provides evidence for the expression of this enzyme. Thus, the sulfate reducing pathway is shown in situ to be active (cf. section 3.1.2.; Figs. 3.11. and 3.12.). The labeling results of D. vulgaris Hildenborough (Fig. 3.11.a) and of course of the SRB in the cold seep biofilm demonstrate the applicability of this novel method. The detected active SRB exhibit mostly a vibrioid morphology localized in close contact to ANME-2 cells. These first 
data on AprB expression of SRB coincide with FISH analysis of Reitner et al. (2005b) and Schreiber et al. (2010), suggesting that the vibrio-like cells are phylogenetically related to DSS, SEEP-SRB1a group.

An expressed sulfate reduction pathway was not self-evident for the bacterial partner of ANME cells. Firstly, bacteria of $\alpha$ - and $\beta$-Proteobacteria without reported sulfate reduction pathway were found in association with ANME (see above). Secondly, it cannot be ruled out, that bacteria of the SRB group use fermentative pathways as energy source. This could be the case under sulfate limitation. Since the organisms in the microbial mats show a very high density (cf. Fig. 3.11.b), similar to the density of pelleted cells, sulfate respiration may cause sulfate depleted microenvironments. Fermentation in absence of sulfate is a prevalent option of SRB for growth (Rabus et al., 2006). Some Desulfovibrio species (Widdel, 1988), Desulfobacterium species (Brysch et al., 1987) and Desulfosarcina variabilis (Widdel, 1980) are able to ferment fumarate and malate (exception D. variabilis), to succinate, acetate, carbon dioxide and propionate. Pyruvate is fermented by many SRB using lactate (Postgate, 1984; Rabus et al., 2006). For Desulfobulbus species, lactate or ethanol fermentation with carbon dioxide was described (Laanbroek et al., 1982; Widdel and Pfennig, 1982). In cocultures with hydrogen-scavenging methanogenic archaea, Desulfovibrio strains were able to grow on ethanol or lactate, but without sulfate. Under these conditions, SRB serve as hydrogen-producing acetogenic bacteria in a syntrophic association (Bryant et al., 1977). However, the immunodetection of AprB at significant level, as shown here, excludes these alternatives and shows an active sulfate respiration of most ANME partner cells (Fig. 3.11.b).

It should be stressed here that in the microscopical analysis the SRB show a vibrioid morphology (cf. Fig. 3.11.c and 3.12.a,c,d), which was also is also reported in other studies (Reitner et al., 2005a; Reitner et al., 2005b; Schreiber et al., 2010). Though morphology is no criterion for phylogenetic classification, for Desulfosarcinal Desulfococcus strains no cultured species with distinct vibrioid morphology has been described so far.

Use of antibodies as markers for metabolic enzymes combined with high resolution TEM shed light on cell types with distinct cellular and subcellular features, which were not assigned to metabolic activities of cells, yet. One prevalent attribute of cells from GHOSTDABS microbial mats are ICM stacks, also described in other studies (Ivanov et 
al., 1991; Reitner et al., 2005b). In this work evidence was given that at least one cell type synthesizing ICM stacks represents active SRB (cf. section 3.1.2. and Fig. 3.12.d,e), but no cell type with ICM stacks showed MDH expression. Though ICM stacks are typical for type I methanotrophs (cf. Fig. 1.3.a and Hanson and Hanson, 1996) they have been also described for some SRB (Rozanova et al., 1988; Mohn et al., 1990).

Another subcellular structure found in cells of GHOSTDABS cold seeps are internal greigite particles, arranged in chains as described for magnetosomes (Reitner et al., 2005a). Here, immunolocalization with $\alpha$-AprB antibodies demonstrates that these cells perform sulfate reduction at significant level (cf. section 3.1.2. and Fig. 3.12.b,c). The function of the magnetosome-like structures has not been studied, yet. Since the cells are embedded in the EPS matrix of the biofilm, geomagnetic navigation as known from aquatic habitats, i.e. magnetotaxis, can be ruled out (Faivre and Schüler, 2008). Processes like storage, a metabolic function or detoxification appear more likely. These features have also been postulated as functions of magnetosomes from magnetotactic bacteria (cf. Vainshtein et al., 2002; Frankel and Bazylinski, 2004; Simmons et al., 2004; Faivre and Schüler, 2008). Here, the greigite particles may be products of intracellular detoxification of hydrogen sulfide. In previous investigations, it was postulated that the high content of authigenic pyrite in the Black Sea cold seeps was caused by extracellular mineralization of sulfide released from SRB (Peckmann et al., 2001b). Regarding the data of this work that sulfate respiration leads to internal greigite precipitates (cf. also Reitner et al., 2005a; Reitner et al., 2005b), it can be postulated that sulfate respiration has also direct influence on intracellular biomineralization.

\subsubsection{AOM, syntrophy of reverse methanogenesis and sulfate reduction?}

The reconstruction of the postulated pathway of reverse methanogenesis in syntrophy with sulfate respiration is mainly based on bulk analysis. Methane uptake and sulfate reduction is measured for the determination of overall AOM activity in enrichment cultures (e.g. Michaelis et al., 2002; Nauhaus et al., 2007; Treude et al., 2007; Wegener et al., 2008). Though, up to now, the single reaction steps in this pathway could not be proven, e.g. by detection of the relevant metabolites. Thermodynamics of the AOM require that reverse methanogenesis has to be simultaneously conducted in direct 
proximity to sulfate reduction. The maximal distances between partner cells are strongly restricted, e.g. for hydrogen $8.4 \mathrm{~nm}$, for methanol $0 \mathrm{~nm}$, for acetate $13 \mathrm{~nm}$ and for formate $66 \mathrm{~nm}$ between electron carrier production and consumption result in a loss of $5 \mathrm{~kJ} /\left(\mathrm{mol} \mathrm{CH}_{4}\right)$ (Sörensen et al., 2001).

By performing a double label approach with $\alpha$-MCR and $\alpha$-AprB antibodies, see Fig. 3.12.f, it could be demonstrated, that in fact, methane oxidation and sulfate reduction are synchronized and in direct proximity. This result supports the hypothesized AOM mechanism (Hoehler et al., 1994; Knittel and Boetius, 2009) and the genomic analyses (Hallam et al., 2004; Meyerdierks et al., 2005; Pernthaler et al., 2008; Meyerdierks et al., 2010).

\subsubsection{Aerobic methanotrophic pathway in anoxic cold seeps}

The stratification of the Black Sea water column provides a permanently anoxic environment for the GHOSTDABS field in a depth of approximately $230 \mathrm{~m}$ (cf. section 1.3.1 and Michaelis et al., 2002). Accordingly, the detection of aerobic methano- or methylotrophic bacteria does not correspond to common expectations for this habitat. So far, methanotrophic bacteria in the Black Sea were only found above methane seeps up to a depth of approximately $150 \mathrm{~m}$ (Durisch-Kaiser et al., 2005). The abundance in this area is based on the availability of oxygen. In contrast, it is demonstrated in this work that cells in the anaerobic GHOSTDABS microbial mats express the MDH, the methano- and methylotrophic key enzyme (see section 3.1.1., Figs. 3.5. and 3.6.). Expression of this methanotrophic key enzyme indicates the metabolic activity of the cells. Therefore it can be excluded, that the cells are inactive remains from the aerobic part of the water column. This conclusion is also supported by cytological features; ICM parallel to the cytoplasmic membrane suggest a relation to type II methanotrophs (cf. Fig. 3.6.a-e). In the water column above methane seeps, methanotrophs were found to be nearly exclusively (at least $\sim 90 \%$ ) of type I (Durisch-Kaiser et al., 2005; Schubert et al., 2006). Consequently, the described bacteria in the biofilms differ from planktonic methanotrophs of the oxic water column. 


\subsubsection{Electron acceptors and microniches}

Investigations of the microscale environment in the microbial mats exhibited the presence of the MDH expressing cells in small colonies (cf. Fig. 3.5.). These colonies were embedded within the EPS matrix between ANME-2/SRB consortia revealing cell division inside the mat. Thus, the cells are actively growing and represent not inactive cell remnants. Instead of colony formation, sedimented and metabolic inactive cells deposits should be found as single cells on the mat's surface and get degraded over the time.

In fact, the aerobic methanotrophic pathway is expected to use oxygen as electron acceptor at high redox levels. This allows a high energy yield of dissimilatory methane oxidation with $\delta G^{0}=-818 \mathrm{~kJ} / \mathrm{mol}$ (cf. section 1.2.2.; Eq. 11). The difficult issue in this environment is the source of electron acceptors for methanotrophs. The question is raised, if the abundance of molecular oxygen in this anaerobic environment is possible. One explanation is a temporal fluctuation of the oxic-anoxic interface zone of euxinic seawater. Perturbation of the stratified water could allow an infiltration of the bottom water with traces of oxygen. The high dynamic oxic-anoxic interface zone is located in a depth between approximately 130 and $180 \mathrm{~m}$ (Luth and Luth, 1997). Some references even assume only 80-100 m (Sinninghe Damsté et al., 1993 and references therein). Although repeated measurements showed only minor differences in the oxic-anoxic interface (Luth and Luth, 1998) up- or downwards shifts of the chemocline cannot be excluded (Luth et al., 1999). Regarding the investigated samples, reverse methanogenesis, sulfate reduction and methanotrophy were conducted simultaneously in the microbial mat (see section 3.1.1 and 3.1.2.). Thus, exposition to oxygen seems rather unlikely in consideration of the high susceptibility to oxygen and the dependency to low redox potentials of (reverse) methanogens (Fetzer and Conrad, 1993). Even small traces of oxygen should have inactivated the ANME metabolism (Fetzer and Conrad, 1993), though it is possible that microenvironments in the microbial mat protect the oxygen-sensitive cells by formation of steep redox gradients (Brusa et al., 1987; Paerl and Prufert, 1987; Belay et al., 1988; Schramm et al., 1999; Whitman et al., 2006).

A second explanation for the detected methanotrophic microcolonies rests may be on the coupling of methane oxidation to nitrate reduction (cf. section 1.2.4.). Bacteria exhibiting this metabolic feature were recently described (Raghoebarsing et al., 2006; Ettwig et al., 2008; Ettwig et al., 2009; Hu et al., 2009; Ettwig et al., 2010). Of course, 
nitrate and nitrite concentrations are typically higher in freshwater environments than in sea water due to inputs from soil fertilization and other anthropogenic sources (Galloway et al., 2004; Seitzinger et al., 2006; Galloway et al., 2008). In marine waters nitrate concentration varies usually between $0.4 \mu \mathrm{M}$ and $8 \mu \mathrm{M}$, whereas nitrate/nitrite dependent AOM experiments were performed at concentrations of $2 \mathrm{mM}$ nitrate (sampled from water containing $0.1 \mathrm{mM}$ nitrate; Morris and Riley, 1963; Raghoebarsing et al., 2006; Ettwig et al., 2010). Consequently, the limiting factor for these organisms will be the electron sink. Microcolonies with only some tens of cells may reflect a minor ecological role of the aerobic methano- or methylotrophs in the methane seeps (cf. section 3.1.1.). Since the nitrate/nitrite based AOM has a significantly higher energy yield of $\Delta \mathrm{G}^{\circ}{ }^{\prime}=-928 \mathrm{~kJ} /\left(\mathrm{mol} \mathrm{CH}_{4}\right)$ compared to $\Delta \mathrm{G}^{\circ}{ }^{\prime}=-21 \mathrm{~kJ} /\left(\mathrm{mol} \mathrm{CH}_{4}\right)$ for the sulfate based AOM (Thauer and Shima, 2008), ANME/SRB consortia should be otherwise outcompeted by bacteria.

Nitrogen compounds can be provided by (a) the sea water, (b) marine snow (Diercks and Asper, 1997) and (c) organic sources of the microbial mats. Nitrogen cycling is known in microbial mats and biofilms (Joye and Paerl, 1994). Rapid recycling and transfer of metabolites within mats has been documented for many bioactive elements, including C, N, S and O (Joye and Paerl, 1994; Guerrero et al., 2002; Beer and Stoodley, 2006). Since no methanol dehydrogenase-expressing organisms could be detected in the pink layer, it could be speculated that nitrate/nitrite is provided from outside of the microbial mats (see section 3.1.1., Fig. 3.3.). A feasible explanation may be that in the black surface layer nitrogen or nitrite concentration is sufficient for bacterial methanotrophy, whereas in the underlying pink layer these compounds are already depleted (see Fig. 4.1.). However, the absence of evidence for MDH expressing cells that conduct nitrate/nitrite dependent AOM means not the evidence of their absence. In line with this assumption a few detections of $\mathrm{NC} 10$ related bacteria were reported even in marine habitats (Zhu et al., 2010). 


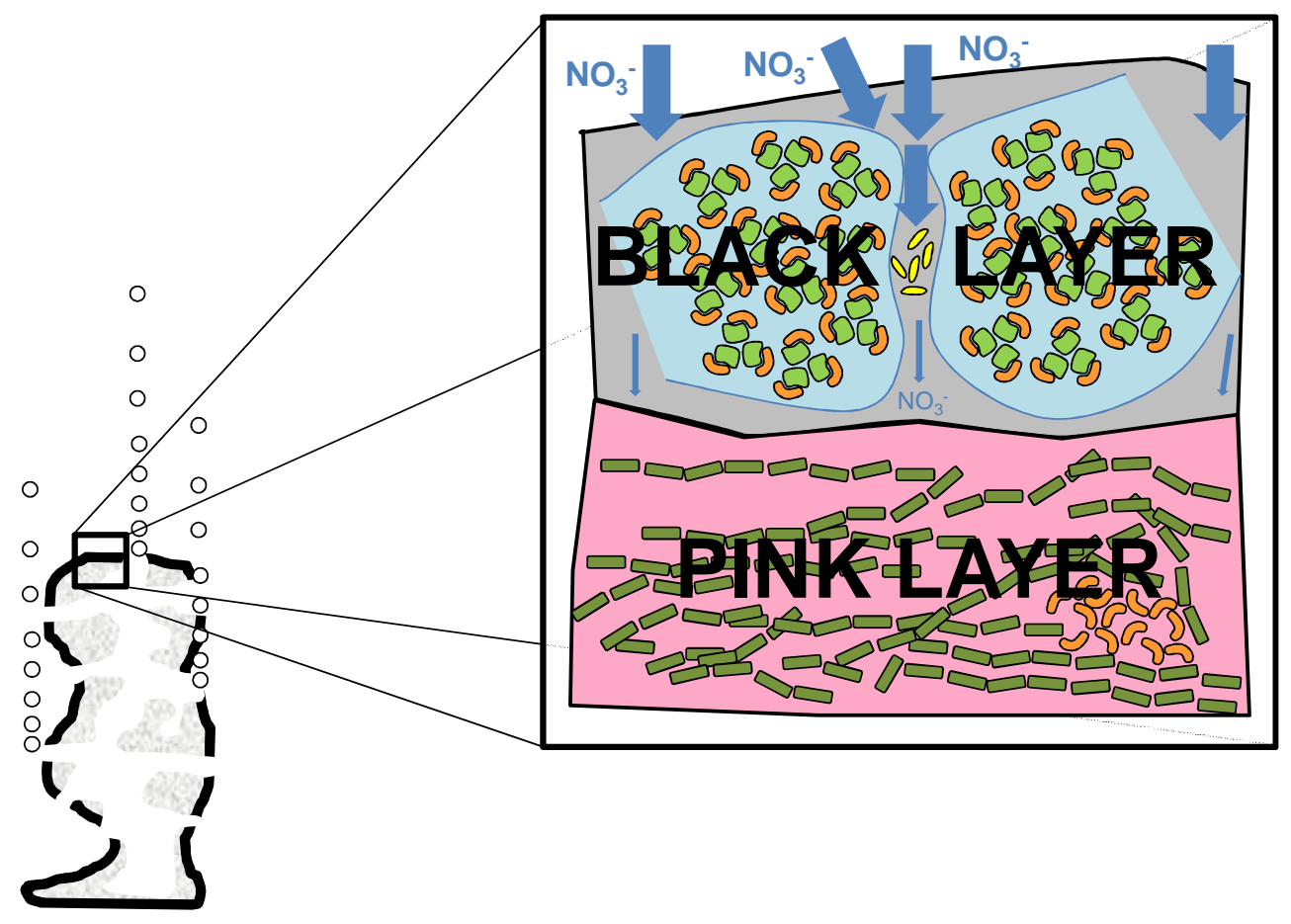

Black Sea cold seeps

Figure 4.1.: Hypothesis of nitrate/nitrite consumption in the black layer.

Illustration shows magnification of GHOSTDABS cold seep microbial mats. Black layer is dominated by ANME-2/SRB (green/orange) aggregates with microcolonies of nitrate/nitrite dependent methanotrophs (yellow). Nitrate of the seawater (blue arrows) diffuses into the microbial mats and gets reduced by bacterial methanotrophs. Only very low concentrations of nitrate reach the pink layer. There, no MDH expression is detectable. Pink layer is dominated by ANME-1 matrix (green) with embedded SRB (orange) colonies.

Microbial mats of GHOSTDABS cold seeps are highly structured and exhibit large amounts of EPS (see section 1.3.1. and Reitner et al., 2005b; Wrede et al., 2008), providing good conditions for distinct microniches. It is described that microniches can cause different redox levels which determine diverse microbial metabolic activities in close proximity. Metabolically similar microbial populations, so called 'guilds', may establish these redox niches and conduct interdependent physiological processes (Davey and O'Toole G, 2000). This is reported for sediments (e.g. Stockdale et al., 2009; Bertics and Ziebis, 2010) as well as for biofilms (e.g. Costerton et al., 1994; Schramm et al., 1999). Since methanotrophic bacteria need higher redox levels compared to ANME/SRB aggregates, their localization in interspaces can be dedicated to microniches in the GHOSTDABS cold seeps (see Fig. 4.2.). Redox potentials should be 
expected at approximately +100 to $+250 \mathrm{mV}$ or higher for nitrate/nitrite or oxygen utilization (Bailey and Beauchamp, 1971; Reeburgh, 1983; Vance, 1996). In comparison, for methanogenesis and sulfate reduction redox levels of approximately $-150 \mathrm{mV}$ and below are necessary (Connell and Patrick, 1968; Reeburgh, 1983; Wang et al., 1993). Aerobic methanotrophs may contribute to the decreased redox levels in ANME/SRB consortia by scavenging oxidized compounds. Also further microorganisms can reduce the redox level by respirations, like heterotrophic bacteria growing with organic compounds inside the microbial mats. This coincides with the observation of several cell types with yet unknown metabolisms between ANME/SRB consortia.

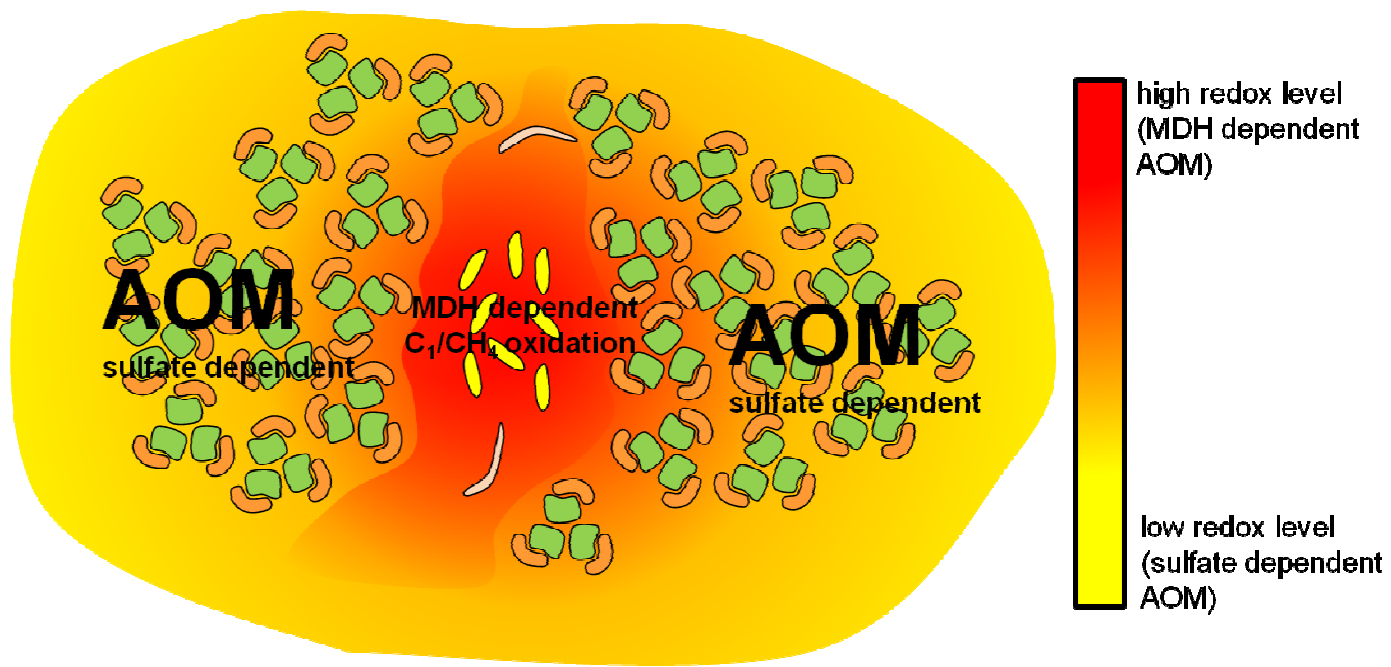

Figure 4.2.: Postulated microniches with different redox level conditions.

Microniches in GHOSTDABS cold seep microbial mats. Black layer is dominated by ANME-2/SRB (green/orange cells) aggregates with microcolonies of nitrate/nitrite dependent methanotrophs (yellow cells). MDH dependent AOM requires higher redox levels for oxygen or nitrate/nitrite respiration. At the same time this metabolism is conditioning the low redox level for ANME-2/SRB dependent AOM. White cells represent microorganisms with unknown metabolism.

In addition, AOM associated archaea coexisted over a distinct time period in nitrite reducing $\mathrm{AOM}$ enrichment cultures together with bacteria of NC10 phylum (Raghoebarsing et al., 2006; Ettwig et al., 2008). This observation suggests a certain tolerance of ANME cells to higher redox levels. 


\subsubsection{Co-occurrence of ANME and methanotrophic bacteria, a unique phenomenon?}

With the detection of MDH expressing cells at anoxic methane seeps the question raises, if this phenomenon is restricted to samples analyzed in this work. In a study applying metagenomics with a direct cell capture method, Pernthaler et al. (2008) focused on the bacterial partner cells of ANME-2 archaea. They detected, besides the expected DSS group and members of Desulfobulbus, cells of $\alpha$ - and $\gamma$-Proteobacteria. These phyla include also type II and type I methanotrophs. Furthermore, bacteria affiliated to the Cytophaga group and $\beta$-Proteobacteria were found. Data from stable isotope probing imply that members of Cytophaga and $\beta$-Proteobacteria are also oxidize methane aerobically (Morris et al., 2002; Radajewski et al., 2002; McDonald et al., 2008), $\beta$-Proteobacteria even at hydrocarbon seeps (Redmond et al., 2010). In addition, genes for denitrification were reported in the study of Pernthaler et al. (2008) for the analyzed $\beta$-Proteobacteria. The $\alpha$ - and $\beta$-Proteobacterial cells were also described to be loosely associated on the periphery of the ANME-2c/DSS aggregates, similar to our findings. Also Knittel et al. (2005) and Schreiber et al. (2010) reported cells in the ANME-2 periphery, which were not identified by SRB FISH probes. The latter study identified in particular $\alpha$ - and $\beta$-Proteobacteria. The organisms do not belong to sulfate reducing groups and an affiliation with $\mathrm{MDH}-$ dependent methanotrophs has to be investigated. However, it is interesting to note certain parallels to our data.

\subsubsection{Implications for biomarkers}

The abundance of methano- or methylotrophic bacteria in anoxic cold seep habitats has also to be considered for biomarkers of these environments. It is the first in situ detection of MDH-dependent methylotrophy in anaerobic cold seeps. Furthermore it is demonstrated here, that these cells are metabolically active. This is in accordance with biomarker data from the GHOSTDABS-field microbial mats (Thiel et al., 2001; Thiel et al., 2003) and other cold seep deposits (e.g. Elvert et al., 2000; Pancost et al., 2000; Hinrichs, 2001). These studies reported biomarkers of aerobic methanotrophs with strong ${ }^{13} \mathrm{C}$ depletions in addition to biomarkers of sulfate dependent AOM (see section 1.2.3.). Isotopically depleted $\mathrm{C}_{30}$ hopanoids (diplopterol, diploptene, and their diagenetic derivatives) are known from aerobic methanotrophs, but were also detected 
in some groups of anaerobic bacteria (Sinninghe Damsté et al., 2004; Härtner et al., 2005; Blumenberg et al., 2006). But in addition biomarkers were found at methane seep deposits which are specific for aerobic methanotrophs, namely ${ }^{13} \mathrm{C}$ depleted hopanoids (3ß-methylated hopanoids) and 4-methylated steroids (lanostanes; Birgel and Peckmann, 2008). With evidence for active methano- or methylotrophic bacteria in recent anoxic methane seeps, given in this work, it has to be considered that biomarker hints are not necessarily based on oxic conditions of methane seeps or anaerobic nonmethanotrophic bacteria. The cell types detected in this work should be taken into account as possible biomarker source.

\subsection{Terrestrial mud volcanoes in Nirano}

\subsubsection{Mud volcanoes as AOM habitat}

The Nirano mud volcano system generates a complex microbial environment. The fluid geochemistry reveals a heterogeneous substrate, consisting of diverse hydrocarbons and limited amounts of appropriate electron acceptors (e.g. Martinelli and Rabbi, 1998; Boschetti et al., 2010). In a previous study, ${ }^{13} \mathrm{C}$-depleted hydroxyarchaeol, detected in the mud volcano fluids, was a hint of AOM conducted by recent organisms in the mud volcano fluids (Heller et al., 2010). The results of this work show that AOM is active in the recent system (see section 3.2.2.).

At an estimated thermal gradient of approximately $20{ }^{\circ} \mathrm{C}$ per $\mathrm{km}$ in the Apennine foredeep (e.g. Teichmüller and Teichmüller, 1986; Harabaglia et al., 1997; Capozzi and Picotti, 2002), organisms in the deep subsurface at a depth of $2000 \mathrm{~m}$ would experience an ambient temperature of approximately $60{ }^{\circ} \mathrm{C}$. In the shallow fluid reservoir, $200 \mathrm{~m}$ beneath the surface, approximately $4{ }^{\circ} \mathrm{C}$ above surface temperature may be expected (cf. Fig. 1.9.c and Fig. 4.3.). The fluid reservoirs along boundaries of different geological units provide an environment of reduced flow velocity, compared with narrower ducts in homogeneous material. Though in the mud cones formed by the Argille Azzurre marine clays, consolidated biofilms could never be observed, it is very well possible that these films can develop along the solid/liquid phase boundaries inside the fluid conduits along thrust faults or other discontinuities, especially, where the fluid velocity is low. Thus, the fluid reservoirs may be the preferred sites of colonization by 
consolidated biofilms. The Marnoso Arenacea deposits and the Epi-Ligurian units provide porous material with wide grain boundaries, i.e. putatively suitable surfaces for colonization. In particular, the shallow fluid reservoir (see Fig. 1.9.c) may provide electron acceptors as sulfate, since Messinian deposits get in contact with the upwelling fluids (cf. Fig. 4.3.). Before final emission, there is a final mud accumulation forming a superficial reservoir approximately $25 \mathrm{~m}$ below the surface (Fig. 4.3.). For the gas-mud mixture a gas volume of $10 \%$ was estimated with seismic data (Accaino et al., 2007).

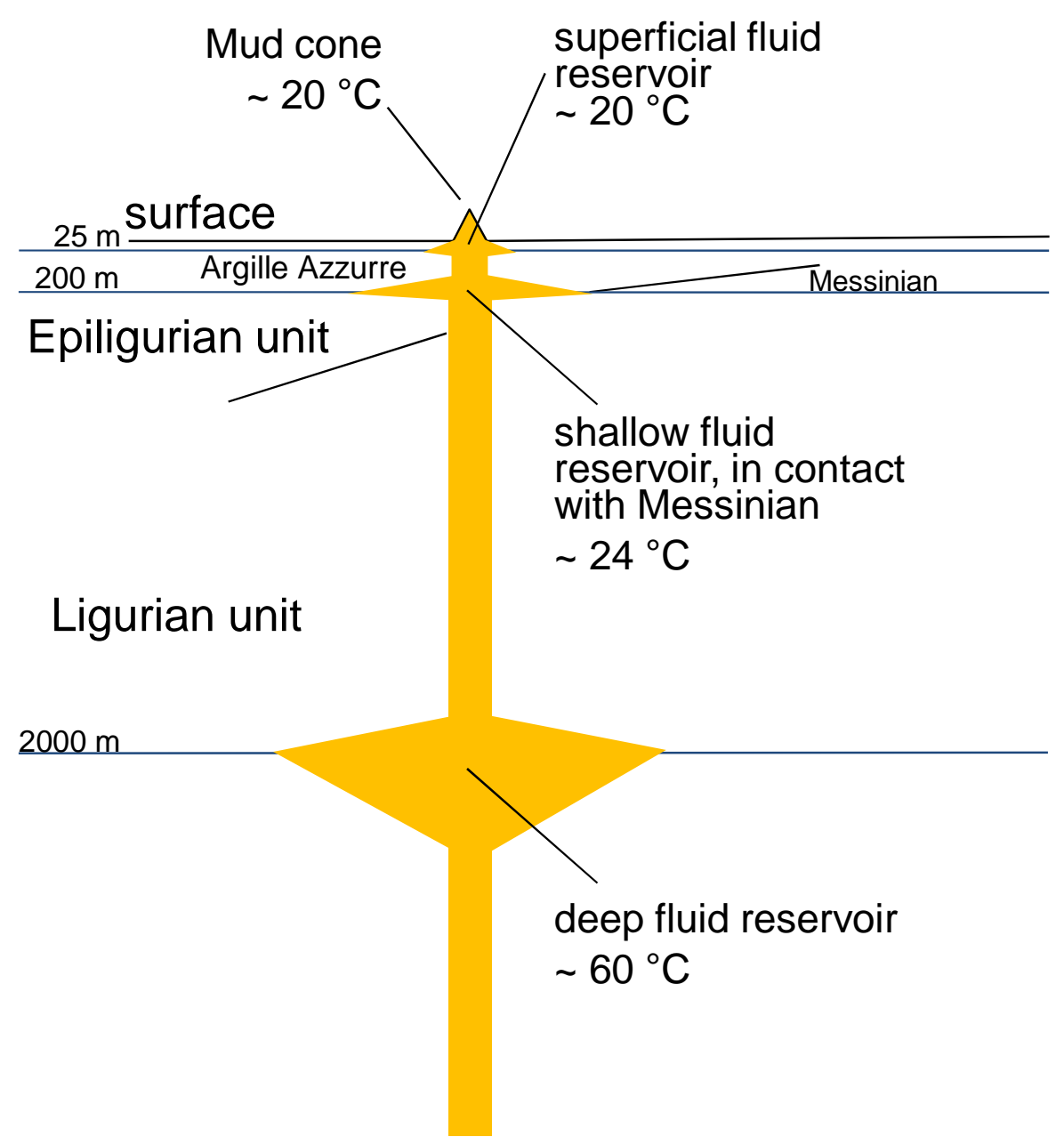

Figure 4.3.: Schematic illustration of mud volcano.

Schematic illustration shows fluid reservoirs of a Nirano mud volcano. A deep fluid reservoir is approximately $2000 \mathrm{~m}$ under the surface with a temperature of approximately $60{ }^{\circ} \mathrm{C}$. Beneath the Argille Azzurre formation a shallow fluid reservoir may be in contact to the Messinian deposits. Directly under the cone in approximately $25 \mathrm{~m}$ depth a superficial fluid reservoir is located. 
The superficial fluid reservoir has also to be considered as AOM habitat, since sulfate and methane are available at a low fluid migration velocity, although methane solubility is already lower than $200 \mathrm{~m}$ below the surface.

Colonization along thrust faults can be expected, too. It is very likely that the observed biofilm flakes (cf. section 3.2.2.; Figs. 3.14., 3.16., 3.17.) have developed under these conditions as part of a biofilm, on a consolidated surface. Though in clay substrata development of small microbial aggregates was observed (approximately $10 \mu \mathrm{m}$ in diameter; Lawrence et al., 2000), the narrow pore spaces in compacted clay (0.1-0.2 $\mu \mathrm{m})$ will not allow the formation of biofilms. The alternative, i.e. the development of aggregations in a gas-pertubated fluid phase enriched with sedimentary material, may also be considered, but due to the migration of fluids through the system (Capozzi and Picotti, 2002; Bonini, 2008) the organisms experience a rather fast change of environmental conditions. Keeping the low growth rates of ANME and other archaea in mind (cf. Fig. 3.20; N Nauhaus et al., 2007), a long retention period of several weeks or months under constant environmental conditions is likely, accounting for a 'fixed-bed' biofilm. The observed pyrite framboids are likely to be a by-product of sulfate reduction and precipitated in the biofilm matrix (cf. section 3.2.2.; Fig. 3.15.).

\subsubsection{Role of detected microorganisms}

The archaean diversity is remarkable and higher as observed for the first characterized mud volcano community (Paclele Mici, Romania; Alain et al., 2006), which is indicative for an important, if not dominant role of diverse AOM in the system. The high number of sequences of Crenarchaeota, known from manganese and iron dependent AOM studies (section 3.2.2. Figs. 3.18 and 3.19.), suggest electron acceptors other than sulfate, which are, however, very limited (section 3.2.1.; Tab. 3.1.). The presence of ANME-2a-2b as shown by sequence and FISH analysis, give a strong hint for abundant sulfate dependent AOM (section 3.2.2.; Figs. 3.17., 3.18., 3.19.). In addition, GoM Arc I and ANME-1 archaea were detected with 16S rRNA gene analysis. The occurrence of sulfate dependent AOM is also supported by methane dependent sulfide production, measured in enrichment cultures (Fig. 3.20.). In the mud volcano system, sulfate-dependent AOM is of course limited by the low sulfate concentrations in the mud volcano fluids (section 3.2.1.; Tab. 3.1). However, the low sulfate 
concentrations may be also a consequence of the high microbial activity in the fluid reservoirs (cf. Capozzi and Picotti, 2002; Boschetti et al., 2010). It has to be further kept in mind that the measured sulfate concentrations highly vary in time between $7 \mathrm{mg} / \mathrm{l}$ and $200 \mathrm{mg} / \mathrm{l}$ (Martinelli and Judd, 2004; Duchi et al., 2005; this work).

The morphology of the detected ANME-2 aggregates corresponds to the mixed-type consortia, known for this ANME group (cf. Figs. 1.5.c,d and 3.17.; Knittel and Boetius, 2009). This is in accordance with the phylogenetic 16S rRNA gene analysis, which showed ANME-2a-2b archaea (cf. Figs. 3.18. and 3.19.), but no ANME-2c archaea, which form shell-type consortia (Figs. 1.5.f,g and 3.18.). Nevertheless, syntrophic SRB of the DSS group were not observed. This occurrence of ANME cells without SRB partner cell is, however, frequently reported from further habitats (Orphan et al., 2001a, 2002; Durisch-Kaiser et al., 2005; Eller et al., 2005; Knittel et al., 2005; Schubert et al., 2006; Lösekann et al., 2007; Treude et al., 2007).

AOM, indeed, appears to be replaced by aerobic methane oxidation wherever possible: Though unexpected in anaerobic environmental samples, diverse methylotrophic bacterial genera could be enriched (cf. section 3.2.2.; Tab. 3.2.). Here, a low concentration of organisms may be present in the fluids and represent a 'seed bank', when, at higher redox potential and under availability of oxygen, aerobic methane oxidation becomes possible. Therefore, already low oxygen concentrations can be sufficient, since genome analysis of Methylococcus capsulatus revealed a good adaptation to microaerophilic conditions and lower redox levels than previously thought for methanotrophic bacteria (Ward et al., 2004). Especially, the phylotypes of the detected methanotrophs enriched from the anaerobic fluids, strongly correlate with a recently published study of methane incorporation of bacteria from a marine hydrocarbon seep (Redmond et al., 2010). In this study, Methylococcaceae, Methylophaga and Methylophilaceae were identified as primary methane assimilating bacteria. Moreover, the Methylococcaceae bacterium ET-SHO was detected in the marine habitat (cf. with section 3.2.2.; Tab. 3.2.). Also from other marine methane seeps the absence of type II methanotrophs, as in this work, has been described (DurischKaiser et al., 2005; Schubert et al., 2006). Comparing these results, rather high similarities between the marine habitats and the terrestrial habitat of this work become obvious. This is also true for most archaeal sequences matching to nearest neighbors of marine methane seepage habitats (section 3.2.2.). Due to the ancient marine deposits, 
dissolved in the migrating fluids of the Nirano mud volcano field, the correlations to marine conditions are reasonable. However, counts of AOM conducting organisms and also total counts of microbial cells are much lower than in marine environments (section 3.2.2.). Thus, the terrestrial methane seeps must be far less effective in oxidation of the greenhouse gas methane as marine methane seeps, which is possibly based on low amounts of available electron acceptors (Knittel and Boetius, 2009).

\subsection{Perspectives}

The results of this work prove that metabolic key enzymes of reverse methanogenesis and sulfate reduction are expressed in directly neighbored ANME-2 and SRB cells. ANME- 1 cells were not analyzed in this work. In future studies, the $\alpha$-AprB antibodies may also be suitable to localize sulfate reduction in other cell types. Since ANME-1 cells, in particular, show no direct proximity to SRB in the pink layer of GHOSTDABS microbial mats, they might be capable of sulfate reduction by themselves (Knittel et al., 2005; Reitner et al., 2005a; Reitner et al., 2005b; Treude et al., 2007). Although no hints for the APS reductase were reported from genomic and transcriptomic analyses of ANME-1 archaea, its abundance could not be excluded (Meyerdierks et al., 2010).

As already described (cf. section 3.1.2.), magnetosome-like structures composed of greigite are abundant in SRB of the black layer (Reitner et al., 2005a). It is assumed that formation of greigite magnetosomes is similar to the formation of magnetite magnetosomes (Bazylinski et al., 1995). Thus an immunocytochemistry approach with antibodies raised against magnetosome-specific proteins could shed light on the similarity of observed structures to magnetosomes. MamK is involved in filament formation, while MamJ mediates the interaction of the filaments to magnetosome vesicles (Komeili, 2007). Since MamK is a homolog of the prevalent cytoskeletal protein MreB, MamJ should be preferred as antibody target to avoid crossreaction with MreB (Komeili, 2007).

In this work evidence for MDH expressing cells in the anoxic methane seeps was given (cf. section 3.1.1.). Further information about these methane oxidizers (in particular, their phylogenetic affiliation) would be interesting. The pMMO and the MDH are conserved enzymes of methanotrophic bacteria allowing phylogenetic investigations by gene analysis (cf. 1.2.2. and McDonald et al., 2008). These enzymes could also be used 
for detection of M. oxyfera, which uses nitrate and nitrite for AOM (Ettwig et al., 2010). Moreover, the 16S rRNA gene could be amplified by primers specific for methanotrophs or even bacteria of the NC10 phylum (McDonald et al., 2008; Ettwig et al., 2009). However, 16S rRNA gene analysis of bacteria from the NC10 phylum revealed that a detection is difficult even in enrichment cultures (Ettwig et al., 2009). Thus, screening for members of this group in GHOSTDABS microbial mats is challenging.

The terrestrial mud volcanoes in Nirano revealed low cell counts in comparison to marine methane seep habitats (cf. section 3.2.2.). Nevertheless, the observed microbial flakes suggests the presence of a consolidated biofilm in the fluid system. Therefore, investigations of conduits and fluid reservoirs would be necessary to understand methane turnover at these sites (cf. section 4.2.1.). Direct sampling of deep fluid reservoirs, however, is nearly impossible. Moreover, deep drilling of mud volcanoes may cause uncontrolled mud flow as discussed for the Lusi mud volcano in Indonesia (Sawolo et al., 2009). In addition most mud volcanoes are protected natural sites and should not be damaged.

The fluids of the mud volcanoes are enriched by compounds of underlying geological formations. Consequently, fluids can be composed of varying concentrations of electron acceptors as sulfate or iron (Martinelli and Judd, 2004; Duchi et al., 2005). Temperature and gas composition (e.g. carbon dioxide as main component) may extremely vary. These conditions cause different environments for microbial populations. Thus, comparative analysis with further mud volcano sites could reveal adaptations of microbial communities to available carbon sources and electron sinks. 


\section{Summary}

Anaerobic oxidation of methane (AOM) is recognized as one key process of methane consumption in oceans. According to phylogenetic and metagenomic analyses, the process is carried out by syntrophic consortia of anaerobic methanotrophic archaea and sulfate reducing bacteria. Here, a more comprehensive view inside methanotrophic consortia from anoxic Black Sea cold seeps is shown. By using a set of antibodies as markers, the metabolic activity of the syntrophic partners could be identified. The key enzymes methyl coenzyme $M$ reductase of the (reverse) methanogenic pathway and APS reductase (sulfate reduction pathway) were detected on cellular and subcellular level. Intriguingly, active methylotrophic bacteria, known for aerobic methane oxidation, could be detected in the anoxic environment by the expressed methanol dehydrogenase. It was shown that aerobic as well as anaerobic methane oxidation occur simultaneously, several tens of micrometers apart, in a complex, redox-stratified consortium. The results confirm the syntrophic AOM as dominant process in these anoxic environments and suggest, at the same time, the overall importance of aerobic methanotrophy, since it is not limited to oxic zones of the oceans.

Moreover, a terrestrial site of methane emission was focused in this work. The diversity of prokaryotic organisms involved in oxidation of methane was investigated in fluid samples from the Salse di Nirano mud volcano field situated in the Northern Apennines (Italy). Cell counts were at approximately $0.7 \times 10^{6} \mathrm{microbial}$ cells $/ \mathrm{ml}$. By fluorescence in situ hybridization analysis a fraction of the microbial biomass was identified as ANME archaea associated in densely populated flakes, of some tens of $\mu \mathrm{m}$ in diameter, embedded in a hyaline matrix. Diversity analysis based on the $16 \mathrm{~S}$ rDNA genes, revealed a high proportion of archaea, involved in sulfate-dependent as well as suggested iron-manganese-dependent AOM. Aerobic methane-oxidizing Proteobacteria could be highly enriched from mud volcano fluids, indicating the presence of aerobic methanotrophic bacteria, which may contribute to methane oxidation, whenever oxygen is readily available. The results imply that biofilms, dominated by ANME archaea, colonize deeply buried parts of the mud volcano venting system. 


\section{Zusammenfassung}

Die anaerobe Oxidation von Methan (AOM) ist als Schlüsselprozess des marinen Methankonsums bekannt. Nach phylogenetischen und metagenomischen Analysen wird der Prozess von Konsortien aus syntrophen Archaeen und Sulfat reduzierenden Bakterien katalysiert. In dieser Arbeit wird ein umfassenderer Einblick in die methanotrophen Konsortien der Cold Seeps des Schwarzen Meeres gezeigt. Die Stoffwechselaktivität der syntrophen Partner konnte durch die Anwendung von Antikörpern identifiziert werden. Die Schlüsselenzyme Methyl Coenzym M Reduktase der (reversen) Methanogenese und APS Reduktase der Sulfatreduktion wurden auf zellulärer und subzellulärer Ebene detektiert. Interessanterweise konnten auch aktive methylotrophe Bakterien, deren Gruppe für die aerobe Methanoxidation bekannt ist, an dem anaeroben Standort gefunden werden. Es wurde gezeigt, dass sowohl anaerobe als auch aerobe Methanoxidation gleichzeitig in einigen zehn Mikrometern Entfernung in einer komplexen mikrobiellen Gemeinschaft mit Redox-Gradienten stattfinden. Die Ergebnisse bestätigen die syntrophe AOM als dominierenden Prozess in diesem anoxischem Lebensraum und weisen zugleich auf die globale Bedeutung des aeroben Stoffwechselweges hin, der nicht auf die oxischen Lebensräume der Ozeane beschränkt zu sein scheint.

Weiterer Gegenstand dieser Arbeit war ein terrestrischer Standort, an dem Methan austritt. Das Schlammvulkan-Feld, Salse di Nirano im nördlichen Apennin (Italien), wurde auf Prokaryoten untersucht, die an der Oxidation von Methan beteiligt sind. Die Zellzahl lag bei ungefähr 0.7 x $10^{6}$ Zellen/ml. Mit Fluoreszenz in situ Hybridisierung konnte ein Teil der Zellen als ANME-Archaea identifiziert werden, die in dicht besiedelten Flocken (einige zehn Mikrometer im Durchmesser) in einer hyalinen Matrix eingebettet sind. Eine Untersuchung der Diversität mit 16S rDNA-Analyse zeigte einen hohen Anteil an Archaeen, die an Sulfat abhängiger als auch Eisen oder Mangan abhängiger AOM beteiligt sind. Die Anreicherung von methanotrophen Bakterien aus aeroben als auch anaeroben Fluiden zeigt, dass sobald Sauerstoff verfügbar wird diese Bakterien an der Oxidation von Methan beteiligt sind. Die Ergebnisse lassen vermuten, dass in tieferen Regionen des vulkanischen Systems von Archaeen dominierte Biofilme angesiedelt sind. 


\section{References}

Accaino, F., Bratus, A., Conti, S., Fontana, D., and Tinivella, U. (2007) Fluid seepage in mud volcanoes of the northern Apennines: An integrated geophysical and geological study. J. Appl. Geophys. 63: 90-101.

Aharon, P., and Fu, B.S. (2000) Microbial sulfate reduction rates and sulfur and oxygen isotope fractionations at oil and gas seeps in deepwater Gulf of Mexico. Geochim. Cosmochim. Acta 64: 233-246.

Alain, K., Holler, T., Musat, F., Elvert, M., Treude, T., and Krüger, M. (2006) Microbiological investigation of methane- and hydrocarbon-discharging mud volcanoes in the Carpathian Mountains, Romania. Environ. Microbiol. 8: 574-590.

Alain, K., Olagnon, M., Desbruyères, D., Pagé, A., Barbier, G., Juniper, S.K. et al. (2002) Phylogenetic characterization of the bacterial assemblage associated with mucous secretions of the hydrothermal vent polychaete Paralvinella palmiformis. FEMS Microbiol. Ecol. 42: 463-476.

Aloisi, G., Pierre, C., Rouchy, J.M., Foucher, J.P., and Woodside, J. (2000) Methanerelated authigenic carbonates of eastern Mediterranean Sea mud volcanoes and their possible relation to gas hydrate destabilisation. Earth Planet. Sci. Lett. 184: 321338.

Aloisi, G., Bouloubassi, I., Heijs, S.K., Pancost, R.D., Pierre, C., Sinninghe Damsté, J.S. et al. (2002) $\mathrm{CH}_{4}$-consuming microorganisms and the formation of carbonate crusts at cold seeps. Earth Planet. Sci. Lett. 203: 195-203.

Altschul, S.F., Gish, W., Miller, W., Myers, E.W., and Lipman, D.J. (1990) Basic local alignment search tool. J. Mol. Biol. 215: 403-410.

Anthony, C. (1982) The biochemistry of methylotrophs. London, UK, New York, USA: Academic Press. 
Anthony, C. (1986) Bacterial oxidation of methane and methanol. Adv. Microb. Physiol. 27: 113-210.

Anthony, C. (1991) Assimilation of carbon by methylotrophs. Biotechnology 18: 79109.

Armbruster, B.L., Carlemalm, E., Chiovetti, R., Garavito, R.M., Hobot, J.A., Kellenberger, E., and Villiger, W. (1982) Specimen preparation for electron microscopy using low temperature embedding resins. J. Microsc. 126: 77-85.

Ashelford, K.E., Chuzhanova, N.A., Fry, J.C., Jones, A.J., and Weightman, A.J. (2006) New screening software shows that most recent large 16S rRNA gene clone libraries contain chimeras. Appl. Environ. Microbiol. 72: 5734-5741.

Bailey, L.D., and Beauchamp, E.G. (1971) Nitrate Reduction, and redox potentials measured with permanently and temporarily placed platinum electrodes in saturated soils. Can. J. Soil Sci. 51: 51-58.

Bange, H.W., Bartell, U.H., Rapsomanikis, S., and Andreae, M.O. (1994) Methane in the Baltic and North Seas and a Reassessment of the Marine Emissions of Methane. Global Biogeochem. Cy. 8: 465-480.

Barnes, R.O., and Goldberg, E.D. (1976) Methane Production and Consumption in Anoxic Marine-Sediments. Geology 4: 297-300.

Bazylinski, D.A., Frankel, R.B., Heywood, B.R., Mann, S., King, J.W., Donaghay, P.L., and Hanson, A.K. (1995) Controlled Biomineralization of Magnetite $\left(\mathrm{Fe}_{3} \mathrm{O}_{4}\right)$ and Greigite $\left(\mathrm{Fe}_{3} \mathrm{~S}_{4}\right)$ in a Magnetotactic Bacterium. Appl. Environ. Microbiol. 61: 32323239.

Beal, E.J., House, C.H., and Orphan, V.J. (2009) Manganese- and Iron-Dependent Marine Methane Oxidation. Science 325: 184-187.

Beer, D., and Stoodley, P. (2006) Microbial Biofilms. In The Prokaryotes. Dworkin, M., Falkow, S., Rosenberg, E., Schleifer, K.-H., and Stackebrandt, E. (eds). New York, USA: Springer, pp. 904-937. 
Belay, N., Johnson, R., Rajagopal, B.S., Conway de Macario, E., and Daniels, L. (1988) Methanogenic bacteria from human dental plaque. Appl. Environ. Microbiol. 54: 600-603.

Bertics, V.J., and Ziebis, W. (2010) Bioturbation and the role of microniches for sulfate reduction in coastal marine sediments. Environ. Microbiol. 12: 3022-3034.

Birgel, D., and Peckmann, J. (2008) Aerobic methanotrophy at ancient marine methane seeps: A synthesis. Org. Geochem. 39: 1659-1667.

Birgel, D., Thiel, V., Hinrichs, K., Elvert, M., Campbell, K., Reitner, J. et al. (2006) Lipid biomarker patterns of methane-seep microbialites from the Mesozoic convergent margin of California. Org. Geochem. 37: 1289-1302.

Blumenberg, M., Seifert, R., Reitner, J., Pape, T., and Michaelis, W. (2004) Membrane lipid patterns typify distinct anaerobic methanotrophic consortia. Proc. Natl. Acad. Sci. USA 101: 11111-11116.

Blumenberg, M., Seifert, R., Nauhaus, K., Pape, T., and Michaelis, W. (2005) In vitro study of lipid biosynthesis in an anaerobically methane-oxidizing microbial mat. Appl. Environ. Microbiol. 71: 4345-4351.

Blumenberg, M., Krüger, M., Nauhaus, K., Talbot, H.M., Oppermann, B.I., Seifert, R. et al. (2006) Biosynthesis of hopanoids by sulfate-reducing bacteria (genus Desulfovibrio). Environ. Microbiol. 8: 1220-1227.

Boetius, A., Ravenschlag, K., Schubert, C.J., Rickert, D., Widdel, F., Gieseke, A. et al. (2000) A marine microbial consortium apparently mediating anaerobic oxidation of methane. Nature 407: 623-626.

Bonfield, J.K., Smith, K.F., and Staden, R. (1995) A new DNA sequence assembly program. Nucleic Acids Res. 23: 4992-4999.

Bonini, M. (2007) Interrelations of mud volcanism, fluid venting, and thrust-anticline folding: Examples from the external northern Apennines (Emilia-Romagna, Italy). J. Geophys. Res.-Solid Earth 112: B08413. 
Bonini, M. (2008) Elliptical mud volcano caldera as stress indicator in an active compressional setting (Nirano, Pede-Apennine margin, northern Italy). Geology 36: 131-134.

Boschetti, T., Toscani, L., Shouakar-Stash, O., Iacumin, P., Venturelli, G., Mucchino, C., and Frape, S. (2010) Salt Waters of the Northern Apennine Foredeep Basin (Italy): Origin and Evolution. Aquat. Geochem. 17: 1-38.

Bowman, J. (2006) The Methanotrophs - The Families Methylococcaceae and Methylocystaceae. In The Prokaryotes. Dworkin, M., Falkow, S., Rosenberg, E., Schleifer, K.-H., and Stackebrandt, E. (eds). New York, USA: Springer, pp. 266289.

Bradford, M.M. (1976) A rapid and sensitive method for the quantitation of microgram quantities of protein utilizing the principle of protein-dye binding. Anal. Biochem. 72: $248-254$.

Brusa, T., Conca, R., Ferrara, A., Ferrari, A., and Pecchioni, A. (1987) The presence of methanobacteria in human subgingival plaque. J. Clin. Periodontol. 14: 470-471.

Bryant, M.P., Campbell, L.L., Reddy, C.A., and Crabill, M.R. (1977) Growth of Desulfovibrio in Lactate or Ethanol Media Low in Sulfate in Association with $\mathrm{H}_{2}$ Utilizing Methanogenic Bacteria. Appl. Environ. Microbiol. 33: 1162-1169.

Brysch, K., Schneider, C., Fuchs, G., and Widdel, F. (1987) Lithoautotrophic Growth of Sulfate-Reducing Bacteria, and Description of Desulfobacterium autotrophicum gen. nov., sp. nov. Arch. Microbiol. 148: 264-274.

Campbell, K.A., and Bottjer, D.J. (1993) Fossil Cold Seeps. Res. Explor. 9: 326-343.

Campbell, K.A., and Bottjer, D.J. (1995) Brachiopods and Chemosymbiotic Bivalves in Phanerozoic Hydrothermal Vent and Cold Seep Environments. Geology 23: 321324.

Campbell, K.A., Farmer, J.D., and Des Marais, D. (2002) Ancient hydrocarbon seeps from the Mesozoic convergent margin of California: carbonate geochemistry, fluids and palaeoenvironments. Geofluids 2: 63-94. 
Capozzi, R., and Picotti, V. (2002) Fluid migration and origin of a mud volcano in the Northern Apennines (Italy): the role of deeply rooted normal faults. Terra Nova 14: 363-370.

Cavanaugh, C.M. (1993) Methanotroph-invertebrate symbioses in the marine environment: ultrastructural, biochemical and molecular studies. In Microbial growth on $C_{1}$ compounds. Murrell, J.C., and Kelly, D.P. (eds). Andover, UK: Intercept, pp. 315-328.

Cavanaugh, C.M., Wirsen, C.O., and Jannasch, H.W. (1992) Evidence for methylotrophic symbionts in a hydrothermal vent mussel (Bivalvia: Mytilidae) from the Mid-atlantic ridge. Appl. Environ. Microbiol. 58: 3799-3803.

Cavanaugh, C.M., Levering, P.R., Maki, J.S., Mitchell, R., and Lidstrom, M.E. (1987) Symbiosis of Methylotrophic Bacteria and Deep-Sea Mussels. Nature 325: 346348.

Chiang, Y.L., Hsieh, Y.C., Fang, J.Y., Liu, E.H., Huang, Y.C., Chuankhayan, P. et al. (2009) Crystal Structure of Adenylylsulfate Reductase from Desulfovibrio gigas Suggests a Potential Self-Regulation Mechanism Involving the C Terminus of the $\beta$-Subunit. J. Bacteriol. 191: 7597-7608.

Childress, J.J., Fisher, C.R., Brooks, J.M., Kennicutt, M.C., 2nd, Bidigare, R., and Anderson, A.E. (1986) A methanotrophic marine molluscan (Bivalvia, Mytilidae) symbiosis: mussels fueled by gas. Science 233: 1306-1308.

Cole, J.R., Chai, B., Marsh, T.L., Farris, R.J., Wang, Q., Kulam, S.A. et al. (2003) The Ribosomal Database Project (RDP-II): previewing a new autoaligner that allows regular updates and the new prokaryotic taxonomy. Nucleic Acids Res. 31: 442-443.

Collins, T.J. (2007) ImageJ for microscopy. Biotechniques 43: 25-30.

Connell, W.E., and Patrick, W.H. (1968) Sulfate Reduction in Soil - Effects of Redox Potential and pH. Science 159: 86-87.

Conrad, R. (2009) The global methane cycle: recent advances in understanding the microbial processes involved. Environ. Microbiol. Rep. 1: 285-292. 
Corpe, W.A. (1985) A method for detecting methylotrophic bacteria on solid surfaces. J. Microbiol. Methods 3: 215-221.

Costerton, J.W., Lewandowski, Z., Debeer, D., Caldwell, D., Korber, D., and James, G. (1994) Biofilms, the Customized Microniche. J. Bacteriol. 176: 2137-2142.

D'Hondt, S., Rutherford, S., and Spivack, A.J. (2002) Metabolic activity of subsurface life in deep-sea sediments. Science 295: 2067-2070.

Daims, H., Bruhl, A., Amann, R., Schleifer, K.H., and Wagner, M. (1999) The domainspecific probe EUB338 is insufficient for the detection of all Bacteria: Development and evaluation of a more comprehensive probe set. Syst. Appl. Microbiol. 22: 434-444.

Davey, M.E., and O'Toole G, A. (2000) Microbial biofilms: from ecology to molecular genetics. Microbiol. Mol. Biol. Rev. 64: 847-867.

DeChaine, E.G., and Cavanaugh, C.M. (2006) Symbioses of methanotrophs and deepsea mussels (Mytilidae: Bathymodiolinae). Prog. Mol. Subcell. Biol. 41: 227-249.

Dedysh, S.N., Panikov, N.S., and Tiedje, J.M. (1998) Acidophilic methanotrophic communities from Sphagnum peat bogs. Appl. Environ. Microbiol. 64: 922-929.

della Vedova, B., Bellani, S., Pellis, G., and Squarci, P. (2001) Deep temperatures and subsurface heatflow distribution. In Anatomy of an Orogen: the Apennines and adjacent Mediterranean Basins. Vai, G.B., and Martini, I.P. (eds). Dordrecht, the Netherlands: Kluwer Academic Publ.

Delong, E.F. (1992) Archaea in Coastal Marine Environments. Proc. Natl. Acad. Sci. USA 89: 5685-5689.

Deplancke, B., Hristova, K.R., Oakley, H.A., McCracken, V.J., Aminov, R., Mackie, R.I., and Gaskins, H.R. (2000) Molecular ecological analysis of the succession and diversity of sulfate-reducing bacteria in the mouse gastrointestinal tract. Appl. Environ. Microbiol. 66: 2166-2174. 
Dickens, G.R. (2003) Rethinking the global carbon cycle with a large, dynamic and microbially mediated gas hydrate capacitor. Earth Planet. Sci. Lett. 213: 169-183.

Diercks, A.R., and Asper, V.L. (1997) In situ settling speeds of marine snow aggregates below the mixed layer: Black Sea and Gulf of Mexico. Deep Sea Res. (I Oceanogr. Res. Pap.) 44: 385-398.

Dimitrov, L.I. (2002) Mud volcanoes - the most important pathway for degassing deeply buried sediments. Earth-Sci. Rev. 59: 49-76.

Distel, D.L., and Cavanaugh, C.M. (1994) Independent phylogenetic origins of methanotrophic and chemoautotrophic bacterial endosymbioses in marine bivalves. J. Bacteriol. 176: 1932-1938.

Dubilier, N., Windoffer, R., and Giere, O. (1998) Ultrastructure and stable carbon isotope composition of the hydrothermal vent mussels Bathymodiolus brevior and B. sp. affinis brevior from the North Fiji Basin, western Pacific. Mar. Ecol. Prog. Ser. 165: 187-193.

Duchi, V., Venturelli, G., Boccasavia, I., Bonicolini, F., Ferrari, C., and Poli, D. (2005) Studio geochimico dei fluidi dell'Appennino Tosco-Emiliano-Romagnolo. 124: 475-491.

Dunfield, P.F. (2007) The soil methane sink. In Greenhouse gas sinks. Reay, D., Hewitt, N., Smith, K.A., and Grace, J. (eds). Wallingford, UK: CABI, pp. 152-170.

Duperron, S., De Beer, D., Zbinden, M., Boetius, A., Schipani, V., Kahil, N., and Gaill, F. (2009) Molecular characterization of bacteria associated with the trophosome and the tube of Lamellibrachia sp., a siboglinid annelid from cold seeps in the eastern Mediterranean. FEMS Microbiol. Ecol. 69: 395-409.

Durisch-Kaiser, E., Klauser, L., Wehrli, B., and Schubert, C. (2005) Evidence of intense archaeal and bacterial methanotrophic activity in the Black Sea water column. Appl. Environ. Microbiol. 71: 8099-8106.

Ehhalt, D.H. (1978) $\mathrm{CH}_{4}$ Concentration over Ocean and Its Possible Variation with Latitude. Tellus 30: 169-176. 
Ehhalt, D.H. (1979) Atmospheric Circulation of Methane. Naturwissenschaften 66: $307-$ 311.

Ehlers, C., Veit, K., Gottschalk, G., and Schmitz, R.A. (2002) Functional organization of a single nif cluster in the mesophilic archaeon Methanosarcina mazei strain Gö1. Archaea 1: 143-150.

Eller, G., Kanel, L., and Krüger, M. (2005) Cooccurrence of aerobic and anaerobic methane oxidation in the water column of Lake Plusssee. Appl. Environ. Microbiol. 71: $8925-8928$.

Elvert, M., Suess, E., Greinert, J., and Whiticar, M.J. (2000) Archaea mediating anaerobic methane oxidation in deep-sea sediments at cold seeps of the eastern Aleutian subduction zone. Org. Geochem. 31: 1175-1187.

Ettwig, K.F., van Alen, T., van de Pas-Schoonen, K.T., Jetten, M.S.M., and Strous, M. (2009) Enrichment and Molecular Detection of Denitrifying Methanotrophic Bacteria of the NC10 Phylum. Appl. Environ. Microbiol. 75: 3656-3662.

Ettwig, K.F., Shima, S., van de Pas-Schoonen, K.T., Kahnt, J., Medema, M.H., op den Camp, H.J.M. et al. (2008) Denitrifying bacteria anaerobically oxidize methane in the absence of Archaea. Environ. Microbiol. 10: 3164-3173.

Ettwig, K.F., Butler, M.K., Le Paslier, D., Pelletier, E., Mangenot, S., Kuypers, M.M.M. et al. (2010) Nitrite-driven anaerobic methane oxidation by oxygenic bacteria. Nature 464: 543-548.

Faivre, D., and Schüler, D. (2008) Magnetotactic bacteria and magnetosomes. Chem. Rev. 108: 4875-4898.

Fassel, T.A., Buchholz, L.A., Collins, M.L., and Remsen, C.C. (1992) Localization of methanol dehydrogenase in two strains of methylotrophic bacteria detected by immunogold labeling. Appl. Environ. Microbiol. 58: 2302-2307.

Ferry, J.G., Smith, P.H., and Wolfe, R.S. (1974) Methanospirillum, a New Genus of Methanogenic Bacteria, and Characterization of Methanospirillum hungatii sp. nov. Int. J. Syst. Bacteriol. 24: 465-469. 
Fetzer, S., and Conrad, R. (1993) Effect of Redox Potential on Methanogenesis by Methanosarcina barkeri. Arch. Microbiol. 160: 108-113.

Fischer, W.W., Summons, R.E., and Pearson, A. (2005) Targeted genomic detection of biosynthetic pathways: anaerobic production of hopanoid biomarkers by a common sedimentary microbe. Geobiology 3: 33-40.

Fisher, C.R. (1990) Chemoautotrophic and methanotrophic symbioses in marine Invertebrates. Rev. Aquat. Sci. 2: 399-436.

Fisher, C.R., Brooks, J.M., Vodenichar, J.S., Zande, J.M., Childress, J.J., and Burke, R.A. (1993) The Cooccurrence of Methanotrophic and Chemoautotrophic SulfurOxidizing Bacterial Symbionts in a Deep-Sea Mussel. Mar. Ecol. 14: 277-289.

Forster, P., Ramaswamy, V., Artaxo, P., Berntsen, T., Betts, R., Fahey, D.W. et al. (2007) Changes in Atmospheric Constituents and in Radiative Forcing. In Climate Change 2007: The Physical Science Basis. Contribution of Working Group I to the Fourth Assessment Report of the Intergovernmental Panel on Climate Change. Solomon, S., Qin, D., Manning, M., Chen, Z., Marquis, M., Averyt, K.B. et al. (eds). Cambridge, UK, New York, USA: Cambridge University Press.

Frankel, R.B., and Bazylinski, D.A. (2004) Magnetosome Mysteries. ASM News 70.4: 176-183.

Fritz, G., Roth, A., Schiffer, A., Büchert, T., Bourenkov, G., Bartunik, H.D. et al. (2002) Structure of adenylylsulfate reductase from the hyperthermophilic Archaeoglobus fulgidus at 1.6-A resolution. Proc. Natl. Acad. Sci. USA 99: 18361841.

Fung, I., John, J., Lerner, J., Matthews, E., Prather, M., Steele, L.P., and Fraser, P.J. (1991) 3-Dimensional Model Synthesis of the Global Methane Cycle. J. Geophys. Res.-Atmos. 96: 13033-13065.

Gaillard, C., Rio, M., Rolin, Y., and Roux, M. (1992) Fossil chemosynthetic communities related to vents or seeps in sedimentary basins; the pseudobioherms of southeastern France compared to other world examples. Palaios 7: 451-465. 
Galloway, J.N., Townsend, A.R., Erisman, J.W., Bekunda, M., Cai, Z.C., Freney, J.R. et al. (2008) Transformation of the nitrogen cycle: Recent trends, questions, and potential solutions. Science 320: 889-892.

Galloway, J.N., Dentener, F.J., Capone, D.G., Boyer, E.W., Howarth, R.W., Seitzinger, S.P. et al. (2004) Nitrogen cycles: past, present, and future. Biogeochemistry 70: 153-226.

Garcia, J.L., Patel, B.K.C., and Ollivier, B. (2000) Taxonomic phylogenetic and ecological diversity of methanogenic Archaea. Anaerobe 6: 205-226.

Gorby, Y.A., Yanina, S., McLean, J.S., Rosso, K.M., Moyles, D., Dohnalkova, A. et al. (2006) Electrically conductive bacterial nanowires produced by Shewanella oneidensis strain MR-1 and other microorganisms. Proc. Natl. Acad. Sci. USA 103: 11358-11363.

Green, P. (2006) Methylobacterium. In The Prokaryotes. Dworkin, M., Falkow, S., Rosenberg, E., Schleifer, K.-H., and Stackebrandt, E. (eds). New York, USA: Springer, pp. 257-265.

Guerrero, R., Piqueras, M., and Berlanga, M. (2002) Microbial mats and the search for minimal ecosystems. Int. Microbiol. 5: 177-188.

Hallam, S.J., Girguis, P.R., Preston, C.M., Richardson, P.M., and DeLong, E.F. (2003) Identification of methyl coenzyme $\mathrm{M}$ reductase $\mathrm{A}$ (mcrA) genes associated with methane-oxidizing archaea. Appl. Environ. Microbiol. 69: 5483-5491.

Hallam, S.J., Putnam, N., Preston, C.M., Detter, J.C., Rokhsar, D., Richardson, P.M., and DeLong, E.F. (2004) Reverse methanogenesis: Testing the hypothesis with environmental genomics. Science 305: 1457-1462.

Hansen, J., Fung, I., Lacis, A., Rind, D., Lebedeff, S., Ruedy, R. et al. (1988) Global Climate Changes as Forecast by Goddard Institute for Space Studies 3-Dimensional Model. J. Geophys. Res.-Atmos. 93: 9341-9364.

Hanson, R.S. (1980) Ecology and Diversity of Methylotrophic Organisms. Adv. Appl. Microbiol. 26: 3-39. 
Hanson, R.S., and Hanson, T.E. (1996) Methanotrophic bacteria. Microbiol. Rev. 60: 439-471.

Hanson, R.S., Tsien, H.C., Tsuji, K., Brusseau, G.A., and Wackett, L.P. (1990) Biodegradation of low-molecular-weight halogenated hydrocarbons by methanotrophic bacteria. FEMS Microbiol. Rev. 7: 273-278.

Harabaglia, P., Mongelli, F., and Zito, G. (1997) Geothermics of the Apenninic subduction. Ann. Geofis. 40: 1261-1274.

Härtner, T., Straub, K.L., and Kannenberg, E. (2005) Occurrence of hopanoid lipids in anaerobic Geobacter species. FEMS Microbiol. Lett. 243: 59-64.

Hayes, J.M. (1994) Global methanotrophy at the Archaean-Proterozoic transition. In Early life on earth. Nobel Symposium no. 84. Bengtson, S. (ed). New York, USA: Columbia University Press, pp. 220-236.

Heijs, S.K., Haese, R.R., Wielen, P.W.J.J., Forney, L.J., and Elsas, J.D. (2007) Use of 16S rRNA Gene Based Clone Libraries to Assess Microbial Communities Potentially Involved in Anaerobic Methane Oxidation in a Mediterranean Cold Seep. Microb. Ecol. 53: 384-398.

Heinzelmann, S. (2010) Screening von Enzymproteinen und enzymatischer Aktivität in Mikrobengemeinschaften aus Methan-Seep-Standorten. Diplomarbeit. Göttingen, Germany.

Heller, C., Hoppert, M., and Reitner, J. (2008) Immunological localization of coenzyme M reductase in anaerobic methane-oxidizing archaea. Geomicrobiol. J. 25: 149156.

Heller, C., Blumenberg, M., Kokoschka, S., Wrede, C., Hoppert, M., Taviani, M., and Reiner, J. (2010) Geomicrobiology of fluid venting structures at the Salse di Nirano mud volcano area in the Northern Apennines (Italy). Lect. Notes Earth Sci. 131: 189-200. 
Henikoff, S., Henikoff, J.G., Alford, W.J., and Pietrokovski, S. (1995) Automated construction and graphical presentation of protein blocks from unaligned sequences. Gene 163: GC17-26.

Henne, A., Daniel, R., Schmitz, R.A., and Gottschalk, G. (1999) Construction of environmental DNA libraries in Escherichia coli and screening for the presence of genes conferring utilization of 4-hydroxybutyrate. Appl. Environ. Microbiol. 65: 3901-3907.

Heyer, J., Malashenko, Y., Berger, U., and Budkova, E. (1984) Verbreitung methanotropher Bakterien. Z. Allg. Mikrobiol. 24: 725-744.

Hinrichs, K.-U. (2001) A molecular recorder of methane hydrate destabilization. Geochem. Geophys. Geosyst. 2: 1029-1033.

Hinrichs, K.-U. (2002) Microbial fixation of methane carbon at $2.7 \mathrm{Ga}$ : Was an anaerobic mechanism possible? Geochem. Geophys. Geosyst. 3: 1042-1052.

Hinrichs, K., and Boetius, A. (2002) The anaerobic oxidation of methane: new insights in microbial ecology and biogeochemistry. In Ocean Margin Systems. Wefer, G., Billett, D., Hebbeln, D., Jørgensen, B.B., Schlüter, M., and van Weering, T. (eds). Heidelberg, Germany: Springer-Verlag, pp. 457-477.

Hinrichs, K.U., Hayes, J.M., Sylva, S.P., Brewer, P.G., and DeLong, E.F. (1999) Methane-consuming archaebacteria in marine sediments. Nature 398: 802-805.

Hoehler, T.M., Alperin, M.J., Albert, D.B., and Martens, C.S. (1994) Field and Laboratory Studies of Methane Oxidation in an Anoxic Marine Sediment Evidence for a Methanogen-Sulfate Reducer Consortium. Global Biogeochem. Cy. 8: $451-463$.

Holmes, A.J., Owens, N.J.P., and Murrell, J.C. (1995) Detection of novel marine methanotrophs using phylogenetic and functional gene probes after methane enrichment. Microbiology 141: 1947-1955.

Hoppert, M. (2003) Microscopic techniques in biotechnology. Weinheim, Germany: Wiley-VCH. 
Hoppert, M., and Holzenburg, A. (1998) Electron microscopy in microbiology. Oxford, UK: Bios-Springer in association with the Royal Microscopical Society.

Hu, S., Zeng, R.J., Burow, L.C., Lant, P., Keller, J., and Yuan, Z. (2009) Enrichment of denitrifying anaerobic methane oxidizing microorganisms. Environ. Microbiol. Rep. 1: 377-384.

Huber, T., Faulkner, G., and Hugenholtz, P. (2004) Bellerophon: a program to detect chimeric sequences in multiple sequence alignments. Bioinformatics 20: 2317 2319.

Inoue, H., Nojima, H., and Okayama, H. (1990) High efficiency transformation of Escherichia coli with plasmids. Gene 96: 23-28.

Islam, T., Jensen, S., Reigstad, L.J., Larsen, O., and Birkeland, N.K. (2008) Methane oxidation at 55 degrees $\mathrm{C}$ and $\mathrm{pH} 2$ by a thermoacidophilic bacterium belonging to the Verrucomicrobia phylum. Proc. Natl. Acad. Sci. USA 105: 300-304.

Ivanov, M.V., Polikarpov, G.G., Lein, A.Y., Galtchenko, V.F., Egorov, V.N., Gulin, S.B. et al. (1991) Biogeochemistry of the carbon cycle in the region of methane gas seeps of the Black Sea. Dokl. Akad. Nauk SSSR 320: 1235-1240.

Iversen, N., and Blackburn, T.H. (1981) Seasonal Rates of Methane Oxidation in Anoxic Marine-Sediments. Appl. Environ. Microbiol. 41: 1295-1300.

Jansen, K., Fuchs, G., and Thauer, R.K. (1985) Autotrophic $\mathrm{CO}_{2}$ Fixation by Desulfovibrio baarsii - Demonstration of Enzyme-Activities Characteristic for the Acetyl-CoA Pathway. FEMS Microbiol. Lett. 28: 311-315.

Jansen, K., Thauer, R.K., Widdel, F., and Fuchs, G. (1984) Carbon Assimilation Pathways in Sulfate Reducing Bacteria - Formate, Carbon-Dioxide, CarbonMonoxide, and Acetate Assimilation by Desulfovibrio baarsii. Arch. Microbiol. 138: $257-262$.

Joergensen, B.B., and Revsbech, N.P. (1989) Oxygen uptake, bacterial distribution, and carbon-nitrogen-sulfur cycling in sediments from the Baltic Sea-North Sea transition. Ophelia 31: 29-49. 
Johnston, H.S. (1984) Human Effects on the Global Atmosphere. Annu. Rev. Phys. Chem. 35: 481-505.

Joye, S.B., and Paerl, H.W. (1994) Nitrogen Cycling in Microbial Mats - Rates and Patterns of Denitrification and Nitrogen-Fixation. Mar. Biol. 119: 285-295.

Kallmeyer, J., Smith, D.C., Spivack, A.J., and D'Hondt, S. (2008) New cell extraction procedure applied to deep subsurface sediments. Limnol. Oceanogr.-Meth. 6: 236245.

Kauffman, E.G., Arthur, M.A., Howe, B., and Scholle, P.A. (1996) Widespread venting of methane-rich fluids in Late Cretaceous (Campanian) submarine springs (Tepee Buttes), Western Interior seaway, U.S.A. Geology 24: 799-802.

Kelly, S.R.A., Ditchfield, P.W., Doubleday, P.A., and Marshall, J.D. (1995) An Upper Jurassic Methane-Seep Limestone from the Fossil Bluff Group Fore-Arc Basin of Alexander Island, Antarctica. J. Sediment. Res. A Sediment. Petrol. Process 65: 274-282.

Kelly, S.R.A., Blanc, E., Price, S.P., and Whitham, A.G. (2000) Early Cretaceous giant bivalves from seep-related limestone mounds, Wollaston Forland, Northeast Greenland. Spec. Publ.-Geol. Soc. Lond. 177: 227-246.

Knab, N.J., Cragg, B.A., Hornibrook, E.R.C., Holmkvist, L., Pancost, R.D., Borowski, C. et al. (2009) Regulation of anaerobic methane oxidation in sediments of the Black Sea. Biogeosciences 6: 1505-1518.

Knittel, K., and Boetius, A. (2009) Anaerobic Oxidation of Methane: Progress with an Unknown Process. Annu. Rev. Microbiol. 63: 311-334.

Knittel, K., Lösekann, T., Boetius, A., Kort, R., and Amann, R. (2005) Diversity and distribution of methanotrophic archaea at cold seeps. Appl. Environ. Microbiol. 71: 467-479.

Komeili, A. (2007) Molecular mechanisms of magnetosome formation. Annu. Rev. Biochem. 76: 351-366. 
Kremer, D.R., Veenhuis, M., Fauque, G., Peck, H.D., Legall, J., Lampreia, J. et al. (1988) Immunocytochemical Localization of Aps Reductase and Bisulfite Reductase in 3 Desulfovibrio Species. Arch. Microbiol. 150: 296-301.

Krüger, M., Treude, T., Wolters, H., Nauhaus, K., and Boetius, A. (2005) Microbial methane turnover in different marine habitats. Palaeogeogr. Palaeoclimatol. Palaeoecol. 227: 6-17.

Krüger, M., Wolters, H., Gehre, M., Joye, S.B., and Richnow, H.-H. (2008a) Tracing the slow growth of anaerobic methane-oxidizing communities by ${ }^{15} \mathrm{~N}$-labelling techniques. FEMS Microbiol. Ecol. 63: 401-411.

Krüger, M., Blumenberg, M., Kasten, S., Wieland, A., Känel, L., Klock, J.-H. et al. (2008b) A novel, multi-layered methanotrophic microbial mat system growing on the sediment of the Black Sea. Environ. Microbiol. 10: 1934-1947.

Krüger, M., Meyerdierks, A., Glockner, F.O., Amann, R., Widdel, F., Kube, M. et al. (2003) A conspicuous nickel protein in microbial mats that oxidize methane anaerobically. Nature 426: 878-881.

Krukenberg, V. (2009) Entwicklung eines Markersystems für MethanolDehydrogenasen aus mikrobiellen Lebensgemeinschaften. Bachelorarbeit. Göttingen, Germany.

Laanbroek, H.J., Abee, T., and Voogd, I.L. (1982) Alcohol Conversions by Desulfobulbus propionicus Lindhorst in the Presence and Absence of Sulfate and Hydrogen. Arch. Microbiol. 133: 178-184.

Lacis, A., Hansen, J., Lee, P., Mitchell, T., and Lebedeff, S. (1981) Greenhouse-Effect of Trace Gases, 1970-1980. Geophys. Res. Lett. 8: 1035-1038.

Laemmli, U.K. (1970) Cleavage of structural proteins during the assembly of the head of bacteriophage T4. Nature 227: 680-685.

Lambert, G., and Schmidt, S. (1993) Reevaluation of the Oceanic Flux of Methane Uncertainties and Long-Term Variations. Chemosphere 26: 579-589. 
Larock, P.A., Hyun, J.H., and Bennison, B.W. (1994) Bacterioplankton Growth and Production at the Louisiana Hydrocarbon Seeps. Geo-Mar. Lett. 14: 104-109.

Lawrence, J.R., Hendry, M.J., Wassenaar, L.I., Germida, J.J., Wolfaardt, G.M., Fortin, N., and Greer, C.W. (2000) Distribution and Biogeochemical Importance of Bacterial Populations in a Thick Clay-Rich Aquitard System. Microb. Ecol. 40: 273-291.

Lee, S.Y., and Holder, G.D. (2001) Methane hydrates potential as a future energy source. Fuel Process. Technol. 71: 181-186.

Lein, A.Y., Ivanov, M.V., Pimenov, N.V., and Gulin, M.B. (2002) Geochemical peculiarities of the carbonate constructions formed during microbial oxidation of methane under anaerobic conditions. Microbiology 71: 78-90.

Lelieveld, J., Crutzen, P.J., and Dentener, F.J. (1998) Changing concentration, lifetime and climate forcing of atmospheric methane. Tellus B 50: 128-150.

Lidstrom, M. (2006) Aerobic Methylotrophic Prokaryotes. In The Prokaryotes. Dworkin, M., Falkow, S., Rosenberg, E., Schleifer, K.-H., and Stackebrandt, E. (eds). New York, USA: Springer, pp. 618-634.

Liu, Y., and Whitman, W.B. (2008) Metabolic, Phylogenetic, and Ecological Diversity of the Methanogenic Archaea. Ann. N. Y. Acad. Sci. 1125: 171-189.

Llobet-Brossa, E., Rossello-Mora, R., and Amann, R. (1998) Microbial Community Composition of Wadden Sea Sediments as Revealed by Fluorescence In Situ Hybridization. Appl. Environ. Microbiol. 64: 2691-2696.

Lloyd, K.G., Lapham, L., and Teske, A. (2006) Anaerobic methane-oxidizing community of ANME-1b archaea in hypersaline Gulf of Mexico sediments. Appl. Environ. Microbiol. 72: 7218-7230.

Lösekann, T., Knittel, K., Nadalig, T., Fuchs, B., Niemann, H., Boetius, A., and Amann, R. (2007) Diversity and abundance of aerobic and anaerobic methane oxidizers at the Haakon Mosby mud volcano, Barents Sea. Appl. Environ. Microbiol. 73: 33483362 . 
Ludwig, W., Strunk, O., Westram, R., Richter, L., Meier, H., Yadhukumar et al. (2004) ARB: a software environment for sequence data. Nucleic Acids Res. 32: 1363-1371.

Luth, C., Luth, U., Gebruk, A.V., and Thiel, H. (1999) Methane gas seeps along the oxic/anoxic gradient in the Black Sea: Manifestations, biogenic sediment compounds and preliminary results on benthic ecology. Mar. Ecol. 20: 221-249.

Luth, U., and Luth, C. (1997) A benthic approach to determine long-term changes of the anoxic interface in the water column of Black Sea. In The responses of marine organisms to their environments. Proceedings of the 30th EMBS. Hawkins, L.E., and Hutchinson, S. (eds). Southampton, UK: University of Southampton, pp. 231242.

Luth, U., and Luth, C. (1998) Benthic meiofauna and macrofauna of a methane seep area south-west of the Crimean peninsula, Black Sea. In Methane Gas Seep Explorations in the Black Sea (MEGASEEBS), Project Report. Berichte aus dem Zentrum für Meeres- und Klimaforschung. Luth, U., Luth, C., and Thiel, H. (eds). Hamburg, Germany: Universität Hamburg, pp. 113-126.

Madigan, M.T., and Martinko, J.M. (2006) Brock Mikrobiologie. 11., überarbeitete Auflage. Munich, Germany: Pearson Education Deutschland GmbH.

Maestrojuan, G.M., Boone, J.E., Mah, R.A., Menaia, J.A.G.F., Sachs, M.S., and Boone, D.R. (1992) Taxonomy and Halotolerance of Mesophilic Methanosarcina Strains, Assignment of Strains to Species, and Synonymy of Methanosarcina mazei and Methanosarcina frisia. Int. J. Syst. Bacteriol. 42: 561-567.

Mahl, H., and Möldner, K. (1973) Herstellung von Formvar-Objektträgern nach dem Eintauchverfahren. Stuttgart, Germany: Wissenschaftliche Verlagsgesellschaft.

Maidak, B.L., Cole, J.R., Lilburn, T.G., Parker, C.T., Saxman, P.R., Farris, R.J. et al. (2001) The RDP-II (Ribosomal Database Project). Nucleic Acids Res. 29: 173-174.

Manz, W., Eisenbrecher, M., Neu, T.R., and Szewzyk, U. (1998) Abundance and spatial organization of Gram-negative sulfate-reducing bacteria in activated sludge 
investigated by in situ probing with specific 16S rRNA targeted oligonucleotides. FEMS Microbiol. Ecol. 25: 43-61.

Martens, C.S., and Berner, R.A. (1974) Methane Production in Interstitial Waters of Sulfate-Depleted Marine Sediments. Science 185: 1167-1169.

Martinelli, G., and Rabbi, E. (1998) The Nirano mud volcanoes. In Abstracts and Guide Book, Vth Int. Conf. on Gas in Marine Sediments. Curzi, P.V., and Judd, A.G. (eds). Bologna, Italy: Grafiche A \& B.

Martinelli, G., and Judd, A. (2004) Mud volcanoes of Italy. Geol. J. 39: 49-61.

Martinez, R.J., Mills, H.J., Story, S., and Sobecky, P.A. (2006) Prokaryotic diversity and metabolically active microbial populations in sediments from an active mud volcano in the Gulf of Mexico. Environ. Microbiol. 8: 1783-1796.

Mayr, S., Latkoczy, C., Krüger, M., Gunther, D., Shima, S., Thauer, R.K. et al. (2008) Structure of an F430 variant from archaea associated with anaerobic oxidation of methane. J. Am. Chem. Soc. 130: 10758-10767.

McDonald, I.R., Bodrossy, L., Chen, Y., and Murrell, J.C. (2008) Molecular Ecology Techniques for the Study of Aerobic Methanotrophs. Appl. Environ. Microbiol. 74: 1305-1315.

Meyer, B., and Kuever, J. (2007) Phylogeny of the alpha and beta subunits of the dissimilatory adenosine-5'-phosphosulfate (APS) reductase from sulfate-reducing prokaryotes - origin and evolution of the dissimilatory sulfate-reduction pathway. Microbiology 153: 2026-2044.

Meyer, B., and Kuever, J. (2008) Homology modeling of dissimilatory APS reductases (AprBA) of sulfur-oxidizing and sulfate-reducing prokaryotes. PLoS One 3: e1514.

Meyerdierks, A., Kube, M., Kostadinov, I., Teeling, H., Glockner, F.O., Reinhardt, R., and Amann, R. (2010) Metagenome and mRNA expression analyses of anaerobic methanotrophic archaea of the ANME-1 group. Environ. Microbiol. 12: 422-439. 
Meyerdierks, A., Kube, M., Lombardot, T., Knittel, K., Bauer, M., Glockner, F.O. et al. (2005) Insights into the genomes of archaea mediating the anaerobic oxidation of methane. Environ. Microbiol. 7: 1937-1951.

Michaelis, W., Seifert, R., Nauhaus, K., Treude, T., Thiel, V., Blumenberg, M. et al. (2002) Microbial reefs in the Black Sea fueled by anaerobic oxidation of methane. Science 297: 1013-1015.

Mills, H.J., Martinez, R.J., Story, S., and Sobecky, P.A. (2005) Characterization of microbial community structure in Gulf of Mexico gas hydrates: Comparative analysis of DNA- and RNA-derived clone libraries. Appl. Environ. Microbiol. 71: 3235-3247.

Mohn, W.W., Linkfield, T.G., Pankratz, H.S., and Tiedje, J.M. (1990) Involvement of a Collar Structure in Polar Growth and Cell-Division of Strain Dcb-1. Appl. Environ. Microbiol. 56: 1206-1211.

Moran, J.J., Beal, E.J., Vrentas, J.M., Orphan, V.J., Freeman, K.H., and House, C.H. (2008) Methyl sulfides as intermediates in the anaerobic oxidation of methane. Environ. Microbiol. 10: 162-173.

Morris, A.W., and Riley, J.P. (1963) The determination of nitrate in sea water. Anal. Chim. Acta 29: 272-279.

Morris, S.A., Radajewski, S., Willison, T.W., and Murrell, J.C. (2002) Identification of the Functionally Active Methanotroph Population in a Peat Soil Microcosm by Stable-Isotope Probing. Appl. Environ. Microbiol. 68: 1446-1453.

Nauhaus, K., Boetius, A., Krüger, M., and Widdel, F. (2002) In vitro demonstration of anaerobic oxidation of methane coupled to sulphate reduction in sediment from a marine gas hydrate area. Environ. Microbiol. 4: 296-305.

Nauhaus, K., Treude, T., Boetius, A., and Krüger, M. (2005) Environmental regulation of the anaerobic oxidation of methane: a comparison of ANME-I and ANME-II communities. Environ. Microbiol. 7: 98-106. 
Nauhaus, K., Albrecht, M., Elvert, M., Boetius, A., and Widdel, F. (2007) In vitro cell growth of marine archaeal-bacterial consortia during anaerobic oxidation of methane with sulfate. Environ. Microbiol. 9: 187-196.

Niemann, H., and Elvert, M. (2008) Diagnostic lipid biomarker and stable carbon isotope signatures of microbial communities mediating the anaerobic oxidation of methane with sulphate. Org. Geochem. 39: 1668-1677.

Niemann, H., Lösekann, T., de Beer, D., Elvert, M., Nadalig, T., Knittel, K. et al. (2006) Novel microbial communities of the Haakon Mosby mud volcano and their role as a methane sink. Nature 443: 854-858.

Ohfuji, H., Boyle, A.P., Prior, D.J., and Rickard, D. (2005) Structure of framboidal pyrite: An electron backscatter diffraction study. Am. Mineral. 90: 1693-1704.

Op den Camp, H.J.M., Islam, T., Stott, M.B., Harhangi, H.R., Hynes, A., Schouten, S. et al. (2009) Environmental, genomic and taxonomic perspectives on methanotrophic Verrucomicrobia. Environ. Microbiol. Rep. 1: 293-306.

Oremland, R.S., and Desmarais, D.J. (1983) Distribution, Abundance and Carbon Isotopic Composition of Gaseous Hydrocarbons in Big-Soda Lake, Nevada - an Alkaline, Meromictic Lake. Geochim. Cosmochim. Acta 47: 2107-2114.

Orphan, V.J., House, C.H., Hinrichs, K.U., McKeegan, K.D., and DeLong, E.F. (2001a) Methane-consuming archaea revealed by directly coupled isotopic and phylogenetic analysis. Science 293: 484-487.

Orphan, V.J., House, C.H., Hinrichs, K.U., McKeegan, K.D., and DeLong, E.F. (2002) Multiple archaeal groups mediate methane oxidation in anoxic cold seep sediments. Proc. Natl. Acad. Sci. USA 99: 7663-7668.

Orphan, V.J., Hinrichs, K.U., Ussler, W., 3rd, Paull, C.K., Taylor, L.T., Sylva, S.P. et al. (2001b) Comparative analysis of methane-oxidizing archaea and sulfatereducing bacteria in anoxic marine sediments. Appl. Environ. Microbiol. 67: 19221934 
Paerl, H.W., and Prufert, L.E. (1987) Oxygen-poor microzones as potential sites of microbial $\mathrm{N}_{2}$ fixation in nitrogen-depleted aerobic marine waters. Appl. Environ. Microbiol. 53: 1078-1087.

Pancost, R.D., Sinninghe Damsté, J.S., de Lint, S., van der Maarel, M.J.E.C., Gottschal, J.C., and Party, M.S.S. (2000) Biomarker evidence for widespread anaerobic methane oxidation in Mediterranean sediments by a consortium of methanogenic archaea and bacteria. Appl. Environ. Microbiol. 66: 1126-1132.

Pape, T., Blumenberg, M., Seifert, R., Bohrmann, G., and Michaelis, W. (2008) Marine Methane Biogeochemistry of the Black Sea: A Review. In Links Between Geological Processes, Microbial Activities \& Evolution of Life. Dilek, Y., Furnes, H., and Muehlenbachs, K. (eds). Dordrecht, the Netherlands: Springer, pp. 281-311.

Patel, G.B., Roth, L.A., van den Berg, L., and Clark, D.S. (1976) Characterization of a strain of Methanospirillum hungatei. Can. J. Microbiol. 22: 1404-1410.

Peckmann, J., and Thiel, V. (2004) Carbon cycling at ancient methane-seeps. Chem. Geol. 205: 443-467.

Peckmann, J., Walliser, O.H., Riegel, W., and Reitner, J. (1999a) Signatures of hydrocarbon venting Middle Devonian carbonate mound (Hollard Mound) at the Hamar Laghdad (Antiatlas, Morocco). Facies 40: 281-296.

Peckmann, J., Gischler, E., Oschmann, W., and Reitner, J. (2001a) An early carboniferous seep community and hydrocarbon-derived carbonates from the Harz Mountains, Germany. Geology 29: 271-274.

Peckmann, J., Thiel, V., Michaelis, W., Clari, P., Gaillard, C., Martire, L., and Reitner, J. (1999b) Cold seep deposits of Beauvoisin (Oxfordian; southeastern France) and Marmorito (Miocene; northern Italy): microbially induced authigenic carbonates. Int. J. Earth Sci. 88: 60-75.

Peckmann, J., Reimer, A., Luth, U., Luth, C., Hansen, B.T., Heinicke, C. et al. (2001b) Methane-derived carbonates and authigenic pyrite from the northwestern Black Sea. Mar. Geol. 177: 129-150. 
Pernthaler, A., Dekas, A.E., Brown, C.T., Goffredi, S.K., Embaye, T., and Orphan, V.J. (2008) Diverse syntrophic partnerships from deep-sea methane vents revealed by direct cell capture and metagenomics. Proc. Natl. Acad. Sci. USA 105: 7052-7057.

Pernthaler, J., Glockner, F.O., Schonhuber, W., and Amann, R. (2001) Fluorescence in situ hybridization (FISH) with rRNA-targeted oligonucleotide probes. Methods Microbiol. 30: 207-226.

Pfennig, N., and Lippert, K.D. (1966) Über Das Vitamin B12-Bedürfnis Phototropher Schwefelbakterien. Arch. Mikrobiol. 55: 245-256.

Pfennig, N., and Trüper, H.G. (1981) Isolation of members of the families Chromatiaceae and Chlorobiaceae. In The Prokaryotes. Starr, M.P., Trüper, H.G., Bellows, A., and Schlegel, H.G. (eds). Berlin, Germany: Springer.

Pol, A., Heijmans, K., Harhangi, H.R., Tedesco, D., Jetten, M.S.M., and den Camp, H.J.M.O. (2007) Methanotrophy below pH 1 by a new Verrucomicrobia species. Nature 450: 874-U817.

Pollock, W., Heidt, L.E., Lueb, R., and Ehhalt, D.H. (1980) Measurement of Stratospheric Water-Vapor by Cryogenic Collection. J. Geophys. Res.-Oc. Atm. 85: $5555-5568$.

Postgate, J.R. (1984) The sulphate-reducing bacteria. Cambridge, UK: Cambridge University Press.

Postgate, J.R., and Campbell, L.L. (1966) Classification of Desulfovibrio species, the nonsporulating sulfate-reducing bacteria. Bacteriol. Rev. 30: 732-738.

Rabus, R., Hansen, T., and Widdel, F. (2006) Dissimilatory Sulfate- and SulfurReducing Prokaryotes. In The Prokaryotes. Dworkin, M., Falkow, S., Rosenberg, E., Schleifer, K.-H., and Stackebrandt, E. (eds). New York, USA: Springer, pp. 659-768.

Radajewski, S., Webster, G., Reay, D.S., Morris, S.A., Ineson, P., Nedwell, D.B. et al. (2002) Identification of active methylotroph populations in an acidic forest soil by stable-isotope probing. Microbiology 148: 2331-2342. 
Raghoebarsing, A.A., Pol, A., van de Pas-Schoonen, K.T., Smolders, A.J.P., Ettwig, K.F., Rijpstra, W.I.C. et al. (2006) A microbial consortium couples anaerobic methane oxidation to denitrification. Nature 440: 918-921.

Ramanathan, V. (1988) The Greenhouse Theory of Climate Change - a Test by an Inadvertent Global Experiment. Science 240: 293-299.

Redmond, M.C., Valentine, D.L., and Sessions, A.L. (2010) Identification of novel methane-, ethane-, and propane-oxidizing bacteria at marine hydrocarbon seeps by stable isotope probing. Appl. Environ. Microbiol. 76: 6412-6422.

Reeburgh, W.S. (1976) Methane Consumption in Cariaco Trench Waters and Sediments. Earth Planet. Sci. Lett. 28: 337-344.

Reeburgh, W.S. (1980) Anaerobic Methane Oxidation - Rate Depth Distributions in Skan Bay Sediments. Earth Planet. Sci. Lett. 47: 345-352.

Reeburgh, W.S. (1983) Rates of Biogeochemical Processes in Anoxic Sediments. Annu. Rev. Earth Planet. Sci. 11: 269-298.

Reeburgh, W.S. (2007) Oceanic Methane Biogeochemistry. Chem. Rev. 107: 486-513.

Reitner, J., Reimer, A., Schumann, G., Thiel, V., and Peckmann, J. (2005b) Methanederived carbonate build-ups and associated microbial communities at cold seeps on the lower Crimean shelf (Black Sea). Facies 51: 71-84.

Reitner, J., Peckmann, J., Blumenberg, M., Michaelis, W., Reimer, A., and Thiel, V. (2005a) Concretionary methane-seep carbonates and associated microbial communities in Black Sea sediments. Palaeogeogr. Palaeoclimatol. Palaeoecol. 227: $18-30$.

Rodhe, H. (1990) A Comparison of the Contribution of Various Gases to the Greenhouse-Effect. Science 248: 1217-1219.

Rohde, M., Gerberding, H., Mund, T., and Kohring, G.-W. (1988) Immunoelectron Microscopic Localization of Bacterial Enzymes: Pre- and Post-embedding 
Labelling Techniques on Resin-embedded Samples. In Methods Microbiol. Mayer, F. (ed). London, UK, San Diego, USA: Academic Press, pp. 175-210.

Rose, T.M., Schultz, E.R., Henikoff, J.G., Pietrokovski, S., McCallum, C.M., and Henikoff, S. (1998) Consensus-degenerate hybrid oligonucleotide primers for amplification of distantly related sequences. Nucleic Acids Res. 26: 1628-1635.

Roth, J., Bendayan, M., Carlemalm, E., Villiger, W., and Garavito, M. (1981) Enhancement of structural preservation and immunocytochemical staining in low temperature embedded pancreatic tissue. J. Histochem. Cytochem. 29: 663-671.

Rozanova, E.P., Nazina, T.N., and Galushko, A.S. (1988) Isolation of a New Genus of Sulfate-Reducing Bacteria and Description of a New Species of This Genus, Desulfomicrobium apsheronum Gen-Nov., Sp-Nov. Microbiology 57: 514-520.

Sambrook, J., Fritsch, E.F., and Maniatis, T. (1989) Molecular cloning: a laboratory manual. New York, USA: Cold Spring Harbor Laboratory.

Sanger, F., Nicklen, S., and Coulson, A.R. (1977) DNA sequencing with chainterminating inhibitors. Proc. Natl. Acad. Sci. USA 74: 5463-5467.

Sawolo, N., Sutriono, E., Istadi, B.P., and Darmoyo, A.B. (2009) The LUSI mud volcano triggering controversy: Was it caused by drilling? Mar. Pet. Geol. 26: 1766-1784.

Schäfer, H., Bernard, L., Courties, C., Lebaron, P., Servais, P., Pukall, R. et al. (2001) Microbial community dynamics in Mediterranean nutrient-enriched seawater mesocosms: changes in the genetic diversity of bacterial populations. FEMS Microbiol. Ecol. 34: 243-253.

Schauder, R., Widdel, F., and Fuchs, G. (1987) Carbon Assimilation Pathways in Sulfate-Reducing Bacteria. II. Enzymes of a Reductive Citric-Acid Cycle in the autotrophic Desulfobacter hydrogenophilus. Arch. Microbiol. 148: 218-225.

Schauder, R., Preuss, A., Jetten, M., and Fuchs, G. (1989) Oxidative and Reductive Acetyl Coa Carbon Monoxide Dehydrogenase Pathway in Desulfobacterium 
autotrophicum. 2. Demonstration of the Enzymes of the Pathway and Comparison of Co Dehydrogenase. Arch. Microbiol. 151: 84-89.

Schirmer, F., Ehrt, S., and Hillen, W. (1997) Expression, inducer spectrum, domain structure, and function of MopR, the regulator of phenol degradation in Acinetobacter calcoaceticus NCIB8250. J. Bacteriol. 179: 1329-1336.

Schloss, P.D., and Handelsman, J. (2005) Introducing DOTUR, a computer program for defining operational taxonomic units and estimating species richness. Appl. Environ. Microbiol. 71: 1501-1506.

Schönheit, P., Kristjansson, J.K., and Thauer, R.K. (1982) Kinetic mechanism for the ability of sulfate reducers to out-compete methanogens for acetate. Arch. Microbiol. 132: $285-288$.

Schramm, A., Santegoeds, C.M., Nielsen, H.K., Ploug, H., Wagner, M., Pribyl, M. et al. (1999) On the occurrence of anoxic microniches, denitrification, and sulfate reduction in aerated activated sludge. Appl. Environ. Microbiol. 65: 4189-4196.

Schreiber, L., Holler, T., Knittel, K., Meyerdierks, A., and Amann, R. (2010) Identification of the dominant sulfate-reducing bacterial partner of anaerobic methanotrophs of the ANME-2 clade. Environ. Microbiol. 12: 2327-2340.

Schubert, C.J., Coolen, M.J., Neretin, L.N., Schippers, A., Abbas, B., Durisch-Kaiser, E. et al. (2006) Aerobic and anaerobic methanotrophs in the Black Sea water column. Environ. Microbiol. 8: 1844-1856.

Seifert, R., Nauhaus, K., Blumenberg, M., Krüger, M., and Michaelis, W. (2006) Methane dynamics in a microbial community of the Black Sea traced by stable carbon isotopes in vitro. Org. Geochem. 37: 1411-1419.

Seitzinger, S., Harrison, J.A., Bohlke, J.K., Bouwman, A.F., Lowrance, R., Peterson, B. et al. (2006) Denitrification across landscapes and waterscapes: a synthesis. Ecol. Appl. 16: 2064-2090.

Sherr, B., Sherr, E., and del Giorgio, P. (2001) Enumeration of total and highly active bacteria. Methods Microbiol. 30: 129-159. 
Shuman, S. (1991) Site-specific DNA cleavage by vaccinia virus DNA topoisomerase I. Role of nucleotide sequence and DNA secondary structure. J. Biol. Chem. 266: 1796-1803.

Shuman, S. (1994) Novel approach to molecular cloning and polynucleotide synthesis using vaccinia DNA topoisomerase. J. Biol. Chem. 269: 32678-32684.

Sieburth, J.N., Johnson, P.W., Eberhardt, M.A., Sieracki, M.E., Lidstrom, M., and Laux, D. (1987) The first methane-oxidizing bacterium from the upper mixing layer of the deep ocean: Methylomonas pelagica sp. nov. . Curr. Microbiol. 14: 285-293.

Simmons, S.L., Sievert, S.M., Frankel, R.B., Bazylinski, D.A., and Edwards, K.J. (2004) Spatiotemporal Distribution of Marine Magnetotactic Bacteria in a Seasonally Stratified Coastal Salt Pond. Appl. Environ. Microbiol. 70: 6230-6239.

Sinninghe Damsté, J.S., Wakeham, S.G., Kohnen, M.E.L., Hayes, J.M., and Deleeuw, J.W. (1993) A 6,000-Year Sedimentary Molecular Record of Chemocline Excursions in the Black-Sea. Nature 362: 827-829.

Sinninghe Damsté, J.S., Rijpstra, W.I.C., Schouten, S., Fuerst, J.A., Jetten, M.S.M., and Strous, M. (2004) The occurrence of hopanoids in planctomycetes: implications for the sedimentary biomarker record. Org. Geochem. 35: 561-566.

Söhngen, N.L. (1906) Über Bakterien, welche Methan als Kohlenstoffnahrung and Energiequelle gebrauchen. Zentr. Bakteriol. Parasitenk., Abt. II 15: 513-517.

Sörensen, K.B., Finster, K., and Ramsing, N.B. (2001) Thermodynamic and Kinetic Requirements in Anaerobic Methane Oxidizing Consortia Exclude Hydrogen, Acetate, and Methanol as Possible Electron Shuttles. Microb. Ecol. 42: 1-10.

Sowers, K.R., and Noll, K.M. (1995) Techniques for Anaerobic Growth. In Archaea: A laboratory manual. Robb, F.T., Place, A.R., Sowers, K.R., Schreier, H.J., DasSarma, S., and Fleischmann, E.M. (eds). Plainview, USA: Cold Spring Harbor Laboratory Press.

Spurr, A.R. (1969) A Low-Viscosity Epoxy Resin Embedding Medium for Electron Microscopy. J. Ultrastruct. Res. 26: 31-43. 
Stadnitskaia, A., Muyzer, G., Abbas, B., Coolen, M.J.L., Hopmans, E.C., Baas, M. et al. (2005) Biomarker and 16S rDNA evidence for anaerobic oxidation of methane and related carbonate precipitation in deep-sea mud volcanoes of the Sorokin Trough, Black Sea. Mar. Geol. 217: 67-96.

Stahl, D.A., and Amann, R.I. (1991) Development and application of nucleic acid probes in bacterial systematics. In Nucleic acid techniques in bacterial systematics. Stackebrandt, E., and Goodfellow, M. (eds). Chichester, UK: John Wiley \& Sons, pp. 205-248.

Stockdale, A., Davison, W., and Zhang, H. (2009) Micro-scale biogeochemical heterogeneity in sediments: A review of available technology and observed evidence. Earth-Sci. Rev. 92: 81-97.

Stoecker, K., Bendinger, B., Schoning, B., Nielsen, P.H., Nielsen, J.L., Baranyi, C. et al. (2006) Cohn's Crenothrix is a filamentous methane oxidizer with an unusual methane monooxygenase. Proc. Natl. Acad. Sci. USA 103: 2363-2367.

Strand, S.E., and Lidstrom, M.E. (1984) Characterization of a new marine methylotroph. FEMS Microbiol. Lett. 21: 247-251.

Taviani, M. (2001) Fluid venting and associated processes. In Anatomy of an Orogen: the Apennines and adjacent Mediterranean Basins. Vai, G.B., and Martini, I.P. (eds). Dordrecht, the Netherlands: Kluwer Academic Publ., pp. 351-366.

Teichmüller, R., and Teichmüller, M. (1986) Relations between Coalification and Pataoeogeothermics in Variscan and Alpidic foredeeps of Western Europe. Lect. Notes Earth Sci. 5: 53-78.

Thauer, R.K. (1998) Biochemistry of methanogenesis: a tribute to Marjory Stephenson. 1998 Marjory Stephenson Prize Lecture. Microbiology 144: 2377-2406.

Thauer, R.K., and Shima, S. (2008) Methane as Fuel for Anaerobic Microorganisms. Ann. N. Y. Acad. Sci. 1125: 158-170. 
Thauer, R.K., Kaster, A.-K., Seedorf, H., Buckel, W., and Hedderich, R. (2008) Methanogenic archaea: ecologically relevant differences in energy conservation. Nat. Rev. Micro. 6: 579-591.

Thiel, V., Blumenberg, M., Pape, T., Seifert, R., and Michaelis, W. (2003) Unexpected occurrence of hopanoids at gas seeps in the Black Sea. Org. Geochem. 34: 81-87.

Thiel, V., Peckmann, J., Seifert, R., Wehrung, P., Reitner, J., and Michaelis, W. (1999) Highly isotopically depleted isoprenoids: Molecular markers for ancient methane venting. Geochim. Cosmochim. Acta 63: 3959-3966.

Thiel, V., Peckmann, J., Richnow, H.H., Luth, U., Reitner, J., and Michaelis, W. (2001) Molecular signals for anaerobic methane oxidation in Black Sea seep carbonates and a microbial mat. Mar. Chem. 73: 97-112.

Treude, T., Knittel, K., Blumenberg, M., Seifert, R., and Boetius, A. (2005) Subsurface Microbial Methanotrophic Mats in the Black Sea. Appl. Environ. Microbiol. 71: 6375-6378.

Treude, T., Orphan, V., Knittel, K., Gieseke, A., House, C.H., and Boetius, A. (2007) Consumption of Methane and $\mathrm{CO}_{2}$ by Methanotrophic Microbial Mats from Gas Seeps of the Anoxic Black Sea. Appl. Environ. Microbiol. 73: 2271-2283.

Trotsenko, Y.A., and Murrell, J.C. (2008) Metabolic aspects of aerobic obligate methanotrophy. Adv. Appl. Microbiol. 63: 183-229.

Vainshtein, M., Suzina, N., Kudryashova, E., and Ariskina, E. (2002) New magnetsensitive structures in bacterial and archaeal cells. Biol. Cell 94: 29-35.

Vance, D.B. (1996) Redox reactions in remediation. Environ. Technol. 6: 24-25.

Venable, J.H., and Coggesha, R. (1965) A Simplified Lead Citrate Stain for Use in Electron Microscopy. J. Cell Biol. 25: 407-408.

Vigliotta, G., Nutricati, E., Carata, E., Tredici, S.M., De Stefano, M., Pontieri, P. et al. (2007) Clonothrix fusca Roze 1896, a filamentous, sheathed, methanotrophic gamma-proteobacterium. Appl. Environ. Microbiol. 73: 3556-3565. 
Vuilleumier, S., Chistoserdova, L., Lee, M.C., Bringel, F., Lajus, A., Zhou, Y. et al. (2009) Methylobacterium genome sequences: a reference blueprint to investigate microbial metabolism of $\mathrm{C} 1$ compounds from natural and industrial sources. PLoS One 4: e5584.

Wahlen, M. (1993) The Global Methane Cycle. Annu. Rev. Earth Planet. Sci. 21: 407426.

Wang, Z.P., Lindau, C.W., Delaune, R.D., and Patrick, W.H. (1993) Methane emission and entrapment in flooded rice soils as affected by soil properties. Biol. Fertil. Soils 16: $163-168$.

Ward, N., Larsen, Ø., Sakwa, J., Bruseth, L., Khouri, H., Durkin, A.S. et al. (2004) Genomic Insights into Methanotrophy: The Complete Genome Sequence of Methylococcus capsulatus (Bath). PLoS Biol. 2: e303.

Wegener, G., Niemann, H., Elvert, M., Hinrichs, K.U., and Boetius, A. (2008) Assimilation of methane and inorganic carbon by microbial communities mediating the anaerobic oxidation of methane. Environ. Microbiol. 10: 2287-2298.

Whitman, W., Bowen, T., and Boone, D. (2006) The Methanogenic Bacteria. In The Prokaryotes. Dworkin, M., Falkow, S., Rosenberg, E., Schleifer, K.-H., and Stackebrandt, E. (eds). New York, USA: Springer, pp. 165-207.

Whittenbury, R., Phillips, K.C., and Wilkinson, J.F. (1970) Enrichment, Isolation and Some Properties of Methane-utilizing Bacteria. J. Gen. Microbiol. 61: 205-218.

Widdel, F. (1980) Anaerober Abbau von Fettsäuren und Benzoesäure durch neu isolierte Arten sulfatreduzierender Bakterien. Dissertation. Göttingen, Germany.

Widdel, F. (1988) Microbiology and ecology of sulfate- and sulfur-reducing bacteria. In Biology of Anaerobic Microorganisms. Zehnder, A.J.B. (ed). New York, USA: John Wiley \& Sons, pp. 469-585.

Widdel, F. (2002) Mikroorganismen des Meeres - Katalysatoren globaler Stoffkreisläufe. In Rundgespräche der Kommission für Ökologie, Bd.23, Bedeutung 
der Mikroorganismen für die Umwelt. Schleifer, K.H. (ed). Munich, Germany: Verlag Dr. Friedrich Pfeil, pp. 67-84.

Widdel, F., and Pfennig, N. (1982) Studies on Dissimilatory Sulfate-Reducing Bacteria That Decompose Fatty-Acids. 2. Incomplete Oxidation of Propionate by Desulfobulbus propionicus gen. nov., sp. nov. Arch. Microbiol. 131: 360-365.

Widdel, F., Boetius, A., and Rabus, R. (2006) Anaerobic Biodegradation of Hydrocarbons Including Methane. In The Prokaryotes. Dworkin, M., Falkow, S., Rosenberg, E., Schleifer, K.-H., and Stackebrandt, E. (eds). New York, USA: Springer, pp. 1028-1049.

Williams, P.A., Coates, L., Mohammed, F., Gill, R., Erskine, P.T., Coker, A. et al. (2005) The atomic resolution structure of methanol dehydrogenase from Methylobacterium extorquens. Acta. Crystallogr. D Biol. Crystallogr. 61: 75-79.

Wolin, E.A., Wolin, M.J., and Wolfe, R.S. (1963) Formation of Methane by Bacterial Extracts. J. Biol. Chem. 238: 2882-2886.

Wrede, C. (2007) Strukturelle und funktionelle in situ-Charakterisierung von mikrobiellen Matten aus Methan-Seeps. Diplomarbeit. Göttingen, Germany.

Wrede, C., Heller, C., Reitner, J., and Hoppert, M. (2008) Correlative light/electron microscopy for the investigation of microbial mats from Black Sea Cold Seeps. $J$. Microbiol. Methods 73: 85-91.

Wrede, C., Heller, C., Krukenberg, V., Reitner, J., and Hoppert, M. (subm.) Anoxic cold seeps: Evidence for two active methane oxidation pathways.

Zhu, G., Jetten, M., Kuschk, P., Ettwig, K., and Yin, C. (2010) Potential roles of anaerobic ammonium and methane oxidation in the nitrogen cycle of wetland ecosystems. Appl. Microbiol. Biotechnol. 86: 1043-1055. 


\section{Appendix}

\subsection{Materials}

\subsubsection{Chemicals}

Chemicals with the highest commercially available purity level were used for preparation of buffers and media.

2-Mercaptoethanol

Acrylamide

Agar

Agarose

Ammonium persulfate

Ampicillin

Bacto-Agar

Bromophenol blue

CDP-Star

Chloroform

Coomassie Brillant Blue, G250

DAPI

dNTPs mixture

DPX

Ethanol

Ethidium bromide

Formvar (Polyvinylformaldehyd)

Glutardialdehyde

Imidazole

IPTG

Lowicryl K4M resin
Merck, Darmstadt, Germany

Roth, Karlsruhe, Germany

Roth, Karlsruhe, Germany

Biozym, Hessisch Oldendorf, Germany

Serva, Heidelberg, Germany

Sigma, Munich, Germany

DIFCO, Lawrence, USA

Serva, Heidelberg, Germany

Roche Applied Science, Basel,

Switzerland

Roth, Karlsruhe, Germany

Serva, Heidelberg, Germany

AppliChem, Darmstadt, Germany

MBI Fermentas, St. Leon-Rot, Germany

Sigma, Munich, Germany

Roth, Karlsruhe, Germany

Merck, Darmstadt, Germany

Plano, Wetzlar, Germany

Sigma, Munich, Germany

Serva, Heidelberg, Germany

AppliChem, Darmstadt, Germany

Electron Microscopy Sciences, Hatfield, USA 


$\begin{array}{ll}\text { Methanol } & \text { Roth, Karlsruhe, Germany } \\ \mathrm{Ni}^{2+} \text {-NTA } & \text { Qiagen, Hilden, Germany } \\ \text { Nycodenz } & \text { Serva, Heidelberg, Germany } \\ \text { Oktanol } & \text { Roth, Karlsruhe, Germany } \\ \text { Osmium tetroxide } & \text { Science Services, Munich, Germany } \\ \text { PCR water } & \text { AppliChem, Darmstadt, Germany } \\ \text { SDS } & \text { Roth, Karlsruhe, Germany } \\ \text { TEMED } & \text { Merck, Darmstadt, Germany } \\ \text { Tris } & \text { Roth, Karlsruhe, Germany } \\ \text { Tryptone } & \text { Oxoid, Heidelberg, Germany } \\ \text { Tween } 20 & \text { Sigma, Munich, Germany } \\ \text { Tween } 80 & \text { Sigma, Munich, Germany }\end{array}$

Chemicals and biochemicals were purchased, unless specified otherwise, from the companies AppliChem (Darmstadt, Germany), Fluka (Buchs, Switzerland), Merck (Darmstadt, Germany), Roth (Karlsruhe, Germany), Sigma Aldrich (Munich, Germany).

\subsubsection{Auxiliary material}

$0.2 \mu \mathrm{m}$ polycarbonate filters

$0.45 \mu \mathrm{m}$ cellulose nitrate support filters

Centrifuge cups

Cuvettes (microlitre, plastic)

Dialysis tubes

Gelatin capsules

Gene Amp Reaction Tubes (PCR)

Glas pipet

Glass strips

Grids $(\mathrm{Cu}$ or $\mathrm{Ni})$

Microfuge tube

Microlitre pipets

$(10 \mu \mathrm{l}, 20 \mu \mathrm{l}, 200 \mu \mathrm{l}, 1000 \mu \mathrm{l})$

\author{
Millipore, Schwalbach, Germany \\ Millipore, Schwalbach, Germany \\ Beckmann, Munich, Germany \\ Greiner, Nürtingen, Germany \\ Serva, Heidelberg, Germany \\ Plano, Wetzlar, Germany \\ Perkin Elmer, Weiterstadt, Germany \\ Brand, Wertheim, Germany \\ LKB, Bromma, Sweden \\ Plano, Wetzlar, Germany \\ Greiner, Nürtingen, Germany \\ VWR, Darmstadt, Germany
}


non-returnable syringe

Parafilm

Petri dishes

Pipet tip

Plastic trays

Protino Columns

PVDF membrane

\subsubsection{Instrumentation}

$1,024 \times 1,024$ charge-coupled device detector (HSS 512/1024) for TEM 902A

Axioskop 40 FL fluorescence

microscope equipped with digital

camera and AxioVision software

Biofuge

Biofuge fresco

Chemiluminescence imager

Filter set 43

(BP: 545/25, FT 570, LP: 605/70)

Filter set 49

(G: 365, FT: 395, BP: 445/50

Filter set EGFP HC

FlexCycler (Thermocycler)

French pressure cell press

Gel electrophoresis apparatus

Horizontal shaker VXR basic

Ice maschine

INGENYphorU system
Terumo, Tokyo, Japan

Pechiney Plastic Packaging Company, Chicago, USA

Greiner, Nürtingen, Germany

Sarstedt, Nümbrecht, Germany

Plano, Wetzlar, Germany

Macherey-Nagel, Düren, Germany

AppliChem, Darmstadt, Germany
Proscan Electronic Systems,

Lagerlechfeld, Germany

Carl Zeiss AG, Oberkochen, Germany

Heraeus Christ, Osterode, Germany

Heraeus Christ, Osterode, Germany

PEQLAB, Erlangen, Germany

Carl Zeiss AG, Oberkochen, Germany

Carl Zeiss AG, Oberkochen, Germany

AHF Analysentechnik, Tübingen, Germany

Analytik Jena, Jena, Germany

SLM Aminco, Lorch, Germany

PEQLAB, Erlangen, Germany

IKA, Staufen, Germany

Ziegra, Isernhagen, Germany

Ingeny, Goes, Netherlands 


\begin{tabular}{|c|c|}
\hline Innova 44R (incubator shaker) & $\begin{array}{l}\text { New Brunswick, Neu-Isenburg, } \\
\text { Germany }\end{array}$ \\
\hline InoLab 7200 (pH meter) & WTW, Weilheim, Germany \\
\hline Knife-maker II LKB 7800 & LKB, Bromma, Sweden \\
\hline Magnetic stirrer Reo basic C & IKA, Staufen, Germany \\
\hline Mikro-Dismembrator S & Sartorius, Göttingen, Germany \\
\hline Minigel-Twin (gel electrophoresis) & Biometra, Göttingen, Germany \\
\hline Orbital shaker G10 & $\begin{array}{l}\text { New Brunswick, Neu-Isenburg, } \\
\text { Germany }\end{array}$ \\
\hline Power pack & Biometra, Göttingen, Germany \\
\hline $\begin{array}{l}\text { Refrigerated centrifuge RC5C Sorvall } \\
\text { Instruments }\end{array}$ & Kendro, Hanau, Germany \\
\hline Rotating milling cutter TM 60 & Reichert-Jung, Heidelberg, Germany \\
\hline Scale & Sartorius, Göttingen, Germany \\
\hline Special accuracy weighing machine & Sartorius, Göttingen, Germany \\
\hline Spektralphotometer Ultraspec 3000 & $\begin{array}{l}\text { Amersham Pharmacia, Uppsala, } \\
\text { Sweden }\end{array}$ \\
\hline Steam autoclave & $\begin{array}{l}\text { Thermo Scientific, Waltham, MA, } \\
\text { USA }\end{array}$ \\
\hline ThermoStat & Eppendorf, Hamburg, Germany \\
\hline $\begin{array}{l}\text { Transmission Electron Microscope } \\
\text { 902A }\end{array}$ & Carl Zeiss AG, Oberkochen, Germany \\
\hline Ultramicrotome FC 4 & Reichert-Jung, Heidelberg, Germany \\
\hline Ultrasonic unit UP200S & $\begin{array}{l}\text { Dr. Hielscher GmbH, Teltow, } \\
\text { Germany }\end{array}$ \\
\hline UniSampler (fluid sampler) & Bürkle, Bad Bellingen, Germany \\
\hline UV Transilluminator 2000 & Bio-Rad, Munich, Germany \\
\hline Vortex Genie 2 & $\begin{array}{l}\text { Bender \& Hobeing, Zurich, } \\
\text { Switzerland }\end{array}$ \\
\hline Water desalination plant & Millipore, Schwalbach, Germany \\
\hline
\end{tabular}




\subsubsection{Commercial systems}

Goat normal serum

goat-anti-rabbit IgG $(\mathrm{H}+\mathrm{L})$ AlexaFluor 488

conjugate

goat-anti-rabbit IgG AlexaFluor 546

conjugate

goat-anti-rabbit IgG alkaline phosphatase

conjugate

Goat-anti-rabbit IgG-10 nm gold conjugate

High Pure PCR Template Preparation Kit

Nanocolor ${ }^{\circledR}$ Sulfid Kit

NucleoSpin ${ }^{\circledR}$ Food Kit

peqGOLD Gel Extraction Kit

peqGOLD MicroSpin Cycle-Pure Kit

peqGOLD Plasmid Miniprep Kit I

Prestained Protein Molecular Weight Marker

Protease inhibitor complete EDTA free

Protino Ni-TED 2000 Packed Columns

Quick-Load $^{\circledR} 1$ kb DNA Ladder

Roti-Quant

SybrGold solution
Jackson ImmunoResearch Europe,

Suffolk, UK

Cell Signaling Technology, Danvers, USA

Molecular Probes, Eugene, USA

Promega, Madison, USA

British Biocell International, Cardiff, UK

Roche Applied Science, Basel, Switzerland

Macherey-Nagel, Düren, Germany

Macherey-Nagel, Düren, Germany

PEQLAB, Erlangen, Germany

PEQLAB, Erlangen, Germany

PEQLAB, Erlangen, Germany

MBI Fermentas, St. Leon-Rot,

Germany

Roche Applied Science, Basel,

Switzerland

Macherey-Nagel, Düren, Germany

NEB Biolabs, Frankfurt am Main

Roth, Karlsruhe, Germany

Molecular Probes, Eugene, USA 


\subsubsection{Enzymes}

Calf intestinal alkaline phosphatase (CIAP) MBI Fermentas, St. Leon-Rot, Germany Chicken Egg White Lysozyme Merck, Darmstadt, Germany (178000 U/mg)

Phusion ${ }^{\circledR}$ High-Fidelity DNA Polymerase NEB Biolabs, Frankfurt am Main, Germany

Proteinase K AppliChem, Darmstadt, Germany

Restriction endonucleases MBI Fermentas, St. Leon-Rot, Germany

T4 DNA Ligase

Taq DNA Polymerase MBI Fermentas, St. Leon-Rot, Germany NEB Biolabs, Frankfurt am Main, Germany

\subsection{Oligonucleotides}

All unlabeled oligonucleotides were purchased from Eurofins MWG Operon (Ebersberg, Germany). Oligonucleotides with fluorochromes were purchased from biomers (Ulm, Germany).

Table 7.1.: Oligonucleotides

\begin{tabular}{|c|c|c|c|}
\hline Name & Sequence $\left(5^{\prime} \rightarrow 3^{\prime}\right)^{1}$ & $\begin{array}{l}\text { Restriction } \\
\text { site or dye }\end{array}$ & Description \\
\hline \multirow{2}{*}{$\begin{array}{l}\text { CWAprB1- } \\
\text { fw }\end{array}$} & AGTTGGTATGCCGACTTWY & & first step of nested PCR for \\
\hline & GTNRAYCC & & $a p r B$ gene amplification \\
\hline \multirow[t]{3}{*}{ AprA-5-RV } & GCGCCAACYGGRCCRTA & & first step of nested PCR for \\
\hline & & & apr $B$ gene amplification \\
\hline & & & (Meyer and Kuever, 2007) \\
\hline \multirow{2}{*}{$\begin{array}{l}\text { CWAprB3- } \\
\text { fw }\end{array}$} & CCGACTTATGTTGATCCGG & & second step of nested PCR \\
\hline & CNAARTGYGAYGG & & $\begin{array}{l}\text { for } a p r B \text { gene amplifica- } \\
\text { tion }\end{array}$ \\
\hline
\end{tabular}




\begin{tabular}{|c|c|c|c|}
\hline Name & Sequence $\left(5^{\prime} \rightarrow 3^{\prime}\right)^{1}$ & $\begin{array}{l}\text { Restriction } \\
\text { site or dye }\end{array}$ & Description \\
\hline APS-RV & $\begin{array}{l}\text { GGGCCGTAACCGTCCTT } \\
\text { GAA }\end{array}$ & & $\begin{array}{l}\text { second step of nested PCR } \\
\text { for } a p r B \text { gene amplifica- } \\
\text { tion (Deplancke et al., } \\
2000 \text { ) }\end{array}$ \\
\hline CWAprBK1 & AAAGGATCCATGCCGAC & BamHI & cloning apr $B$ gene in \\
\hline $1-\mathrm{fw}$ & TTATGTTGATCCGGC & & pWH844 \\
\hline CWAprBK1 & TTTAAGCTTTCACTGTCGC & HindIII & cloning $a p r B$ gene in \\
\hline 2-rev & CTTGCTAGAC & & pWH844 \\
\hline $\begin{array}{l}\text { CWMDHa } \\
\text { fw }\end{array}$ & $\begin{array}{l}\text { AAAGGATCCATGAGCAG } \\
\text { GTTTGTGACATCAG }\end{array}$ & BamHI & $\begin{array}{l}\text { cloning } m x a F \text { gene in } \\
\text { pWH844 }\end{array}$ \\
\hline $\begin{array}{l}\text { CWMDHa } \\
\text { rev }\end{array}$ & $\begin{array}{l}\text { TTTAAGCTTTTACTTGGCG } \\
\text { GCTGACTTC }\end{array}$ & HindIII & $\begin{array}{l}\text { cloning } m x a F \text { gene in } \\
\text { pWH844 }\end{array}$ \\
\hline $\begin{array}{l}\text { CWMDHa } \\
\text { seq }\end{array}$ & CTCGACGCTCACGATCG & & sequencing of $m x a F$ gene \\
\hline $8 \mathrm{f}$ & $\begin{array}{l}\text { AGAGTTTGATCATGGCT } \\
\text { CAG }\end{array}$ & & $\begin{array}{l}\text { 16S rDNA amplification } \\
\text { (Alain et al., 2002) }\end{array}$ \\
\hline $1492 \mathrm{r}$ & GTTACCTTGTTACGACTT & & $\begin{array}{l}\text { 16S rDNA amplification } \\
\text { (Alain et al., 2002) }\end{array}$ \\
\hline $\operatorname{Arch} 21 \mathrm{~F}$ & $\begin{array}{l}\text { TTCCGGTTGATCCYGCC } \\
\text { GGA }\end{array}$ & & $\begin{array}{l}\text { 16S rDNA amplification } \\
\text { (Delong, 1992) }\end{array}$ \\
\hline Arch958R & YCCGGCGTTGAMTCCAATT & & $\begin{array}{l}\text { 16S rDNA amplification } \\
\text { (Delong, 1992) }\end{array}$ \\
\hline $341 \mathrm{f}$ & CCTACGGGAGGCAGCAG & & $\begin{array}{l}\text { DGGE, reamplification } \\
\text { (Schäfer et al., 2001) }\end{array}$ \\
\hline
\end{tabular}




\begin{tabular}{|c|c|c|c|}
\hline Name & Sequence $\left(5^{\prime} \rightarrow 3^{\prime}\right)^{1}$ & $\begin{array}{l}\text { Restriction } \\
\text { site or dye }\end{array}$ & Description \\
\hline \multirow[t]{3}{*}{$341 \mathrm{f}-\mathrm{GC}$} & CGCCCGCCGCGCCCCGCGC & & DGGE, with GC-clamp \\
\hline & CCGGCCCGCCGCCCCCGCC & & (Stadnitskaia et al., 2005) \\
\hline & CCCCTACGGGAGGCAGCAG & & \\
\hline \multirow[t]{2}{*}{ 907Rc } & CCGTCAATTCCTTTGAGT & & DGGE (Schäfer et al., \\
\hline & & & 2001) \\
\hline \multirow[t]{2}{*}{ 907Ra } & CCGTCAATTCATTTGAGT & & DGGE (Schäfer et al., \\
\hline & & & 2001) \\
\hline \multirow{2}{*}{ M13f } & GTAAAACGACGGCCAG & & checking and sequencing \\
\hline & & & of pCR2.1-TOPO inserts \\
\hline \multirow[t]{2}{*}{ M13r } & CAGGAAACAGCTATGAC & & checking and sequencing \\
\hline & & & of pCR2.1-TOPO inserts \\
\hline \multirow[t]{2}{*}{ JS39 } & TCTATCAACAGGAGTCCA & - & checking and sequencing \\
\hline & AGC & & of pWH844 inserts \\
\hline \multirow[t]{2}{*}{ pWH844fw } & TATGAGAGGATCGCATC & - & checking and sequencing \\
\hline & ACCAT & & of pWH844 inserts \\
\hline \multirow[t]{3}{*}{ Arch915 } & GTGCTCCCCCGCCAATT & CY3 & specific for most archaea \\
\hline & $\mathrm{CCT}$ & & (Stahl and Amann, 1991; \\
\hline & & & Lösekann et al., 2007) \\
\hline \multirow[t]{6}{*}{ DSS658 } & TCСАСТТСССТСТСССАТ & 6-FAM & specific for \\
\hline & & & Desulfosarcinal \\
\hline & & & Desulfococcus branch \\
\hline & & & (Manz et al., 1998; Boetius \\
\hline & & & et al., 2000; Lösekann et \\
\hline & & & al., 2007) \\
\hline
\end{tabular}




\begin{tabular}{|c|c|c|c|}
\hline Name & Sequence $\left(5^{\prime} \rightarrow 3^{\prime}\right)^{1}$ & $\begin{array}{l}\text { Restriction } \\
\text { site or dye }\end{array}$ & Description \\
\hline EelMS932 & AGCTCCACCCGTTGTAGT & CY3 & $\begin{array}{l}\text { Specific for ANME-2 } \\
\text { archaea (Boetius et al., } \\
\text { 2000) }\end{array}$ \\
\hline EUB338 I & GCTGCCTCCCGTAGGAGT & CY3 & EUB338 I-III specific for \\
\hline EUB338 II & GCAGCCACCCGTAGGTGT & CY3 & $\begin{array}{l}\text { most bacteria (Daims et al., } \\
\text { 1999) }\end{array}$ \\
\hline EUB338 III & GCTGCCACCCGTAGGTGT & CY3 & \\
\hline
\end{tabular}

\subsection{Sequences}

aprB gene sequence used for heterologous overexpression:

5'-ATGCCGACTTATGTTGATCCGGCTAAATGCGACGGCTGCAAGGGGGGAG ACAAAACCGCTCGTATGTACATCTGCCCAAACGACCTTATGATTCTCGACCC CGATGAGATGAAGGCCTTCAACCAGGAACCCGACGCGTGCTGGGAGTGTTA TTCCTGCGTGAAGATCTGCCCCCAAGGCGCGATTACGGCCCGTCCGTATGCG GACTTCGCCCCCATGGGCGGAACTTCCATTCCGCTTCGCGGCTCCGACGACA TCATGTGGACCATTAAATTCCGCAACGGCAGCGTCAAGCGGTTCAAATTCCC CATCCGCACCACGCCTGAGGGCTCGATCAAGCCTTACGAGGGCAAACCCGA ACCCGCGGACCTGGAAAACGAAATGTACTTCAACGAGACCGAACTTAAATC GCCCGCGGATGCCATGGGCAAGAAGTTCGACATCGCCGAGGCCGACAAGAC CGTGACCTCCATGGCCTCCGCAGTCTAGCAAGGCGACAGTGA-3’ 


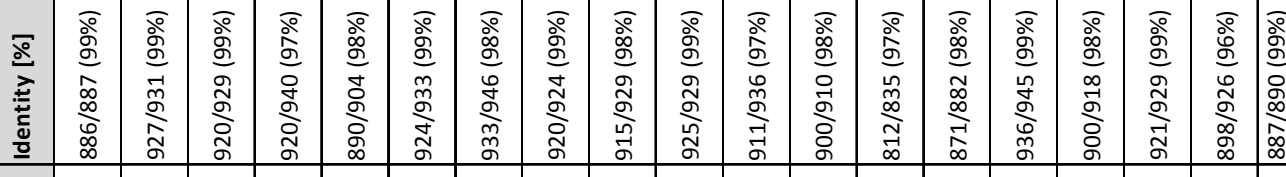

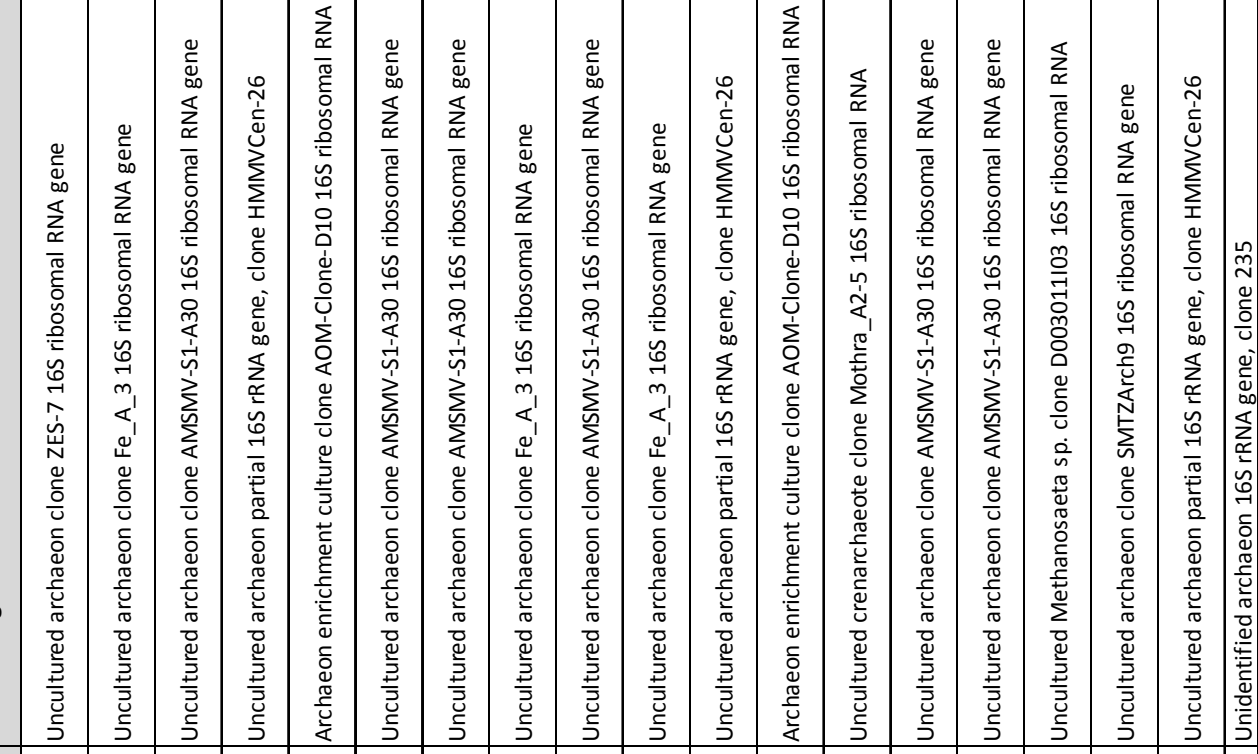

产

을

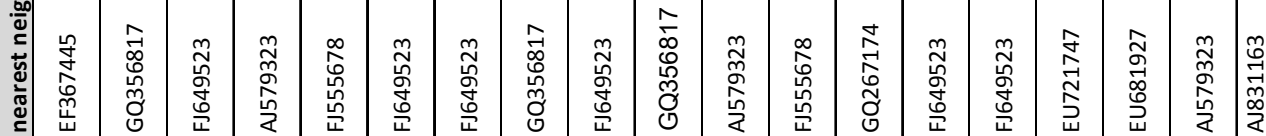

\begin{tabular}{|c|c|c|c|c|c|c|c|c|c|c|c|c|c|c|c|c|c|c|c|}
\hline 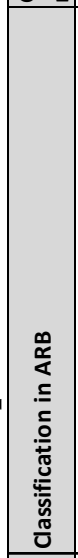 & 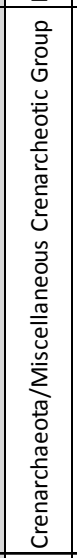 & 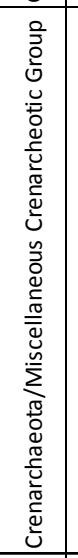 & 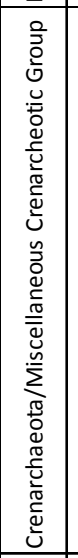 & 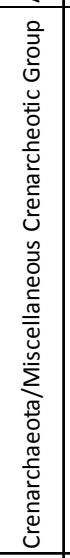 & 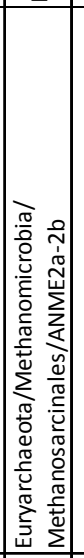 & 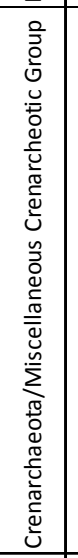 & 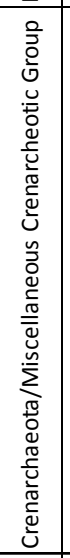 & 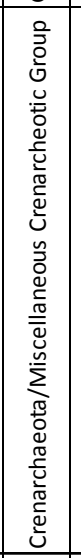 & 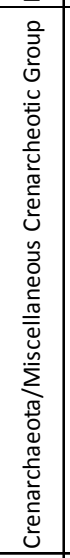 & 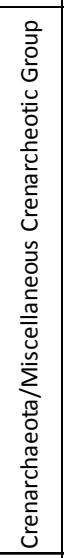 & 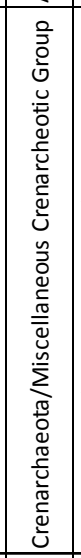 & 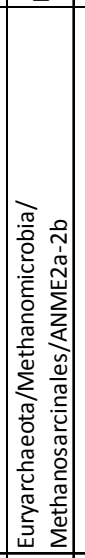 & 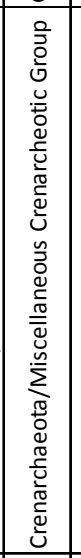 & 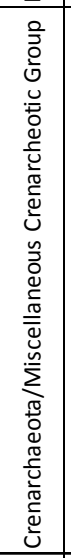 & 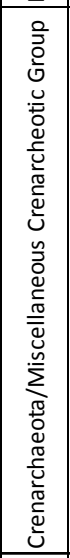 & 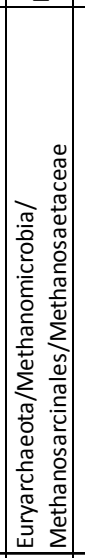 & 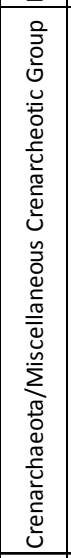 & 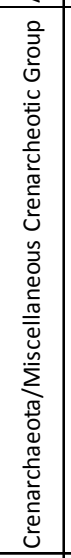 & 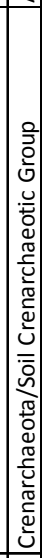 \\
\hline 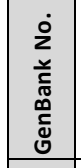 & \begin{tabular}{l}
$\infty$ \\
$\infty$ \\
\multirow{4}{0}{} \\
0 \\
0 \\
\end{tabular} & 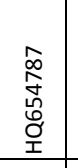 & 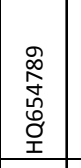 & 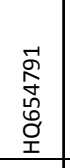 & 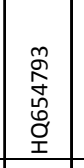 & 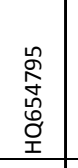 & 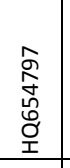 & 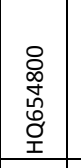 & 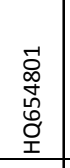 & 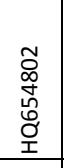 & 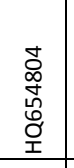 & 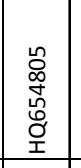 & 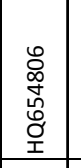 & 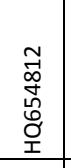 & 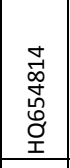 & 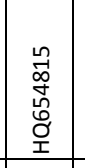 & 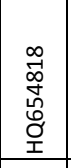 & 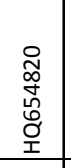 & \\
\hline 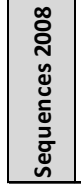 & 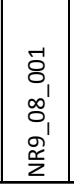 & $\begin{array}{l}\tilde{\delta} \\
o^{\prime} \\
o^{\prime} \\
\sigma^{\prime} \\
\frac{\sigma^{2}}{2}\end{array}$ & $\begin{array}{l}0 \\
o_{1} \\
o^{\prime} \\
\sigma_{1}^{\prime} \\
\frac{\tilde{s}}{2}\end{array}$ & $\begin{array}{l}d^{\prime} \\
o^{\prime} \\
o^{\prime} \\
O^{\prime} \\
\frac{\sigma^{\prime}}{2}\end{array}$ & $\begin{array}{l}\tilde{o}^{\prime} \\
\infty^{\prime} \\
0^{\prime} \\
\sigma^{\prime} \\
\frac{1}{z}\end{array}$ & 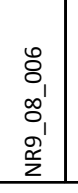 & $\begin{array}{l}\hat{o} \\
o_{1} \\
o_{1} \\
\sigma_{1} \\
\frac{1}{z}\end{array}$ & $\begin{array}{l}\infty \\
\delta_{1} \\
\infty \\
o_{1}^{\prime} \\
o^{\prime} \\
\frac{1}{z}\end{array}$ & $\begin{array}{l}\delta_{1} \\
o^{\prime} \\
o_{0}^{\prime} \\
\sigma^{\prime} \\
\frac{\sigma^{\prime}}{z}\end{array}$ & $\begin{array}{l}0 \\
0 \\
o^{\prime} \\
\alpha_{1}^{\prime} \\
\sigma^{\prime} \\
\aleph^{2}\end{array}$ & 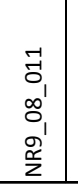 & $\begin{array}{l}\tilde{z} \\
\sigma^{\prime} \\
\infty^{\prime} \\
\sigma^{\prime} \\
\frac{\sigma^{\prime}}{z}\end{array}$ & $\begin{array}{l}m \\
\sigma_{1} \\
\infty_{1}^{\prime} \\
\sigma_{1}^{\prime} \\
\frac{\sigma^{2}}{2}\end{array}$ & $\begin{array}{l}\Delta \\
\sigma_{1} \\
o^{\prime} \\
\sigma_{1}^{\prime} \\
\sigma^{\prime} \\
\frac{\tilde{c}}{z}\end{array}$ & 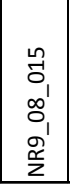 & 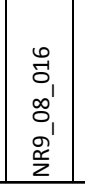 & $\mid \begin{array}{l}\hat{\sigma} \\
o_{1} \\
o^{\prime} \\
\sigma^{\prime} \\
\frac{\tilde{z}}{2}\end{array}$ & $\begin{array}{l}\infty \\
\sigma_{1} \\
\infty^{\prime} \\
\sigma_{1}^{\prime} \\
\sigma^{\prime} \\
\frac{\tilde{c}}{z}\end{array}$ & \\
\hline
\end{tabular}




\begin{tabular}{|c|c|c|c|c|c|c|c|c|c|c|c|c|c|c|c|c|c|c|c|}
\hline 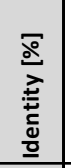 & 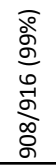 & 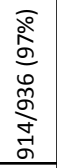 & 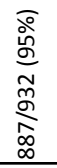 & 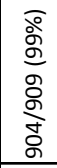 & 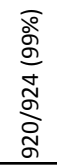 & 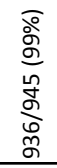 & 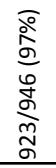 & 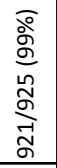 & 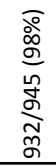 & 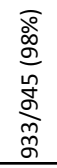 & 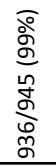 & 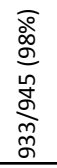 & 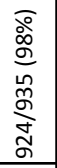 & 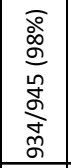 & 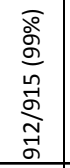 & 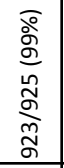 & 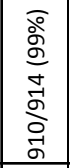 & 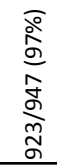 & 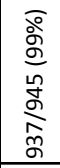 \\
\hline 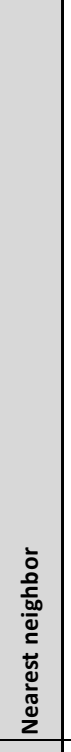 & 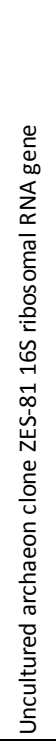 & 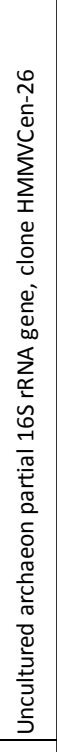 & 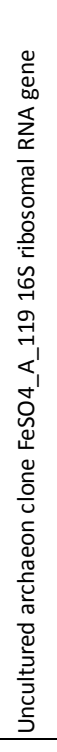 & 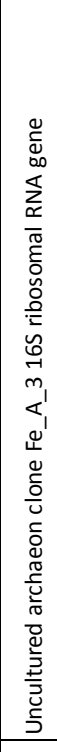 & 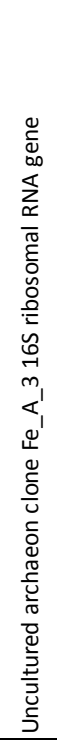 & 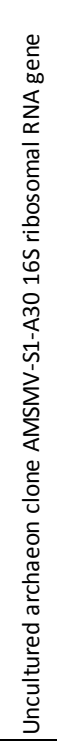 & 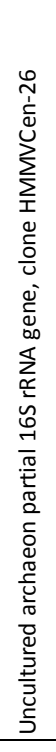 & 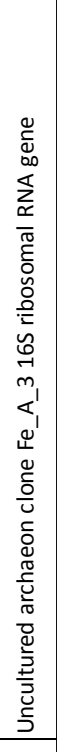 & 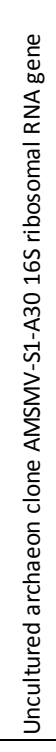 & 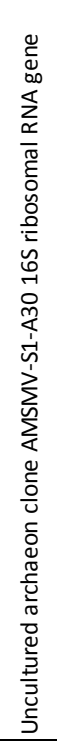 & 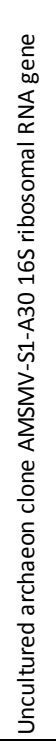 & 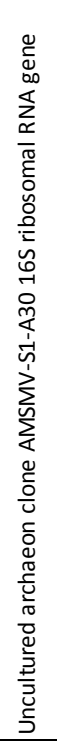 & 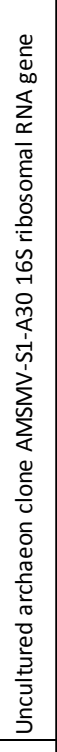 & 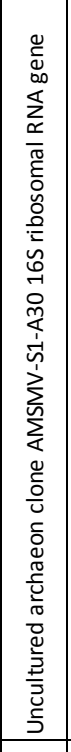 & 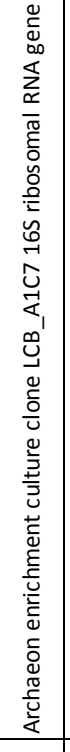 & 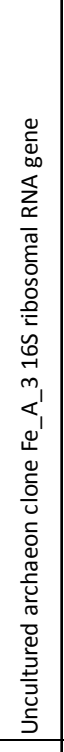 & 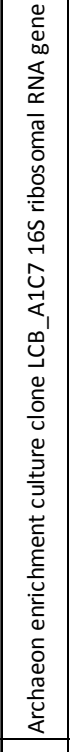 & 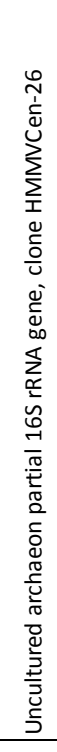 & 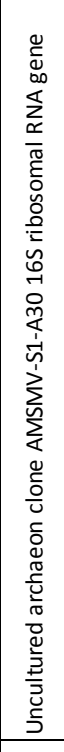 \\
\hline 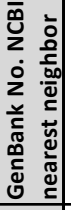 & 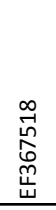 & 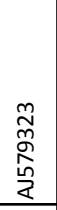 & 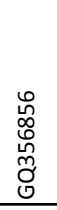 & $\begin{array}{l}\text { ̃ } \\
0 \\
0 \\
0 \\
0, \\
0\end{array}$ & $\begin{array}{l}\text { ने } \\
0 \\
0 \\
0 \\
0 \\
0\end{array}$ & 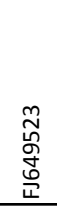 & 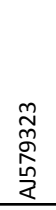 & 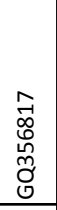 & 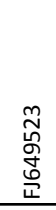 & 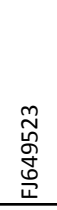 & 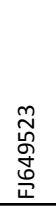 & 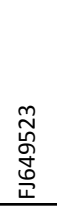 & 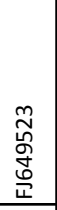 & 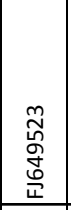 & 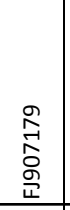 & $\begin{array}{l}\text { जे } \\
0 \\
0 \\
0 \\
0 \\
0\end{array}$ & 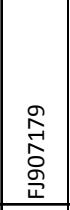 & 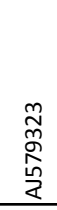 & 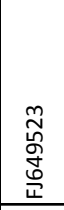 \\
\hline 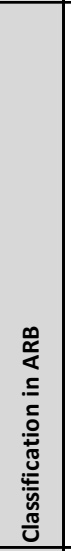 & 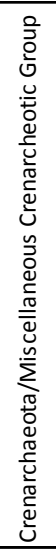 & 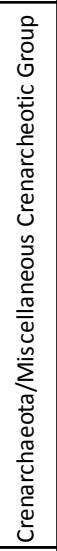 & 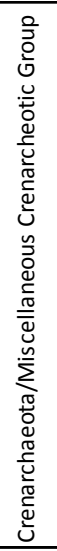 & 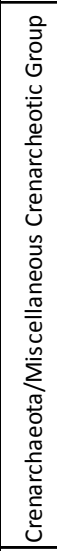 & 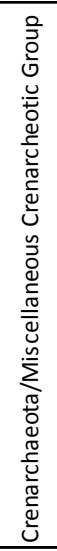 & 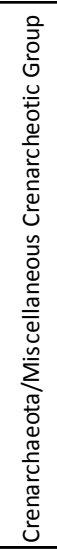 & 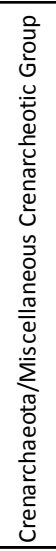 & 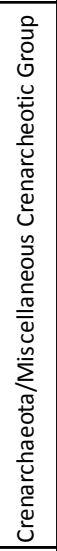 & 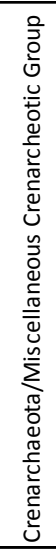 & 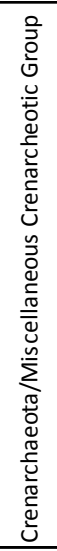 & 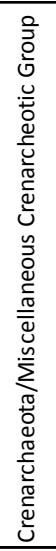 & 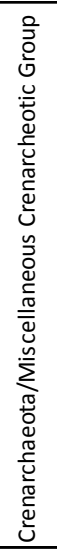 & 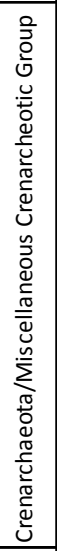 & 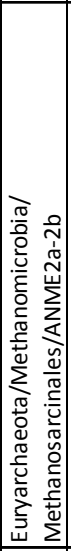 & 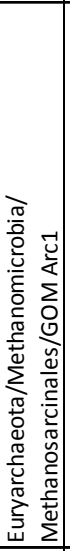 & 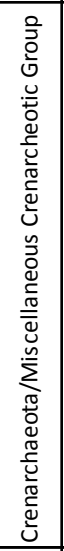 & 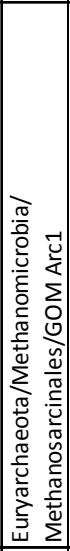 & 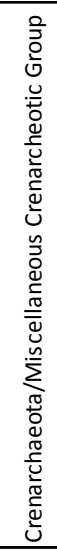 & 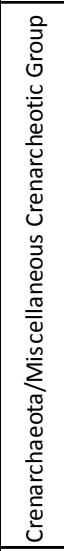 \\
\hline 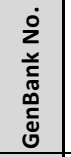 & 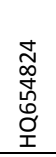 & 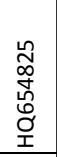 & 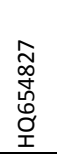 & 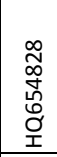 & 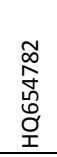 & $\begin{array}{l}\infty \\
\stackrel{\infty}{0} \\
\dot{0} \\
\stackrel{0}{1} \\
\text { I. }\end{array}$ & 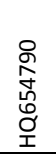 & 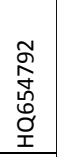 & 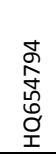 & $\begin{array}{l}0 \\
\stackrel{8}{ } \\
\dot{0} \\
\stackrel{0}{0} \\
\text { 오 }\end{array}$ & 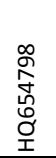 & 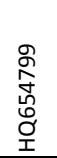 & 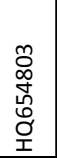 & 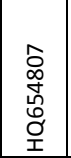 & 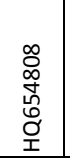 & 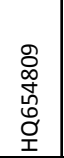 & 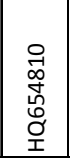 & 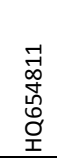 & 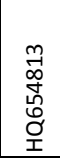 \\
\hline 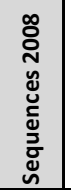 & $\begin{array}{l}\stackrel{0}{ } \\
\sigma_{1} \\
\infty_{1}^{\prime} \\
\sigma_{1}^{\prime} \\
\frac{2}{2}\end{array}$ & $\begin{array}{l}\vec{z} \\
\sigma_{1} \\
\infty_{1}^{\prime} \\
\sigma_{1}^{\prime} \\
\frac{\tilde{\sigma}}{z}\end{array}$ & $\begin{array}{l}\tilde{\Xi}_{1} \\
\infty^{\prime} \\
\sigma_{1} \\
\sigma^{\prime} \\
\frac{\tilde{z}}{z}\end{array}$ & $\begin{array}{l}\tilde{N} \\
\sigma_{1} \\
\infty^{\prime} \\
\sigma_{1} \\
\frac{2}{z}\end{array}$ & 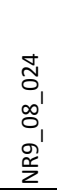 & $\begin{array}{l}\stackrel{0}{ } \\
\mathbf{O}_{1} \\
\infty^{\prime} \\
O_{1} \\
\sigma^{\prime} \\
\stackrel{2}{z}\end{array}$ & $\begin{array}{l}0 \\
\sigma_{1} \\
\infty_{1}^{\prime} \\
\sigma_{1}^{\prime} \\
\frac{1}{z}\end{array}$ & $\begin{array}{l}\hat{\sigma}_{1} \\
\infty^{\prime} \\
\sigma_{1} \\
\sigma^{\prime} \\
\frac{\tilde{c}}{z}\end{array}$ & $\begin{array}{l}\stackrel{\infty}{0}_{0} \\
\infty_{1} \\
\sigma_{1} \\
\sigma^{\frac{c}{z}} \\
\end{array}$ & $\begin{array}{l}\text { ఫે } \\
\sigma_{1} \\
\infty_{1} \\
\sigma_{1}^{\prime} \\
\frac{\tilde{r}}{2}\end{array}$ & 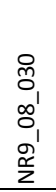 & $\begin{array}{l}\overrightarrow{0} \\
\tilde{O}_{1} \\
\infty_{1}^{\prime} \\
\sigma_{1} \\
\sigma^{2} \\
\frac{\tilde{c}}{z}\end{array}$ & $\begin{array}{l}\tilde{\tilde{o}} \\
o_{1}^{\prime} \\
\infty_{1}^{\prime} \\
\sigma_{1}^{\prime} \\
\frac{\tilde{c}}{2}\end{array}$ & $\begin{array}{l}m \\
\tilde{m}_{1} \\
o^{\prime} \\
o_{1}^{\prime} \\
\sigma^{\prime} \\
\frac{\tilde{c}}{z}\end{array}$ & $\begin{array}{l}\tilde{O}_{1}^{+} \\
\sigma_{1} \\
o_{0}^{\prime} \\
\sigma_{1}^{\prime} \\
\frac{\tilde{c}}{z}\end{array}$ & $\begin{array}{l}\tilde{m}_{0} \\
\infty_{1}^{\prime} \\
\infty_{1}^{\prime} \\
\sigma^{\prime} \\
\frac{\tilde{c}}{z}\end{array}$ & $\mid \begin{array}{l}0 \\
\tilde{O}_{1} \\
\infty_{1} \\
0_{1}^{\prime} \\
\sigma^{\prime} \\
\frac{\tilde{c}}{z} \\
\end{array}$ & $\begin{array}{l}\hat{0} \\
o_{1} \\
o_{0} \\
\sigma_{1} \\
\frac{\tilde{c}}{z}\end{array}$ & $\begin{array}{l}\infty \\
\tilde{o}_{1} \\
\infty^{\prime} \\
\sigma_{1}^{\prime} \\
\sigma^{\prime} \\
\frac{c}{z}\end{array}$ \\
\hline
\end{tabular}




\begin{tabular}{|c|c|c|c|c|c|c|c|c|c|c|}
\hline 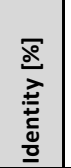 & 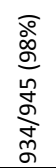 & 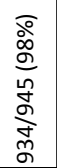 & 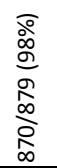 & 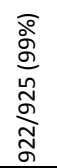 & 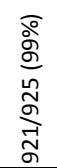 & 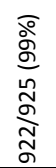 & 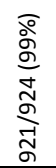 & 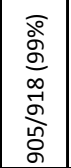 & 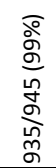 & 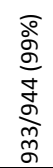 \\
\hline 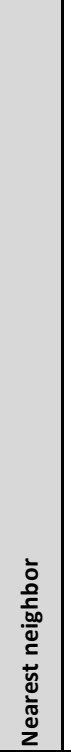 & 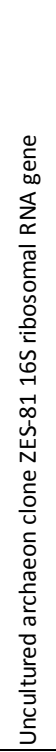 & 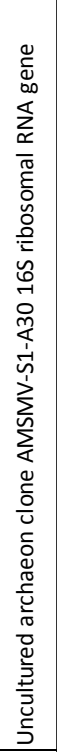 & 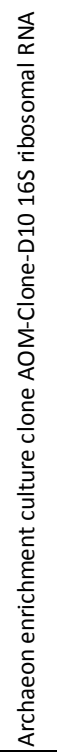 & 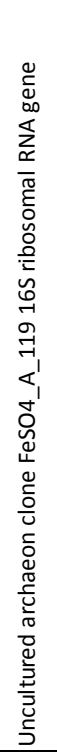 & 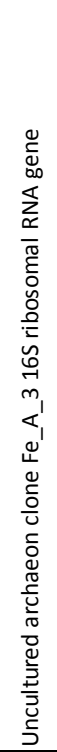 & 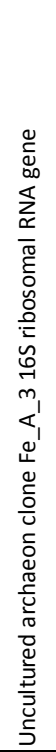 & 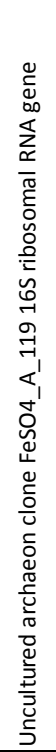 & 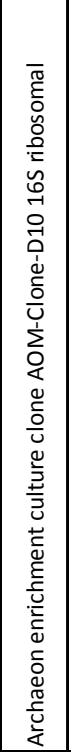 & 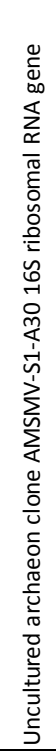 & 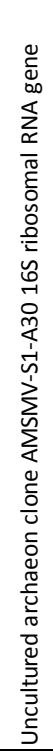 \\
\hline 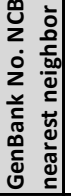 & $\begin{array}{l}\infty \\
\stackrel{\infty}{n} \\
0 \\
0 \\
\tilde{W}\end{array}$ & \begin{tabular}{l}
$\tilde{N}$ \\
$\widetilde{\Omega}$ \\
\multirow{O}{*}{}
\end{tabular} & 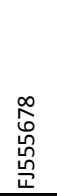 & 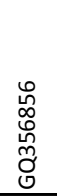 & $\begin{array}{l}\hat{0} \\
0 \\
0 \\
0 \\
0 \\
0\end{array}$ & 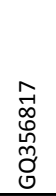 & $\begin{array}{l}0 \\
0 \\
0 \\
0 \\
0 \\
0 \\
0\end{array}$ & 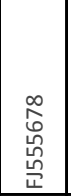 & 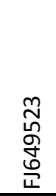 & 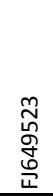 \\
\hline 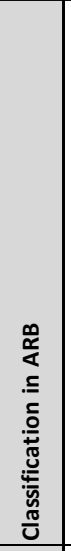 & 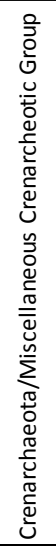 & 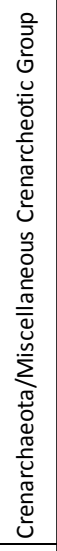 & 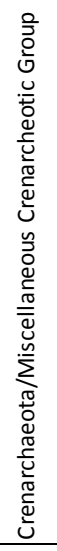 & 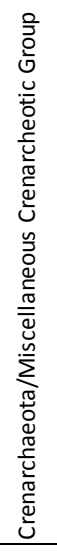 & 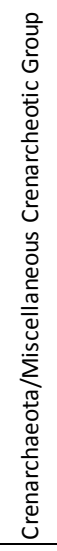 & 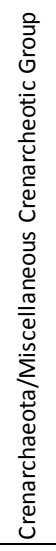 & 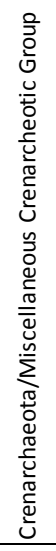 & 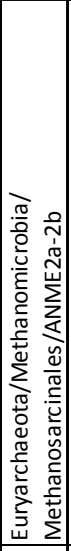 & 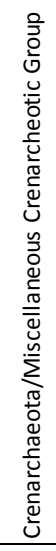 & 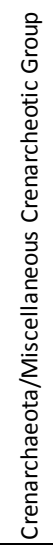 \\
\hline 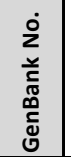 & 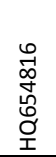 & 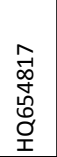 & 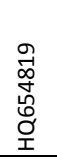 & \begin{tabular}{l}
$\vec{I}$ \\
o \\
\multirow{0}{0}{} \\
오
\end{tabular} & 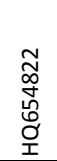 & 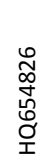 & 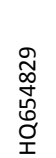 & \begin{tabular}{l}
$\infty$ \\
$\stackrel{\infty}{0}$ \\
\multirow{0}{0}{} \\
$\stackrel{0}{0}$
\end{tabular} & 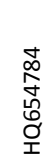 & 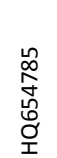 \\
\hline 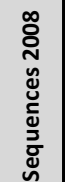 & $\begin{array}{l}\sigma^{\prime} \\
\tilde{O}^{\prime} \\
\infty^{\prime} \\
o^{\prime} \\
\sigma^{\prime}\end{array}$ & $\begin{array}{l}g^{\prime} \\
0^{\prime} \\
\infty^{\prime} \\
o^{\prime} \\
\frac{\aleph^{\prime}}{z}\end{array}$ & $\begin{array}{l}\vec{y} \\
\sigma^{\prime} \\
o^{\prime} \\
\sigma^{\prime} \\
\frac{\sigma^{\prime}}{z}\end{array}$ & $\begin{array}{l}\mathcal{Z} \\
\overbrace{}^{\prime} \\
\infty^{\prime} \\
O_{1} \\
\sigma^{\prime} \\
\frac{\tilde{c}}{2}\end{array}$ & $\begin{array}{l}m \\
\delta^{\prime} \\
\infty^{\prime} \\
\sigma^{\prime} \\
\frac{\sigma^{\prime}}{z}\end{array}$ & $\begin{array}{l}\mathbb{J} \\
\delta^{\prime} \\
\infty^{\prime} \\
\sigma_{1} \\
\sigma^{\prime} \\
\frac{1}{z}\end{array}$ & $\begin{array}{l}\underbrace{2} \\
\infty^{\prime} \\
0^{\prime} \\
\sigma^{\prime} \\
\frac{1}{z}\end{array}$ & $\begin{array}{l}0 \\
0 \\
0 \\
\infty^{\prime} \\
0^{\prime} \\
\sigma^{\prime}\end{array}$ & $\begin{array}{l}\hat{\sigma} \\
\sigma^{\prime} \\
\delta^{\prime} \\
\sigma^{\prime} \\
\frac{o}{z}\end{array}$ & \begin{tabular}{l}
$\infty$ \\
\multirow{\sigma}{*}{} \\
$\infty^{\prime}$ \\
$\infty^{\prime}$ \\
$\sigma^{\prime}$ \\
$\frac{1}{z}$
\end{tabular} \\
\hline
\end{tabular}




\begin{tabular}{|c|c|c|c|c|c|c|c|c|c|c|c|c|c|c|c|}
\hline 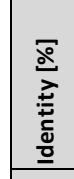 & 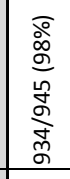 & 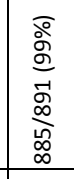 & 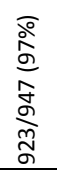 & 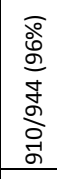 & 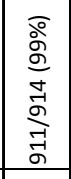 & 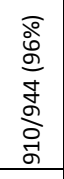 & 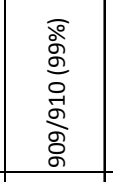 & 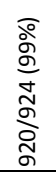 & 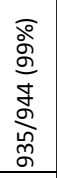 & 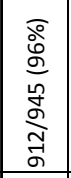 & 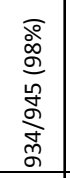 & 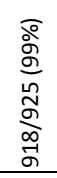 & 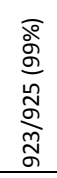 & 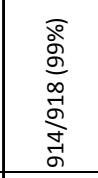 & 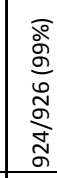 \\
\hline 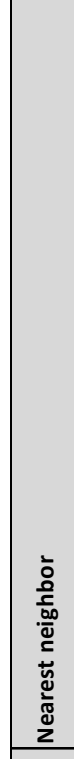 & 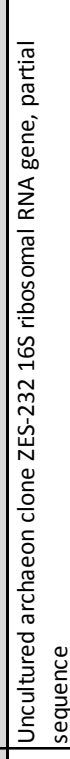 & 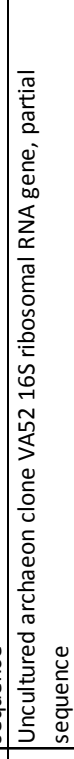 & 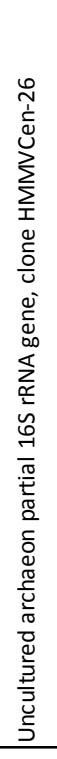 & 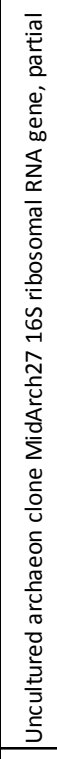 & 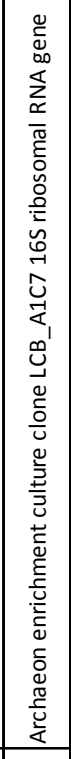 & 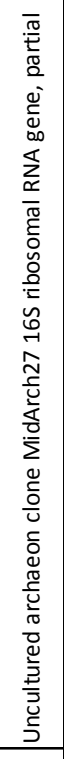 & 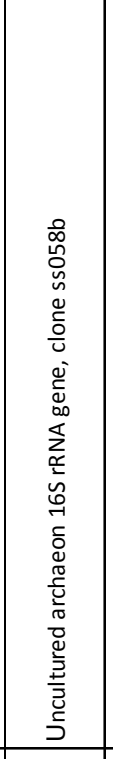 & 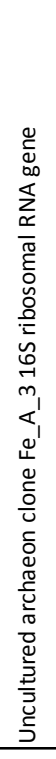 & 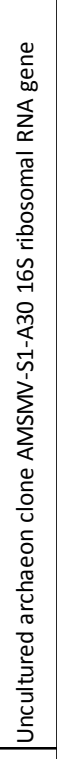 & 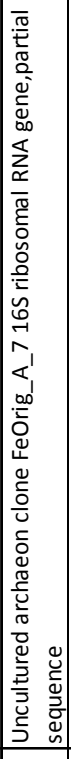 & 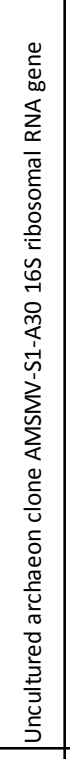 & 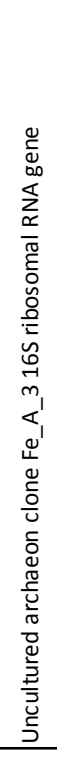 & 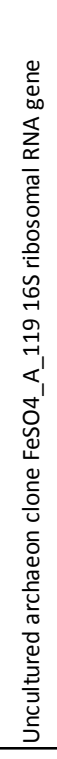 & 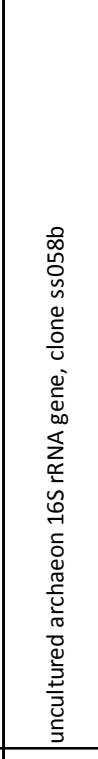 & 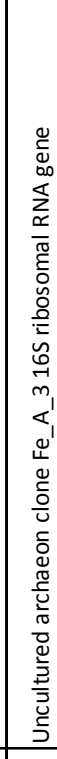 \\
\hline 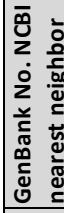 & $\begin{array}{l}0 \\
0 \\
0 \\
0 \\
0 \\
\tilde{W}\end{array}$ & 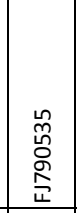 & 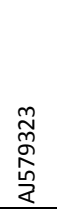 & 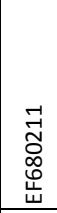 & $\begin{array}{l}\stackrel{8}{\hat{1}} \\
\stackrel{8}{8} \\
\frac{8}{4}\end{array}$ & 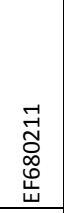 & 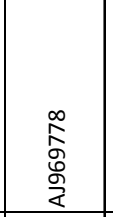 & $\begin{array}{l}\text { ⿵े } \\
0 \\
0 \\
0 \\
0 \\
0\end{array}$ & 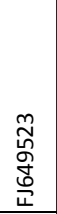 & $\begin{array}{l}\text { ने } \\
\text { } \\
\stackrel{0}{0} \\
\text { ర్ర }\end{array}$ & 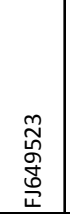 & $\begin{array}{l}\text { ⿵人 } \\
0 \\
0 \\
0 \\
0 \\
0\end{array}$ & 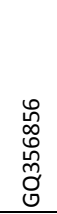 & $\begin{array}{l}\text { o } \\
\hat{\alpha} \\
0 \\
\frac{Q}{2}\end{array}$ & $\begin{array}{l}\text { जे } \\
0 \\
0 \\
0 \\
0\end{array}$ \\
\hline 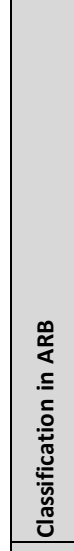 & 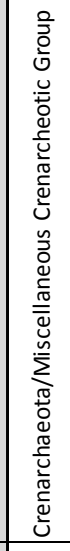 & 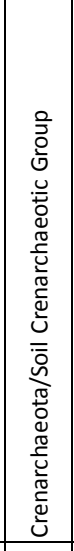 & 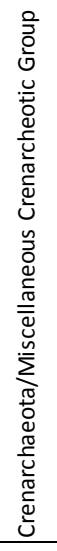 & 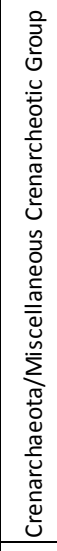 & 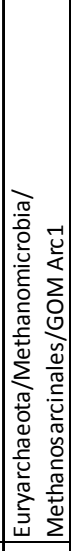 & 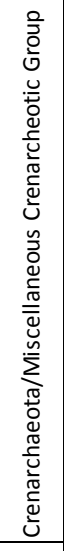 & 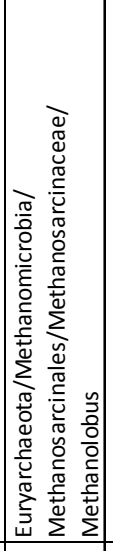 & 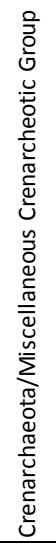 & 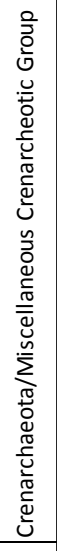 & 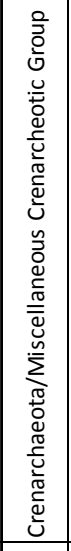 & 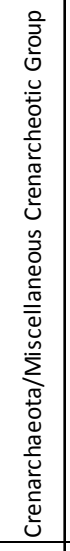 & 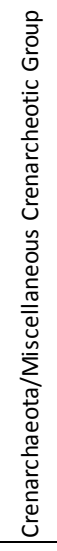 & 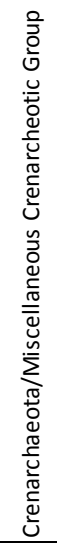 & 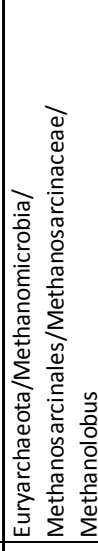 & 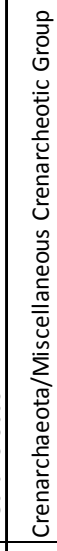 \\
\hline 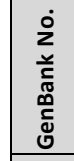 & $\begin{array}{l}0 \\
0 \\
0 \\
0 \\
0 \\
0 \\
\text { ơ } \\
\text {. }\end{array}$ & 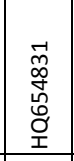 & 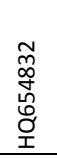 & 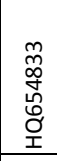 & 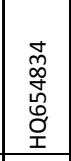 & 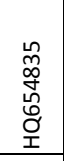 & 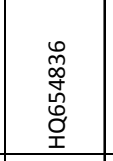 & 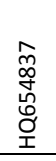 & 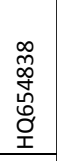 & 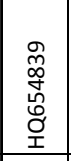 & 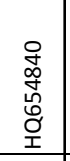 & 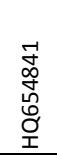 & $\begin{array}{l}\text { fี } \\
\text { a } \\
\stackrel{0}{0} \\
\text { 오 }\end{array}$ & 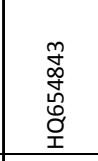 & 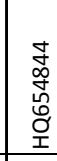 \\
\hline 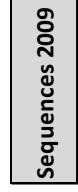 & $\begin{array}{l}\overrightarrow{\sigma_{1}} \\
\sigma_{1} \\
\sigma_{1} \\
\sigma_{2}^{2} \\
\end{array}$ & $\begin{array}{l}\delta_{1} \\
\delta_{1} \\
\delta_{1} \\
\sigma_{1}^{2} \\
\end{array}$ & $\begin{array}{l}m \\
\tilde{o}_{1} \\
\sigma_{1} \\
\sigma_{1} \\
\frac{\tilde{c}}{z}\end{array}$ & $\begin{array}{l}\delta_{1} \\
\delta_{1} \\
g_{1} \\
\sigma^{2} \\
\frac{\tilde{c}}{2}\end{array}$ & $\begin{array}{l}n \\
\delta_{1} \\
g_{1} \\
\sigma_{1} \\
\frac{\tilde{\sigma}}{2}\end{array}$ & $\begin{array}{l}\varnothing_{1} \\
\delta_{1}^{\prime} \\
\sigma_{1}^{2} \\
\frac{\pi}{2}\end{array}$ & $\begin{array}{l}\hat{\sigma} \\
\hat{g}_{1} \\
\delta_{1} \\
\hat{\sigma}^{2} \\
\end{array}$ & $\begin{array}{l}\infty \\
\delta_{1} \\
\sigma_{1} \\
\sigma_{1} \\
\frac{2}{2}\end{array}$ & $\begin{array}{l}\sigma_{1} \\
o_{1} \\
\sigma_{1} \\
\sigma^{\prime} \\
\frac{\alpha}{z}\end{array}$ & $\begin{array}{l}\rho_{1} \\
\sigma_{1} \\
g_{1} \\
\sigma_{1} \\
\frac{g^{2}}{z} \\
\end{array}$ & $\begin{array}{l}-\sigma_{1} \\
\sigma_{1} \\
\sigma_{1} \\
\sigma^{\prime} \\
\frac{\sigma}{2}\end{array}$ & $\begin{array}{l}\tilde{z} \\
\sigma_{1} \\
\sigma_{1} \\
\sigma_{1} \\
\frac{\alpha}{2}\end{array}$ & $\begin{array}{l}m \\
\sigma_{1} \\
g_{1} \\
\sigma_{1} \\
\frac{\tilde{c}}{2}\end{array}$ & $\begin{array}{l}\Delta \\
\sigma_{1} \\
g_{1} \\
\sigma_{1} \\
\frac{\partial}{z}\end{array}$ & $\begin{array}{l}\text { ㅇ } \\
0 \\
0 \\
0 \\
0\end{array}$ \\
\hline
\end{tabular}




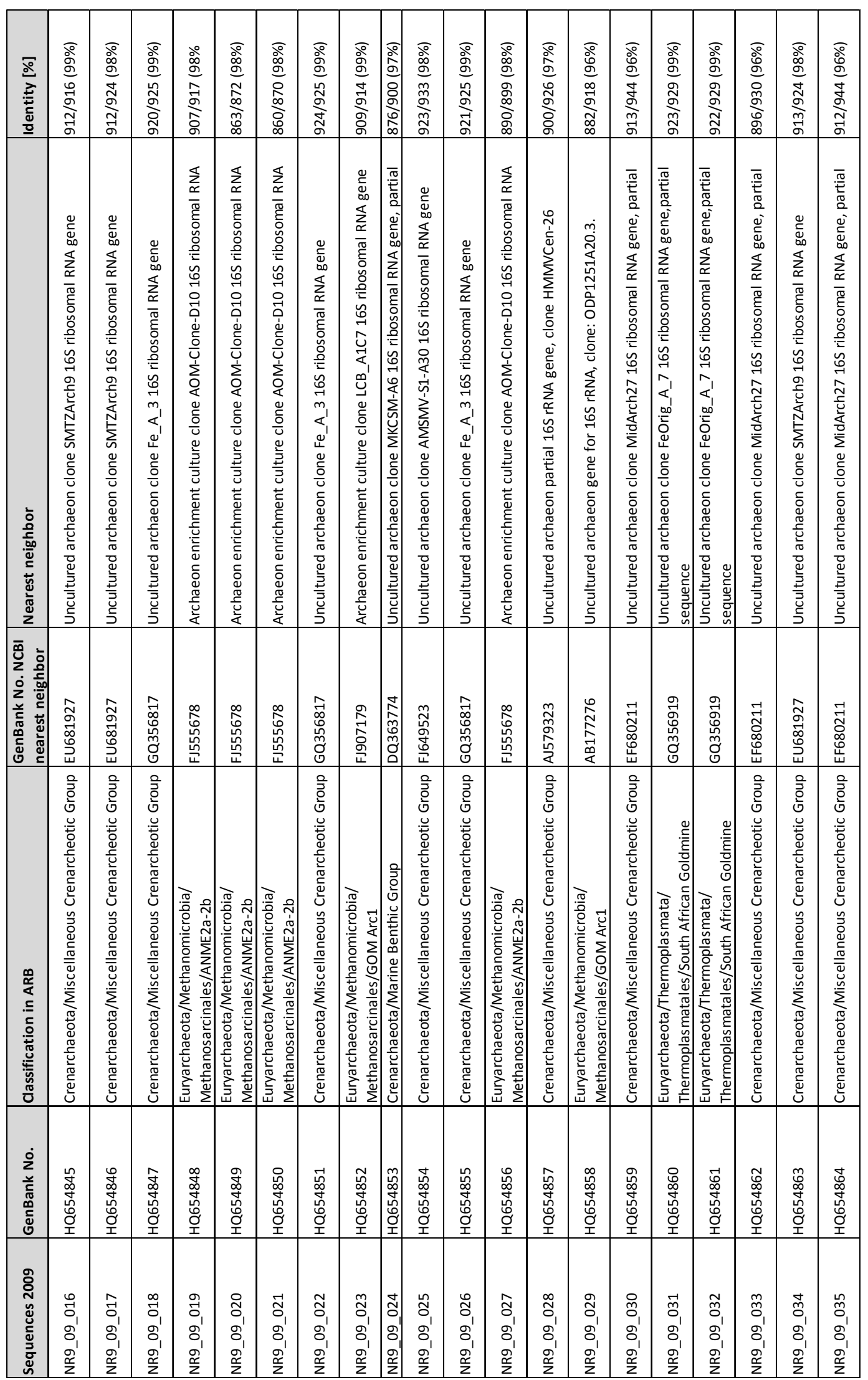




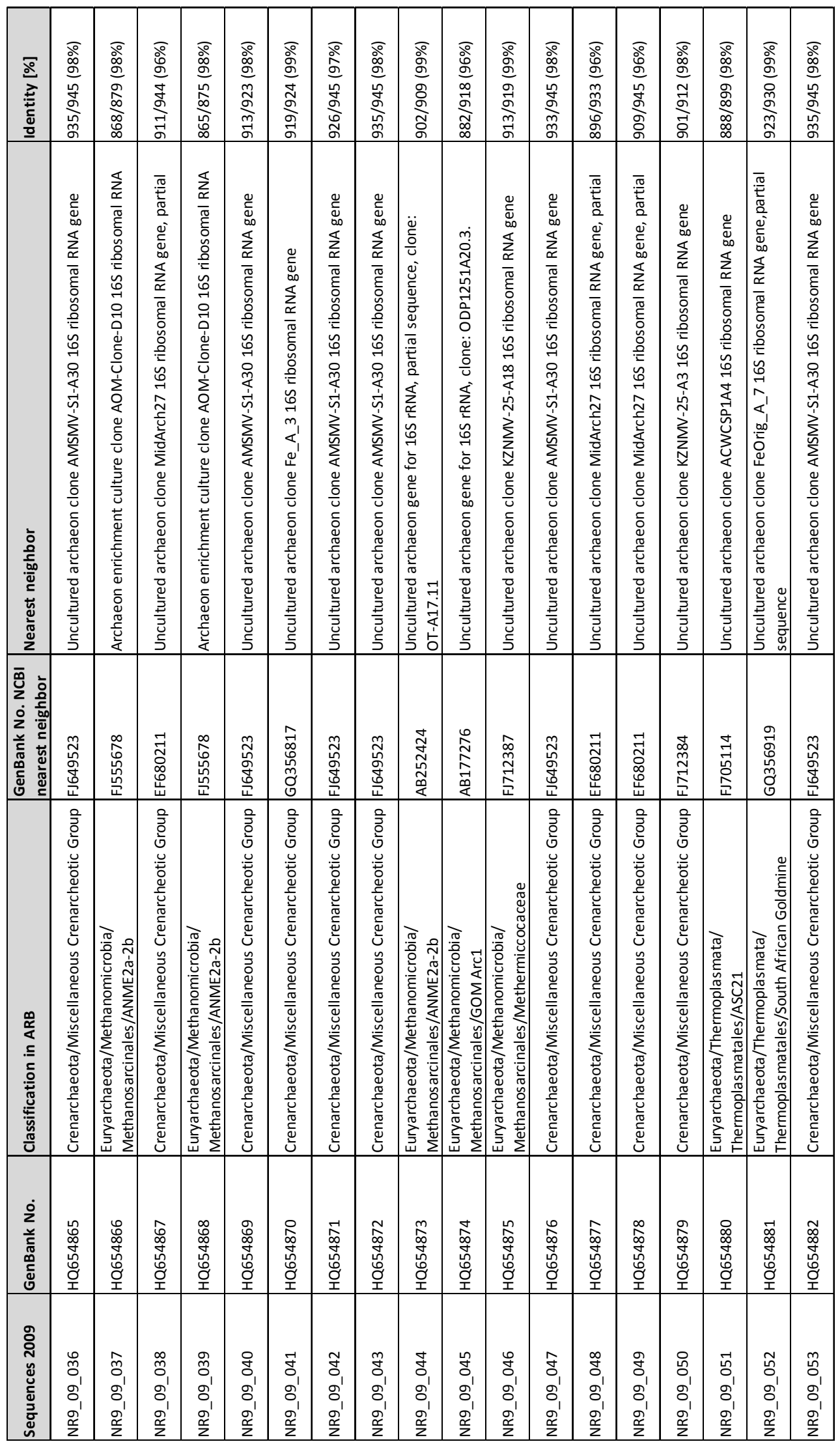




\begin{tabular}{|c|c|c|c|c|c|c|c|}
\hline 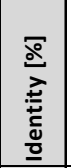 & 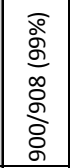 & 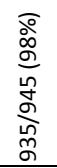 & 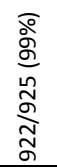 & 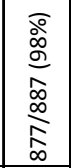 & 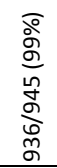 & 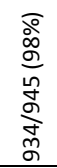 & 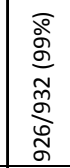 \\
\hline 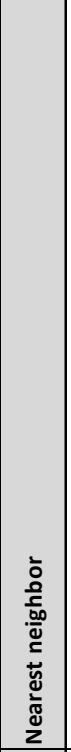 & 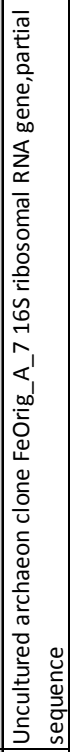 & 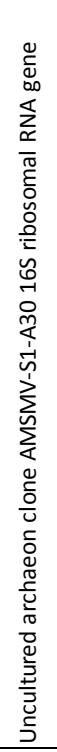 & 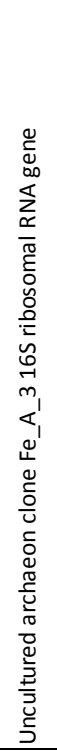 & 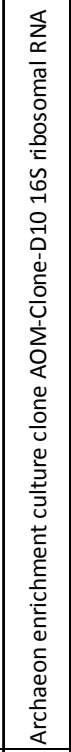 & 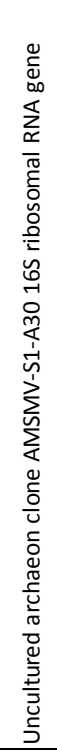 & 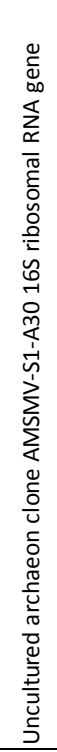 & 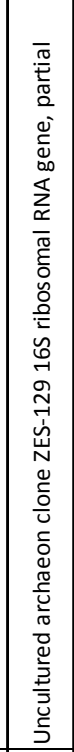 \\
\hline 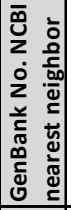 & $\begin{array}{l}\text { ने } \\
0 \\
0 \\
0 \\
0 \\
0\end{array}$ & 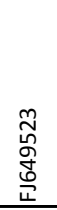 & $\begin{array}{l}\text { 今े } \\
0 \\
0 \\
0 \\
0 \\
0\end{array}$ & 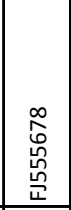 & 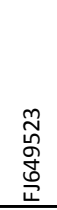 & 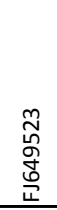 & 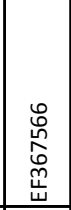 \\
\hline 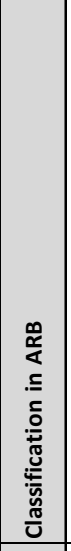 & 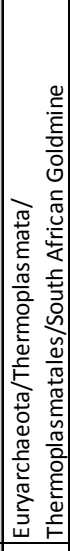 & 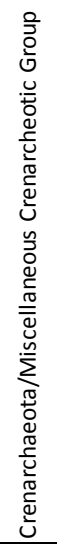 & 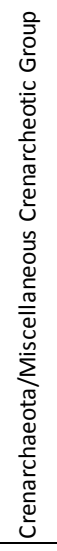 & 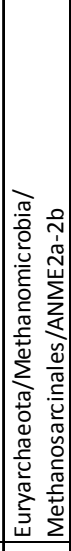 & 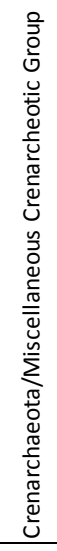 & 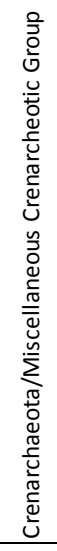 & 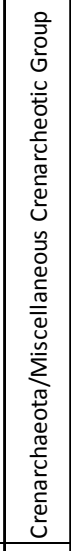 \\
\hline 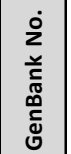 & 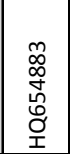 & 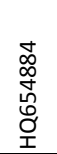 & 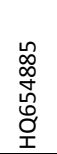 & $\begin{array}{l}\mathscr{0} \\
\infty \\
0 \\
0 \\
0\end{array}$ & \begin{tabular}{l}
$\widehat{\infty}$ \\
$\infty$ \\
\multirow{0}{0}{} \\
$\stackrel{0}{0}$ \\
오
\end{tabular} & $\begin{array}{l}\text { o } \\
0 \\
0 \\
0\end{array}$ & $\begin{array}{l}\text { o } \\
\text { d } \\
\text { d. }\end{array}$ \\
\hline 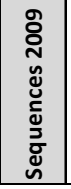 & $\begin{array}{l}J_{0} \\
\sigma_{1} \\
\sigma_{1} \\
\sigma^{\prime} \\
\frac{\tilde{c}}{2}\end{array}$ & $\begin{array}{l}\text { 애 } \\
\sigma^{\prime} \\
\sigma^{\prime} \\
\sigma^{\prime} \\
\frac{0}{2}\end{array}$ & $\begin{array}{l}0 \\
\mathscr{o}_{1} \\
\sigma_{1} \\
\sigma_{1} \\
\sigma^{2}\end{array}$ & $\begin{array}{l}\hat{n} \\
\sigma_{1} \\
\sigma^{\prime} \\
\sigma^{\prime} \\
\frac{x^{2}}{2}\end{array}$ & $\begin{array}{l}\infty \\
\tilde{o}_{1} \\
\sigma^{\prime} \\
\sigma^{\prime} \\
\frac{\alpha}{2}\end{array}$ & $\begin{array}{l}\text { Oू } \\
0_{1} \\
\sigma_{1} \\
\sigma_{1} \\
\frac{0}{2}\end{array}$ & $\begin{array}{l}{ }_{2} \\
\sigma^{\prime}\end{array}$ \\
\hline
\end{tabular}




\begin{tabular}{|c|c|c|c|c|c|c|c|c|c|c|c|c|c|c|c|c|c|c|c|c|}
\hline 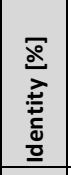 & $\begin{array}{l}\bar{o} \\
\stackrel{0}{0} \\
\stackrel{0}{0} \\
\infty \\
\infty \\
0 \\
\infty \\
\infty\end{array}$ & 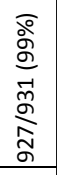 & 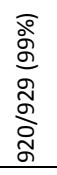 & 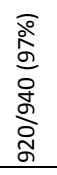 & 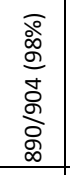 & $\begin{array}{l}\bar{o} \\
\text { ò } \\
\text { m } \\
\text { o. } \\
\text { নे } \\
\sigma\end{array}$ & 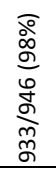 & 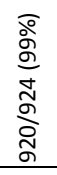 & 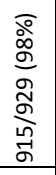 & 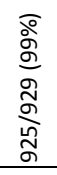 & 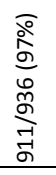 & 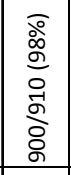 & 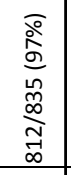 & $\begin{array}{l}\overline{0} \\
\infty \\
o \\
\stackrel{0}{2} \\
\infty \\
\infty \\
\stackrel{0}{7} \\
\infty\end{array}$ & 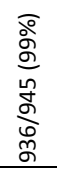 & 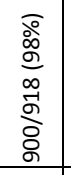 & 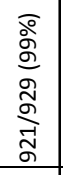 & 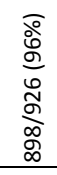 & 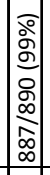 & 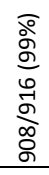 \\
\hline 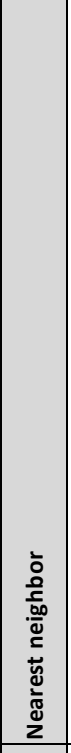 & 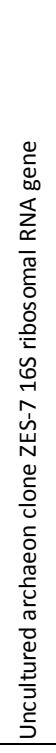 & 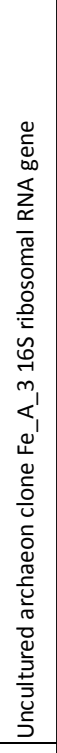 & 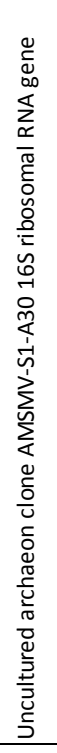 & 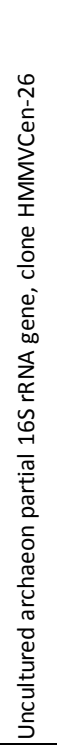 & 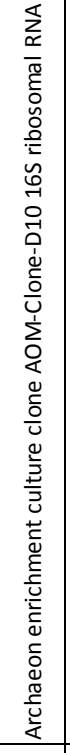 & 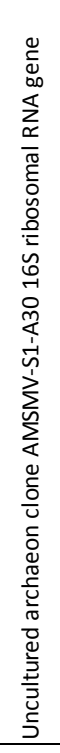 & 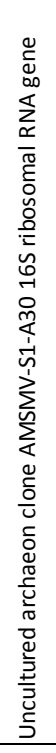 & 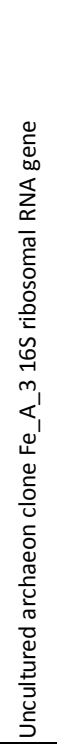 & 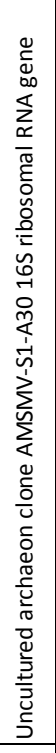 & 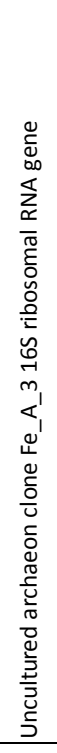 & 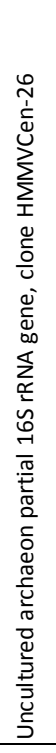 & 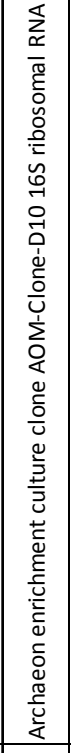 & 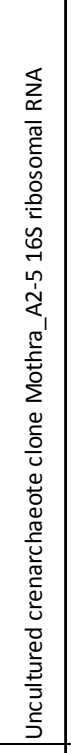 & 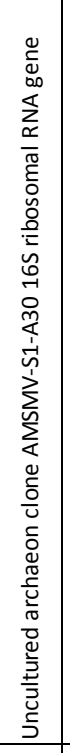 & 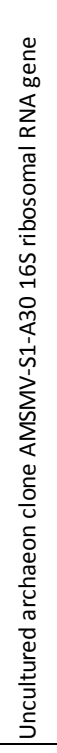 & 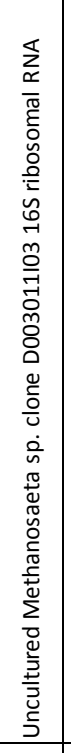 & 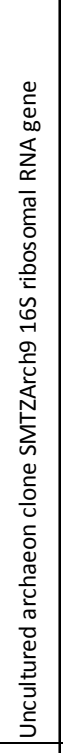 & 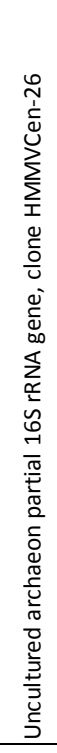 & 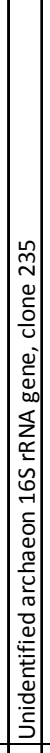 & 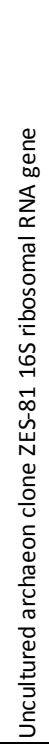 \\
\hline 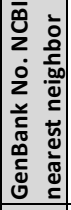 & $\begin{array}{l}\text { 导 } \\
\text { D } \\
\text { 岀 }\end{array}$ & $\begin{array}{l}\text { Iิ } \\
0 \\
0 \\
0 \\
0 \\
0\end{array}$ & 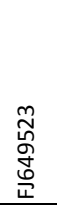 & 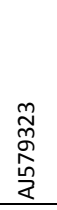 & 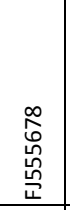 & 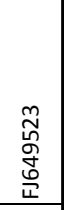 & 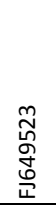 & 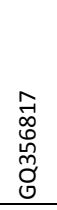 & 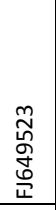 & $\begin{array}{l}\widehat{r} \\
0 \\
o \\
o 0 \\
o 0 \\
0\end{array}$ & $\begin{array}{l}\stackrel{n}{\tilde{N}} \\
\alpha \\
\stackrel{n}{<}\end{array}$ & 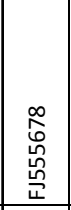 & 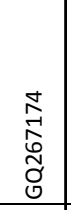 & 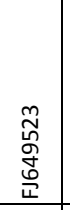 & 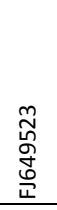 & 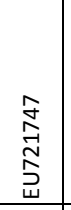 & 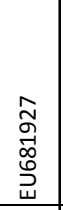 & 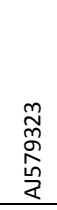 & $\mid$\begin{tabular}{|c|}
0 \\
0 \\
$\overrightarrow{0}$ \\
0 \\
$\alpha$ \\
\end{tabular} & 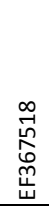 \\
\hline 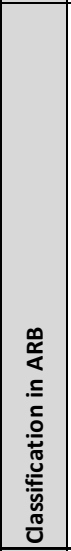 & 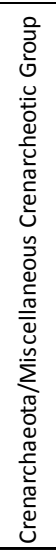 & 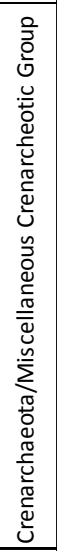 & 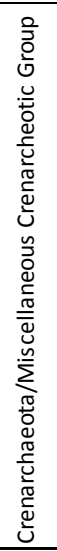 & 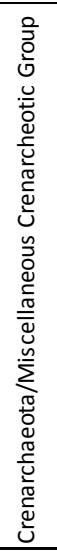 & 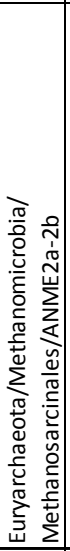 & 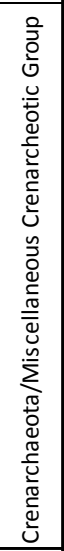 & 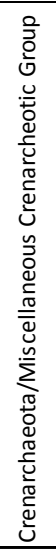 & 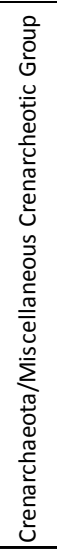 & 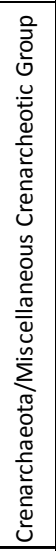 & 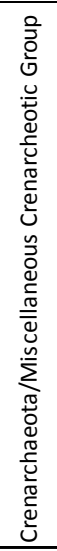 & 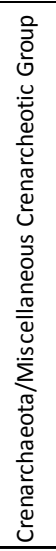 & 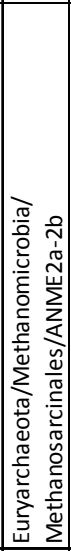 & 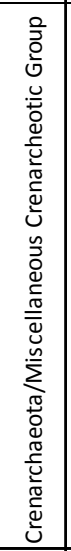 & 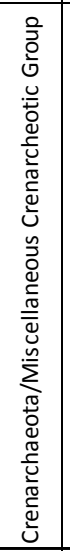 & 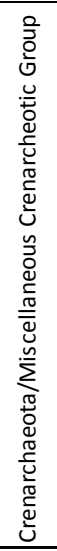 & 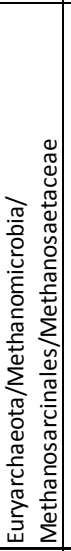 & 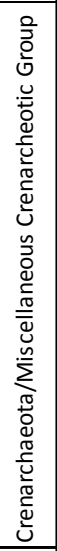 & 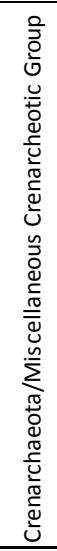 & 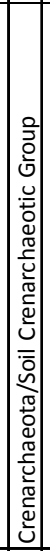 & 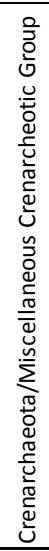 \\
\hline 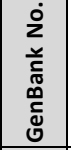 & 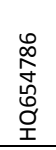 & 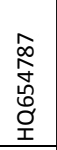 & 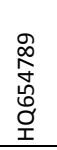 & 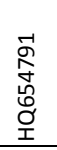 & 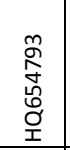 & 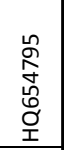 & 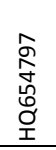 & 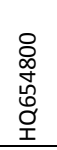 & 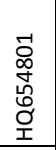 & 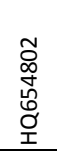 & 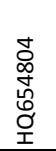 & $\begin{array}{l}\text { 另 } \\
\stackrel{o}{0} \\
\stackrel{0}{0} \\
\text { 오 }\end{array}$ & $\begin{array}{l}0 \\
\stackrel{0}{\circ} \\
\stackrel{0}{0} \\
\stackrel{0}{1}\end{array}$ & 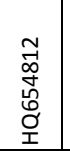 & 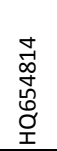 & 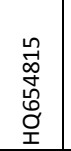 & $\begin{array}{l}\stackrel{\infty}{0} \\
\stackrel{0}{0} \\
\stackrel{0}{0} \\
\stackrel{0}{1}\end{array}$ & 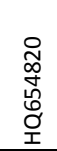 & 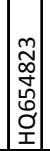 & 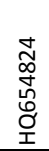 \\
\hline 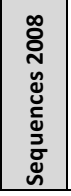 & $\begin{array}{l}\overrightarrow{0} \\
o^{\prime} \\
\infty_{1}^{\prime} \\
\sigma^{\prime} \\
\frac{2}{z}\end{array}$ & $\begin{array}{l}\tilde{\delta} \\
o_{1}^{\prime} \\
\infty^{\prime} \\
\sigma^{\prime} \\
\frac{\tilde{c}}{z}\end{array}$ & $\begin{array}{l}0 \\
\sigma_{1} \\
\infty^{\prime} \\
\sigma^{\prime} \\
\frac{\tilde{c}}{2}\end{array}$ & $\begin{array}{l}\text { ठ̀ } \\
o^{\prime} \\
\infty^{\prime} \\
\sigma_{1}^{\prime} \\
\frac{\sigma^{\prime}}{z}\end{array}$ & $\begin{array}{l}\tilde{o}^{\prime} \\
o^{\prime} \\
o^{\prime} \\
\sigma^{\prime} \\
\frac{\sigma^{2}}{2}\end{array}$ & $\begin{array}{l}\stackrel{0}{ } \\
o^{\prime} \\
o^{\prime} \\
\sigma^{\prime} \\
\frac{\sigma^{2}}{2}\end{array}$ & $\begin{array}{l}\hat{\mathbf{o}} \\
o^{\prime} \\
o_{1}^{\prime} \\
\sigma^{\prime} \\
\frac{\sigma^{2}}{z}\end{array}$ & 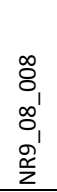 & $\begin{array}{l}\stackrel{8}{ } \\
\varnothing^{\prime} \\
\infty^{\prime} \\
o^{\prime} \\
\frac{\sigma^{\prime}}{2}\end{array}$ & $\begin{array}{l}0 \\
0 \\
0 \\
\infty^{\prime} \\
\sigma_{1}^{\prime} \\
\sigma^{\prime} \\
\frac{2}{2}\end{array}$ & $\begin{array}{l}\vec{y} \\
\sigma^{\prime} \\
\infty^{\prime} \\
\sigma^{\prime} \\
\frac{\sigma^{\prime}}{z}\end{array}$ & $\begin{array}{l}\tilde{I} \\
\sigma^{\prime} \\
\infty^{\prime} \\
\sigma^{\prime} \\
\frac{\sigma^{2}}{2}\end{array}$ & $\begin{array}{l}m \\
\sigma_{0} \\
o^{\prime} \\
\sigma_{1}^{\prime} \\
\sigma^{\prime} \\
\frac{c^{2}}{z}\end{array}$ & $\begin{array}{l}\vec{J} \\
\sigma^{\prime} \\
o^{\prime} \\
\sigma^{\prime} \\
\sigma^{\prime} \\
\frac{2}{z}\end{array}$ & 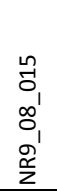 & $\begin{array}{l}0 \\
\sigma_{1} \\
o^{\prime} \\
\sigma_{1}^{\prime} \\
\sigma^{\prime} \\
\frac{\tilde{c}}{z}\end{array}$ & $\begin{array}{l}\hat{O} \\
o^{\prime} \\
o^{\prime} \\
\sigma^{\prime} \\
\frac{\sigma^{2}}{2}\end{array}$ & $\begin{array}{l}\infty \\
\sigma^{\prime} \\
\infty^{\prime} \\
\sigma^{\prime} \\
\mathscr{o}^{\prime}\end{array}$ & $\mid \begin{array}{l}2 \\
\frac{2}{2}\end{array}$ & 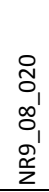 \\
\hline
\end{tabular}


7.4. Internet programs and software

Table 7.3.: Internet programs and software.

\begin{tabular}{|c|c|c|}
\hline URL/Software & Provider & Application \\
\hline $\begin{array}{l}\text { http://cmr.tigr.org/tigr- } \\
\text { scripts/CMR/CmrHomePage.cgi }\end{array}$ & $\begin{array}{l}\text { The Institute for } \\
\text { Genomic Research, } \\
\text { Rockville, USA }\end{array}$ & sequence analysis \\
\hline http://www.ncbi.nlm.nih.gov/ & $\begin{array}{l}\text { National Institutes } \\
\text { of Health, Bethesda, } \\
\text { USA }\end{array}$ & literature enquiry \\
\hline $\begin{array}{l}\text { http://portal.isiknowledge.com/porta } \\
\text { l.cgi }\end{array}$ & $\begin{array}{l}\text { The Thomson } \\
\text { Corporation, } \\
\text { Toronto, Canada }\end{array}$ & literature enquiry \\
\hline http://www.molecularcloning.com & $\begin{array}{l}\text { Cold Spring Harbor } \\
\text { Laboratory Press, } \\
\text { New York, USA }\end{array}$ & Molecular protocols \\
\hline http://tools.neb.com/NEBcutter2/ & $\begin{array}{l}\text { NEB Biolabs, } \\
\text { Frankfurt am Main, } \\
\text { Germany }\end{array}$ & restriction sites analysis \\
\hline http://us.expasy.org/ & $\begin{array}{l}\text { Swiss Institute of } \\
\text { Bioinformatics, } \\
\text { Geneva, Switzerland }\end{array}$ & protein structure analysis \\
\hline $\begin{array}{l}\text { http://blocks.fhcrc.org/blocks/block } \\
\text { mkr/make_blocks.html }\end{array}$ & $\begin{array}{l}\text { Fred Hutchinson } \\
\text { Cancer Research } \\
\text { Center, Seattle, USA }\end{array}$ & $\begin{array}{l}\text { alingments of conserved } \\
\text { sequences }\end{array}$ \\
\hline $\begin{array}{l}\text { http://bioinformatics.weizmann.ac.il } \\
\text { /blocks/codehop.html }\end{array}$ & $\begin{array}{l}\text { Fred Hutchinson } \\
\text { Cancer Research } \\
\text { Center, Seattle, USA }\end{array}$ & degenerate primer design \\
\hline
\end{tabular}




\section{URL/Software}

ARB program package

Bellerophon

CHIMERA_CHECK program

gap4 program

Geneious

iTEM

Image J

\section{Provider}

The ARB Project, phylogenetic tree

München, Germany construction

(Ludwig et al.,

2004)

Australian National chimera analysis

University,

Canberra, Australia

(Huber et al., 2004)

Ribosomal Database chimera analysis

Project, East

Lansing, USA

(Maidak et al., 2001)

MRC Laboratory of sequence analysis

Molecular Biology,

Cambridge, UK

(Staden Package;

Bonfield et al.,

1995)

Biomatters Ltd, sequence analysis

Auckland,

New Zealand

Olympus, Tokyo, camera control EM 902,

Japan image processing

National Institutes image analyses

of Health, Bethesda,

USA 


\begin{tabular}{lll}
\hline URL/Software & Provider & Application \\
\hline Mallard & Cardiff University, & chimera analysis \\
& Cardiff, UK & \\
& Ashelford et al., & \\
& 2006) & \\
Microsoft Office 2007 & Microsoft Inc., & text and data processing \\
& Redmond, USA & \\
Photoshop 8.0 & Adobe Corp., San & image processing \\
SeqMan & & \\
& Jose, USA & \\
II 5.07 & DNASTAR Inc., & sequence analysis \\
VectorNTI & Madison, USA & \\
& Invitrogen, & sequence analysis \\
& Carlsbad, USA & \\
\hline
\end{tabular}




\section{Curriculum Vitae}

Name Christoph Wrede

Geburtsdatum 8. November 1981

Geburtsort Norden

$08 / 1988$ bis $06 / 2001$

$07 / 2001$ bis $04 / 2002$

$04 / 2002$ bis $09 / 2002$

$10 / 2002$ bis $01 / 2007$

$02 / 2007$ bis $11 / 2007$

$12 / 2007$ bis $04 / 2008$

$05 / 2008$

\section{Schulausbildung}

Abitur, Cuxhaven

\section{Zivildienst}

Seniorenpension Meier \& Wätjen $\mathrm{GmbH}$, Cuxhaven

Lehramtsstudium für die Sekundarstufe II, Georg-August-Universität Göttingen

Fächerkombination: Chemie/Biologie

Diplomstudium Biologie,

Georg-August-Universität Göttingen

Hauptfach: Mikrobiologie

Nebenfächer: Immunologie, Org. Chemie

\section{Anfertigung der Diplomarbeit}

„Strukturelle und funktionelle in situ Charakterisierung von mikrobiellen Matten aus Methan-Seeps“

Arbeitsgruppe von PD Dr. Michael Hoppert, Inst. f.

Mikrobiologie und Genetik, Georg-August-Universität

Göttingen

Vorbereitende experimentelle Versuche zur Promotion

Posterpreis der GBM und VAAM im März 2008

Promotion „Metabolismus und Biomineralisation in anaerob Methan-oxidierenden Lebensgemeinschaften“ Arbeitsgruppe von PD Dr. Michael Hoppert, Inst. f. Mikrobiologie und Genetik, Georg-August-Universität Göttingen 